\title{
IV. Das Ende der Ära Müller 1948/1949
}

\section{1. „Der Arzt als Mörder“" . Fritz Schäffer und die Rebellion des Bezirksverbands Oberbayern}

Am 18. November 1947 endete das Spruchkammerverfahren, das Fritz Schäffer gegen sich selbst beantragt hatte, nachdem er von der Militärregierung kaltgestellt worden war. Der Staatsrat wurde als vom Befreiungsgesetz nicht betroffen erklärt und das Verfahren eingestellt ${ }^{2}$. Zwei Monate später hob die Militärregierung auch das gegen Schäffer verhängte Verbot politischer Betätigung auf. Damit war es ihm wieder erlaubt, Parteiämter oder Abgeordnetenmandate zu übernehmen, die Militärregierung untersagte es Schäffer aber nach wie vor, ein öffentliches Amt mit Exekutivfunktionen auszuüben, bei dem Zusammenarbeit mit den Besatzungsbehörden notwendig sei ${ }^{3}$. Die oppositionellen Kräfte in der CSU zögerten nicht, Schäffers Rehabilitierung publik zu machen. Alois Hundhammer teilte den in Marktredwitz versammelten Delegierten der Landesversammlung am 24. Januar 1948 erfreut mit, die Militärregierung habe dem Staatsrat "wieder volle politische Bewegungsfreiheit" gewährt".

Zu diesem Zeitpunkt hatten sich wieder einmal schwere Gewitterwolken über der bayerischen Unionspartei zusammengebraut. Die Gegner Josef Müllers hatten ihr Ziel, den verhaßten Parteivorsitzenden zu entmachten, keineswegs aufgegeben, auch wenn all ihre diesbezüglichen Initiativen und Intrigen bisher erfolglos geblieben waren. Am 20. Januar 1948 trafen sich die Mitglieder des Bezirksvorstands der oberbayerischen CSU, fast alle eingeschworene Widersacher des Ochsensepp, um über die verfahrene Situation der Partei und über die Marschroute für den bevorstehenden Parteitag zu beraten $^{5}$. Diesmal sollte eine Entscheidung herbeigeführt werden - so oder so. „Es herrschte einmütige Auffassung darüber", mußte Josef Müller in einer vertraulichen Aktennotiz lesen, daß der Bezirksverband Oberbayern „diesmal das letztemal zu einer Landesversammlung fahren würde“. Für den Fall, daß es nicht gelänge, die eigenen Ansichten und Forderungen durchzusetzen, wollte man geschlossen den Parteitag verlassen.

Doch dabei blieb es nicht. Der Bezirksvorstand der oberbayerischen CSU beschloß überdies, Hans Ehard für das Amt des Landesvorsitzenden zu nominieren. Die Kandidatur des populären und von allen Gruppierungen der zerstrittenen CSU respektierten Ministerpräsidenten hätte erstmals in der Geschichte der CSU zu einer Kampfabstim-

\footnotetext{
1 Protokoll der Sitzung des Landesausschusses der CSU am 28./29. 2. 1948 in Regensburg, in: Protokolle und Materialien, S. 1625 (Gerhard Kroll).

2 IfZ-Archiv, RG 260, AG 1948-27/2, Entscheidung im Spruchkammerverfahren gegen Fritz Schäffer vom 18. 11. 1947. Vgl. dazu auch Henzler, Fritz Schäffer, S. 208-228.

${ }^{3}$ IfZ-Archiv, RG 260, AG 1948-27/2, EUCOM an OSS vom 19. 1. 1948.

${ }^{4}$ Protokoll der Landesversammlung der CSU am 24./25. 1. 1948 in Marktredwitz, in: Protokolle und Materialien, S. 1402.

${ }^{5}$ ACSP, NL Müller 109, vertrauliche Aktennotiz Josef Plonners für Josef Müller über die Sitzung des Bezirksvorstands der CSU Oberbayern am 20.1. 1948; das folgende nach dieser Aktennotiz.
} 
mung um den Parteivorsitz geführt und Müller mit einem gefährlichen Gegenkandidaten konfrontiert. Ob Ehard überhaupt dazu bereit war, gegen Müller anzutreten, war aber unklar, und für den Fall, daß er die ihm angetragene Kandidatur ausschlug, vereinbarten die Mitglieder des Bezirksvorstands, Anton Pfeiffer ins Rennen zu schicken. In diesem Zusammenhang fiel auch der Name Fritz Schäffer; der Gedanke, den Staatsrat für den Landesvorsitz vorzuschlagen, fand aber selbst in diesem Gremium keine Mehrheit. Der ehemalige BVP-Vorsitzende wirke auf viele fränkische Delegierte „noch wie ein rotes Tuch“, hieß es. Doch es sollte nur noch wenige Wochen dauern, bis der Staatsrat mit einem Paukenschlag auf die politische Bühne zurückkehrte.

Gänzlich unerwartet kam das Comeback Fritz Schäffers für die Parteiführung der CSU nicht. Schon Ende November wurde er als möglicher Kandidat für das Amt des Landesvorsitzenden gehandelt. Zugleich kursierte in der Landesgeschäftsstelle das Gerücht, Heinrich Krehle würde den Vorsitz des Bezirksverbands München zugunsten Schäffers niederlegen, der die Münchner CSU im Frühjahr 1946 bereits kurze Zeit geführt hatte ${ }^{6}$. Die vorliegenden Dokumente lassen kaum Rückschlüsse auf etwaige Absprachen des Staatsrats mit seinen politischen Freunden für sein Comeback zu ${ }^{7}$, sicher ist nur, daß Schäffer um die Jahreswende 1947/1948 engen Kontakt mit Alois Hundhammer und Joseph Baumgartner hielt ${ }^{8}$. Die Überlegungen, die man in der Landesleitung der bayerischen Unionspartei anstellte, gingen aber vermutlich in die richtige Richtung - mit einer Abweichung: Es war nicht Heinrich Krehle, der seinen Platz für Schäffer räumte, sondern Alois Hundhammer. Der Bezirksverband Oberbayern, den Hundhammer seit 1946 führte, stellte die ideale Plattform für einen Angriff auf den innerparteilichen status quo dar, den Schäffer dann auch sofort startete. Die knapp 21.000 Mitglieder, die der oberbayerischen CSU 1947 angehörten, machten etwa ein Viertel der gesamten Mitgliedschaft aus'; zudem hatten die Kontrahenten Josef Müllers gerade dort ihre stärksten Bastionen.

Ausgangspunkt für den „Staatsstreich“ Fritz Schäffers gegen die Parteiführung war die Bezirksversammlung der CSU Oberbayern am 14. Februar $1948^{10}$. Von starkem

${ }^{6}$ IfZ-Archiv, MA 1420/13, Bericht Paul Burns' über Besprechungen mit Hanswolf Haunhorst am 24.11. und 28. 11. 1947 vom 4. 12. 1947; IfZ-Archiv, RG 260, 7/29-1/13-16, Sam E. Woods an das State Department vom 12.1. 1948. Arbeitsminister Krehle hatte die Delegierten der Bezirksversammlung im November 1947 dringend gebeten, ihn wegen seiner vielfältigen Verpflichtungen nicht wiederzuwählen; die Bezirksversammlung hatte ihn jedoch dennoch im Amt des ersten Vorsitzenden des Bezirksverbands München bestätigt. ACSP, NL Müller 68, Protokoll der Bezirksversammlung der CSU München am 12. 11. 1947.

7 Vgl. Henzler, Fritz Schäffer, S. 238. In einer streng vertraulichen Aktennotiz Sepp Horts über ein Gespräch mit dem oberbayerischen Landtagsabgeordneten Franz Schäfer am 16. 7.1947 hieß es jedoch bereits: „Wir warten bloss, bis Staatsrat Schäffer fertig ist mit seiner Spruchkammergeschichte. Dann schlagen wir mit ihm an der Spitze los, und zwar blitzartig. Wir brauchen dazu ca. 45-50 Abgeordnete. Name der neuen Partei [. . . ]: „Katholischer Volksblock Bayern.“ ACSP, NL Müller 394.

8 ACSP, CSU-LTF I, 15-12/4 und 5, Fritz Schäffer an Alois Hundhammer vom 19.12. 1947 und dessen Antwortschreiben vom 22. 12. 1947. Schäffer warf bereits am 19. Dezember die Frage auf, ob man die umstrittenen Satzungsfragen, die auch nach der außerordentlichen Landesversammlung weiterhin im Raum standen, "zur Entscheidung für den inneren Zusammenhalt der CSU“ machen wolle. Die Entscheidung über das Comeback des Staatsrats fiel wohl erst Anfang Februar 1948. Am 9. Februar ließ Schäffer den mittlerweile zur Bayernpartei übergetretenen Baumgartner „unserer seinerzeitigen Verabredung entsprechend“ wissen, er könne "wohl nicht mehr länger warten " und müsse "noch in dieser Woche entscheidende Entschlüsse fassen“. BAK, NL Schäffer 23, Bl. 266.

"Exakte Zahlen bei Mintzel, Geschichte der CSU, S. 131. Der Bezirksverband München hatte dagegen nur knapp 2700 Mitglieder.

10 Mitteilungen der Christlich-Sozialen Union vom 21. 2. 1948: „CSU Oberbayern gegen Landesleitung. Kritik an den Satzungen und an der Politik“; Südost-Kurier vom 18. 2. 1948: „Der ,Staats- 
Beifall begleitet, unterbreitete Hundhammer selbst den Delegierten den Vorschlag, an seiner Stelle Schäffer zum Vorsitzenden des Bezirksverbands zu wählen ${ }^{11}$. Die aggressive Rede des Staatsrats traf offensichtlich genau den richtigen Ton. Begleitet von scharfen Angriffen gegen Josef Müller zeichnete Schäffer ein düsteres Bild der Situation. Die Vorwürfe, die der ehemalige BVP-Vorsitzende dabei erhob, glichen denen, die er bereits im Frühjahr 1946 vorgebracht hatte; ja es scheint fast so, als wollte Schäffer nahtlos dort anknüpfen, wo er von der Militärregierung so abrupt unterbrochen worden war. Zugleich versuchte der Staatsrat, ein gleichsam religiöses Charisma zu verbreiten:

„Drum sage ich: Wenn mich etwas veranlassen könnte, Ihrem Ruf zu folgen, dann wäre es das Bestreben, in der Union, die das Wort ,christlich' aufs Schild erhoben und diesen Namen angenommen hat, dahin zu wirken, daß sie wieder eine Partei wird, in der nur mit christlichen Methoden gearbeitet wird (lebhafter Beifall) und die dann auch die christlichen Grundsätze im öffentlichen Leben bedingungslos und kompromißlos vertritt. (Zustimmung.) Ich bin im praktischen Leben sehr für Kompromisse; aber da, wo das Gewissen spricht, da, wo es um Grundsätze geht, kann es Kompromisse nicht geben! Unser Heiland hat gesagt: Ich bin in die Welt gekommen, nicht um den Frieden, sondern um das Schwert zu bringen. Das gilt für jeden, der aus einem christlichen Gewissen heraus im öffentlichen Leben steht. Im öffentlichen Leben muß ich mich zu meinen Grundsätzen bekennen; und das ist das Schlimme, wenn eine Demokratie dazu führt, daß die Wendigen und Geschmeidigen, die Grundsatzlosen, sich an die Spitze drängen, und die aufrechten Männer, die Grundsätze haben, zerrieben und an die Seite gestellt werden. (Beifall.) Deswegen sage ich: Wenn mich etwas veranlassen könnte, ist es der Gesichtspunkt, die Christlich-Soziale Union zu einer Partei der christlichen Methode und zu einer Partei der christlichen Zielsetzung im politischen Kampf zu machen, (bravo!) zu einer Partei, die sich nicht um Kleinigkeiten kümmert, sondern darum - ich möchte sagen, so, wie es die Inder in dem Mahatma Gandhi gehabt haben, der in seinen politischen Ansprachen gar nicht Politik getrieben, sondern der als Heide seinem Volk das Neue Testament, die Bergpredigt und die acht Seligkeiten vorgelesen hat -, den Weg zur Seele unseres Volkes zu finden (sehr gut!) und unserem Volk damit wieder innerliche Stärke und Hoffnung zu geben, (sehr gut!) die unser Volk braucht, weil es sie heute nicht mehr hat."

Schäffer warf dem Landesvorsitzenden vor, sich bei der Führung der bayerischen Unionspartei undemokratischer, ja diktatorischer Methoden zu bedienen. Er erkannte offensichtlich nicht, wie paradox die Situation war, als er die Delegierten zugleich aufforderte, ihm für die bevorstehende Auseinandersetzung mit der Landesleitung uneingeschränkte Handlungsvollmacht zu erteilen ${ }^{12}$. Dabei handelte der Staatsrat nach dem Prinzip: Wer nicht für mich ist, ist gegen mich, und er ließ es nicht zu, daß in der entscheidenden Phase der Sitzung Widerspruch laut wurde ${ }^{13}$. Auch in den folgenden Wochen tat Schäffer alles, um Versuche einzelner Kreisverbände zu unterbinden, sich direkt mit der Parteiführung in Verbindung zu setzen ${ }^{14}$.

streich` Dr. Schäffers“. Zur oberbayerischen Rebellion vgl. Henzler, Fritz Schäffer, S. 306-348; Hettler, Josef Müller, S. 354-386; Mintzel, Anatomie, S. 225-234, und Fait, Einleitung zu: Protokolle und Materialien, S. LXVI-LXXXIV. In der Isar Post vom 13. 2. 1948 stand unter der Überschrift „Neue Kämpfe in der CSU?" bereits zu lesen, daß es geplant sei, Schäffer anstelle Hundhammers zum Vorsitzenden der oberbayerischen CSU zu wählen.

$"$ BAK, NL Schäffer 22, Bl. 1-48 (hier Bl. 4), Protokoll der Bezirksversammlung der CSU Oberbayern am 14. 2. 1948 in München; das folgende Zitat ebenda, Bl. $11 \mathrm{f}$.

12 Vgl. Hettler, Josef Müller, S. 359.

13 BAK, NL Schäffer 22, Bl. 1-48 (hier Bl. 30), Protokoll der Bezirksversammlung der CSU Oberbayern am 14. 2. 1948 in München.

14 BAK, NL Schäffer 23, Bl. 182, Rundschreiben Fritz Schäffers an die Vorsitzenden der oberbayerischen Kreisverbände vom 18. 2. 1948, und Bl. 54, Fritz Schäffer an Rupert Steindl vom 6. 4. 1948. 
Der frühere BVP-Vorsitzende machte den Anwesenden klar, daß er gleichsam eine offene Feldschlacht plante, um die Forderungen der innerparteilichen Opposition durchzusetzen, die bisher an den Mehrheitsverhältnissen in den zuständigen Gremien gescheitert waren:

„Das ist es, worum es heute geht. Wenn Sie mich wählen wollen und wenn ich [...] wirklich Eurem Ruf folgen soll, dann muß ich wissen, daß der Bezirksverband Oberbayern - ich werde Euch dann bestimmte Vorschläge machen - zusammenhalten will, auch wenn er dabei den offenen Kampf mit der Landesleitung der CSU aufnehmen muß. (Bravo-Rufe und lebhafter Beifall.) Ich bitte, mir zu glauben, daß ich, wenn ich Euch das sage, das wirklich - ich möchte sagen - aus einer Gewissensnot heraus tue. Mir ist es ja unter Umständen viel lieber [...], Ihr folgt meinen Vorschlägen nicht; aber mein Gewissen sagt: Es geht für Bayerns Politik, für Bayerns Chance etwas verloren, und ich fürchte, daß der Name ,christliche Partei in Bayern dann auch für ewig seine Achtung verliert und für ewig verloren ist. (Sehr richtig!) [...] Wie ist es in den einzelnen Kreisverbänden; wird mein Name, wenn er als der des Vorsitzenden des Bezirksverbandes Oberbayern erscheint, den Zusammenhalt für die CSU bringen? Wird er das Abwandern der Wähler in andere Parteien verhindern und wird er damit den Bestand der CSU retten? (Zurufe: Jawohl!) Das ist die Frage. Seid Ihr aber, wenn die Frage so ist und die CSU nur auf dem Weg in ihre[m] jetzigen Bestand und ihrer jetzigen Stärke erhalten werden kann, dann auch bereit, mit mir auch einen offenen Kampf gegen die Landesleitung auf Biegen oder Brechen aufzunehmen, nicht um die CSU zu spalten, sondern um sie zu erhalten? (Stürmischer Beifall.) ${ }^{15}$

Die Wahl Schäffers zum Bezirksvorsitzenden war verknüpft mit der Abstimmung über einen Maßnahmenkatalog, der im Falle seiner Billigung der Parteiführung unterbreitet werden sollte ${ }^{16}$. An erster Stelle stand die Forderung nach einer Änderung der Satzung, um „jedes persönliche Regiment innerhalb der Partei“ in Zukunft zu verhindern und zugleich eine grundlegende Modifikation des Delegiertenschlüssels zugunsten der wähler- und mitgliederstarken Kreis- und Bezirksverbände zu erreichen. Um das Pressemonopol der Landesleitung zu brechen, verlangte man darüber hinaus ein eigenes Mitteilungsblatt. In dieselbe Richtung ging die Ankündigung, Besoldung und Kontrolle der hauptamtlichen Mitarbeiter im Bereich des Bezirksverbands Oberbayern in eigener Regie zu übernehmen und bis auf weiteres keine Beiträge mehr an die Landesgeschäftsstelle abzuführen. Weiter hieß es in den von Schäffer vorgetragenen „Mindestforderungen“:

„Solange diese Verhandlungen nicht zu einem von der Bezirksversammlung Oberbayern gebilligten Ergebnis geführt haben, erklärt sich der Bezirksverband Oberbayern durch Beschlüsse der Landesleitung, des Landesausschusses und der Landesversammlung für nicht gebunden; (sehr richtig!) er erkennt insbesondere Weisungen des I. Landesvorsitzenden und Erklärungen, die er im Namen der CSU abgibt, für sich selbst nicht an. (Sehr gut!)“

Am Ende stand die nicht näher präzisierte, aber unverhüllte Drohung, daß die Voraussetzungen für ein Verbleiben des Bezirksverbands in der CSU nur dann gegeben seien, wenn die „innere Reform“ der Partei gelinge.

Das Ziel Schäffers ging jedoch über die bloße Änderung des innerparteilichen status quo hinaus. Ihm ging es darum, die seit dem Erstarken der Bayernpartei drohende parteipolitische Spaltung der altbayerisch-katholischen Bevölkerung zu verhindern und einen einheitlichen katholischen Wählerblock zu bilden, wobei er den Verlust der seit 1945 mühsam gewonnenen fränkisch-protestantischen Kreise einkalkulierte. Allen ge-

15 BAK, NL Schäffer 22, Bl. 1-48 (hier Bl. 28f.), Protokoll der Bezirksversammlung der CSU Oberbayern am 14. 2. 1948 in München.

16 Hierzu und zum folgenden ebenda, Bl. 32-35. 
genteiligen Beteuerungen zum Trotz ${ }^{17}$ implizierte dies eine Neuinterpretation, vielleicht sogar eine Aufkündigung des Unionsgedankens, wie er bei der Gründung der CSU formuliert worden war ${ }^{18}$.

Die Bezirksversammlung reagierte auf Schäffers Rede geradezu euphorisch. Bei fünf Gegenstimmen und vier ungültigen Stimmen sprachen sich 71 Delegierte für den Staatsrat aus ${ }^{19}$. Der neue Bezirksvorsitzende machte sich unverzüglich an die Arbeit. Noch am 14. Februar lud er seine Kollegen aus den übrigen Bezirken zu einer Besprechung nach München $e^{20}{ }^{20}$; zugleich setzte er Hans Ehard, Josef Müller und Konrad Adenauer von den Beschlüssen der Bezirksversammlung in Kenntnis ${ }^{21}$.

Daß ein ganzer Bezirksverband der Landesleitung die Gefolgschaft aufkündigte, war selbst in der krisengeschüttelten CSU noch nicht vorgekommen. Die Forderungen, die Schäffer den Delegierten der Bezirksversammlung am 14. Februar vorlegte, waren dagegen keineswegs neu, sondern entsprachen den Bemühungen um eine Reform der Parteiorganisation, die die Opposition um Alois Hundhammer und Anton Pfeiffer seit mehr als eineinhalb Jahren erfolglos unternommen hatte. Stein des Anstoßes war die Parteisatzung, die die Landesversammlung im Mai 1946 verabschiedet hatte und die nach einer Intervention der Militärregierung im Oktober desselben Jahres vom Landesausschuß noch einmal modifiziert worden war $^{22}$. Die katholisch-konservativen Kräfte in der CSU und später auch die einflußreichen Bauernvertreter lehnten die Statuten in drei wesentlichen Punkten ab. Zum einen war ihnen die starke Stellung des Landesvorsitzenden ein Dorn im Auge, der die Partei nicht nur nach außen vertrat, sondern auch das Recht hatte, die Mitglieder des geschäftsführenden Landesvorstands zu ernennen ${ }^{23}$. Zum anderen enthielt die Satzung einen schematischen Delegiertenschlüssel, der die gleiche Stimmenzahl für alle Kreis- und Bezirksverbände in Landesversammlung und Landesausschuß vorsah ${ }^{24}$. Von diesem Prinzip, nach dem die fränkischen Diasporagebiete ebenso behandelt wurden wie die organisatorischen Gravitationszentren der CSU in Altbayern, erhoffte sich Josef Müller positive Rückwirkungen auf die Entwicklung der Partei im protestantischen Franken. Zugleich diente die ge-

17 IfZ-Archiv, ED $720 \mathrm{Smlg}$. Mintzel 37, Rundschreiben des Bezirksverbands Oberbayern der CSU vom 26. 7. 1948: "Verlauf der Bemühungen des Bezirksverbandes Oberbayern um eine innere Reform der CSU“; BayHStA, NL Ehard 887, „Was will der Bezirksverband Oberbayern der CSU?“, undatiert; BAK, NL Schäffer 23, Bl. 138, Fritz Schäffer an Karl Sigmund Mayr vom 24. 8. 1948.

18 Vgl. Henzler, Fritz Schäffer, S. 246, und Mintzel, Anatomie, S. 226f. So auch BAK, NL Schäffer 23, Bl. 32 f. Fritz Schäffer an Amia von Montgelas vom 12.4. 1948, und Stadtarchiv Bamberg, NL Etzel 18, Fritz Schäffer an Hermann Etzel vom 11. 11. 1948.

19 BAK, NL Schäffer 22, Bl. 1-48 (hier B1. 38), Protokoll der Bezirksversammlung der CSU Oberbayern am 14. 2. 1948 in München.

20 BAK, NL Schäffer 23, Bl. 195, Rundschreiben Fritz Schäffers an die Vorsitzenden der CSU-Bezirksverbände vom 14. 2. 1948 .

21 BAK, NL Schäffer 23, Bl. 202, Fritz Schäffer an Hans Ehard vom 14. 2. 1948, Bl. 203, Fritz Schäffer an Josef Müller vom 14. 2. 1948, und Bl. 201, Fritz Schäffer an Konrad Adenauer vom 14. 2. 1948, und Bl. 175, Konrad Adenauer an Fritz Schäffer vom 19. 2. 1948.

22 Vgl. dazu Fait, Einleitung zu: Protokolle und Materialien, S. XLVIII-LXVI, zu den Interventionen der Militärregierung S. LIV ff.

${ }^{23}$ Satzung der CSU in der Fassung vom 4. 10. 1946, abgedruckt in: Protokolle und Materialien, S. 1783-1803. In der vorläufigen Satzung der CSU vom Januar 1946 war ein stellvertretender Landesvorsitzender vorgesehen gewesen. Die entsprechende Bestimmung wurde jedoch nie wirksam; ebenda, S. 1755 f. Zur Kritik am „Führerprinzip“ in der CSU vgl. Mintzel, Anatomie, S. 110-118.

24 Als Beispiele für die teils vehement vorgetragene Kritik gegen diese Regelung vgl. BayHStA, NL Schwalber 5, Joseph Eberl an Josef Schwalber vom 8.4. 1948 und dessen Antwortschreiben an Joseph Eberl vom 21.4. 1948. 
messen an den Mitgliederzahlen und Wahlergebnissen überproportionale Vertretung der Bezirke Nürnberg-Fürth, Mittel- und Oberfranken der Sicherung seiner eigenen Machtstellung ${ }^{25}$. Der dritte Kritikpunkt der Opposition betraf den Parteiapparat. Die Satzung erlaubte es dem Landesvorstand, Geschäftsstellen auf Kreis- und Bezirksebene einzurichten; auch die Anstellung und Besoldung des Personals war Sache des Landesvorstands. Dadurch hatte die Parteiführung die Möglichkeit, die politische Arbeit zu steuern und Einfluß auf die Suborganisationen der Partei zu nehmen. In der Konzeption Josef Müllers, der die Partei als „Instrument gesellschaftlich-politischer Integration und demokratischer Bewußtseinsbildung " betrachtete ${ }^{26}$, kam den Geschäftsstellen als dem Rückgrat des Parteiapparats zweifellos eine Schlüsselfunktion $\mathrm{zu}^{27}$.

Die oppositionellen Kräfte in der CSU, die überwiegend am Modell einer Honoratiorenpartei nach dem Muster der untergegangenen BVP orientiert waren, liefen immer wieder gegen diese Regelungen Sturm. Zuletzt hatte die Landtagsfraktion auf der auBerordentlichen Landesversammlung am 30. und 31. August 1947 vergeblich versucht, eine kollektive Parteiführung, eine Änderung des Delegiertenschlüssels und eine effektive Kontrolle des Parteiapparats zu erzwingen ${ }^{28}$. Nach einer langen Reihe von Auseinandersetzungen, die nichts anderes waren als der „Kampf um die Parteiführung mit statuarischen Waffen "29, fanden die Delegierten der Landesversammlung am 24. Januar 1948 einen Kompromiß, der tragfähig zu sein schien. Man beschloß nach teilweise hitzigen Debatten, dem Landesvorsitzenden zwei durch den Landesausschuß zu wählende Stellvertreter an die Seite zu stellen. Auch der Delegiertenschlüssel wurde neu geregelt. Zwar sollte jeder Kreisverband, dem bis zu 500 Mitglieder angehörten, weiterhin mit zwei Stimmen in der Landesversammlung vertreten sein; für je weitere 500 Mitglieder konnte ein Kreisverband jedoch eine zusätzliche Stimme erhalten, wobei die Zahl der Zusatzstimmen zwei nicht überschreiten durfte ${ }^{30}$. Josef Müller konnte mit diesen Entscheidungen leben, da sie seine Machtposition nicht wesentlich einschränkten. Für die Gegner des Parteichefs war der Kompromiß von Marktredwitz allerdings zu weit von ihren ursprünglichen Forderungen entfernt, um wirklich akzeptabel zu sein. Michael Horlacher hatte darauf gehofft, daß die Landesversammlung vom 24. und 25. Januar 1948 als „Parteitag der Einigung“ in die Geschichte der CSU eingehen würde. Schon drei Wochen später sollten sich diese Hoffnungen als Illusion erweisen.

Nachdem die Landesleitung von den Beschlüssen der Bezirksversammlung vom 14. Februar 1948 erfahren hatte, versuchte sie zunächst, Zeit zu gewinnen und die Ereignisse herunterzuspielen, nicht zuletzt auch deshalb, weil Kommunalwahlen bevorstanden, die man nicht durch erneute Streitigkeiten stören wollte ${ }^{31}$. Während sich der

25 Zur Auseinandersetzung um den Delegiertenschlüssel vgl. Fait, Einleitung zu: Protokolle und Materialien, S. XLVIII-LI, und Hettler, Josef Müller, S. $261 \mathrm{ff.}$

${ }^{26}$ Mintzel, Anatomie, S. 140.

27 Vgl. ebenda, S. 139-153.

28 Vgl. S. 206-213.

29 Mintzel, Anatomie, S. 99; vgl. auch die Zusammenfassung bei Fait, Einleitung zu: Protokolle und Materialien, S. XLVIII-LXVI.

30 Protokoll der Landesversammlung der CSU am 24./25. 1. 1948 in Marktredwitz, in: Protokolle und Materialien, S. 1423 f. und S. 1450; das folgende Zitat ebenda, S. 1412. Zu den Forderungen und Verhandlungen im Vorfeld der Landesversammlung vgl. BayHStA, NL Pfeiffer 533, Rundschreiben des CSU-Bezirksverbands Oberbayern an die Mitglieder des Landesausschusses vom 23.12. 1947, und NL Pfeiffer 535, Anton Pfeiffer an Josef Müller vom 22. 1. 1948.

${ }^{31} \mathrm{Vgl}$. Henzler, Fritz Schäffer, S. $242 \mathrm{f}$. 
Staatsrat um Unterstützung bei den anderen altbayerischen Bezirksverbänden bemüh$\mathrm{te}^{32}$, formierte sich bei seinen Gegnern der Widerstand. Der Vorstand des Bezirksverbands Nürnberg-Fürth forderte ebenso wie der ständige Ausschuß des Parlaments der Jungen Union, keine Verhandlungen mit Schäffer zu führen. Auch der oberbayerische Kreisverband Garmisch-Partenkirchen billigte das Vorgehen Schäffers nicht und sprach dem Landesvorsitzenden das Vertrauen aus. Am weitesten ging eine Resolution des Bezirksrats der Jungen Union Nürnberg-Fürth:

„Die Herren Minister Dr. Hundhammer und Dr. Pfeiffer sowie Herr Staatsrat a. D. Schäffer haben durch ihr Verhalten die Gefahr einer Krisis für Kabinett und Parlament heraufbeschworen, weil sie es nicht über sich brachten, sich den klaren Mehrheitsbeschlüssen in der CSU zu beugen. Sie wenden sich damit gegen das Bestreben der CSU, die so dringend notwendige klare Verantwortlichkeit in der Demokratie zu entwickeln und zu verhindern, dass diese noch einmal den undurchsichtigen Machenschaften von Klüngeln und damit dem erneuten Untergang preisgegeben wird. Um der politischen Sauberkeit willen fordert die Junge Union des Bezirksverbandes Nürnberg-Fürth ohne Rücksicht auf irgendwelche parteitaktischen Erwägungen die Entfernung der Herren Dr. Hundhammer, Dr. Pfeiffer und Schäffer sowie ihrer Mitläufer aus der CSU. Die Junge Union Nürnbergs ist der festen Überzeugung, dass nicht nur das christliche bayerische Volk der so gereinigten Union umso grösseres Vertrauen entgegen bringen wird. “33

Nach einem ergebnislosen Briefwechsel zwischen Schäffer und dem geschäftsführenden Landesvorstand ${ }^{34} \mathrm{kam}$ es am 25. Februar zu einem ersten Gespräch. Josef Müller und August Haußleiter vertraten dabei den Standpunkt, der Bezirksverband Oberbayern habe mit seinen Forderungen den Boden der CSU verlassen, Verhandlungen seien erst dann möglich, wenn sich der Bezirksverband von seinen Beschlüssen distanziert habe. Diese Argumentation ließ natürlich keinen Raum für eine Lösung des Konflikts auf dem Verhandlungsweg ${ }^{35}$.

Das wurde auch in einer Sitzung des Landesausschusses deutlich, der am 28. und 29. Februar 1948 in Regensburg tagte. Schäffer, der in einer langen Rechtfertigungsrede die Geschichte der Führungs- und Flügelkämpfe neu aufrollte, stand von vornherein auf verlorenem Posten. Der Ochsensepp und seine politischen Freunde blockierten jede Diskussion über die Forderungen, die der Bezirksverband Oberbayern zwei Wochen zuvor erhoben hatte, und stellten statt dessen die Frage in den Mittelpunkt, inwieweit das Vorgehen der Oberbayern durch die geltende Satzung gedeckt $\operatorname{sei}^{36}$. Ein Entschließungsantrag, den prominente Vertreter der Partei aus acht Bezirksverbänden eingebracht hatten, bestritt dies entschieden:

„Der Landesausschuß der Christlich-Sozialen Union in Bayern stellt fest, daß ein Teil der von der Bezirksversammlung Oberbayern am 14. Februar 1948 gefaßten Beschlüsse gegen die Satzungen der Christlich-Sozialen Union in Bayern verstößt. Er verurteilt dieses Vorgehen als parteischädi-

32 BAK, NL Schäffer 22, Bl. 49-69, Protokoll der Bezirksversammlung der CSU München am 20. 2. 1948 in München, und Bl. 70-89, Rede Fritz Schäffers vor den Delegierten der Bezirksversammlung der CSU Niederbayern am 27. 2. 1948 in Plattling.

33 BAK, NL Schäffer 23, Bl. 135ff., Rundschreiben 5/48 der Landesgeschäftsstelle der CSU vom 24.2. 1948; zum vorstehenden ebenda.

34 Der Briefwechsel wurde während der Sitzung des Landesausschusses der CSU am 28./29. 2. 1948 in Regensburg verlesen; Protokolle und Materialien, S. 1562-1568.

35 ACSP, CSU-LL, Protokoll der Sitzung des geschäftsführenden Landesvorstands am 25. 2. 1948; BAK, NL Schäffer 23, Bl. 120, Aktennotiz über eine Besprechung Fritz Schäffers mit dem geschäftsführenden Landesvorstand der CSU am 25. 2. 1948.

36 Vgl. Henzler, Fritz Schäffer, S. 246. 
gend. Dadurch, daß Herr Staatsrat a. D. Schäffer in seiner Eigenschaft als erster Vorsitzender des Bezirksverbandes Oberbayern außerdem in einem an den Zonenvorsitzenden der Christlich-Demokratischen Union der britischen Zone gerichteten Brief die Legitimation des Landesvorsitzenden bestritten hat, die Christlich-Soziale Union nach außen zu vertreten, hat er namens des Bezirksverbandes Oberbayern das Ansehen der Partei und das Ansehen des Landes Bayern in einer für die politische Stellung und Bedeutung Bayerns entscheidenden Stunde schwer beeinträchtigt. Wer den satzungswidrigen Beschlüssen des Bezirksverbandes Oberbayern Folge leistet, hat sich damit von selber außerhalb der Christlich-Sozialen Union in Bayern gestellt. Zur Wiederherstellung satzungsgemäßer Zustände innerhalb des Bezirksverbandes Oberbayern wird der Landesvorstand beauftragt, unverzüglich eine Erklärung der einzelnen Kreisverbände Oberbayerns bezüglich ihres Verhältnisses zur Christlich-Sozialen Union in Bayern herbeizuführen und gegebenenfalls den Bezirksverband neu zu organisieren. ${ }^{37}$

Daß der Landesausschuß diese Resolution mit großer Mehrheit annahm ${ }^{38}$, war für Schäffer zweifellos eine empfindliche Niederlage, die ihm vor Augen führen mußte, wie isoliert er in der CSU war. Die Parteiführung hatte nun im äußersten Fall die Möglichkeit, direkt im rebellierenden oberbayerischen Bezirksverband zu intervenieren.

Schäffer ließ sich dadurch freilich nicht entmutigen. Die Bezirksversammlung der CSU Oberbayern bestätigte am 10. März seinen Kurs und hielt - in leicht modifizierter Form - an ihren Forderungen fest. Da seine Verhandlungen mit der ungeliebten Landesleitung nichts gefruchtet hatten, änderte der ehemalige BVP-Vorsitzende seine Strategie. Er drängte nun darauf, zur Klärung der Lage einen außerordentlichen Parteitag einzuberufen ${ }^{39}$. In dieser Situation griffen die Kontrahenten Schäffers zu einer scharfen Waffe: Am 13. März 1948 beantragte der Bezirksverband Oberfranken, Fritz Schäffer und Anton Pfeiffer aus der CSU auszuschließen ${ }^{40}$. Damit stellte sich die Frage, ob es dem Staatsrat gelingen würde, genügend Unterstützung für seine Forderung nach einer außerordentlichen Landesversammlung zu finden, ehe ein Schiedsgerichtsverfahren gegen ihn in Gang gesetzt werden konnte. Um die Einberufung eines Parteitags zu erzwingen, war ein Antrag von fünf Bezirksverbänden notwendig. Angesichts der Kräfteverhältnisse in der CSU hatte Schäffer jedoch nur wenig Chancen, neben Oberbayern vier weitere Bezirksverbände für sein Vorhaben zu gewinnen ${ }^{41}$. Auch Hans Ehard, auf dessen Rückendeckung der Staatsrat gehofft hatte, reagierte vor den Land- und Stadtkreiswahlen im Mai zunehmend unwillig und machte deutlich, daß er Schäffers Vorgehen als für Partei und Regierung schädlich ansah und ablehnte ${ }^{42}$.

Zwei Monate später begann die Situation für den Staatsrat brenzlig zu werden. Am 17. Juli 1948 beschloß der Landesvorstand nach kontroverser Diskussion in geheimer Abstimmung, den Antrag Oberfrankens auf Einleitung eines Parteiausschlußverfahrens an das Landesschiedsgericht zu überweisen ${ }^{43}$. Die Bezirksversammlung Oberbay-

37 Protokoll der Sitzung des Landesausschusses der CSU am 28./29. 2. 1948 in Regensburg, in: Protokolle und Materialien, S. 1661.

3868 Delegierte stimmten dafür, 18 dagegen, 23 enthielten sich. Ebenda, S. 1684.

39 BAK, NL Schäffer 22, Bl. 292-358, Protokoll der Bezirksversammlung der CSU Oberbayern am 10. 3. 1948 in München. Zu den Bemühungen um die Einberufung einer außerordentlichen Landesversammlung vgl. Henzler, Fritz Schäffer, S. 249 f. und S. 259 f.

to Vgl. ebenda, S. 251.

$41 \mathrm{Zu}$ den diesbezüglichen Satzungsbestimmungen vgl. die Satzung der CSU in der Fassung vom 4.10. 1946, abgedruckt in: Protokolle und Materialien, S. 1783-1803.

42 BSB, NL Schwend 1, Ansprache Hans Ehards zu den Kommunalwahlen vom 12. 5. 1948.

43 ACSP, CSU-LL, Protokoll der Sitzung des Landesvorstands am 17. 7. 1948. In der gleichen Sitzung wurde das Verfahren gegen Pfeiffer zunächst ausgesetzt, um zuvor eine interne Klärung zu versuchen. 
ern hatte bereits im Juni für diesen Fall mit ernsten Konsequenzen gedroht ${ }^{44}$. Die Parteiführung ließ sich davon aber nicht beeindrucken und beharrte darauf, der Rebellion Schäffers notfalls durch dessen Entfernung aus der CSU den Boden zu entziehen. Der ehemalige BVP-Vorsitzende hatte jedoch noch ein As im Ärmel. Wie schon zur Jahreswende 1947/1948 erwog Schäffer einen Übertritt zur Bayernpartei, möglicherweise zusammen mit seinem Bezirksverband. Diesbezügliche Überlegungen und Verhandlungen scheiterten aber sowohl an der unentschlossenen Haltung des Staatsrats als auch an Bedingungen und Vorbehalten aus der Führung der BP, wo man dem ehrgeizigen Schäffer zum Teil höchst skeptisch gegenüberstand ${ }^{45}$.

Bevor das Landesschiedsgericht über einen Ausschluß des Staatsrats verhandeln konnte, versuchte Alois Hundhammer in der Landtagsfraktion, seinen Kampfgefährten aus der politischen Schußlinie zu ziehen. Bereits im Februar 1948, wenige Tage nach der turbulenten Bezirksversammlung der oberbayerischen CSU, hatte man in der Fraktion ergebnislos über eine Entsendung Schäffers in den Frankfurter Wirtschaftsrat debattiert ${ }^{46}$. Als die Abgeordneten im August 1948 darüber zu entscheiden hatten, wer die bayerische Unionspartei im Parlamentarischen Rat vertreten sollte, machte Hundhammer den Vorschlag, Fritz Schäffer zu nominieren. Der Fraktionsvorsitzende verlieh seiner Empfehlung mit den Worten Nachdruck, daß von „der Frage, ob Schäffer delegiert werde oder nicht, [. . .] die künftige Einheit der Partei“ abhänge ${ }^{47}$. In einer ersten Abstimmung sprach sich die Unionsfraktion mit 48 gegen 16 Stimmen bei acht Enthaltungen für den Staatsrat aus.

Josef Müller und seine politischen Freunde liefen gegen die Nominierung Schäffers Sturm. Müller erklärte sogar: „Wenn [S]ie sich so entscheiden, zwingen [S]ie mich, aus dieser Partei auszutreten.“ Dabei spielten nicht nur die oberbayerische Revolte und Schäffers Kontakte zur Bayernpartei eine Rolle, sondern auch eine Zeugenaussage des Staatsrats in einem Beleidigungsprozeß, den der CSU-Vorsitzende gegen Anton Donhauser angestrengt hatte. In diesem Prozeß hatte der ehemalige BVP-Vorsitzende nach übereinstimmenden Angaben die Frage, ob er Josef Müller für einen „Befehlsempfänger" der SMAD in Karlshorst halte, mit Ja beantwortet ${ }^{48}$.

Schäffer lastete es später dem Landesvorsitzenden an, daß er nicht in den Parlamentarischen Rat delegiert wurde ${ }^{49}$. Tatsächlich waren es jedoch die Warnungen Hans Ehards, die die Fraktion schließlich umstimmten. Der Ministerpräsident forderte die Beilegung der persönlichen Differenzen zwischen Müller und Schäffer als Voraussetzung für die Nominierung des Staatsrats ${ }^{50}$. Sichtlich verärgert über die anhaltenden Auseinandersetzungen in der CSU, die auch dazu angetan waren, die Stellung Bayerns im Konzert der westdeutschen Länder zu schwächen, fügte Ehard hinzu: „Wenn der

44 IfZ-Archiv, ED 720 Smlg. Mintzel 37, Rundschreiben des Bezirksverbands Oberbayern der CSU vom 26. 7. 1948: "Verlauf der Bemühungen des Bezirksverbandes Oberbayern um eine innere Reform der CSU“.

45 Vgl. dazu Henzler, Fritz Schäffer, S. 155-265. Interessant ist auch der diesbezügliche Briefwechsel im Stadtarchiv Bamberg, NL Etzel 18.

46 ACSP, CSU-LTF 1, 15-14, Protokoll der Fraktionssitzung am 18. 2. 1948.

47 ACSP, CSU-LTF I, 15-14, Protokoll der Fraktionssitzung am 24. 8. 1948; das folgende nach dem Protokoll dieser Fraktionssitzung. Vgl. auch Kock, Bayerns Weg, S. 286, und Gelberg, Hans Ehard, S. 180-188.

48 ACSP, CSU-LTF I, 15-14, Protokoll der Fraktionssitzung am 25. 8. 1948.

49 BayHStA, NL Ehard 1675, Fritz Schäffer an Hans Ehard vom 20.12. 1948.

50 ACSP, CSU-LTF I, 15-14, Protokoll der Fraktionssitzung am 24. 8. 1948; das folgende Zitat ebenda. 
Ausgleich nicht herbeigeführt werden könne, müsse ein Schnitt gemacht werden." Die Fraktion beauftragte daraufhin Georg Meixner, Karl Schmid und Josef Fischer, einen Vermittlungsversuch zu unternehmen. Nachdem diese Initiative gescheitert war ${ }^{51}$, sahen sich die Abgeordneten erneut vor die Entscheidung gestellt, ob der Staatsrat nominiert werden sollte oder nicht. Diesmal sprach sich der Ministerpräsident vor der Abstimmung entschieden gegen Schäffer aus. Man könne nicht den Landesvorsitzenden durch die Aufstellung Schäffers desavouieren und zugleich Kompromisse in wichtigen Verfassungsfragen gefährden, die zwischen den verschiedenen innerparteilichen Gruppierungen mühsam ausgehandelt worden seien ${ }^{52}$. Obwohl diese Ausführungen den Überzeugungen und Intentionen Hundhammers zuwider liefen, gelang es dem Fraktionsvorsitzenden diesmal nicht, die Abgeordneten in seinem Sinne zu beeinflussen. Das Prestige des Ministerpräsidenten war dafür bereits zu groß. In der zweiten Abstimmung über eine Nominierung Schäffers votierten bei einer Enthaltung 62 Abgeordnete dagegen und nur 14 dafür $^{53}$.

Bezeichnend für diese Auseinandersetzung in der Fraktion war die Tatsache, daß viele Abgeordete für den Streit zwischen Müller und Schäffer kein Verständnis mehr aufbringen konnten und die Führungs- und Flügelkämpfe als rein persönlich motivierten Konflikt betrachteten. Josef Piechl sprach dies unter starkem Beifall am deutlichsten aus: „Wir auf dem Land hätten es satt, uns als Prügelknaben behandeln zu lassen für Schwierigkeiten einiger Persönlichkeiten, die bei gutem Willen aus der Welt zu schaffen wären. Wenn die Herren sich nicht einigen könnten, müssten beide weg.“

Zur gleichen Zeit kündigte das Landesschiedsgericht der CSU an, daß die Mitgliedschaft Schäffers vorübergehend ruhe und daß er am 16 . September vor die höchste Schiedsstelle der bayerischen Unionspartei geladen sei ${ }^{54}$. Doch dazu kam es nicht. Am 14. September trat Fritz Schäffer aus der CSU aus ${ }^{55}$. Unversöhnlich und etwas selbstgerecht begründete der Staatsrat diesen Schritt im Dezember 1948 so:

„Der Grund für mein Ausscheiden aus der CSU war ein sachlicher. Mein Bemühen war zu verhindern, dass die gutgesinnte, bodenständige bayerische Bevölkerung, die in den Tagen der Bayerischen Volkspartei zu einem Block zusammengeschmiedet worden war, der unzerbrechlich schien, in 2 Parteien auseinanderfallen würde. Nach den Wahlen zu den Kreistagen und Stadträten war es klar geworden, dass dieser Zerfall eingetreten war. Es war meine Ueberzeugung, dass dieser Zerfall die Schuld der Landesleitung der CSU war und dass diese die aufgerissene Kluft nur noch vertiefen würde. Wollte ich nunmehr meinem Ziel treu bleiben, so konnte ich meine Aufgabe nurmehr darin sehen, mich für eine spätere Zeit bereit zu halten, wo etwas dafür getan werden $\mathrm{k}[0 ̈] n n t e$, dass sich diese Wählerschaft wieder zusammenfinden würde. Dies setzt aber voraus, dass ich mich mit meinem Namen nicht an eine Richtung band, von der ich annehmen mußte, dass sie alles tun würde, ein solches Zusammenfinden zu verhindern. Der persönliche Grund

51 BayHStA, NL Ehard 1006, Aktennotiz über Vermittlungsversuche zwischen Fritz Schäffer und Josef Müller, ungezeichnet, undatiert; ACSP, CSU-LTF I, 15-14, Protokoll der Fraktionssitzung am 25. 8. 1948.

52 Ebenda. In diesem Protokoll heißt es weiter: „Ministerpräsident Dr. Ehard wandte sich gegen die Darstellung, dass nur Schäffer etwas verstünde. Seit 1945 hätte sich die Situation in einigem geändert. Die Atmosphäre sei so außerordentlich schwierig, dass man sie bloss durch Zusehen von aussen nicht kennen lernen könne.“ Ähnlich hatte er sich bereits am Tag zuvor geäußert: ACSP, CSU-LTF I, 15-14, Protokoll der Fraktionssitzung am 24. 8. 1948.

53 ACSP, CSU-LTF I, 15-14, Protokoll der Fraktionssitzung am 25. 8. 1948; das folgende Zitat ebenda.

54 Vgl. Henzler, Fritz Schäffer, S. 263 f.; BAK, NL Schäffer 24, Bl. 65 f., Fritz Schäffer an Heinrich Krehle vom 27. 8. 1948; interessantes Material über das Verfahren gegen Schäffer vor dem Landesschiedsgericht der CSU findet sich im ACSP, CSU-LSG, Mappe Fritz Schäffer.

55 BAK, NL Schäffer 24, Bl. 60, Fritz Schäffer an Josef Fuhrmann vom 14. 9. 1948. 
stand erst in zweiter Reihe. Auch er war nicht ein persönliches Gekränktsein. [...] Solange meine Rechte als Mitglied der CSU ruhten und ich formell Mitglied noch war, war ich nicht nur politisch völlig ausgeschaltet, ich war auch persönlich webrlos, innerhalb der CSU und außerhalb der CSU. Das Zwischenspiel in der Fraktion, wo meine Wahl in den Parlamentarischen Rat auf einen rein persönlich begründeten Widerspruch von Dr. Josef Müller hin abgelehnt wurde [...], war nur bezeichnend dafür, wie wenig sich meine Auffassungen über Ritterlichkeit in der Austragung meiner Meinungsverschiedenheiten mit denen der CSU deckten. ${ }^{\text {“56 }}$

Die oberbayerische Rebellion, die mit einem Paukenschlag begonnen hatte, endete, ohne besonderes Aufsehen zu erregen. Hundhammer übernahm erneut die Führung des Bezirksverbands, und kein Kreisverband war schließlich bereit, aus der CSU auszuscheiden ${ }^{57}$.

\section{Neue Konkurrenten und erste Wahlschlappen}

Die oberbayerische Rebellion ist nur verständlich, wenn man die wachsenden Erfolge der Bayernpartei mit in die Betrachtung einbezieht ${ }^{58}$. Diese bayerische Heimatpartei, die sich bald zum Kristallisationskern der „bayerischen Bewegung“ mauserte" ${ }^{59}$, ging auf die Demokratische Union zurück, die im November 1945 im Stadt- und Landkreis München gegründet worden war. Am 28. Oktober 1946 gab sich diese Gruppierung den Namen Bayernpartei. Die Militärregierung verweigerte der BP jedoch die Lizenz, so daß sie bis 1948 von den Wahlen ausgeschlossen blieb. Mit ihrem radikal bayerischföderalistischen Programm war die BP vor allem für diejenigen Wähler und Mitglieder der CSU interessant, die sich durch die bayerische Unionspartei nicht ausreichend vertreten sahen. Erste Warnsignale zeigten sich bereits im Vorfeld der außerordentlichen Landesversammlung der CSU in Eichstätt, als mit Anton von Aretin und Anton Donhauser zwei prominente Mitbegründer der CSU zur Bayernpartei übertraten ${ }^{60}$.

Zur Führungs- und Integrationsfigur der BP wurde der überaus populäre Joseph Baumgartner, der nach seinem Rücktritt als bayerischer Landwirtschaftsminister im Januar 1948 auch der CSU den Rücken kehrte und in der Bayernpartei schnell zum Landesvorsitzenden aufstieg ${ }^{61}$. Ob Josef Müller die Zeichen der Zeit erkannt hatte, ist ungewiß. Vor der Landtagsfraktion versuchte er jedenfalls noch im Januar 1948, die von der BP ausgehende Gefahr herunterzuspielen, wie aus einem Sitzungsprotokoll zu ersehen ist:

56 BayHStA, NL Ehard 1675, Fritz Schäffer an Hans Ehard vom 20.12. 1948; Hervorhebungen im Original.

57 Vgl. Henzler, Fritz Schäffer, S. 264 f.

58 Zur Geschichte der Bayernpartei bis 1948 vgl. den Überblick bei Mintzel, Bayernpartei, in: Stöss (Hrsg.), Parteien-Handbuch, Bd. 1, S. 397-402.

59 Vgl. Unger, Bayerische Bewegung, S. II.

${ }^{60}$ So warnte der Abgeordnete Max Allwein, der später ebenfalls zur Bayernpartei wechselte, im Sommer 1947 seine Fraktionskollegen: „Nicht Vogel-Strauss-Politik spielen in Bezug auf die BayernPartei. Sie birgt die Gefahr in sich, dass sie die CSU aufspalten könnte. Wenn wir nicht ernstlich daran gehen, ernstlich bayerische Politik zu treiben, so nimmt uns die Bayernpartei die Hälfte der Mandate weg. Noch hat die Bayernpartei keinen Kopf, wenn er da ist, dann werden wir zu beissen haben." ACSP, CSU-LTF I, 15-14, Protokoll der Fraktionssitzung am 21.8. 1947. Zur Perzeption der Bedrohung durch die Bayernpartei in der CSU-Führung: ACSP, NL Müller 394, Aktennotiz Josef Plonners für Josef Müller und Franz Liedig vom 21. 1. 1947 und Aktennotiz Emil Rettingers für Josef Müller vom 15. 7. 1947.

61 Vgl. Vossen, Joseph Baumgartner, S. 70. 
„Wenn nun Dr. Baumgartner zur Bayernpartei übergetreten sei, sehe er trotzdem keine Gefahr. In diesem Jahr würden wahrscheinlich Wahlen für ein deutsches Gremium kommen. Dabei werde die Bayernpartei der Union nicht schaden, weil sie in einem gesamtdeutschen Gremium nicht ins Gewicht fallen könne. Eine Chance könnte sich für die Bayernpartei nur ergeben, wenn Leute von anderen Parteien zu ihr stossen würden. Dr. Hoegner wird in seiner Partei stark erschüttert, selbst wenn er zur Bayernpartei ginge, würde er nicht viel mitnehmen. Wir seien mit Loritz fertig geworden und würden auch mit der Bayernpartei fertig werden. Dr. Müller zog die Parallele Bayernpartei - Patriotenpartei 1870 und wies darauf hin, dass auch bei der Patriotenpartei nach kurzer Zeit sich erwiesen hätte, in Deutschland könnten immer nur Weltanschauungsparteien Erfolg haben. Sollte die Bayernpartei, was er nicht annehme, aus der Fraktion 10-15 Leute herausreissen, würde eine Landtagswahl unvermeidlich, der Wahlkampf würde mit äusserster Härte geführt werden und wir würden ihn gewinnen. Er glaube, dass wir die Majorität in Bayern halten könnten. ${ }^{\text {"62 }}$

Wie weit diese Überlegungen des Ochsensepp an der Realität vorbeigingen, zeigte sich bald. Am 29. März 1948 wurde die Bayernpartei durch die Militärregierung auf Landesebene lizenziert. Damit war es der BP bei den Kommunalwahlen im April und Mai 1948 möglich, sich den Wählern zu stellen.

Seit die CSU 1946 von Wahlsieg zu Wahlsieg geeilt war, hatte sich die politische Szenerie grundlegend verändert. Der Unionsgedanke, der nach Kriegsende so vielen Menschen als Rettungsanker und Ausweg aus der deutschen Katastrophe erschienen war, hatte sich im Feuer der innerparteilichen Führungs- und Flügelkämpfe verzehrt, und die Aufbruchsstimmung aus den Gründungstagen war einer tiefgehenden Ernüchterung, ja Resignation gewichen. Diejenigen, die 1946 noch geglaubt hatten, die Auseinandersetzungen in der CSU seien mehr oder weniger zwangsläufige Kinderkrankheiten einer jungen Sammlungsbewegung, hatten feststellen müssen, daß sich die inneren Konflikte mit der Zeit verselbständigt und eine eigene Dynamik gewonnen hatten. Mit der Rückkehr Fritz Schäffers auf die politische Bühne wurde die innere Zerrissenheit der bayerischen Unionspartei auch für die breite Öffentlichkeit deutlicher denn je.

Aber auch die Rahmenbedingungen waren nicht mehr dieselben wie 1946. Dieser Faktor war für die Niederlagen der CSU bei den Kommunalwahlen des Frühjahrs 1948 vielleicht wichtiger als die anhaltenden innerparteilichen Auseinandersetzungen. Während bei den ersten Wahlen das Problem der staatlichen Neuordnung Deutschlands nur eine untergeordnete Rolle gespielt hatte, war die Diskussion um die „bayerische Frage“ zwei Jahre später voll entbrannt. Vor allem die angeblich höchst zentralistische Politik des Frankfurter Wirtschaftsrats wurde von den bayerisch-patriotischen Kreisen mit großem Mißtrauen verfolgt und zu einem zentralen Wahlkampfthema gemacht. Diese Strategie hatte auch Erfolg ${ }^{63}$. Schließlich lag der aufsehenerregende „bayerische Kartoffelkrieg“, den bayerische und bizonale Behörden - an der Spitze Landwirtschaftsminister Baumgartner und Hans Schlange-Schöningen, der Direktor der Verwaltung für Ernährung, Landwirtschaft und Forsten des Vereinigten Wirtschaftsgebiets um die Lieferung von Nahrungsmitteln aus Bayern in andere Länder der Bizone ausge-

62 ACSP, CSU-LTF I, 15-14, Protokoll der Fraktionssitzung am 27. 1. 1948.

${ }^{63}$ Zur Kritik am Frankfurter Wirtschaftsrat vgl. Kock, Bayerns Weg, S. 250-255, und Gelberg, Hans Ehard, S. 93-122. In einem Kommentar Edmund Goldschaggs hieß es nach den Kommunalwahlen in München: „Dieser Wahlausfall wird weitgehend bedingt durch die Ernährungs- und Wirtschaftspolitik des Wirtschaftsrates in Frankfurt und der dortigen Zweizonen-Behörden, die der Bayernpartei nahezu täglich neuen Agitationsstoff lieferten und im Lande eine Stimmung erzeugten, die bei der Wahl einer politischen Neuerscheinung wie der Bayernpartei zugute kommen mußte." SZ vom 1.6. 1948: „Ein Volksentscheid“. 
fochten hatten, erst wenige Monate zurück ${ }^{64}$. Zudem befand sich die CSU als alleinige Regierungspartei in einer Zeit der Unsicherheit und des allgegenwärtigen Mangels generell in einer schlechteren Ausgangsposition als 1946 ${ }^{65}$; konnte man damals noch aus der Rolle einer wenigstens nominellen Oppositionspartei heraus agieren, hieß es nun, unpopuläre Entscheidungen zu verteidigen, Mißerfolge zu vertreten und die Unzufriedenheit breiter Bevölkerungsschichten aufzufangen. Dies mußte der CSU um so schwerer fallen, als die amerikanische Militärregierung ihre bislang restriktive Haltung bei der Lizenzierung politischer Parteien lockerte und damit ein weiteres Stück auf dem Weg zur Demokratisierung der deutschen Gesellschaft freigab. 1946 hatte sich OMGBY nach der Lizenzierung von fünf Parteien geweigert, weiteren Gruppierungen die politische Betätigung auf Landesebene zu gestatten. Unter diesen Bedingungen kam es bei den ersten Wahlen zu einem Konzentrationsprozeß, von dem vor allem die CSU profitierte. Zwei Jahre später, im Vorfeld der Kommunalwahlen, erhielt nicht nur die Bayernpartei die lange erstrebte Lizenz, die Militärregierung ließ es auch erstmals zu, daß sich Flüchtlingsgruppierungen mit eigenen Listen zur Wahl stellten ${ }^{66}$.

Die Kommunalwahlen des Jahres 1948 brachten tatsächlich eine gewisse Zersplitterung des Parteiensystems mit sich, die sich in den kommenden Jahren fortsetzen sollte ${ }^{67}$. CSU und SPD konnten zwar erneut die Mehrheit der Stimmen gewinnen; die CSU mußte aber schwere, zum Teil erdrutschartige Verluste hinnehmen, während die SPD mehr oder weniger stagnierte. Die eindeutigen Gewinner der Kommunalwahlen waren die Bayernpartei und Flüchtlingsgruppierungen wie der Neubürgerbund. Zudem wurden 1948 vor allem bei den Gemeindewahlen wesentlich mehr parteiunabhängige Kandidaten gewählt als zwei Jahre zuvor. Die von inneren Krisen geschüttelte CSU kämpfte bei den Wahlen des Jahres 1948 an vier Fronten zugleich: Gegen die SPD, gegen die FDP, die sich vor allem in Franken als protestantische Alternative zur Union präsentierte und dort der CSU teilweise ähnlich zusetzte wie die Bayernpartei im Süden und Südosten Bayerns ${ }^{68}$, gegen die Flücht-

${ }^{6+}$ Vgl. Stelzle, Föderalismus und Eigenstaatlichkeit, S. 144-158, und Vossen, Joseph Baumgartner, S. 58-68, sowie Günter J. Trittel, Hunger und Politik. Die Ernährungskrise in der Bizone 1945-1949, Frankfurt am Main, New York 1990, S. 144-154; zu Schlange-Schöningen vgl. Günter J. Trittel, Hans Schlange-Schöningen. Ein vergessener Politiker der "Ersten Stunde“, in: VfZ 35 (1987), S. 25-63.

${ }^{65}$ Dies wurde in der Führungsriege der CSU allenthalben beklagt: Vgl. z. B. SZ vom 1. 6. 1948: „Auflösung des Landtags und Neuwahlen gefordert. Stimmen zum Ergebnis der Stadtratswahlen" "Josef Müller), oder IfZ-Archiv, RG 260, 10/90-3/4, „Subject: Stimmen zur Wahl“ vom 2.6. 1948 (Gespräch mit Adolf Miller) und „Subject: Stimmen zur Wahl“ vom 3. 6. 1948 (Gespräch mit dem Chefredakteur einer Münchner Zeitung).

${ }^{66}$ Zur Lockerung der Lizenzierungsbestimmungen vgl. Schröder, Parteien-Lizenzierungspolitik, in: ders., Bayern 1945, S. 14; zur Lizenzierung der Bayernpartei vgl. Konstanze Wolf, CSU und Bayernpartei. Ein besonderes Konkurrenzverhältnis, 1948-1960, Köln ${ }^{2} 1984$, S. 53 f.; zu den Anfängen der Flüchtlingsparteien am Beispiel Ansbach und Fürth vgl. Woller, Gesellschaft und Politik, S. 218-221.

${ }^{67}$ In einer vom Bayerischen Statistischen Landesamt herausgegebenen Analyse hieß es: „Die Gemeindewahlen des Jahres 1948 haben eine völlige Veränderung der politischen Struktur gebracht. [...] Der Wählerwille hat sich gewandelt. Die Zersplitterung der intellektuellen und bürgerlichen Schichten wirkt sich aus." Richard Schachtner, Die Wahlen in den Gemeinden und Kreisen Bayerns 1946 und 1948, München 1949, S. 10. Zur Zersplitterung und Neuordnung des westdeutschen Parteiensystems nach 1949 vgl. die skizzenhafte Darstellung von Andreas Biefang, Die Wiederentstehung politischer Parteien in Deutschland nach 1945, in: APuZ 18-19/95, S. 34-46, hier S. 35. Zu den Wahlergebnissen der CSU zwischen 1946 und 1950 vgl. auch Berberich, Historische Entwicklung, S. $128-158$.

${ }^{68}$ Vgl. Thränhardt, Wahlen und politische Strukturen, S. 316 und 320. 
lingsgruppierungen, die der CSU vor allem die katholischen und christlich-sozial eingestellten Wähler aus Schlesien und dem Sudetenland abspenstig machten ${ }^{69}$, und gegen die Bayernpartei, die mit ihrer prononciert bayerischen, radikal föderalistischen Programmatik bei vielen bisherigen Anhängern der CSU offene Türen einrannte. Die Bayernpartei trat im Wahlkampf selbstbewußt und dynamisch auf. Ihre Spitzenpolitiker agitierten gegen die bestehende Wohnungsnot oder die Ernährungskrise und besonders scharf gegen den Frankfurter Zentralismus. In München kündigten die mit weiß-blauen Rauten geschmückten Wahlplakate der Bayernpartei siegessicher an: „Wir kommen! “70

Mit den Kommunalwahlen des Frühjahrs 1948 begann für die CSU eine Serie von Niederlagen, die bis 1953 anhalten sollte. Bei den Gemeindewahlen am 25. April 1948 verlor die bayerische Unionspartei mehr als 15 Prozent der Stimmen und kam nur noch auf 28,3 Prozent; im Januar 1946 hatten noch 43,6 Prozent der Wähler für die CSU votiert. Da war es kein Trost, daß die SPD kein Kapital aus der Wahlschlappe der Union schlagen konnte und alle anderen Parteien, die erstmals antretende Bayernpartei eingeschlossen, unter der zwei-Prozent-Marke blieben.

\begin{tabular}{|c|c|c|}
\hline Partei & 1946 & 1948 \\
\hline CSU & 43,6 Prozent & 28,3 Prozent \\
\hline SPD & 16,6 Prozent & 17,6 Prozent \\
\hline KPD & 2,3 Prozent & 1,9 Prozent \\
\hline WAV & $\ldots$ & 0,2 Prozent \\
\hline FDP & 0,8 Prozent & 1,3 Prozent \\
\hline Deutscher Block & $\cdots-$ & 0,1 Prozent \\
\hline Bayernpartei & -..... & 1,8 Prozent \\
\hline Flüchtlingsgruppen & $\ldots$ & 11,3 Prozent \\
\hline Sonstige & 14,1 Prozent & 32,5 Prozent \\
\hline ohne Wahlvorschlag & 22,6 Prozent & 5,0 Prozent \\
\hline
\end{tabular}

${ }^{69}$ Diese Gefahr hatte man bei Teilen der CSU durchaus erkannt. So warnte der Bezirksverband Oberfranken bereits im Februar 1948 vor den überparteilichen Flüchtlingsgruppierungen und empfahl, die Union der Ausgewiesenen, die Flüchtlings- und Vertriebenenorganisation der CSU, mit eigenen Listen in den Wahlkampf zu schicken, um so wenigstens einen Teil dieses Wählerpotentials bei der CSU zu halten (ACSP, NL Müller 133, Alexander Schönwiese an Josef Müller vom 24. 2. 1948). Die Landesleitung folgte dieser Strategie, die jedoch nur teilweise aufging. August Haußleiter vermutete im Juni 1948, daß bei den Kommunalwahlen immerhin vier Prozent der Stimmen auf die Listen der UdA entfallen seien (ACSP, NL Müller 363, August Haußleiter an Josef Müller vom 14.6. 1948).

70 Vgl. dazu Wolf, CSU und BP, S. 53. Auf eine Umfrage der Süddeutschen Zeitung im Vorfeld der Stadtratswahlen in München antwortete die Bayernpartei: „Wir sorgen auch im Rathaus für eine bayerische Personalpolitik und bemühen uns um die Rückkehr aller evakuierten Münchner, ferner um eine scharfe Überwachung des Zuzugs, der Meldepflicht und des Arbeitsmarktes sowie um eine Erhöhung der öffentlichen Sicherheit. Der Großstadtjugend gilt unser Schutz vor körperlicher und seelischer Not und dem Sport unsere Förderung. Wir wünschen Vereinfachung des Bewirtschaftungswesens und Pflege des heimischen Handwerks und Gewerbes. Dem Wiederaufbau, der Verkehrsverbesserung, der Unterstützung der Opfer der vergangenen Katastrophenpolitik und dem kulturellen Ruf Münchens werden wir die notwendige Aufmerksamkeit widmen." SZ vom 29. 5. 1948: "Pläne der Parteien - Hoffnungen der Wähler. Zwölf Programme für die kommende Stadtratsarbeit. Letzte Vorbereitungen zum Wahlsonntag".

"Zusammengestellt nach Schachtner, Wahlen in den Gemeinden und Kreisen Bayerns, S. 10. 
Die Sieger der Gemeindewahlen standen außerhalb des bisherigen Parteienspektrums. Die Flüchtlingsgruppierungen gewannen 11,3 Prozent der Stimmen und konnten damit in vielen Stadt- und Gemeinderäten ein gewichtiges Wort mitsprechen. Auf nicht parteigebundene Kandidaten - ein Reflex auf die verbreiteten Ressentiments gegen politische Parteien - entfielen gar mehr als 30 Prozent. Es war auch den Zeitgenossen klar, daß sich Kommunalwahlen nicht mit den gleichen Maßstäben messen ließen wie Wahlen auf Landesebene ${ }^{72}$, aber dennoch deutete sich bereits bei den Gemeindewahlen eine schwerwiegende Veränderung der politischen Verhältnisse an.

Noch härter traf es die CSU bei den Kreistagswahlen, die am selben Tag stattfanden. Die bayerische Unionspartei blieb zwar die stärkste Kraft in den Landkreisen, sie verlor jedoch sage und schreibe 23,7 Prozent der Stimmen und kam nur noch auf 44,2 Prozent, nachdem sie zwei Jahre zuvor mit 67,9 Prozent einen triumphalen Wahlsieg gefeiert hatte. Neben den Flüchtlingsgruppen zählte diesmal vor allem die Bayernpartei zu den Wahlsiegern. Obwohl sie überhaupt nur in 37 - vor allem ober- und niederbayerischen - Landkreisen kandidiert hatte, errang sie landesweit 6,4 Prozent der Stimmen; die Bayernpartei hatte also in den Landkreisen, in denen sie sich zur Wahl gestellt hatte, 21,1 Prozent gewonnen! Daß dieser Erfolg vor allem auf Kosten der CSU zustandekam, steht außer Frage ${ }^{73}$.

$\begin{array}{lcc}\text { Ergebnisse der Kreistagswablen in Bayern } 1946 \text { und } 1948 \text { im Vergleich }^{74} \\ \text { Partei } & 1946 & 1948 \\ \text { CSU } & \text { 67,9 Prozent } & 44,2 \text { Prozent } \\ \text { SPD } & 22,9 \text { Prozent } & 21,4 \text { Prozent } \\ \text { KPD } & 3,9 \text { Prozent } & 2,7 \text { Prozent } \\ \text { WAV } & 0,5 \text { Prozent } & 0,9 \text { Prozent } \\ \text { FDP } & 1,5 \text { Prozent } & 4,0 \text { Prozent } \\ \text { Deutscher Block } & -\ldots-. & 0,3 \text { Prozent } \\ \text { Bayernpartei } & -\ldots .- & 6,4 \text { Prozent } \\ \text { Flüchtlingsgruppen } & --.-- & 15,2 \text { Prozent } \\ \text { Sonstige } & 3,3 \text { Prozent } & 4,9 \text { Prozent }\end{array}$

In Oberbayern, dem Zentrum der innerparteilichen Opposition gegen Josef Müller, waren die Verluste der CSU und die Stimmengewinne der Bayernpartei am größten.

\footnotetext{
72 Vgl. SZ vom 1. 6. 1948: „Auflösung des Landtags und Neuwahlen gefordert. Stimmen zum Ergebnis der Stadtratswahlen“; zu den Gemeindewahlen und zum neuen Wahlrecht, das erstmals auch das Kumulieren und Panaschieren der Stimmen erlaubte, vgl. auch Der Tag vom 21. 4. 1948: „Bayern wählt seine Gemeinderäte. Personen statt Listen - ein kompliziertes Wahlsystem “, und SZ vom 27. 4. 1948: „Sehr hohe Beteiligung bei den Gemeindewahlen. Wählermehrheit für Listenwahl. Bayernpartei und Flüchtlingslisten stark beachtet".

$73 \mathrm{Vgl}$. M. Hagmann, Die Land- und Stadtkreiswahlen in Bayern am 25. April und am 30. Mai 1948. Sonderheft der Reihe Bayern in Zahlen. Monatshefte des Bayerischen Statistischen Landesamts, München 1948, S. 3, und Thränhardt, Wahlen und politische Strukturen, S. 315-320, sowie Ilse Unger, Die Bayernpartei. Geschichte und Struktur 1945-1957, Stuttgart 1979, S. 96 ff.

${ }^{74}$ Zusammengestellt nach Schachtner, Wahlen in den Gemeinden und Kreisen Bayerns, S. 44.
} 


\section{Ergebnisse von CSU und Bayermpartei in oberbayerischen Landkreisen} bei den Kreistagswablen am 2S. April 1948

$\begin{array}{llll}\text { Landkreis } & \text { CSU 1946 } & \text { CSU 1948 } & \text { BP 1948 } \\ \text { Altötting } & \text { 67,5 Prozent } & \text { 33,4 Prozent } & \text { 22,0 Prozent } \\ \text { Bad Aibling } & \text { 63,0 Prozent } & \text { 27,8 Prozent } & \text { 25,7 Prozent } \\ \text { Dachau } & \text { keine Angabe } & \text { 42,2 Prozent } & 15,0 \text { Prozent } \\ \text { Ebersberg } & \text { 75,2 Prozent } & \text { 36,1 Prozent } & \text { 27,2 Prozent } \\ \text { Erding } & \text { 80,2 Prozent } & \text { 27,3 Prozent } & \text { 38,2 Prozent } \\ \text { Fürstenfeldbruck } & \text { 68,1 Prozent } & \text { 26,7 Prozent } & \text { 22,6 Prozent } \\ \text { Garmisch-Partenkirchen } & \text { 62,9 Prozent } & \text { 28,8 Prozent } & \text { 20,5 Prozent } \\ \text { Mübldorf } & \text { 76,1 Prozent } & \text { 27,0 Prozent } & \text { 30,9 Prozent } \\ \text { München-Land } & \text { 52,6 Prozent } & \text { 27,1 Prozent } & \text { 14,5 Prozent } \\ \text { Pfaffenhofen } & \text { 65,5 Prozent } & \text { 35,8 Prozent } & \text { 25,2 Prozent } \\ \text { Rosenheim } & \text { 74,1 Prozent } & \text { 32,6 Prozent } & \text { 29,6 Prozent } \\ \text { Schongau } & \text { 65,5 Prozent } & \text { 42,1 Prozent } & 12,8 \text { Prozent } \\ \text { Starnberg } & \text { 62,3 Prozent } & \text { 36,4 Prozent } & 16,5 \text { Prozent } \\ \text { Traunstein } & \text { 72,3 Prozent } & \text { 28,4 Prozent } & 31,4 \text { Prozent } \\ \text { Wasserburg } & \text { 83,2 Prozent } & \text { 31,2 Prozent } & 33,1 \text { Prozent } \\ \text { Wolfratshausen } & \text { 67,9 Prozent } & \text { 28,9 Prozent } & 17,4 \text { Prozent }\end{array}$

Bei einem Vergleich der Ergebnisse von CSU und Bayernpartei in 16 oberbayerischen Landkreisen fällt vor allem zweierlei auf: Zum einen führte die Kandidatur der Bayernpartei in all den oberbayerischen Landkreisen, in denen sie sich zur Wahl stellte, zum Verlust der absoluten Mehrheit der CSU. In den Landkreisen Erding, Mühldorf, Traunstein und Wasserburg wurde die BP sogar stärkste Partei und verwies die CSU auf den zweiten Platz; in Erding lag die BP mit 38,2 Prozent sogar fast elf Punkte vor der Union $^{75}$. Zum anderen waren die Verluste der CSU größer als die Stimmenanteile der erstmals auftretenden Bayernpartei. Die von inneren Konflikten zerrissene CSU verlor somit auch Stimmen an andere Parteien oder Wählervereinigungen, so daß man ihre Wahlniederlagen im Frühjahr 1948 nicht allein auf die Konkurrenz der Bayernpartei zurückführen kann. Die Union begann sichtbar an mehreren Stellen zu zerbröckeln.

Vier Wochen später, am 30. Mai 1948, erlebte die CSU bei den Wahlen in den Stadtkreisen ein erneutes Debakel. Nur noch 20,4 Prozent der Wähler waren bereit, der Union ihr Vertrauen zu schenken; 1946 waren es mehr als doppelt so viele gewesen. Auch die Sozialdemokratie verlor ca. acht Prozent der Stimmen, konnte sich aber trotz dieser Verluste als stärkste politische Kraft in den Stadtkreisen etablieren.

$\begin{array}{lcc}\text { Ergebnisse der Stadtkreiswablen in Bayern } 1946 \text { und } & 1948 \text { im } \text { Vergleich }^{76} \\ \text { Partei } & 1946 & 1948 \\ \text { CSU } & 45,1 \text { Prozent } & 20,4 \text { Prozent } \\ \text { SPD } & 38,0 \text { Prozent } & 29,8 \text { Prozent } \\ \text { WAV } & 3,3 \text { Prozent } & 3,7 \text { Prozent } \\ \text { KPD } & 6,9 \text { Prozent } & 9,7 \text { Prozent } \\ \text { FDP } & 3,9 \text { Prozent } & 8,4 \text { Prozent } \\ \text { Flüchtlingsgruppen } & -\cdots-. & 5,6 \text { Prozent } \\ \text { BP } & -. .- & 15,6 \text { Prozent } \\ \text { Deutscher Block } & -. .- & 0,8 \text { Prozent } \\ \text { Sonstige } & 2,8 \text { Prozent } & 6,6 \text { Prozent }\end{array}$

\footnotetext{
75 Vgl. Hagmann, Land- und Stadtkreiswahlen in Bayern, S. 3 und S. 14-17; danach auch die vorstehende Tabelle, in der alle oberbayerischen Landkreise aufgeführt sind, in denen die Bayernpartei kandidierte; die Namen der Landkreise, in denen die Bayernpartei vor der CSU lag, sind kursiv gesetzt.

${ }^{76}$ Zusammengestelit nach Schachtner, Wahlen in den Gemeinden und Kreisen Bayerns, S. 30.
} 
Den spektakulärsten Erfolg erzielte auch hier die Bayernpartei, die auf Anhieb mehr als 15 Prozent der Stimmen gewinnen konnte, obwohl sie nur in 26 Stadtkreisen kandidiert hatte. Mit 36,6 Prozent triumphierte die BP in Traunstein, auch in Deggendorf (34,5 Prozent) und Bamberg (26 Prozent) schnitt sie überdurchschnittlich gut ab, und selbst in Ansbach, dem protestantischen Herzen Mittelfrankens, stimmten 14,4 Prozent aller Wähler für die Bayernpartei ${ }^{77}$. Besonders schwer trafen die CSU die Niederlagen in den Metropolen München und Nürnberg. In der Landeshauptstadt verlor die Union mehr als 26 Prozent der Stimmen und fiel mit 18,7 Prozent hinter die SPD und die Bayernpartei auf den dritten Platz zurück. Selbst die konfessionell begrenzte BVP hatte bei den Reichstagswahlen im November 1932 mit 24,9 Prozent in München einen größeren Stimmenanteil erringen können als die Union 1948! In Nürnberg konnte die CSU nach 35,5 Prozent im Mai 1946 nur noch ganze 13,7 Prozent der Stimmen gewinnen ${ }^{78}$.

Dabei hatte sich die CSU bei den Stadtrats- und Kreistagswahlen in den mehrheitlich protestantischen Regierungsbezirken Mittel- und Oberfranken noch vergleichsweise gut geschlagen, wenn man bedenkt, daß das Ergebnis Oberfrankens (33,8 Prozent) noch vor dem Ergebnis Oberbayerns (30,1 Prozent) lag und selbst Mittelfranken mit 28,9 Prozent nur knapp hinter dem Ergebnis dieser geschleiften CSU-Bastion zurückblieb ${ }^{79}$. Die 50-Prozent-Marke konnte die Union lediglich in der Oberpfalz erreichen; in Unterfranken blieb sie knapp darunter. In allen anderen Regierungsbezirken lag die absolute Mehrheit außerhalb ihrer Reichweite.

\begin{tabular}{|c|c|c|c|}
\hline Regierungsbezirk & CSU & Bayernpartei & FDP \\
\hline $\begin{array}{l}\text { Oberbayern } \\
\text { Niederbayern } \\
\text { Oberpfalz } \\
\text { Oberfranken } \\
\text { Mittelfranken } \\
\text { Unterfranken } \\
\text { Schwaben } \\
\text { Bayern gesamt }\end{array}$ & $\begin{array}{l}\text { 30,1 Prozent } \\
\text { 44,8 Prozent } \\
\text { 50,0 Prozent } \\
\text { 33,8 Prozent } \\
\text { 28,9 Prozent } \\
\text { 49,6 Prozent } \\
\text { 43,9 Prozent } \\
\text { 37,8 Prozent }\end{array}$ & $\begin{array}{l}\text { 19,0 Prozent } \\
\text { 11,9 Prozent } \\
\text { 5,5 Prozent } \\
\text { 2,8 Prozent } \\
\text { 2,5 Prozent } \\
\text { 1,9 Prozent } \\
\text { 4,9 Prozent } \\
\text { 8,7 Prozent }\end{array}$ & $\begin{array}{r}\text { 3,5 Prozent } \\
\text { 1,8 Prozent } \\
\text { 2,1 Prozent } \\
\text { 10,4 Prozent } \\
\text { 12,1 Prozent } \\
\text { 2,6 Prozent } \\
\text { 2,5 Prozent } \\
\text { 5,1 Prozent }\end{array}$ \\
\hline
\end{tabular}

Eine vergleichende Untersuchung der Wahlergebnisse von CSU, FDP und Bayernpartei auf Bezirksebene zeigt deutlich, daß innerbayerische Regionalismen und Verwerfungen, die 1945/1946 in den Hintergrund gerückt waren, die politische Geographie Bayerns erneut zu beeinflussen begannen. Der Erfolg der Bayernpartei in Ober- und Niederbayern verwies auf die politische Spaltung der katholisch-konservativ und bayerisch-föderalistisch eingestellten Bevölkerung in zwei Lager, wie sie schon vor 1933 bestanden hatte. Die aufsehenerregenden Stimmengewinne der FDP in Ober- und Mittelfranken, die nahezu vollständig zu Lasten der CSU gingen, schwächten nicht nur die

77 Vgl. Hagmann, Land- und Stadtkreiswahlen in Bayern, S. 3 und S. 20-25.

$78 \mathrm{Vgl}$. Thränhardt, Wahlen und politische Strukturen, S. 308.

79 Josef Müller stellte nach den Stadtkreiswahlen fest, daß "sich das Schwergewicht der CSU von Oberbayern nach Franken und Südschwaben verschoben“ habe. SZ vom 5.6. 1948: „Dr. Müller: ,Empfindliche Belastung ““.

${ }^{80}$ Zusammengestellt nach Hagmann, Land- und Stadtkreiswahlen in Bayern, S. $6 \mathrm{f}$.; die folgenden Graphiken finden sich im Anhang zu: Schachtner, Wahlen in den Gemeinden und Kreisen Bayerns. 


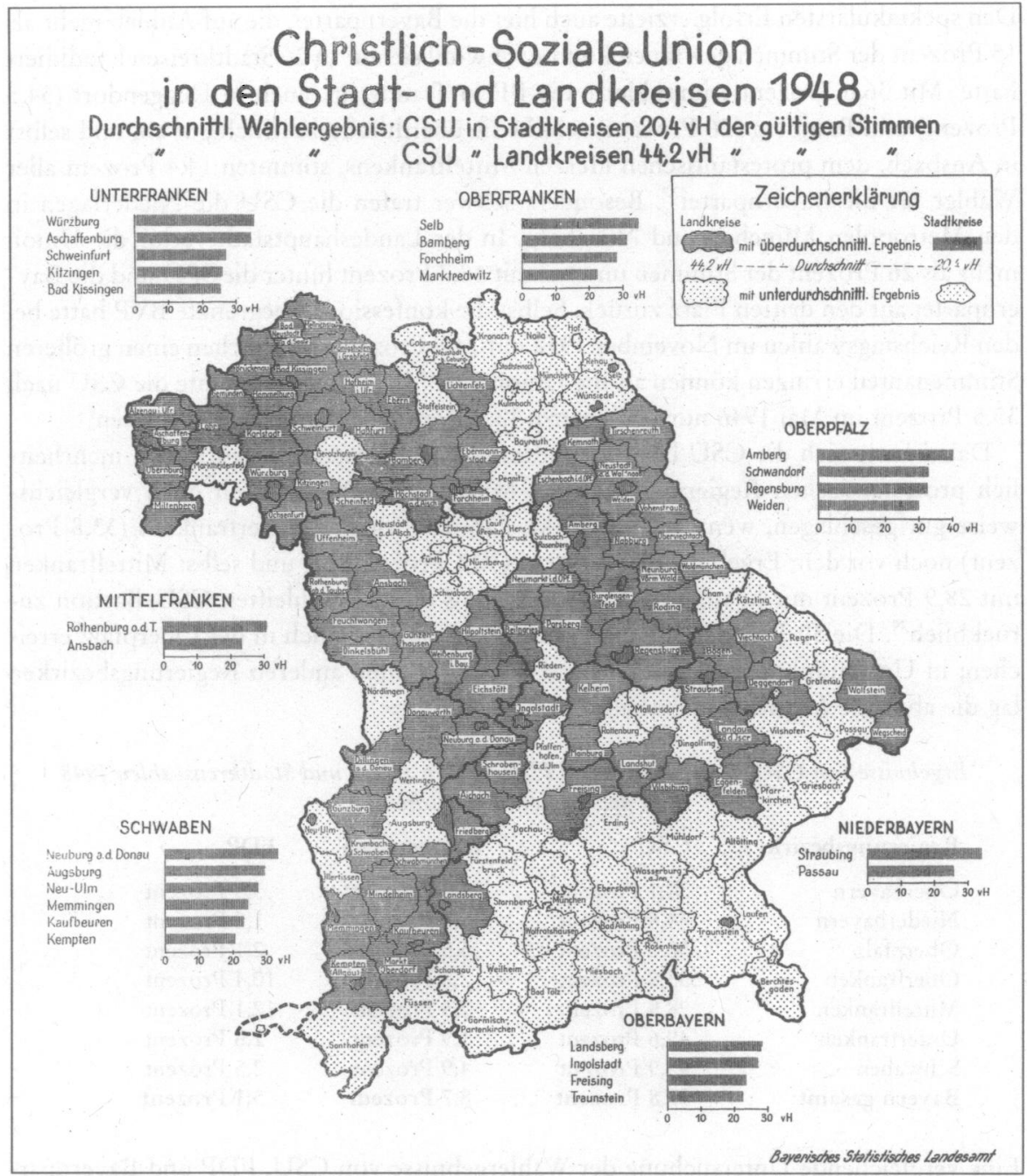

protestantische Komponente der Union nachhaltig, sondern erinnerten auch daran, daß diese Regionen einst zu den deutschnationalen und nationalliberalen Hochburgen gezählt hatten. Die CSU war zwar noch immer in allen Regierungsbezirken stark verankert - die Union hatte sogar in Mittelfranken noch fast 30 Prozent der Stimmen erhalten -, von den Erfolgen aus den Gründungstagen war die Partei aber weit entfernt.

Zwar hatte die Parteiführung nicht erwartet, daß man die zum Teil triumphalen Erfolge aus dem Jahre 1946 würde wiederholen können, mit einem derartigen Fiasko hatte jedoch niemand gerechnet ${ }^{81}$. Die erdrutschartigen Verluste bei den Kommunalwahlen führten zu

${ }^{81}$ IfZ-Archiv, RG 260, 10/90-3/4, „Subject: Stimmen zur Wahl“ vom 2.6. 1948 (Gespräch mit Adolf Miller). 


\section{Bayernpartei in den Stadt- und Landkpeisen 1948} Durchschnittl.Wahlergebnis: Bayernpartei in Stadtkpeisen 15,0 vH der gültigen Stimmen " Bayernpartei "Landkreisen 6,4 vH "
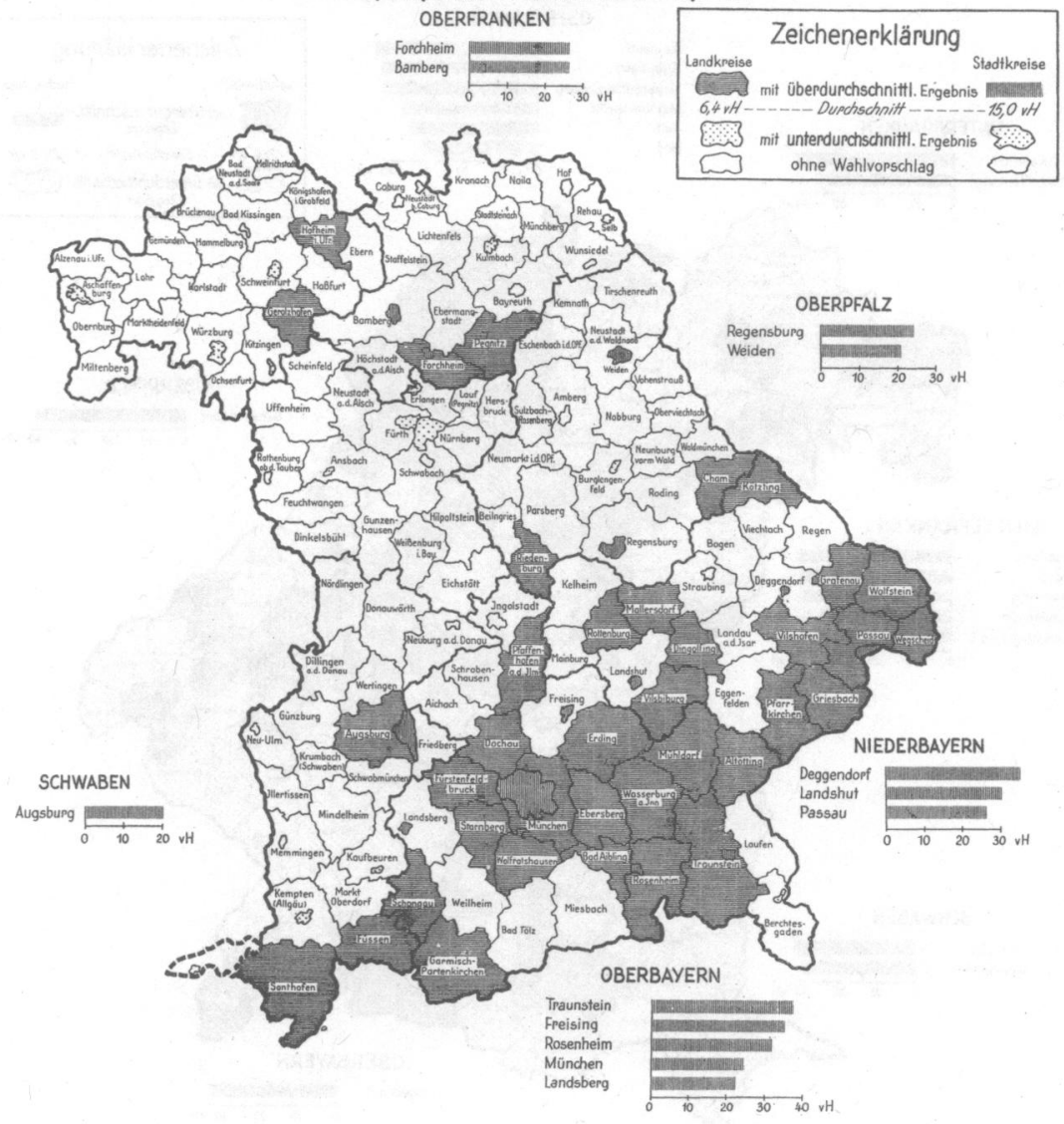

Bayenisches Statistisches Landesamt

einer sofortigen Verschärfung der parteïnternen Führungs- und Flügelkämpfe und brachten insbesondere den umstrittenen Parteivorsitzenden in die Bredouille. Müller und seine Mitstreiter versuchten zwar, die Bedeutung der Wahlniederlagen herunterzuspielen, angesichts des Ausmaßes der Stimmenverluste mußten solche Bemühungen aber auch dann hilflos, ja fast lächerlich erscheinen, wenn sie mit einigen durchaus vernünftigen Argumenten untermauert wurden ${ }^{82}$. Noch bevor die Kommunalwahlen zu Ende gegan-

\$2 ACSP, NL Müller 17, Rundschreiben der Landesgeschäftsstelle der CSU, Organisationsabteilung, an alle Bezirks- und Kreisverbände vom 30. 4. 1948; NL Müller 363, Telegramm Josef Müllers an Konrad Adenauer vom 1.6. 1948 und August Haußleiter an Konrad Adenauer vom 14.6. 1948; SZ vom 


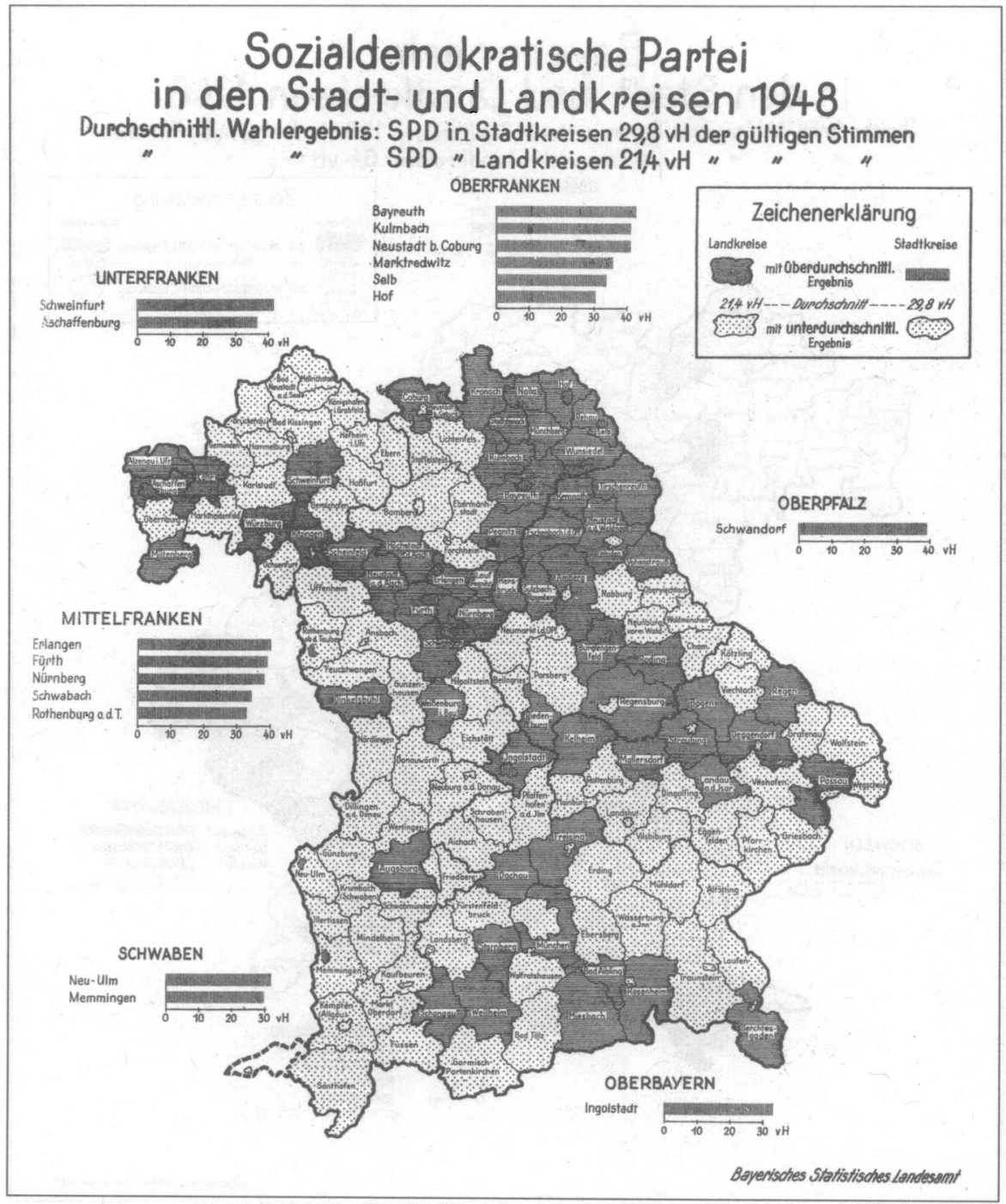

gen waren, begann in der CSU ein Streit über den künftigen Umgang mit der aufstrebenden Bayernpartei, der in den folgenden Jahren immer wieder aufflammen sollte ${ }^{83}$. Für den Landesvorsitzenden war die Sachlage klar: Eine Zusammenarbeit mit der BP kam keinesfalls in Frage; der Ochsensepp hielt vielmehr eine offensive Auseinandersetzung für das Gebot der Stunde ${ }^{84}$. So hieß es auch in einer Stellungnahme der Landesleitung zu den

1.6. 1948: „Auflösung des Landtags und Neuwahlen gefordert. Stimmen zum Ergebnis der Stadtratswahlen."

${ }^{3}$ Vgl. dazu ausführlich Wolf, CSU und BP, passim.

${ }^{84}$ SZ vom 5. 6. 1948: „Dr. Müller: ,Empfindliche Belastung،“. 


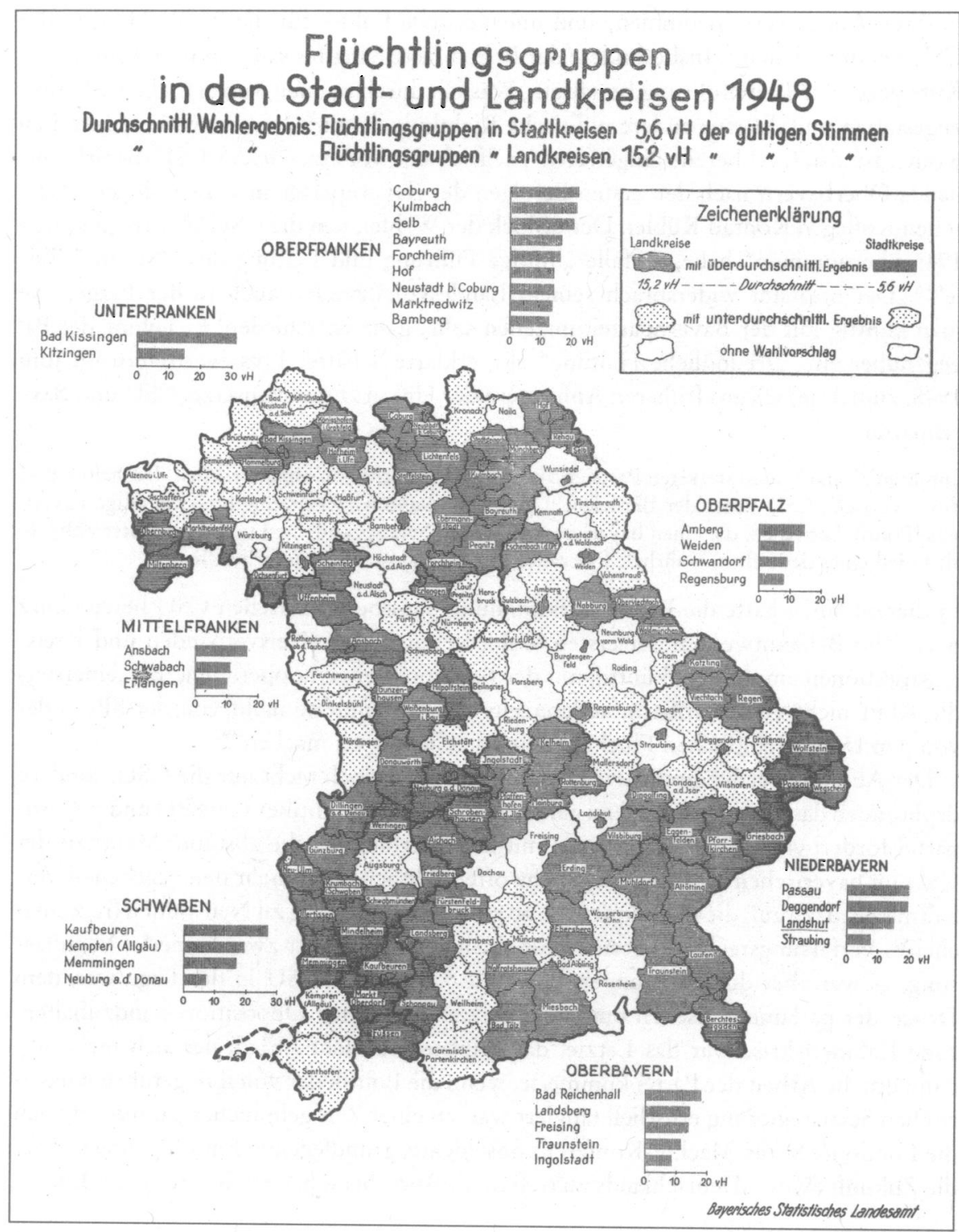

Ergebnissen der Gemeinde- und Kreistagswahlen, die Bayernpartei habe meist dort Erfolge erzielt, wo die CSU „nicht klar und eindeutig“ gegen sie Stellung genommen habe ${ }^{85}$. Die Vertreter der innerparteilichen Opposition schätzten die Situation grundlegend anders ein. Sie machten Josef Müller, „dieses nationale Unglück Bayerns“86, und seine

85 ACSP, NL Müller 17, Rundschreiben der Landesgeschäftsstelle der CSU, Organisationsabteilung, an alle Bezirks- und Kreisverbände vom 30. 4. 1948.

86 IfZ-Archiv, RG 260, 10/90-3/4, „Subject: Äußerungen zur Wahl“ vom 2.6. 1948; das Zitat stammt von Richard Jaeger. Der Vertrauensmann der Militärregierung notierte: „Jaeger war wic alle Leute 
in ihren Augen verschwommene und unbayerische Politik für die Wahlschlappen der CSU verantwortlich ${ }^{87}$. Insbesondere der Rebell Fritz Schäffer sah sich in seinem harten Kurs gegen die Parteiführung bestätigt: „Was ich durch meinen Versuch, die CSU umzugestalten und ihr eine andere politische Richtlinie damit zu geben, verhindert sehen wollte, ist also [...] bereits eingetreten“, schrieb der Vorsitzende des CSU-Bezirksverbands Oberbayern nach den ersten Erfolgen der Bayernpartei an seinen niederbayerischen Kollegen Konrad Kübler. Der „Block der Wähler, den die CSU als Erbe im Jahre 1945 übernommen“ habe, zerfalle ,infolge Führung und Leitung der CSU in 2 Teile ${ }^{\text {“88. }}$. Der Staatsrat widersprach seinem Landesvorsitzenden auch in der Frage, wie man künftig mit der Bayernpartei umgehen solle, ganz entschieden. Er nehme der BP gegenüber eine „freundliche Haltung“ ein, erklärte Schäffer Pressevertretern im Juni 1948, zumal sie sich aus früheren Anhängern der Union zusammensetze. CSU und Bayernpartei

„müßten als die beiden stärksten Parteien zum Wohle Bayerns zusammenarbeiten. Deshalb müsse die bayerische CSU unter der Berücksichtigung der Ausgewiesenen eine bodenständige bayerische Politik betreiben, die einen bayerischen Staat mit Staatspräsidenten und Mehrheitswahlrecht als Glied eines deutschen, wahrhaft föderalistischen Bundesstaates zum Ziele habe. ${ }^{\text {(89 }}$

In diesem Sinne hatte die Bezirksversammlung der oberbayerischen CSU bereits kurz nach dem Bekanntwerden der ersten Wahlergebnisse den Kreisverbänden und Kreistagsfraktionen empfohlen, künftig mit der Bayernpartei zu kooperieren, um „einerseits die Kluft nicht zu vergrößern, andererseits unsere Landräte nicht von der SPD oder von den Union-feindlichen Flüchtlingslisten abhängig zu machen “90.

Der Ausgang der Kommunalwahlen erschütterte jedoch nicht nur die CSU, sondern drohte auch das Kabinett Ehard zu gefährden. Führende Politiker von SPD und Bayernpartei forderten die Regierungspartei mit der Begründung, die absolute Mehrheit der CSU im bayerischen Landtag entspreche offensichtlich nicht mehr den gegebenen Verhältnissen, dazu auf, die Konsequenzen zu ziehen und den Weg zu Neuwahlen freizumachen $^{91}$. Verfassungsrechtlich bestand für einen solchen Schritt zwar keinerlei Veranlassung, es war aber durchaus ungewiß, ob die zerstrittene CSU in der Lage war, dem Druck der parlamentarischen und außerparlamentarischen Opposition standzuhalten. Eine Kabinettskrise war das Letzte, das Ministerpräsident Ehard, der sich meist nur dann um die Arbeit der Partei kümmerte, wenn die Politik der von ihm geführten bayerischen Staatsregierung ernstlich tangiert war, zu einer Zeit gebrauchen konnte, als sich die Londoner Sechs-Mächte-Konferenz anschickte, grundlegende Entscheidungen über die Zukunft (West-)Deutschlands zu treffen. Entsprechend harsch fiel die Kritik Ehards

der CSU, die ich bis jetzt nach der Wahl sprechen konnte, sehr von dem Ergebnis beeindruckt. Nur wurde mir nicht ganz klar, ob es mehr eine Enttäuschung über die Niederlage der Union war oder eine Freude über den Erfolg der Bayernpartei."

87 IfZ-Archiv, RG 260, 10/90-3/4, „Subject: Äußerungen zur Wahl“ vom 2.6. 1948 (Gespräch mit Adolf Miller); BAK, NL Schäffer 25, Bl. 155, August Albert an Fritz Schäffer vom 8. 6. 1948.

${ }^{88}$ BAK, NL Schäffer 25, Bl. 187, Fritz Schäffer an Konrad Kübler vom 30. 4. 1948.

${ }^{89}$ SZ vom 12. 6. 1948: „Schäffer für Zusammenarbeit mit der Bayernpartei“; Hervorhebung im Original.

90 BayHStA, NL Pfeiffer 535, Rundschreiben des CSU-Bezirksverbands Oberbayern an die „Herren Kreisvorsitzenden aller oberbayerischen Kreisverbände“, die Ergebnisse der Bezirksversammlung am 8.5. 1948 betreffend, vom 11.5. 1948.

"1 SZ vom 1. 6. 1948: „Auflösung des Landtags und Neuwahlen gefordert. Stimmen zum Ergebnis der Stadtratswahlen" und der Kommentar Edmund Goldschaggs "Ein Volksentscheid“, sowie der Kommentar "Nach den Wahlen" von "Junius“ (Hermann Proebst) in der SZ vom 5. 6. 1948. 
an Josef Müller aus, den er als Parteichef für die katastrophalen Wahlergebnisse der CSU verantwortlich machte. Der Ochsensepp wies solche Vorwürfe zwar weit von sich und kritisierte seinerseits die Regierungspolitik ${ }^{92}$. Ein ernstes Zerwürfnis mit dem populären und allseits geachteten Ministerpräsidenten, der längst als möglicher Nachfolger Müllers gehandelt wurde, konnte er sich jedoch keinesfalls leisten, da dies seine ohnehin geschwächte Stellung in der CSU noch weiter untergraben hätte. Die Gegner Müllers in der Landtagsfraktion ließen die Gelegenheit nicht ungenutzt verstreichen. In einer stürmischen Fraktionssitzung forderten sie Müller offen auf, seine Parteiämter niederzulegen - und sie standen nicht allein: Auch der Bezirksrat der Jungen Union München verlangte ultimativ den Rücktritt des Parteivorsitzenden ${ }^{93}$. Doch wieder einmal bewies Josef Müller Stehvermögen, und nachdem Ehard im Verein mit dem Parteivorsitzenden und der CSU-Fraktion den Vorstoß der SPD bezüglich der vorzeitigen Auflösung des Landtags abgewehrt hatte ${ }^{94}$, schien sich die Situation wieder zu beruhigen.

Die Parteiführung um den Ochsensepp geriet aber noch von einer anderen Seite her unter Beschuß. Die alarmierenden Stimmenverluste hatten Konrad Adenauer, den mächtigen und machtbewußten Vorsitzenden der CDU in der britischen Besatzungszone, dazu veranlaßt, sich zu Wort zu melden. Nachdem das Ergebnis der Stadtratswahlen in Bayern bekannt geworden war, erklärte Adenauer vor Pressevertretern, die Verluste der CSU seien vor allem auf die innerparteilichen Streitigkeiten zurückzuführen, die damit den "gefürchteten Erfolg“ gehabt hätten. „Man könne davon ausgehen“, so Adenauer weiter, daß die großen Stimmengewinne der Bayernpartei „zu einem sehr erheblichen Teil auf der Unzufriedenheit der Wählerschaft mit den fortgesetzten Kämpfen innerhalb der Leitung der CSU in Bayern“ beruhten. Im Namen der gesamten Anhänger und Freunde der CSU in allen Zonen richtete Adenauer „die dringende Bitte und das wärmste Verlangen an die CSU in Bayern, nun endlich Schluss zu machen mit dem Streit um die Führung“, da durch diesen "ständigen Streit [...] die gemeinsame christliche Sache in ganz Deutschland empfindlich geschädigt worden" sei ${ }^{95}$. Josef Müller und wenig später auch der stellvertretende Landesvorsitzende August Haußleiter reagierten empört auf diesen „Eingriff in die innerparteilichen Verhältnisse Bayerns“, zu dem kein Anlaß bestanden habe ${ }^{96}$. Die Erklärung Adenauers erbitterte den CSU-Vorsitzenden und seinen Stellvertreter vor allem deshalb, weil sie ihre Strategie, die Wahlschlappen der CSU als Resultat einer ungünstigen politischen Konstellation zu charakterisieren, konterkarierte und bei dem bekanntermaßen gespannten Verhältnis zwischen dem zu Jakob Kaiser neigenden Müller und Adenauer wie ein Mißtrauensvotum gegen die CSU-Führung um den Ochsensepp wirken mußte. Die Eröffnung einer weiteren Front in den innerparteilichen Führungs- und Flügelkämpfen belastete den angeschlagenen Landesvorsitzenden zusätzlich. Nach der Rebellion des Bezirksverbands Oberbayern und der Niederlagenserie bei den Kommunalwahlen kämpfte Müller nur noch um sein politisches Überleben.

92 Der Tag vom 9. 6. 1948: „Der Kurs der CSU-Fraktion in Bayern“; zum folgenden vgl. ebenda.

${ }^{93} \mathrm{SZ}$ vom 5. 6. 1948: „Münchner, Junge Union“ verlangt Rücktritt“.

94 Der Tag vom 10.6. 1948: „CSU-Regierung tritt nicht zurück“, und SZ vom 12.6. 1948: „Auflösung des bayerischen Landtags abgelehnt. Antwort der Regierung auf eine Interpellation der "SPD“.

95 ACSP, NL Müller 363, Wortlaut der Erklärung Konrad Adenauers zu den Stadtkreiswahlen in Bayern vom 31. 5. 1948. Vgl. dazu auch Mintzel, Anatomie, S. 246, der den Vorfall jedoch falsch datiert und offensichtlich auch das Verhältnis zwischen Müller und Adenauer nicht richtig einschätzt.

96 ACSP, NL Müller 363, Telegramm Josef Müllers an Konrad Adenauer vom 1.6. 1948 und August Haußleiter an Konrad Adenauer vom 14. 6. 1948; das Zitat ist dem Schreiben Haußleiters entnommen. 


\section{Die Währungsreform und der Zusammenbruch des Parteiapparats}

Neben der Revolte des Bezirksverbands Oberbayern, dem bedrohlichen Anwachsen der Bayernpartei und den Niederlagen bei den Kommunalwahlen war der Zerfall des mühsam errichteten Parteiapparats die vierte große Herausforderung, vor die sich die CSU im Jahre 1948 gestellt sah. Die Währungsreform in den Westzonen am 21. Juni 1948 entzog der bayerischen Unionspartei gleichsam über Nacht die finanzielle Basis, erzwang das Ende jeder zentral gesteuerten Organisationspolitik und setzte eine Entwicklung in Gang, die die CSU zu einer Honoratiorenpartei degenerieren ließ.

Der Aufbau der Parteiverwaltung, der 1946 im Zeichen zahlreicher Wahlkämpfe begonnen hatte, war auf eine Vielzahl von Hindernissen gestoßen ${ }^{97}$. Die unterschiedlichen, ja entgegengesetzten organisationspolitischen Konzeptionen Josef Müllers und des katholisch-konservativen Flügels waren dabei ein Problem erster Ordnung. Während der Landesvorsitzende versuchte, eine christlich-interkonfessionelle Sammlungspartei auf breiter Basis aufzubauen, und sich dabei eines zentral gesteuerten Parteiapparats zu bedienen gedachte ${ }^{98}$, weigerte sich die weitgehend an der Struktur der BVP orientierte Opposition um Alois Hundhammer, dem ungeliebten Parteichef ein solches Machtinstrument in die Hand zu geben. Bis zum Herbst 1946 wirkte es sich auch negativ aus, daß eine von der Militärregierung genehmigte und von den zuständigen Parteigremien verabschiedete Satzung fehlte ${ }^{99}$, ganz zu schweigen von einem Finanzstatut $^{100}$, dem der Landesausschuß erst am 3. Januar 1948 zustimmte ${ }^{101}$. Zwar setzte der Landesausschuß das Finanzstatut rückwirkend zum Januar 1947 in Kraft, Tatsache ist aber, daß die CSU bis 1948 ohne satzungsmäßig festgeschriebene Regelungen auskommen mußte. Als das Finanzstatut dann endlich verabschiedet war, verhinderte der mitglieder- und finanzstarke Bezirksverband Oberbayern mit seiner Weigerung, Mitgliederbeiträge an die Landesleitung abzuführen, eine geordnete Geschäftsführung. Die Währungsreform ließ das umstrittene Finanzstatut wenige Monate später endgültig zu Makulatur werden.

${ }^{97}$ Die noch immer beste Darstellung der Entwicklung des Parteiapparates der CSU bis 1948 bei Mintzel, Anatomie, S. 139-157.

98 Vgl. ebenda, S. 148.

99 ACSP, NL Müller 17, Notiz über eine „Besprechung organisatorischer Mängel in der Arbeit der Union und Diskussion von Verbesserungsvorschlägen" am 19. 8. 1946. Am Ende der Besprechung zog man folgendes Fazit: „Die Aussprache ergab, dass im ganzen Land die Kritik an der Führung und an der organisatorischen Arbeit der Union sehr lebhaft ist. Es besteht der Eindruck, dass eine klare Linie völlig fehlt und dass zuviel improvisiert und zu wenig planmässig gearbeitet wird. Die Kritik ist in wesentlichen Punkten berechtigt. Abhilfe ist notwendig."

100 Verschiedene Entwürfe für ein Finanzstatut der CSU aus den Jahren 1946 und 1947 finden sich im ACSP, NL Müller 19 und 20.

101 Finanzstatut der Christlich-Sozialen Union in Bayern, mit rückwirkender Geltung ab 1. 1. 1947 beschlossen am 3. 1. 1948, abgedruckt in: Protokolle und Materialien, S. 1811-1815. Zu den diesbezüglichen Querelen vgl. ACSP, NL Müller 17, Notiz über eine „Besprechung organisatorischer Mängel in der Arbeit der Union und Diskussion von Verbesserungsvorschlägen“ am 19.8. 1946. Noch im Januar 1947 bemerkte Landesgeschäftsführer Liedig: „Kreise und Bezirke hätten das Finanzstatut kritisiert, es sei unübersichtlich, unklar, und man wisse nicht, wie man sich verhalten solle. Die Kritiker seien aufgefordert worden, Gegenvorschläge einzureichen." ACSP, CSU-LL, Protokoll der Sitzung des geschäftsführenden Landesvorstands am 22. 1. 1947. 
Müller hatte seine Vorstellungen von einer effizienten Parteiverwaltung trotz aller Widerstände in der Satzung verankern können: Der Landesvorstand hatte das Recht erhalten, „zur Sicherung eines reibungslosen Geschäftsbetriebes“ in den Bezirken und Kreisen Geschäftsstellen einzurichten. Das Personal der Parteiverwaltung wurde vom Landesverband angestellt und besoldet. Obwohl festgelegt war, daß die Geschäftsstellen "rein verwaltungsmäßigen Charakter" haben müßten und nicht berechtigt seien, „sich in die politischen inneren Angelegenheiten der Verbände einzumischen “ ${ }^{102}$, ließ diese Regelung der Parteiführung genügend Spielraum zur Umsetzung ihrer organisationspolitischen Konzeption. Parteibüros wurden auf drei Ebenen errichtet: die Landesgeschäftsstelle in München als Zentrale des gesamten Parteiapparats, acht Bezirksgeschäftsstellen ${ }^{103}$ und Geschäftsstellen bei den Kreisverbänden. Bis 1948 gab es bei insgesamt 143 Kreisverbänden 99 Kreisgeschäftsstellen, sechs weitere Kreise wurden mitbetreut; bis zum 31. Juli 1948 waren damit noch 38 Kreisverbände ohne Geschäftsstelle. Der Landesvorstand hatte 78 hauptamtliche und neun nebenamtliche Kreisgeschäftsführer angestellt, zwölf Kreisgeschäftsführer arbeiteten ehrenamtlich ${ }^{104}$. In der Landesgeschäftsstelle war im ersten Halbjahr 1948 mit 45 Mitarbeitern der höchste Personalstand erreicht ${ }^{105}$. Zum Zeitpunkt der Währungsreform beschäftigte die bayerische Unionspartei ca. 185 haupt- und nebenamtliche Mitarbeiter ${ }^{106}$ und verfügte damit über ein Potential, das das der untergegangenen BVP bei weitem übertraf.

Allerdings hatte es schon früh kritische Stimmen gegeben. Ein so großer Parteiapparat sei im Falle einer Währungsumstellung nicht mehr zu finanzieren, hieß es. Solche Warnungen kamen nicht etwa nur aus den Reihen der innerparteilichen Opposition, die die Organisationspolitik der Parteiführung generell ablehnte, sondern auch von Mitarbeitern Josef Müllers wie Richard Schachtner ${ }^{107}$. Der Leiter der Abteilung Statistik und Finanzen in der Landesgeschäftsstelle hatte im November 1947 vor der Bezirksversammlung der niederbayerischen CSU erklärt, der Anteil der Personalkosten an den Gesamtausgaben der Partei sei mit ca. 75 Prozent so hoch, daß ihre finanzielle Handlungsfähigkeit sehr eingeschränkt sei. Nach „Beendigung der organisatorischen Anlaufszeit“, so hatte er weiter ausgeführt, sei es nötig, neue, kostengünstigere Wege zu suchen, da die "ausschliessliche Beschäftigung hauptamtlicher Kreisgeschäftsführer“ noch nicht „die Ideallösung der Parteiapparatur“ zu sein schien. In diesem Sinne hatte er angeregt, mehrere Geschäftsstellen zusammenzulegen oder die Kreisgeschäftsstellen ehrenamtlich durch die bisherigen Geschäftsführer weiterbetreuen zu lassen, nachdem man diese in gesicherte Positionen gebracht habe.

102 Satzung der CSU in der Fassung vom 4. 10. 1946, abgedruckt in: Protokolle und Materialien, S. 1783-1803, hier S. 1800.

103 Die Bezirksverbände Nürnberg-Fürth und Mittelfranken errichteten eine gemeinsame Geschäftsstelle in Nürnberg, die Bezirksverbände Augsburg und Schwaben in Augsburg; die übrigen Bezirksgeschäftsstellen waren in München (Oberbayern), Straubing (Niederbayern), Regensburg (Oberpfalz), München (München), Bamberg (Oberfranken), Würzburg (Unterfranken). Vgl. Mintzel, Anatomie, S. 152.

104 Zahlen nach ebenda, S. $151 \mathrm{f}$.

105 BayHStA, NL Ehard 131, Rundschreiben Richard Schachtners „Unions-Finanzen“ vom 23. 5. 1949.

106 Zahlenangaben nach den Daten bei Mintzel, Anatomie, S. 151, und Richard Schachtner: BayHStA, NL Ehard 131, Rundschreiben „Unions-Finanzen“ vom 23. 5. 1949.

107 ACSP, NL Müller 19, Memorandum Richard Schachtners „Die Finanzen der Union nach der Währungsreform" vom 24. 9. 1948; das folgende nach ebenda. Schachtner zitiert in diesem Memorandum seine Ausführungen vor der Bezirksversammlung der CSU Niederbayern im November 1947. Ähnlich auch ACSP, CSU-LTF I, 15-20/1, Hans Bartel an Alois Hundhammer vom 3. 11. 1948. 
Aufbau der CSU-Landesgeschäftsstelle am 1. Januar 1948 108 :

\begin{tabular}{|c|c|c|c|}
\hline & \multicolumn{3}{|c|}{$\begin{array}{l}\text { Landesgeschäftsführer: } \\
\text { Dr. Otto Schedl }\end{array}$} \\
\hline & Sekretariat: Egger, S. Hort & \multicolumn{2}{|c|}{$\begin{array}{l}\text { Verbindung zur Militär- } \\
\text { regierung: H. Haunhorst }\end{array}$} \\
\hline Arbeitsabteilungen & Ausschüsse & \multicolumn{2}{|c|}{ Arbeitsgemeinschaften } \\
\hline $\begin{array}{l}\text { Abt. I: Verwaltung } \\
\text { (Berlinghoff) }\end{array}$ & $\begin{array}{l}\text { Hauptbüro der Ausschüsse: } \\
\text { (Meyer-Gmunden) }\end{array}$ & & $\begin{array}{l}\text { Junge Union } \\
\text { (W. Fischer) }\end{array}$ \\
\hline $\begin{array}{l}\begin{array}{l}\text { Abt. II: Organisation } \\
\text { (W. Fischer) }\end{array} \\
\end{array}$ & & & $\begin{array}{l}\text { Flüchtlinge } \\
\text { (G. Nentwig) }\end{array}$ \\
\hline \multirow{2}{*}{$\begin{array}{c}\text { Abt. III: Statistik und } \\
\text { Finanzen } \\
\text { (R. Schachtner) } \\
\end{array}$} & \multicolumn{2}{|c|}{ Zwischenstaatlicher Ausschuß } & \multirow{2}{*}{$\begin{array}{c}\text { Frauen } \\
\text { (M. Probst) }\end{array}$} \\
\hline & \multicolumn{2}{|c|}{ Wirtschaftspolitischer Ausschuß } & \\
\hline \multirow{2}{*}{$\begin{array}{l}\text { Abt. IV: Werbung } \\
\text { (Dr. Schwink) }\end{array}$} & \multicolumn{2}{|c|}{ Sozialpolitischer Ausschuß } & $\begin{array}{l}\text { Arbeitnehmer } \\
\text { (S. Imhoff) }\end{array}$ \\
\hline & \multicolumn{2}{|c|}{ Ausschuß für Denazifizierungsfragen } & Handel, Gewerbe, \\
\hline \multirow{4}{*}{$\begin{array}{l}\text { Abt. V: Archiv und } \\
\text { Presse (H. Bengl) }\end{array}$} & \multicolumn{2}{|c|}{ Ausschuß für Verfassungsfragen } & Industrie \\
\hline & \multicolumn{2}{|c|}{ Kulturpolitischer Ausschuß } & \\
\hline & \multicolumn{2}{|c|}{ Agrarpolitischer Ausschuß } & \\
\hline & \multicolumn{2}{|c|}{ Kommunalpolitischer Ausschuß } & \\
\hline
\end{tabular}

Schachtners Mahnungen und Vorschläge stießen bei den Verantwortlichen zwar auf wenig Gegenliebe, die Währungsreform traf die CSU aber dennoch nicht gänzlich unvorbereitet. Als Müllers alter Kampfgefährte Franz Liedig im April 1948 die Nachfolge des unglücklich agierenden Max Grasmann ${ }^{109} \mathrm{im}$ Amt des Landesschatzmeisters antrat, ging er sofort daran, die beträchtlichen Beitragsrückstände bei den Bezirks- und Kreisverbänden einzutreiben ${ }^{110}$, um die Illiquidität der Landesgeschäftsstelle zu beseitigen und dem Tag der Währungsumstellung mit einem möglichst großen Guthaben entgegensehen zu können ${ }^{111}$. Tatsächlich blieben Liedigs Bemühungen nicht ohne Erfolg; im Juni 1948 war der Landesverband schuldenfrei und verfügte immerhin über

108 Stadtarchiv Ingolstadt, XXI/31, Schema des Aufbaus der CSU-Landesgeschäftsstelle am 1. 1. 1948.

109 ACSP, NL Müller 19, Aktennotiz Richard Schachtners „Kredit für die Parteien“ für Franz Liedig vom 13. 7. 1948.

110 Beispielsweise ACSP, CSU-LTF I, 15-12/4 und 5, Franz Liedig an Alois Hundhammer und nachrichtlich an den CSU-Kreisverband Ebersberg vom 14.6. 1948; nach einer Auskunft Franz Liedigs betrugen die „buchmäßig berechtigten Forderungen“ des Landesverbands "gegenüber den Parteiorganisationen im Lande rund 700.000 RM“. ACSP, CSU-LL, Protokoll der Sitzung des Landesvorstands am 17. 7. 1948.

11 ACSP, NL Müller 20, Rundschreiben Franz Liedigs an die Bezirks- und Kreisvorsitzenden sowie an die Bezirks- und Kreisgeschäftsführer vom 26. 6. 1948; ACSP, CSU-LL, Protokoll der Sitzung des Landesvorstands am 17. 7. 1948 (Franz Liedig). 
ein Guthaben von $160.000 \mathrm{RM}^{112}$. Die Frage war nur: was würde davon übrigbleiben? Die führenden CSU-Politiker hatten noch bis zuletzt gehofft, das Vermögen der Parteien würde ähnlich wie in der Tschechoslowakei oder in der sowjetischen Besatzungszone zu einem günstigeren Kurs umgerechnet werden ${ }^{113}$. Doch diese von Gerüchten und Spekulationen genährte Erwartung erwies sich als irrig, und Parteivermögen wurde am Tag der Währungsreform in den Westzonen zu demselben Satz abgewertet wie alle anderen Vermögenswerte. Nachdem das Kind in den Brunnen gefallen war, intervenierten Vertreter der wichtigsten bayerischen Parteien sowohl bei den zuständigen deutschen Stellen als auch bei der amerikanischen Militärregierung mit dem Ziel, eine nachträgliche Besserstellung zu erreichen. Sie forderten entweder eine Korrektur der Umwertungssätze - Parteivermögen sollte wenn schon nicht im Verhältnis 1:1, dann wenigstens im Verhältnis 5:1 in D-Mark umgerechnet werden -, eine Dotation aus öffentlichen Mitteln in der doppelten Höhe der höchsten Monatsausgaben seit Januar 1948 oder eine Zuwendung in der Höhe von 20-25 Pfennig je Wählerstimme bei den letzten Landtagswahlen ${ }^{114}$. Die Verhandlungsführer der Parteien begründeten ihre Forderungen damit, daß gerade in den schwierigen Wochen nach der Währungsreform ihre Aktivitäten besonders wichtig seien und $\mathrm{da}$ es eine politische Notwendigkeit sei, die Handlungsfähigkeit der Parteien auch in finanzieller Hinsicht zu gewährleisten $^{115}$. Hanswolf Haunhorst, der Verbindungsmann der CSU-Landesgeschäftsstelle zur Militärregierung, wies Anfang Juli den Chef der Governmental and Political Branch von OMGBY eindringlich darauf hin, daß seiner Partei unter den gegenwärtigen Bedingungen der sichere Bankrott drohe. Der Landesgeschäftsstelle stünden gerade einmal 8000 DM zur Verfügung, aber nur um die laufenden Personalkosten bestreiten zu können, benötige die Partei mehr als 100000 DM $^{116}$ !

Doch die Parteien drangen bei der Militärregierung mit ihren Forderungen nicht durch. Wenn man deren Wunsch nach Sonderkonditionen nachgeben würde, hieß es in einem Memorandum, würde man einen Präzedenzfall schaffen und eine Vielzahl anderer Organisationen ermuntern, dieselben Privilegien zu fordern ${ }^{117}$. Die Stabilität der neuen Währung hatte aber auch in den Augen der Militärregierung eindeutig Vorrang - bei allem Verständnis, das man den Sorgen und Nöten der Parteien entgegenbrachte. Hoffnung bestand lediglich auf einen zinsgünstigen Staatskredit, doch die Verhandlungen darüber zogen sich quälend lange hin ${ }^{118}$.

Inzwischen war guter Rat teuer und der Mangel an Geldmitteln in der neuen Währung allgegenwärtig. Um das schlimmste zu verhindern, hatte der Landesvorstand be-

112 Ebenda; IfZ-Archiv, RG 260, 13/149-3/3, Notiz John P. Bradfords „Complaint of the Political Parties" für Albert C. Schweizer vom 9. 7. 1948.

113 ACSP, CSU-LL, Protokoll der Sitzung des Landesvorstands am 17. 7. 1948 (Franz Liedig).

114 ACSP, NL Müller 20, Franz Liedig an den Generalsekretär der Arbeitsgemeinschaft von CDU und CSU, den Landesvorstand der CDU Hessen und den Landesvorstand der CDU Württemberg-Baden vom 29. 6. 1948.

115 ACSP, NL Müller 20, Aktennotiz über eine Besprechung von Parteivertretern mit Vertretern der amerikanischen Militärregierung am 24.6. 1948.

116 IfZ-Archiv, RG 260, 13/149-3/3, Notiz John P. Bradfords "Complaint of the Political Parties“ für Albert C. Schweizer vom 9. 7. 1948.

11 IfZ-Archiv, RG 260, 10/130-3/1, Memorandum „Currency Reform Cripples Party Finances“, undatiert.

118 ACSP, NL Müller 19, Aktennotiz Richard Schachtners „Kredit für die Parteien“ für Franz Liedig vom 13. 7. 1948 
reits Ende Juni allen haupt- und nebenamtlichen Geschäftsführern und den von der Landesgeschäftsstelle besoldeten Hilfskräften mit Wirkung vom 31. Juli 1948 vorsorglich gekündigt ${ }^{119}$. Da die Gehälter der Parteiangestellten für die Monate Juni und Juli aber bereits in voller Höhe in D-Mark ausbezahlt werden mußten, geriet das Budget des Landesverbands dennoch aus den Fugen ${ }^{120}$. Den Verantwortlichen war klar, daß der Parteiapparat erheblich reduziert werden mußte. Sie versuchten jedoch, das bisherige System zumindest im Kern beizubehalten und das organisatorische Gerüst einer zentral gesteuerten Parteiverwaltung über die finanzielle Durststrecke hinweg zu retten. Als Richard Pflaum, der Vertreter des Bezirksverbands München im Landesvorstand, am 17. Juli vorschlug, zur Entlastung des Landesverbands die Kreisverbände selbst für die Finanzierung ihrer Geschäftsstellen aufkommen zu lassen, lehnte Josef Müller ab:

„Freund Pflaum, es ist das eine alte Frage. Aber erfahrungsgemäß werden dort am meisten Mitglieder geworben, wo wir tüchtige Geschäftsführer haben. Die große Sorge war die Mitgliederwerbung. Hier ist daher ein Überblick unbedingt notwendig. Es ist etwas anderes, ob man nun alle Kreisgeschäftsführer draußen beläßt, ob man nicht einige Kreise zusammenfaßt; aber organisatorisch wird die Partei immer viel besser fundiert sein, wenn die Geschäftsführer zentral gesteuert werden. Das hat gar nichts zu tun mit Ihrer Politik draußen. Es kommt darauf an, daß die Organisation als solche immer funktioniert. Wir haben die Erfahrung gemacht: Wenn man es dem einzelnen Geschäftsführer überläßt, wird es viel schwieriger und dann kommt vor allem in jeden einzelnen Ort bald der Krach hinein."

In diesem Sinne sollten in der Landesgeschäftsstelle zwei Drittel des Personals, in den Bezirken und Kreisen möglichst 35 bis 50 Prozent gehalten werden ${ }^{121}$. Allerdings war die Zahl der Kreisgeschäftsführer, die man in der Landesleitung für brauchbar hielt, ohnehin begrenzt ${ }^{122}$. Von den 99 haupt-, neben- und ehrenamtlichen Kreisgeschäftsführern wurden lediglich 20-22 als wirklicher Gewinn für die Partei erachtet, also weniger als 25 Prozent! Mit dieser Feststellung gab die Organisationsabteilung der Landesgeschäftsstelle selbst ein vernichtendes Urteil über die Personalpolitik der letzten Jahre ab. Doch nun gedachte man aus der Not eine Tugend zu machen. Statt möglichst viele hauptamtliche Kräfte zu beschäftigen, sollte in Zukunft ein zwar zahlenmäßig begrenzter, aber hochqualifizierter Mitarbeiterstamm herangebildet werden. In diesem Sinne sahen die Planungen der Landesleitung vor, möglichst viele Personalkosten zu sparen, aber wenigstens ein weitmaschiges Netz an Parteibüros aufrechtzuerhalten. Man machte den Bezirksgeschäftsstellen daher den Vorschlag, je drei bis vier Kreisgeschäftsstellen zu sogenannten Kreishauptgeschäftsstellen zusammenzufassen. Etwa vier oder fünf solcher Parteibüros mit je einem hauptamtlichen Geschäftsführer an der Spitze sollten in jedem Bezirk die Weiterführung der politischen und organisatorischen Arbeit vor Ort gewährleisten ${ }^{123}$.

119 ACSP, CSU-LL, Protokoll der Sitzung des Landesvorstands am 17. 7. 1948 (Franz Liedig); vgl. auch Mintzel, Anatomie, S. 234.

120 ACSP, CSU-LL, Protokoll der Sitzung des Landesvorstands am 17. 7. 1948 (Franz Liedig); das folgende Zitat ebenda.

121 Angaben nach ebenda, und ACSP, NL Müller 21, Notiz der Organisationsabteilung der Landesgeschäftsstelle, gez. Oskar Dinkel, bezüglich der „Kündigung der haupt- und nebenamtlichen Kräfte bei den Bezirks- und Kreisverbänden“"vom 2. 7. 1948; vgl. auch Mintzel, Anatomie, S. 235.

122 ACSP, NL Müller 21, Notiz der Organisationsabteilung der Landesgeschäftsstelle, gez. Oskar Dinkel, bezüglich der „Kündigung der haupt- und nebenamtlichen Kräfte bei den Bezirks- und Kreisverbänden" vom 2. 7. 1948.

$123 \mathrm{Vgl}$. Mintzel, Anatomie, S. 234. 
Doch auch das kostete Geld. Um die notwendigsten Mittel aufzutreiben, verstärkte die Landesleitung unmittelbar nach der Währungsreform ihre Werbungs- und Sammlungstätigkeit; dies brachte im Juni und Juli 1948 immerhin 10000 DM ein ${ }^{124}$. Zugleich versuchte man, Spenden von den Parteimitgliedern zu erwirken, die Mandate innehatten oder öffentliche Ämter bekleideten. Dies schien für viele verantwortliche CSU-Politiker auf Landes-, Bezirks- und Kreisebene das einzige Mittel zu sein, um wenigstens an einen Teil des benötigten Geldes zu kommen. Einfache Parteimitglieder konnte man nicht zwingen, ihre Beiträge zu bezahlen. Minister, Staatssekretäre, Landräte oder Landtagsabgeordnete ließen sich dagegen nicht nur moralisch unter Druck setzen, sondern auch durch die mehr oder weniger versteckte Drohung, die CSU werde das nächste Mal ihre Kandidatur nicht mehr unterstützen, wenn sie der Partei jetzt nicht finanziell unter die Arme griffen ${ }^{125}$. So machte Otto Schedl den Vorschlag, von den rund 250 Personen, „die ihre Stellung und damit ihr Einkommen der Union verdanken und dieserhalb zu erhöhten Opfern moralisch verpflichtet sind“, eine Gesamtsumme von $24800 \mathrm{DM}$ zu erheben. Schedl machte gegenüber dem Parteivorsitzenden aus seiner Entschlossenheit, die Amts- und Mandatsträger zur Kasse zu bitten, keinen Hehl:

„Wenn dieser Personenkreis in dieser kritischen Stunde nicht bereit ist, ein fühlbares Opfer zu bringen, dann ist er an den falschen Platz gestellt und dann ist es Zeit, dass die Gesamtpartei hier einen grundlegenden Wechsel vornimmt. Sollte aber, was ich nicht im Entferntesten annehme, die Union unter der gegenwärtigen wirtschaftlichen Krise zusammenbrechen, dann hat sie kein anderes Schicksal verdient. [...] Sollte ein Minister an 500 Mark mehr kleben als an der Union, so sei so freundlich und befreie die Union von solchen Repräsentanten.“

Die dringenden Bitten, ein Opfer für die Partei zu bringen, stießen freilich meist auf taube Ohren. Die Landtagsfraktion gewährte zunächst nur eine einmalige Abgabe von $25 \mathrm{DM}$ pro Mitglied - unter strengen Auflagen ${ }^{126}$. Im Durchschnitt führte ein Landtagsabgeordneter nach der Währungsreform gerade sieben DM pro Monat an den Landesverband $a b^{127}$. Bei den Regierungsmitgliedern hatte die Aktion noch weniger Erfolg. Etwa die Hälfte der Minister und Staatssekretäre hatte vier Wochen nach der Währungsumstellung trotz teilweise wiederholter Bitten nichts gezahlt. Insgesamt spendeten die Kabinettsmitglieder bis Mai 1949 ganze 3090 DM. In der Parteizentrale

${ }^{124}$ BayHStA, NL Ehard 131, Rundschreiben „Unions-Finanzen“ vom 23. 5. 1949; ACSP, CSU-LL, Protokoll der Sitzung des Landesvorstands am 17. 7. 1948 (Franz Liedig); ACSP, NL Müller 19, "Reisebericht über die von der Notgemeinschaft durchgeführte Rundreise“ vom 14.-17. 7. 1948.

125 ACSP, NL Müller 19, Aktennotiz Richard Schachtners vom 30. 6. 1948; NL Müller 109, Rundschreiben Fritz Schäffers an die Vorsitzenden der oberbayerischen Kreisverbände vom 2. 7. 1948; NL Müller 150, Georg Gamperl an Josef Müller vom 5. 7. 1948; BayHStA, NL Pfeiffer 535, Fritz Schäffer an Anton Pfeiffer vom 1.7. und 2. 7. 1948; ACSP, NL Müller 18, Otto Schedl an Josef Müller vom 5. 7. 1948; die folgenden Zitate ebenda.

126 Diesen Beschluß faßte die Landtagsfraktion am 30. 6. 1948; ACSP, CSU-LTF I, 15-14, Protokoll der Fraktionssitzung am 30.6. 1948. Die Fraktionsgeschäftsstelle informierte die Bezirksverbände, für die zwei Fünftel des Geldes gedacht waren, am 6. 7. 1948 mit einem Rundschreiben über den Beschluß der Abgeordneten. Am 25. 8.1948 hatten von 103 CSU-Abgeordneten immerhin 94 die fälligen 25 DM bezahlt. Die Landesgeschäftsstelle hatte sich schon am 1. 7.1948 im voraus bei der Fraktion bedankt. Alle zitierten Dokumente finden sich im ACSP, CSU-LTF, Mappe Sonderumlage. Weitere finanzielle Hilfsmaßnahmen beschloß die Fraktion im Dezember 1948 und Februar 1949. ACSP, CSU-LTF I, 15-14, Protokolle der Fraktionssitzungen am 14. 12. 1948 und 17. 2. 1949.

127 BayHStA, NL Ehard 131, Rundschreiben "Unions-Finanzen“" vom 23. 5. 1949; zum folgenden vgl. ebenda. 
war man mit diesem Ergebnis alles andere als zufrieden. Besonders die Mitarbeiter der Landesgeschäftsstelle, die sich angesichts der katastrophalen Lage zu einer „Notgemeinschaft" zusammengeschlossen hatten, fühlten sich im Stich gelassen. Die einmalige Spende der Landtagsfraktion stehe „hinsichtlich der Opferbereitschaft für die Christlich-Soziale Union in keinem Verhältnis zu der Tatsache, daß das hauptberufliche Personal der Partei bis heute“ mit lächerlich geringen Überbrückungshilfen, den sogenannten "Schwimmwestenbeträgen“, zu arbeiten bereit gewesen sei, hieß es am 10. September 1948 in einem Schreiben der „Notgemeinschaft“ an den geschäftsführenden Landesvorstand der CSU ${ }^{128}$. Solidarität und Spendenfreudigkeit der festbesoldeten Amts- und Mandatsträger nahmen jedoch auch in den folgenden Monaten nicht zu.

Die Landesgeschäftsstelle hatte Ende Juni auch die Bezirks- und Kreisverbände aufgefordert, der Parteizentrale je nach Möglichkeit Geldmittel zukommen zu lassen ${ }^{129}$. Wegen der miserablen Zahlungsmoral der meisten Suborganisationen hatte diese Initiative aber von vornherein nur wenig Aussicht auf Erfolg. Immerhin versuchten die Arbeitsgemeinschaften, den angeschlagenen Landesverband finanziell $\mathrm{zu}$ unterstützen, wenngleich diese Bemühungen trotz einiger Anfangserfolge ebenfalls zum Scheitern verurteilt waren. Daran änderte auch der neu gegründete Wirtschaftsbeirat der Union nichts, in den man anfangs große Hoffnungen gesetzt hatte ${ }^{130}$. Das mag auch daran gelegen haben, daß der Landesvorsitzende wenigstens in den ersten Wochen der Misere einer bestimmten Art von Spenden gegenüber skeptisch blieb:

„Wir haben im Rahmen des Möglichen alles unternommen. Es kommt mir heute wie ehedem darauf an, keine Mittel zu nehmen, die irgendwie politisch zweckgebunden sind. Denn unsere Partei als eine christliche und soziale Partei kann es sich nicht leisten, daß sie in Abhängigkeit gerät von irgendwelchen, ich möchte sagen, um das Kind beim Namen zu nennen, kapitalistischen Gruppen. Das wäre unmöglich. Wenn man das tun würde, ginge es vielleicht leichter. Ich habe aber Aktionen eingeleitet von Leuten, die uns nahe standen, und ich habe die berechtigte Hoffnung, daß wir wenigstens soviel haben, daß wir einigermaßen den Betrieb durchhalten können. ${ }^{\text {"131 }}$

Dieses optimistische Fazit, das sich letztlich als illusionär erweisen sollte, lag vor allem in der Hoffnung auf einen zinsgünstigen Kredit begründet, für den der bayerische Staat die Bürgschaft übernehmen sollte. Diesbezügliche Verhandlungen wurden bereits wenige Tage nach der Währungsreform aufgenommen, und am 22. Juli 1948 erhielt die CSU auf Weisung des Finanzministeriums tatsächlich einen Kredit in der Höhe von 79700 DM, der mit 3 1/8 Prozent verzinst und im Laufe des Jahres 1949 zurückgezahlt werden sollte. Schon am 23. Juli kam die erste Rate in einer Höhe von 39850 DM zur Auszahlung, den Rest sollte die CSU am 15. bzw. 31. August bekommen ${ }^{132}$. Doch ab-

128 ACSP, NL Müller 20, „Notgemeinschaft“ der Mitarbeiter der CSU-Landesgeschäftsstelle an den geschäftsführenden Landesvorstand vom 10. 9. 1948.

129 ACSP, NL Müller 20, Rundschreiben Franz Liedigs an die Bezirks- und Kreisvorsitzenden sowie an die Bezirks- und Kreisgeschäftsführer vom 26. 6. 1948.

130 ACSP, CSU-LL, Protokoll.der Sitzung des geschäftsführenden Landesvorstands am 23. 12. 1948; Dokumente zum Aufbau des Wirtschaftsbeirats der Union finden sich im ACSP, NL Müller 49; in diesem Zusammenhang besonders interessant ist ein Memorandum mit der Überschrift „Vorschlag des Wirtschaftsbeirates der Union zur finanziellen Sicherung der Parteien“; eine erste, sehr mäßige Bilanz der Sammlungstätigkeit des Wirtschaftsbeirats findet sich im ACSP, NL Müller 19, Aufstellung der Abteilung Statistik und Finanzen der Landesgeschäftsstelle vom 3. 9. 1948.

131 ACSP, CSU-LL, Protokoll der Sitzung des Landesvorstands am 17. 7. 1948.

132 IfZ-Archiv, RG 260, 13/150-3/1, Bayerische Staatsbank an CSU-Landesgeschäftsstelle vom 26. 7. 
gesehen davon, daß sich die Verantwortlichen keine Gedanken über die Rückzahlung des Kredits gemacht hatten, reichte er gerade aus, um die größten Löcher im Budget der Landesgeschäftsstelle zu stopfen. Überdies erlebten die Verantwortlichen bald eine böse Überraschung. Nach einer Intervention der Finanzabteilung von OMGUS weigerte sich die Bayerische Staatsbank, die zweite Hälfte des bereits bewilligten Kredits auszuzahlen ${ }^{133}$.

Damit waren die Planungen der Verantwortlichen in der Landesgeschäftsstelle einmal mehr über den Haufen geworfen. Diese Entwicklung war um so schmerzlicher, als die sonstigen Einnahmen bei weitem nicht ausreichten, um die laufenden Kosten zu decken. Von den 79352,71 DM, die bei der Landesgeschäftsstelle zwischen dem 21. Juni und dem 20. September 1948 eingingen, stammten 52818,40 DM aus dem Kredit der Bayerischen Staatsbank oder sonstigen Überbrückungshilfen, 3659,20 DM aus dem Verkauf von Unions-Bausteinen, 8330,60 DM aus dem Pressefonds der Partei, 10995,37 DM aus Spenden und 341,90 DM aus sonstigen Quellen. An Mitgliederbeiträgen waren dagegen nur 3207,24 DM in der Parteizentrale eingegangen; eigentlich hätte dieser Posten seit Juni 1948 bei monatlich 36945 DM liegen müssen ${ }^{134}$ ! Richard Schachtner erklärte im September 1948 unmißverständlich, es sei nur dann möglich, den Parteiapparat im bisherigen Umfang zu erhalten, wenn die Mitgliederbeiträge auch wirklich in der vollen Höhe an die Landesgeschäftsstelle abgeführt würden, und er fügte hinzu: „Allen denen, die heute der Union die Beiträge vorenthalten, wird es noch einmal klar aufgehen, dass sie die große Union zu ihrer eigenen Interessenvertretung bitter notwendig hätten. " 135

Schwierigkeiten mit den Mitgliederbeiträgen hatte es in der CSU schon lange gegeben. So standen dem Landesverband laut Finanzstatut vom normalen Beitragssatz, der eine Mark im Monat betrug, für das Jahr 194750 Pfennig pro Monat und Mitglied zu. Tatsächlich gingen im Durchschnitt nur 32 Pfennig bei der Landesgeschäftsstelle ein. 1948 verschlechterte sich die Lage dramatisch. Anstatt der im Finanzstatut für das erste Halbjahr 1948 vorgesehenen 45 Pfennig pro Mitglied und Monat wurden nur 18 Pfennig an den Landesverband abgeführt. Von den 20 Pfennig pro Mitglied und Monat, die dem Landesverband nach einigen organisatorischen Änderungen seit dem zweiten Halbjahr 1948 zugestanden hätten, wurden gar nur noch vier Pfennig bezahlt. Diese Tendenz hielt auch 1949 an. In den ersten Monaten des Jahres erhielt die Landesleitung anstatt der vorgesehenen 20 Pfennig lediglich drei Pfennig pro Mitglied und Monat von den Kreisverbänden. So entstand die paradoxe Situation, daß die Landesgeschäftsstelle nicht einmal mehr die dringendsten Rechnungen begleichen konnte,

1948. Die Höhe des Kredits richtete sich nach der Anzahl der Wählerstimmen, die die CSU bei den Landtagswahlen im Dezember 1946 erhalten hatte. Für jede Stimme wurden der CSU fünf Pfennig gutgeschrieben. Das war zwar besser als nichts, blieb aber erheblich hinter den Erwartungen der Parteien zurück, die mit 20-25 Pfennig pro Wählerstimme kalkuliert hatten. ACSP, NL Müller 20, Franz Liedig an den Generalsekretär der Arbeitsgemeinschaft von CDU und CSU, den Landesvorstand der CDU Hessen und den Landesvorstand der CDU Württemberg-Baden vom 29. 6. 1948.

133 ACSP, NL Müller 19, Aktennotiz Richard Schachtners für Josef Müller vom 20. 8. 1948, und NL Müller 20, Franz Liedig an Josef Müller vom 26. 10. 1948.

134 ACSP, NL Müller 19, Memorandum Richard Schachtners „Die Finanzen der Union nach der Währungsreform" vom 24. 9. 1948.

135 ACSP, NL Müller 19, Aufstellung Richard Schachtners „Mitglieder und Organisation der Union im Monat Juli $1948 “$ vom 9. 9. 1948. 
während ihre Forderungen an die Kreise mehrere hunderttausend Mark betrugen. Für die Zeit zwischen Anfang 1947 und Juni 1948 verzeichnete man Beitragsrückstände von 308000 RM, von Juli 1948 bis März 1949 waren noch einmal 112000 DM aufgelaufen $^{136}$. Bis Dezember 1948 zählte die Landesgeschäftsstelle nur 58 Kreisverbände, die seit der Währungsreform Beiträge an den Landesverband abgeführt hatten, wenn diese auch zumeist weit unter dem Soll lagen ${ }^{137}$. Von den 176 Kreisverbänden blieben bis Mai 1949130 mehr als die Hälfte ihrer Beiträge schuldig ${ }^{138}$.

Eng mit dem Beitragsaufkommen und damit mit der Finanzlage der bayerischen Unionspartei insgesamt verknüpft war die Entwicklung der Mitgliederzahl, die im April 1948 mit 85646 ihren höchsten Stand erreicht hatte ${ }^{139}$. Im Juni, dem Monat der Währungsreform, hatte sich die Zahl der CSU-Mitglieder mit 85310 noch nicht wesentlich von dieser Marke entfernt; die Partei konnte in diesem Monat sogar noch einmal mehr neue Mitglieder gewinnen (547), als sie durch Austritte, Wegzug oder Tod verlor (484). Der Bezirksverband Oberbayern zählte 22817 Mitglieder, Niederbayern und die Oberpfalz 26315, Oberfranken und Mittelfranken 14462, Unterfranken 10255 und Schwaben $11461^{140}$. Daß im Juli 1948 ungefähr 1200 Männer und Frauen aus der CSU austraten ${ }^{141}$, nahm man in der Landesgeschäftsstelle nicht besonders tragisch. Unter den überaus ungünstigen wirtschaftlichen Verhältnissen nach der Währungsreform könne diese Zahl "als ein Zeichen bester Unions-Stabilität“ gewertet werden, stellte Richard Schachtner zufrieden fest ${ }^{142}$. Allerdings mußte er einräumen, daß die Abgänge weiter anhalten würden, insbesondere dann, wenn die Kreisvorsitzenden wieder den Mut aufbrächten, Mitgliederbeiträge zu kassieren. Schachtner vermutete sogar, daß viele Vorsitzende „dazu ein förmliches Verbot an ihre Geschäftsführer erteilt“ hätten, um eine Austrittswelle zu verhindern. In der Tat hatten einige Kreisverbände bereits in den Monaten Juni und Juli empfindliche Verluste erlitten. Der Kreisverband Schongau, die politische Heimat von Franz Josef Strauß, verlor in diesen Wochen 236 Mitglieder, Hilpoltstein büßte allein im Juli 132 Mitglieder ein, Krumbach und Neu-Ulm-Land je 101. Daß kein Grund zum Optimismus vorlag, zeigt auch ein Blick auf die Zahl der Ortsverbände, von denen im Juli 1948 immerhin 18 aufgelöst werden mußten; damit sank die Zahl der Ortsverbände auf 3256 und die

136 BayHStA, NL Ehard 131, Rundschreiben „Unions-Finanzen“ vom 23. 5. 1949.

137 ACSP, NL Müller 19, Bericht Richard Schachtners über die Finanzlage der Union vom 17. 12.1948.

138 ACSP, NL Müller 16, Rundschreiben Franz Josef Strauß‘ vom 6. 5. 1949.

139 BayHStA, NL Ehard 131, Rundschreiben „Unions-Finanzen“ vom 23. 5. 1949; Mintzel, Anatomie, S. 169, ging von rund 82000 als dem höchsten Mitgliederstand aus. Eine detaillierte Analyse der Mitgliederstruktur ebenda, S. 166-193.

140 IfZ-Archiv, RG 260, 13/150-1/16, Politischer Tätigkeitsbericht der CSU für den Monat Juni 1948 vom 9. 7. 1948. Diese Mitgliederzahlen sind nicht unproblematisch, da sie auf den Meldungen der Bezirks- und Kreisverbände an die Landesgeschäftsstelle beruhen. Da diese Meldungen aber immer wieder verspätet, unvollständig oder überhaupt nicht eingingen, war die Landesgeschäftsstelle gezwungen, auf veraltetes oder fehlerhaftes Zahlenmaterial zurückzugreifen. Aus diesem Grund sind die Angaben der Landesgeschäftsstelle teilweise widersprüchlich und unzuverlässig, und je weiter der Zerfall des Parteiapparats fortschritt, desto weniger Verlaß ist auf die Daten der Landesleitung.

141 ACSP, NL Müller 19, Aufstellung Richard Schachtners „Mitglieder und Organisation der Union im Monat Juli 1948“ vom 9. 9. 1948, und IfZ-Archiv, RG 260, 13/150-1/15, Politischer Tätigkeitsbericht der CSU für den Monat Juli 1948 vom 12. 8. 1948.

142 Hierzu und zum folgenden ACSP, NL Müller 19, Aufstellung Richard Schachtners „Mitglieder und Organisation der Union im Monat Juli 1948“ vom 9. 9. 1948. 
Organisationsdichte der CSU auf 47,5 Prozent. Doch es sollte noch weitaus schlimmer kommen. Im November 1948 hatte die CSU bereits weniger als 80000 Mitglieder ${ }^{143}$, und im März 1949 wies sie einen Mitgliederstand auf, der unter dem vom Dezember 1946 lag (ca. 73000$)^{144}$. Im Mai 1949 gehörten nur noch 69444 Männer und Frauen der CSU an ${ }^{145}$, die damit in einem Jahr mehr als 15000 Mitglieder verloren hatte.

Die Gründe für den erdrutschartigen Verlust an Mitgliedern waren vielfältig. $\mathrm{Zu}$ nennen wäre etwa der Protest gegen die Parteiführung um Josef Müller, der besonders in Ober- und Niederbayern dazu führte, daß viele der CSU den Rücken kehrten und teilweise der Bayernpartei beitraten, die 1947 und 1948 einen großen Mitgliederzuwachs zu verzeichnen hatte ${ }^{146}$. Hinzu kam die Frustration über die andauernden Führungs- und Flügelkämpfe, die ähnliche Konsequenzen hatte. Ein Teil der Mitglieder ließ die Mitgliedschaft im Zuge der Währungsreform auch einfach erlöschen. Anton Kunze, der Geschäftsführer des CSU-Kreisverbands Freising, berichtete im November 1948 alarmiert an die Landesgeschäftsstelle:

„Unsere aktivsten Mitglieder, Kreistagsmitglieder und Ortsvereinsobmänner erklären den Austritt bzw. drohen damit. Als Grund wird meist angegeben: Lassts mich in Ruh, ich will nichts mehr wissen. Die Mitgliedsbeiträge dürften im kommenden Jahre kaum zur Hälfte eingehen. An Spenden ist, besonders unter der Landbevölkerung, kaum zu denken. Diese Teilnahmslosigkeit hat besonders in den letzten Wochen überhand genommen. Der Grund ist wohl die Entäuschung über die Währungsreform. Früher hatten die Leute Geld, und wenn sie auch dafür nichts erhielten, sie konnten sich einbilden, etwas zu besitzen. Durch die Wegnahme der Sparvermögen ist die Unzufriedenheit derart stark geworden, dass ich für das Bestehen der CSU die stärksten Befürchtungen habe." 147

Mitgliederschwund und Finanzkrise gingen eine unheilvolle Allianz ein. Durch die wachsende Zahl derer, die der Union die Gefolgschaft verweigerten, sank - verstärkt durch die ohnehin miserable Zahlungsmoral - das Beitragsaufkommen kontinuierlich. Dadurch war der Parteiapparat nicht mehr finanzierbar und mußte abgebaut werden, so daß es kaum mehr möglich war, neue Mitglieder zu werben oder auch nur vor Ort die fälligen Beiträge zu kassieren. August Haußleiter brachte das Problem auf den Punkt, als er vor der Fraktion erklärte: „Es herrscht ein Circulus vitiosus. Wir haben kein Geld, weil wir keine Organisation haben, und wir haben keine Organisation, weil wir kein Geld haben. “148

143 IfZ-Archiv, RG 260, 13/150-1/13, Politischer Tätigkeitsbericht der CSU für den Monat Oktober 1948 vom 12.11. 1948.

144 IfZ-Archiv, RG 260, 13/150-1/5, Politischer Tätigkeitsbericht der CSU für den Monat März 1949 vom 18. 4. 1949, und BayHStA, NL Ehard 131, Rundschreiben "Unions-Finanzen“ vom 23. 5. 1949.

145 IfZ-Archiv, RG 260, 13/150-1/9, Politischer Tätigkeitsbericht der CSU für den Monat Mai 1949 vom 20. 6. 1949.

146 Vgl. dazu Mintzel, Anatomie, S. 236. Die Bayernpartei konnte ihren Mitgliederstand zwischen Dezember 1948 und Oktober 1949 trotz der Währungsreform von 15060 auf 25763 erhöhen. Vgl. Unger, Bayernpartei, S. 73.

147 ACSP, NL Müller 117, Anton Kunze an die Landesgeschäftsstelle der CSU und die Geschäftsstelle des Bezirksverbands Oberbayern vom 30.11. 1948; ähnlich auch BSB, NL Schwend 2, Karl Niebling an den CSU-Kreisverband Ansbach, den Bezirksverband Mittelfranken und den Landesverband vom 17.8. 1948.

148 ACSP, CSU-LTF I, 15-14, Protokoll der Fraktionssitzung am 12. 10. 1948. 
Mitgliederentwicklung zwischen Juni 1948 und Mai $1949^{149}$

$\begin{array}{lllc}\text { Monat } & \text { Gesamtzahl } & \text { Neuaufnahmen } & \text { Abgänge } \\ \text { Juni } & 85310 & 547 & 484 \\ \text { Juli } & 83260 & 357 & 2360^{150} \\ \text { August } & 82102 & 242 & 1477 \\ \text { September } & 81514 & 135 & 955 \\ \text { Oktober } & 80437 & 118 & 1124 \\ \text { November } & 79008 & 101 & 1275 \\ \text { Dezember } & 76402 & 132 & 2359 \\ \text { Januar } & 75151 & 243 & 1593 \\ \text { Februar } & 73333 & 129 & 1577 \\ \text { März } & 72570 & 102 & 814 \\ \text { April } & 70436 & 137 & 1716 \\ \text { Mai } & 69444 & 154 & 950\end{array}$

Schon vor der Währungsreform hatten die Mitgliederbeiträge kaum ausgereicht, um die anfallenden Personalkosten zu decken ${ }^{151}$. So mußte die Landesleitung zusätzliche Geldquellen erschließen, um ihren Verpflichtungen nachkommen zu können. Seit 1948 überstiegen die außerordentlichen Einnahmen die regulären Einkünfte des Landesverbands aus Mitgliederbeiträgen, nachdem sie sich 1947 noch einigermaßen die Waage gehalten hatten. Insgesamt nahm die Landesgeschäftsstelle zwischen 1946 und Mai 1949 rund zwei Millionen Mark ein, wovon nur 35 Prozent aus Beiträgen stammten. Nach der Währungsreform nahm das Mißverhältnis zwischen Mitgliederbeiträgen und außerordentlichen Einnahmen krasse Ausmaße an. Von 100 DM, die in der Landesgeschäftsstelle eingingen, stammten gerade einmal zehn DM aus Beitragsgeldern ${ }^{152}$. Die Umstellung von der Reichsmark auf die D-Mark brachte den endgültigen Zusammenbruch der ohnehin schlechten Zahlungsdisziplin - mit katastrophalen Folgen für die Landespartei. Schatzmeister Schachtner schrieb resigniert:

„Erklärend ist zu bemerken, daß die Union noch nie ein Zahlverein war. In ihrer Mitgliederschichtung stellen die kleinbürgerlichen und kleinbäuerlichen Kreise die Hauptanteile. Wie sich gezeigt hat, sind Normalbeiträge bei uns nicht ohne weiteres durchführbar. Die Arbeiterparteien haben es leichter. Sie erheben vielfach am Arbeitsplatz und beim Lohnempfang ihren Parteibeitrag. Bei uns führte die Beitragserhebung vor allem nach der Geldreform nicht selten zu Austritten. Selbst gut situierte Parteifreunde haben bereits bei ihrem Eintritt erklärt, daß sie sich zu einem Beitragssatz nur bis zur Währungsreform verpflichten können. Dabei wollen wir nicht vergessen, daß unsere Mitglieder nicht unerheblich an der Aufbringung der Beiträge für die Kirchen,

149 Zusammengestellt nach den Politischen Tätigkeitsberichten der CSU für die Monate Juni 1948 bis Mai 1949; IfZ-Archiv, RG 260, 13/150-1/1; 13/150-1/2; 13/150-1/3; 13/150-1/5; 13/150-1/6; 13/150-1/9; $13 / 150-1 / 13 ; 13 / 150-1 / 14 ; 13 / 150-1 / 15 ; 13 / 150-1 / 16$. Die Zahlenangaben der Landesgeschäftsstellc für die amerikanische Militärregierung sind an einigen Stellen offensichtlich nicht stimmig, an anderen standen keine aktuellen Zahlen zur Verfügung. Die Rubrik „Abgaenge im laufenden Monat“ setzt sich zusammen aus der Summe der Parteiaustritte, der Ausgeschlossenen, der Verzogenen und der Verstorbenen; dazu kam eine laufende Berichtigung der Mitgliederzahl, d. h. die Beseitigung von „Karteileichen“. Zwischen März und Mai 1949 beziehen sich die Angaben jeweils auf den letzten Tag des Vormonats.

150 Nach dem Tätigkeitsbericht der CSU für den Monat Juli 1948 (IfZ-Archiv, RG 260, 13/150-1/15) setzt sich diese Zahl folgendermaßen zusammen: Austritte: 1180, Ausschlüsse: 18, Verstorbene: 86 , durch Wegzug: 68, durch Berichtigung der Mitgliederzahl: 1008.

151 ACSP, NL Müller 19, Memorandum Richard Schachtners „Die Finanzen der Union nach der Währungsreform" vom 24. 9. 1948.

152 BayHStA, NL Ehard 131, Rundschreiben „Unions-Finanzen“ vom 23. 5. 1949; das folgende Zitat ebenda. 
für die Caritas und für die Innere Mission beteiligt sind. Die Neigung und die Bereitschaft, Parteibeiträge zu bezahlen oder größere freiwillige Spenden zu leisten, ist nach der Währungsreform am Nullpunkt angelangt. In der Union haben wir es erlebt, daß große Gebietseinheiten sich vorübergehend selbständig gemacht haben und keine Beitragsanteile abführten oder willkürlich vom $\mathrm{Fi}$ nanzstatut abweichend andere Sätze festlegten."

Kein Wunder, daß die Etatentwürfe und Finanzierungsmodelle, die in der Landesgeschäftsstelle ausgearbeitet wurden, praktisch mit ihrer Entstehung bereits Makulatur waren. Es gab einfach keine feste Basis, von der aus man kalkulieren konnte. Statt dessen hatten Sparvorschläge Hochkonjunktur. Ein Etatentwurf Richard Schachtners vom 1. Juli 1948 sah beispielsweise vor, ab August die Ausgaben der Landesgeschäftsstelle um 43,4 Prozent zu kürzen. Schachtner stellte den durchschnittlichen Aufwendungen in den Monaten April bis Juni 1948 seinen Finanzplan für August gegenüber ${ }^{153}$. Es war nur natürlich, daß man versuchte, die Personalkosten zu senken, die im Durchschnitt des Jahres 1948 mit mehr als 70 Prozent den Löwenanteil an den Aufwendungen der Landesgeschäftsstelle ausmachten. Doch Schachtner bezweifelte, ob selbst dieser Sparetat finanzierbar sein würde. Er rechnete bestenfalls mit Einnahmen in einer Höhe von knapp 33000 DM für August 1948, das heißt mit Einnahmeausfällen in einer Größenordnung von ca. 76 Prozent im Vergleich zu den Monaten April bis Juni. Der Leiter der Abteilung Statistik und Finanzen der Landesgeschäftsstelle und Landesschatzmeister Liedig waren sich darüber einig, daß es selbst bei größter Sparsamkeit unmöglich sein würde, das nötige Geld aufzutreiben ${ }^{154}$.

\section{Etatentwurf Richard Schachtners für August 1948}

\begin{tabular}{|c|c|c|c|}
\hline Aufwendungen & $\begin{array}{l}\text { Ausgaben im Monats- } \\
\text { durchschnitt des } \\
\text { 2. Quartals } 1948 \text { in RM }\end{array}$ & $\begin{array}{l}\text { Voraussichtliche } \\
\text { Ausgaben im August } \\
1948 \text { in DM }\end{array}$ & $\begin{array}{l}\text { Geplante monat- } \\
\text { liche Einsparungen } \\
\text { in Prozent }\end{array}$ \\
\hline $\begin{array}{l}\text { Gehälter Landes- } \\
\text { geschäftsstelle }\end{array}$ & 17950 & 12816,30 & 28,6 \\
\hline $\begin{array}{l}\text { Gehälter Bezirks- } \\
\text { und Kreisgeschäftsstellen }\end{array}$ & 33051,84 & 16525,84 & 50,0 \\
\hline Raumkosten & 798,52 & 798,52 & $-\ldots$ \\
\hline Werbung und Reise & 9293,22 & 9293,22 & --- \\
\hline Kraftfahrzeuge & 3723,32 & 3723,32 & $\cdots$ \\
\hline Allgemeine Verwaltung & 7123,45 & 4772,86 & 33,0 \\
\hline $\begin{array}{l}\text { Büro der Ausschüsse } \\
\text { und der Jungen Union }\end{array}$ & 1036,48 & 1036,48 & $\ldots$ \\
\hline Büromaterialien & 341 & 170,50 & 50,0 \\
\hline Büroausbau & 10350,11 & 5175,09 & 50,0 \\
\hline $\begin{array}{l}\text { Rückzahlung des } \\
\text { Bankkredits }\end{array}$ & 12331,50 & -..- & 100,0 \\
\hline Summe & 95999,44 & 54312,13 & 43,4 \\
\hline
\end{tabular}

153 ACSP, NL Müller 19, Etatentwurf Richard Schachtners vom 1. 7. 1948; die Angaben für die nachstehende Tabelle sind diesem Etatentwurf entnommen.

154 ACSP, NL Müller 20, Aktennotiz Franz Liedigs vom 1. 7. 1948. 
So mußte das Personal der Parteiverwaltung, das seit der Währungsreform kein einziges Mal das volle Gehalt ausbezahlt bekommen hatte ${ }^{155}$, Zug um Zug reduziert werden. Bis Ende September 1948 erhielten 60 Mitarbeiter ihre definitive Kündigung. In der Landesgeschäftsstelle verloren 19 Angestellte ihren Arbeitsplatz; damit waren noch 24 Mitarbeiter in der Parteizentrale beschäftigt. In den Bezirks- und Kreisgeschäftsstellen wurde der Personalstand um 41 auf 61 Mitarbeiter verringert ${ }^{156}$.

Doch der Personalabbau ging unaufhaltsam weiter. Bis Dezember 1948 war der Personalstand der Landesgeschäftsstelle auf nur noch 19 Mitarbeiter geschrumpft, und obwohl damit das monatliche Gehaltsvolumen auf 6500 DM gesenkt werden konnte, erwies sich auch dieser Mitarbeiterstab als nicht finanzierbar ${ }^{157}$. Nach neuen Kündigungen im April und Mai 1949 zählte die Belegschaft der Landesgeschäftsstelle nur noch 15 Männer und Frauen, die im Sinne der Einsparungsbemühungen durchwegs neue Verträge - meist zu reduzierten Bezügen - erhalten hatten. Dadurch wurde die Summe der Gehälter nochmals auf 4561 DM pro Monat verringert ${ }^{158}$. Damit sei der Personalstand auf ein Mindestmaß herabgesetzt worden, stellte Karl Sigmund Mayr nach einer umfangreichen Buch- und Rechnungsprüfung fest. Weiter führte er aus: „In personeller Hinsicht ist zu sagen, dass eine noch stärkere Reduzierung des Personalstandes unter den gegenwärtigen Verhältnissen wohl nicht tragbar ist und auch nicht empfehlungswert sein könnte." Die Landesgeschäftsstelle war gerade noch in der Lage, die dringendsten administrativen Aufgaben zu erfüllen und mehr schlecht als recht einen einigermaßen geregelten Geschäftsbetrieb aufrechtzuerhalten. Politische Impulse konnte man von ihr nicht mehr erwarten; die Landesgeschäftsstelle, die vor der Währungsreform ein Motor der Partei gewesen war, degenerierte unter dem Druck der leeren Kassen zu einem einfachen Getriebe. Ein Blick auf die Struktur des in der Parteizentrale beschäftigten Personals bestätigt diese Entwicklung. Mit dem stellvertretenden Landesgeschäftsführer Heinz Heggenreiner und seinem Assistenten Hanswolf Haunhorst verfügte die Landesgeschäftsstelle lediglich über zwei fest angestellte politische Mitarbeiter; ansonsten waren in der Landesleitung fünf Sekretärinnen, Stenotypistinnen oder Bürohilfskräfte, drei Buchhalter oder kaufmännische Angestellte, eine Archivarin, ein Kraftfahrer, eine Dolmetscherin und zwei sonstige Angestellte tätig.

Da die Verantwortlichen kein Mittel fanden, um der Finanzkrise ein Ende zu setzen, waren letztlich alle Versuche, auch nur einen Teil des bisherigen Parteiapparats aufrechtzuerhalten, zum Scheitern verurteilt. Der ständige Finanzausschuß der CSU, der nach der Währungsreform eingesetzt worden war, um einen Ausweg aus der Misere zu finden, empfahl am 28. September als Sofortmaßnahme, die Geschäftsführer in die Obhut der Kreis- und Bezirksverbände zu entlassen ${ }^{159}$. Die Parteiführung akzeptierte

155 ACSP, NL Müller 19, Bericht Richard Schachtners über die Finanzlage der Union vom 17. 12. 1948; NL Müller 20, Aktennotiz von Landesgeschäftsführer Heggenreiner über die „Finanzlage der Landesleitung", undatiert.

156 ACSP, NL Müller 19, Memorandum Richard Schachtners „Die Finanzen der Union nach der Währungsreform" vom 24. 9. 1948.

157 ACSP, NL Müller 19, Bericht Richard Schachtners über die Finanzlage der Union vom 17. 12. 1948.

158 BayHStA, NL Ehard 115, Bericht Karl Sigmund Mayrs über die finanzielle und organisatorische Situation der Landesgeschäftsstelle nach dem Stand vom 31. 5. 1949; das folgende Zitat (Hervorhebung im Original) und die Angaben zur Personalstruktur finden sich ebenda.

159 ACSP, NL Müller 19, Rundschreiben der CSU-Landesgeschäftsstelle, Abteilung Statistik und Finanzen, an alle Kreis- und Bezirksverbände vom 29.9.1948, und Bericht Richard Schachtners über die Finanzlage der Union vom 17. 12. 1948. Vgl. die irrige Datierung bei Mintzel, Anatomie, S. 234. 
diesen Vorschlag und übertrug die Besoldung der noch tätigen haupt- und nebenamtlichen Mitarbeiter rückwirkend zum 1. Juli 1948 den Bezirken und Kreisen. Im Gegenzug wurden die Zahlungsverpflichtungen der Kreisverbände an den Landesverband herabgesetzt. Anstatt 45 Pfennig pro Monat und Mitglied sollten nunmehr lediglich 20 Pfennig pro Monat und Mitglied abgeführt werden. Der Landesausschuß, der am 18. und 19. Dezember 1948 in Forchheim tagte, billigte diesen Beschluß nachträglich $^{160}$. Die Folgen der Währungsreform hatten so das ermöglicht, was die innerparteiliche Opposition zwei Jahre lang nicht hatte durchsetzen können: die organisationspolitische Autonomie der Suborganisationen. Die Konzeption Josef Müllers war damit faktisch gescheitert, und der Parteiapparat hörte auf, ein Machtfaktor in den Führungsund Flügelkämpfen zu sein.

Mit dem Zusammenbruch der zentral gesteuerten Parteiverwaltung begann sich das innerparteiliche Kräfteverhältnis gefährlich zugunsten der Gegner Josef Müllers zu verschieben. Schließlich hatte der Ochsensepp stets darauf geachtet, in der Landesleitung wie in den Bezirks- und Kreisgeschäftsstellen nur zuverlässige Gefolgsleute zu beschäftigen ${ }^{161}$. Gerade die von der Münchner Parteizentrale angestellten und besoldeten Kreisgeschäftsführer zählten zu den Stützen der Parteiführung; in Müller-treuen Regionen waren sie so etwas wie das Rückgrat der $\mathrm{CSU}^{162}$, in den Hochburgen der innerparteilichen Opposition dagegen die Augen und Ohren des Landesvorsitzenden. Otto Schedl bat Josef Müller wenige Tage nach der Währungsreform händeringend, dem drohenden Personalabbau einen Riegel vorzuschieben, und er rief dem Parteichef in Erinnerung, daß der größte Teil der Parteiangestellten immer „rückhaltlos“ und mit außerordentlichem Engagement hinter seiner politischen Konzeption gestanden habe ${ }^{163}$. Doch auch Müller konnte den Zusammenbruch des Parteiapparats nicht aufhalten, der letzten Endes nicht unwesentlich zu seinem Sturz im Mai 1949 beitrug.

Mit der Kapitulation der Parteiführung vor der Finanzmisere wurde die Landesgeschäftsstelle gleichsam blind, taub und stumm. Heinz Heggenreiner beklagte sich Ende 1948 bitter über die herrschenden Zustände:

„Die Christlich-Soziale Union ohne Landesleitung ist aktionsunfähig. Die Landesleitung kann jedoch ebenso wenig wie die Bezirksverbände ohne entsprechende finanzielle Grundlage arbeiten. Sie hat ihr Personal bereits heute auf einen Mindeststand gebracht, ein Zustand, der sich natürlich in der Abwicklung der Geschäfte notwendigerweise nachteilig bemerkbar machen muss. Dieses verringerte Personal lebt seit Monaten nur mehr vom Existenzminimum, seine durchaus bescheidenen Gehälter können ihm nie mehr rechtzeitig ausbezahlt werden. Die Opferwilligkeit dieser Arbeitskräfte, die trotz dieser misslichen Umstände ihre Arbeit aufs Pflichttreueste erfüllen, ist vorbildlich. Es kann jedoch von ihnen auf die Dauer nicht gefordert werden, dass sie weiterhin Opfer bringen, wenn die Partei für sie kein Verständnis aufbringt. In absehbarer Zeit ist mit Wahlen für Bonn zu rechnen. Wenn die Landesleitung nicht rechtzeitig über die nötigen finanziellen

160 Vgl. Berberich, Historische Entwicklung, S. 84.

161 ACSP, NL Müller 9, Protokoll der Sitzung des Landesvorstands am 28. 2. 1947 (Josef Müller).

162 So stellte der oberfränkische Bezirksgeschäftsführer Alexander Schönwiese in seinem Rechenschaftsbericht für das Jahr 1948 vor den Delegierten der Bezirksversammlung am 29.1. 1949 fest: „So war in den meisten Kreisverbaenden der Geschäftsführer der immer anwesende circulus vivendus, das Herz der Union. Den Beweis dafuer, dass er die ganze praktische Arbeit leistete, sehen Sie nach seiner Entlassung: kein Geld, keine neuen Mitglieder, im Gegenteil: rund 1000 Abgaenge, keine Versammlungen, keine Propagandataetigkeit.“ ACSP, NL Müller 133.

163 ACSP, NL Müller 18, Otto Schedl an Josef Müller vom 5. 7. 1948. 
Mittel verfügt, die für Propaganda, Wahlversammlungen und Wahlredner gebraucht werden, so wird die ganze Partei davon den schwersten Schaden haben. " 164

Der Zorn des Landesgeschäftsführers richtete sich hauptsächlich gegen die Kreisverbände, die mehrheitlich auch den reduzierten Zahlungsverpflichtungen nicht nachkamen. Das Beitragsaufkommen für das zweite Halbjahr 1948 betrug nach Berechnungen der Landesgeschäftsstelle lediglich 10,4 Prozent vom Sollbetrag ${ }^{165}$. Aufgeteilt nach Bezirksverbänden ergab sich folgendes Bild: Oberfranken hatte immerhin 36,4 Prozent seiner finanziellen Verpflichtungen gegenüber dem Landesverband erfüllt, Schwaben lag mit 12,8 Prozent auf Platz zwei, es folgten Unterfranken mit 8,8 Prozent, Niederbayern mit 8,2 Prozent, Mittelfranken mit 8,0 Prozent und die Oberpfalz mit 5,6 Prozent; Oberbayern und München hatten nur 4,0 Prozent der fälligen Beiträge an die Landesleitung abgeführt und lagen damit einmal mehr am Ende der Skala. Kreisverbände, die der innerparteilichen Opposition um Alois Hundhammer zuneigten, machten dabei keinen Hehl daraus, daß sie ihre Saumseligkeit in puncto Beitragsabführung als Waffe im Kampf gegen die ungeliebte Parteiführung betrachteten ${ }^{166}$. Andere erklärten, kein Interesse daran zu haben, „Streitigkeiten in der obersten Parteiführung irgendwie finanziell zu unterstützen "167. Auch Hundhammer selbst bemühte sich nach Kräften, alle Sanierungsversuche der Landesleitung zu torpedieren ${ }^{168}$. So schrieb der Kultusminister im Oktober 1948 an Hans Bartel, den Geschäftsführer des CSU-Kreisverbands Dinkelsbühl:

"Ich kenne die besonderen Schwierigkeiten und nahezu unerträglichen Verhältnisse, unter denen die Mitarbeiter unserer Partei seit der Währungsumstellung zu leiden haben. [...] Mir scheint aber eine Änderung im allgemeinen und für ganz Bayern nur dadurch möglich zu sein, dass die Partei reorganisiert wird, sowohl hinsichtlich der Satzungen wie auch der Zusammensetzung der Spitzengremien. Wenn damit dann eine klare christliche und föderalistische Haltung sich verbindet, wird es möglich sein, das Vertrauen und das Interesse des breiten Kreises der Mitgliederschaft zurückzugewinnen und damit dann auch zugleich einen finanziellen Rückhalt wieder zu finden. Die Bereitwilligkeit, für die CSU finanziell etwas zu leisten, hängt ab von dem Vertrauen, das der Partei entgegengebracht wird, und von dem politischen Schwung, der in ihr liegt. In dieser [sic!] Richtung gehen meine Bemühungen. " 169

Richard Schachtner beklagte sich noch im Mai 1949 darüber, daß die „Finanzkraft der Union [...] durch die bewußte Nichtbeachtung des Finanzstatuts zerstört" worden sei. Zugleich erklärte er, daß „verschiedentlich sogar ein finanzieller Boykott gegen die Landesgeschäftsstelle“ festzustellen sei. Weiter führte der Schatzmeister aus:

„Es geht nicht an, daß ordentliche Mitglieder und Kreisverbände nur dann ihre Beiträge bezahlen, wenn der Landesvorsitzende ihr Flügelmann ist. Wir müssen das geldmäßige vom politischen in der Union unbedingt trennen, denn kein Landesvorsitzender, auch wenn [S]ie ihn heute einstimmig wählen, kann die Finanzlast der Union aus eigener Tasche bezahlen. Wenn wir uns in der Union

164 ACSP, NL Müller 20, Aktennotiz von Landesgeschäftsführer Heggenreiner über die „Finanzlage der Landesleitung“, undatiert.

165 ACSP, NL Müller 19, vertrauliche Notiz der Abteilung Statistik und Finanzen der Landesgeschäftsstelle über das Beitragsaufkommen vom 10. 3. 1949; die folgenden Zahlenangaben ebenda.

166 BayHStA, NL Ehard 131, Rundschreiben „Unions-Finanzen“ vom 23. 5. 1949.

167 ACSP, NL Müller 19, vertrauliche Notiz der Abteilung Statistik und Finanzen der Landesgeschäftsstelle über das Beitragsaufkommen vom 10. 3. 1949.

168 ACSP, CSU-LTF I, 15-12/4 und 5, Alois Hundhammer an Wilhelm Winkler (Ebersberg) vom 22.6. 1948; ACSP, NL Müller 16, Protokoll der Landesversammlung der CSU vom 27.-29. 5. 1949 in Straubing.

169 ACSP, CSU-LTF I, 15-20/1, Alois Hundhammer an Hans Bartel vom 29. 10. 1948. 
dagegen wehren, daß das Sprichwort: ,Wer zahlt, schafft an' zum Parteiprinzip erhoben wird, dann dürfen wir aus Billigkeitsgründen noch weniger zulassen, daß die Nichtzahler allein den Ton angeben. [...] Eine Parteibürokratie im üblen Sinne hat es in der Union nie gegeben. Bedenken Sie also bei der Erfüllung oder Nichterfüllung ihrer Beitragsverpflichtungen, daß Sie nicht nur den Landesvorsitzenden allein treffen, sondern daß Sie Einzelexistenzen und Familien erhalten bezw. gefährden. Es ist auch nicht so, daß die hauptamtlichen Mitarbeiter alles Müller-Leute sind. “170

Angesichts der desolaten Finanzlage der gesamten Partei und der miserablen Zahlungsmoral der Mitglieder wurde schnell der Ruf nach Sanktionen laut. Schon am 10. September 1948 forderten prominente Mitarbeiter der Landesgeschäftsstelle den geschäftsführenden Landesvorstand auf, endlich das Finanzstatut durchzusetzen und die fälligen Beiträge von den Kreisverbänden einzutreiben ${ }^{171}$. Im Falle der Zahlungsunwilligkeit sollte der Landesvorstand Paragraph 29 der Satzung zur Anwendung bringen und die betroffenen Kreisverbände „unverzüglich“ auflösen ${ }^{172}$; die Vorstände dieser Kreisverbände sollten überdies persönlich haftbar gemacht werden. Doch die Parteiführung zögerte, diese rigorosen Vorschläge mit ihren unabsehbaren Konsequenzen für die ohnehin von inneren Streitigkeiten zerrissene CSU aufzugreifen. Einige Wochen später brachte Heggenreiner das heikle Thema Sanktionen erneut zur Sprache. In einem Memorandum für die Parteiführung bat er, doch einmal zu überlegen, „ob Kreisverbände, die zwar zahlenmäßig noch einen entsprechenden Mitgliederstand melden, Beiträge jedoch fast überhaupt nicht mehr abführen, noch weiterhin das Stimmrecht in den entsprechenden Gremien der Partei behalten sollen“. Es sei klar, daß „der Ausschluss zahlungsunfähiger Mitglieder eine gefährliche Sache“ sei, es ginge aber andererseits nicht an, daß „der grösste Teil der Kreisverbände sich über die Satzungen hinwegsetzt und überhaupt keine Beiträge oder nur geringe Teile davon an die Landesleitung abführt" ${ }^{\text {173 }}$.

\section{Zablungsverpflichtungen der Landesgeschäftsstelle am 31. Mai $1949^{174}$}

Rückständige Gehälter

Rückständige Sozialversicherungsbeiträge

Rückständige Lohn- und Kirchensteuer; Notopfer

Rückständige Gehälter von Kreis- und Bezirksgeschäftsführern

Bauschulden

Darlehensschulden

Staatskredit

sonstige Verbindlichkeiten

Summe
9096,22 DM

$7948,34 \mathrm{DM}$

$8759,25 \mathrm{DM}$

$7398,84 \mathrm{DM}$

$11271,43 \mathrm{DM}$

$8300,-$ DM

40909,62 DM

$17338,64 \mathrm{DM}$

$111022,34 \mathrm{DM}$

170 BayHStA, NL Ehard 131, Rundschreiben "Unions-Finanzen“ vom 23. 5. 1949. An anderer Stelle hatte Schachtner schon im Dezember 1948 betont, die „massgeblichen Persönlichkeiten der Union“ müßten sich darüber klar werden, daß „die Union auch nach Beseitigung aller Zentralisation nicht bestehen" könne, wenn es keinen Landesverband gebe. ACSP, NL Müller 19, Bericht Richard Schachtners über die Finanzlage der Union vom 17. 12. 1948.

171 ACSP, NL Müller 20, „Notgemeinschaft“ der Mitarbeiter der CSU-Landesgeschäftsstelle an den geschäftsführenden Landesvorstand vom 10. 9. 1948.

172 Satzung der CSU in der Fassung vom 4. 10.1946, abgedruckt in: Protokolle und Materialien, S. $1783-1803$.

173 ACSP, NL Müller 20, Aktennotiz von Landesgeschäftsführer Heggenreiner über die „Finanzlage der Landesleitung", undatiert.

174 BayHStA, NL Ehard 115, Bericht Karl Sigmund Mayrs über die finanzielle und organisatorische Situation der Landesgeschäftsstelle nach dem Stand vom 31. 5. 1949. Eine ähnliche Summe wird genannt in einer Vermögensübersicht der Landesgeschäftsstelle, Abteilung Statistik und Finanzen, 
Diesmal reagierten die Verantwortlichen ${ }^{175}$, und der Landesausschuß beschloß am 19. Dezember 1948, den Kreisverbänden das Stimmrecht in den Gremien der Parteiorganisation auf Bezirks- und Landesebene zu verweigern, wenn sie ihre Zahlungsverpflichtungen nicht erfüllten ${ }^{176}$. Doch wie bei vielen anderen Beschlüssen blieb es auch diesmal bei guten Vorsätzen und Absichtserklärungen; eine energische Durchsetzung des Forchheimer Beschlusses erfolgte nicht ${ }^{177}$. Wahrscheinlich wäre es auch völlig sinnlos gewesen, da die Mehrzahl der Kreisverbände einfach nicht in der Lage war, ihren Beitragsverpflichtungen nachzukommen. Schon im September 1948 hatte Richard Schachtner bezweifelt, daß es einen Weg gebe, die Kreisverbände dazu zu zwingen, ihre Beitragsrückstände in voller Höhe zu bezahlen ${ }^{178}$. Er sollte recht behalten.

In demselben Maße, wie die Beitragszahlungen an den Landesverband ausblieben, wuchsen die Schulden der Landesgeschäftsstelle, die zum Zeitpunkt der Währungsreform wie erwähnt schuldenfrei gewesen war. Sechs Monate nach der Währungsumstellung sah sich die Partei mit Zahlungsverpflichtungen in einer Höhe von 81 936,88 DM konfrontiert ${ }^{179}$; als Hans Ehard im Mai 1949 sein neues Amt als Landesvorsitzender der CSU antrat, war der Schuldenberg auf bedrohliche $111022,34 \mathrm{DM}$ angewachsen.

Die Lage war desolat. Die verantwortlichen Mitarbeiter der Landesgeschäftsstelle mußten sich täglich mit neuen Gläubigern herumschlagen, die nicht länger auf ihr Geld warten wollten; Zahlungsbefehle gingen ein, die nicht ignoriert werden konnten, und um ein Loch zu stopfen, riß man zwei neue auf; Wechsel drohten zu platzen, ungedeckte Schecks wurden ausgestell $t^{180}$. Schließlich kam es, wie es kommen mußte: Der Gerichtsvollzieher pfändete in der Parteizentrale alles, was von einem gewissen Wert war, sogar die Büroeinrichtungen ${ }^{181}$. Um die CSU nicht der Lächerlichkeit preis-

zum 20. 5. 1949 (ACSP, NL Müller 20); in dem Rundschreiben „Unions-Finanzen“ vom 23. 5. 1949 (BayHStA, NL Ehard 131) ist dagegen "nur" von 98500 DM die Rede. Zu den Steuerschulden der CSU vgl. ACSP, NL Müller 20, August Haußleiter an das Finanzamt für Körperschaften vom 29. 10. 1948 und Aktennotiz über eine Besprechung mit Regierungsrat Dr. von Behm vom Finanzamt für Körperschaften vom 12.11. 1948.

175 In einer Aktennotiz Hanswolf Haunhorsts vom 17. 12. 1948 hieß es, auch die amerikanische Militärregierung fordere, sich nicht an fiktiven Mitgliederzahlen zu orientieren, sondern an der Zahl derer, die tatsächlich Beiträge zahlten. ACSP, NL Müller 19; ähnlich auch NL Müller 20, Schreiben prominenter Mitarbeiter der Landesgeschäftsstelle an Josef Müller, Michael Horlacher, August Haußleiter und Franz Josef Strauß vom 16. 2. 1949.

176 ACSP, NL Müller 16, Rundschreiben Franz Josef Strauß` vom 6. 5. 1949. Vgl. auch Berberich, Historische Entwicklung, S. 84.

177 ACSP, NL Müller 19, vertrauliche Notiz der Abteilung Statistik und Finanzen der Landesgeschäftsstelle über das Beitragsaufkommen vom 10. 3. 1949, und NL Müller 20, Schreiben prominenter Mitarbeiter der Landesgeschäftsstelle an Josef Müller, Michael Horlacher, August Haußleiter und Franz Josef Strauß vom 16. 2. 1949.

178 ACSP, NL Müller 19, Memorandum Richard Schachtners „Die Finanzen der Union nach der Währungsreform" vom 24. 9. 1948.

179 ACSP, NL Müller 19, Bericht Richard Schachtners über die Finanzlage der Union vom 17. 12. 1948.

180 ACSP, NL Müller 20, Schreiben prominenter Mitarbeiter der Landesgeschäftsstelle an Josef Müller, Michael Horlacher, August Haußleiter und Franz Josef Strauß vom 16. 2. 1949, NL Müller 17, Franz Liedig an Josef Müller und die Mitglieder des geschäftsführenden Landesvorstands der CSU vom 27. 12. 1948 und Artur Kapfhammer an Josef Müller vom 1. 2. 1949.

181 IfZ-Archiv, RG 260, 10/90-3/9, „Subject: ,Der Gerade Weg' auf krummen Pfaden. Finanzmisere der Landesleitung der CSU“ vom 22. 6. 1949; BayHStA, NL Ehard 115, Bericht Karl Sigmund Mayrs über die finanzielle und organisatorische Situation der Landesgeschäftsstelle nach dem Stand vom 31. 5. 1949. 
zugeben, versuchte die Parteileitung unter allen Umständen zu verheimlichen, wie schlimm es wirklich stand. Charlotte Fleischmann, Mitglied des Bezirksvorstands der Münchner CSU, vertraute sich wenige Wochen vor den ersten Bundestagswahlen einem Informanten der amerikanischen Militärregierung an:

"Die Landesleitung lebt in ständiger Angst, daß all diese kompro[m]ittierenden Tatsachen an die Öffentlichkeit gelangen könnten. Damit, meint man, wäre dann der Wahlkampf eigentlich schon erledigt. Denn keine Dauerreden könnten den miserablen Eindruck wiedergutmachen, der dann entstünde. “182

Der Schuldenstand der Landesgeschäftsstelle spielte auch in den Führungs- und Flügelkämpfen eine nicht zu unterschätzende Rolle. Die innerparteiliche Opposition, allen voran Alois Hundhammer, warf Josef Müller wiederholt vor, für die Finanzmisere mehr oder weniger allein verantwortlich zu sein, und forderte Konsequenzen ${ }^{183}$. Es sei auf eine geradezu „kriminell verantwortungslose Weise gewirtschaftet worden“, hieß es ${ }^{184}$. Solche Vorwürfe heizten die Gerüchteküche weiter an - man munkelte, die CSU habe Schulden in der astronomischen Höhe von 500000 DM - und trugen überdies dazu bei, die Mitglieder der Partei in ganz Bayern zu verunsichern und Müllers Stellung weiter zu unterminieren. Der Parteivorsitzende wurde nicht müde zu betonen, daß die finanziellen Verpflichtungen der Partei durch die Außenstände mehr als gedeckt seien ${ }^{185}$. Tatsächlich wies die Bilanz am 31. Mai 1949 knapp 147000 DM an Aktiva aus, eine Summe, die ausgereicht hätte, um die Schulden der Landesgeschäftsstelle zu begleichen. Doch de facto blieb davon so gut wie nichts übrig; allein die nicht bezahlten Mitgliederbeiträge schlugen mit mehr als 105500 DM zu Buche, dazu kamen noch rund 20500 DM aus dem Verkauf von Unions-Bausteinen, die nie im Landessekretariat eingegangen waren ${ }^{186}$. Die Deckung der Schulden durch die Forderungen an die Suborganisationen erwies sich damit als fiktiv.

Am unmittelbarsten waren die Mitarbeiter in den Geschäftsstellen der CSU auf allen Ebenen der Parteiorganisation von den Folgen der Währungsreform betroffen. Viele verloren ihren Arbeitsplatz, nachdem sie gerade begonnen hatten, sich eine neue Existenz aufzubauen, andere blieben zwar in den Diensten der Partei, mußten ihre Tätigkeit jedoch unter überaus widrigen Bedingungen und bei denkbar schlechter Bezahlung fortsetzen. Es ist erstaunlich, welches $\mathrm{Maß}$ an Idealismus und Opferbereitschaft das Personal des Parteiapparats aufbrachte und wie viele Kreisgeschäftsführer, Sachbearbeiter und Referenten bereit waren, aus politischer Überzeugung und persönlicher Loyalität weiterzuarbeiten, obwohl ihre Bezahlung alles andere als gesichert war.

182 IfZ-Archiv, RG 260, 10/90-3/9, „Subject: ,Der Gerade Weg auf krummen Pfaden. Finanzmisere der Landesleitung der $\mathrm{CSU}^{\prime}$ vom 22. 6. 1949.

183 ACSP, CSU-LTF I, 15-12/4 und 5, Alois Hundhammer an Wilhelm Winkler (Ebersberg) vom 22.6. 1948; ACSP, NL Müller 16, Protokoll der Landesversammlung der CSU vom 27.-29.5. 1949 in Straubing; Bericht über die Sitzung des Landesvorstands am 12. 3. 1949, in: Die Politische Information $9 / 10-49$.

184 IfZ-Archiv, RG 260, 10/90-3/9, „Subject: ,Der Gerade Weg' auf krummen Pfaden. Finanzmisere der Landesleitung der CSU“ vom 22. 6. 1949; das Gerücht, die Verbindlichkeiten der Landesgeschäftsstelle betrügen $500000 \mathrm{DM}$, wird ebenda kolportiert.

185 ACSP, NL Müller 16, Protokoll der Landesversammlung der CSU vom 27.-29. 5. 1949 in Straubing; Bericht über die Sitzung des Landesvorstands am 12.3. 1949, in: Die Politische Information 9/10-49; BayHStA, NL Ehard 131, Rundschreiben „Unions-Finanzen“ vom 23. 5. 1949.

186 BayHStA, NL Ehard 115, Bericht Karl Sigmund Mayrs über die finanzielle und organisatorische $\mathrm{Si}$ tuation der Landesgeschäftsstelle nach dem Stand vom 31. 5. 1949. 
Allerdings wurden die Sofortmaßnahmen der Parteiführung nach der Währungsreform, insbesondere die vorsorgliche Kündigung der haupt- und nebenamtlichen Mitarbeiter, nicht kritiklos hingenommen. Otto Schedl und Georg Gamperl wandten sich entsetzt an den Landesvorsitzenden und teilten ihm mit, daß die pauschalen Kündigungen nicht dem entsprächen, was man von einer christlichen und sozialen Partei erwarten könne ${ }^{187}$. Die beiden Mitstreiter Müllers bemängelten überdies, daß hinter den Entscheidungen der Landesleitung - Schedl sprach von „einem fast kopflosen Handeln" - kein positives Konzept zur Krisenbewältigung stände, sondern daß es einzig und allein darum ginge, die Ausgaben um jeden Preis zu senken, anstatt möglichst viele der verdienten Mitarbeiter zu halten und neue Finanzquellen zu erschließen. In der Tat trugen die vorsorglichen Kündigungen wenige Tage nach der Währungsreform eher zur allgemeinen Verunsicherung als zu einer Klärung der Situation bei. Wer hatte seinen Arbeitsplatz endgültig verloren? Wer konnte nach einer gewissen Übergangszeit mit einer Weiterbeschäftigung durch den Landesverband rechnen? Wer würde von den Bezirks- und Kreisverbänden in eigener Regie finanziert werden?

Indessen rief der Landesschatzmeister die Parteiangestellten am 26. Juni 1948 zur Bildung einer „ernsten Opfergemeinschaft“ auf und bat um Geduld und Verständnis für die in den nächsten Wochen zu erwartenden Liquiditätsprobleme der Parteizentrale. $\mathrm{Da}$ an eine vollständige Auszahlung der Gehälter nicht zu denken war, teilte Liedig dem Personal der Geschäftsstellen mit, daß zunächst nur Überbrückungshilfen ausgezahlt werden könnten; $30 \mathrm{DM}$ für Ledige, $35 \mathrm{DM}$ für Verheiratete, zuzüglich fünf DM für jedes Kind ${ }^{188}$. An Idealismus und Opferbereitschaft fehlte es den Parteiangestellten tatsächlich nicht. Schon wenige Tage nach der Währungsreform schlossen sich Mitarbeiter der Landesgeschäftsstelle zu einer "Notgemeinschaft“ zusammen. Diese „Notgemeinschaft“ hatte nicht nur das Ziel, „aus eigener Initiative unabhängig von den Massnahmen der Landesvorstandschaft Mittel zur Aufrechterhaltung der Parteiorganisation zu beschaffen und Massnahmen durchzuführen, die zu diesem Ziele führen “189, sondern ihre Mitglieder erklärten sich auch bereit, zu Bedingungen weiterzuarbeiten, „die das Existenzminimum unterschreiten“ ${ }^{190}$. In diesem Sinne deckte die „Notgemeinschaft“ in den ersten Tagen nach der Währungsumstellung, als die D-Mark besonders knapp war, die dringendsten Unkosten der Landesgeschäftsstelle aus eigener Tasche ${ }^{191}$, sie unternahm eine Rundreise zu den wichtigsten Bezirks- und Kreisgeschäftsstellen, um die mit dem Tag X praktisch abgerissene Verbindung wiederherzustellen, den Beitragseinzug wieder in Gang zu setzen und Spenden zu sammeln, und sie versuchte, den Verkauf von Unions-Bausteinen anzukurbeln ${ }^{192}$. Der anfängli-

187 ACSP, NL Müller 18, Otto Schedl an Josef Müller vom 5. 7. 1948, und NL Müller 150, Georg Gamperl an Josef Müller vom 5. 7. 1948; ähnlich auch NL Müller 19, Memorandum Richard Schachtners "Die Finanzen der Union nach der Währungsreform“ vom 24. 9. 1948.

188 ACSP, NL Müller 20, Rundschreiben Franz Liedigs an die Bezirks- und Kreisvorsitzenden sowie an die Bezirks- und Kreisgeschäftsführer vom 26. 6. 1948.

189 ACSP, NL Müller 20, Aktennotiz über eine Besprechung von Mitgliedern der „Notgemeinschaft“ mit Josef Müller am 2. 7. 1948.

190 ACSP, NL Müller 20, Rundschreiben der „Notgemeinschaft “ und des Betriebsrats der CSU-Landesgeschäftsstelle an die Bezirks- und Kreisvorsitzenden vom 1. 9. 1948.

191 BayHStA, NL Ehard 131, Rundschreiben „Unions-Finanzen“ vom 23. 5. 1949.

192 ACSP, NL Müller 19, „Reisebericht über die von der Notgemeinschaft durchgeführte Rundreise“ vom 14.-17. 7. 1948. Die sogenannten Unions-Bausteine, gleichsam Anteile an einem Fonds zum Aufbau der Partei, wurden seit Herbst 1947 verkauft und brachten bis zur Währungsreform 
che Erfolg war beachtlich: Bis zum 10. September 1948 konnten fast 10000 DM für die Zwecke der Partei aufgebracht werden ${ }^{193}$. Aber die Mitglieder der „Notgemeinschaft“ mußten schnell erkennen, daß ihre Kräfte nicht ausreichten, um den Zerfall des Parteiapparats auch nur vorübergehend aufzuhalten. Dagegen wuchs die Not bei den Familien vieler Mitarbeiter, die sich im Sommer 1948 der „Notgemeinschaft“ angeschlossen hatten. So hieß es in einem Schreiben an den geschäftsführenden Landesvorstand, das an Deutlichkeit nicht zu wünschen übrig ließ:

„Obwohl bereits fast $1 / 4$ Jahr seit der Währungsreform verstrichen ist, wurden von Seiten der Landesvorstandschaft noch keine wirksamen Maßnahmen ergriffen, um wenigstens für die Einhaltung des Finanzstatuts zu sorgen. Während es inzwischen einer Reihe von Parteifreunden möglich war, sich eine sichere Existenz zu schaffen, sind die finanziellen Verhältnisse der Leute, die bis heute hauptamtlich der Union gedient haben, untragbar geworden. Es hiesse, Schindluder mit dem Idealismus unserer Leute treiben, wollte man ihnen länger zumuten, mit diesen weit unter dem Existenzminimum liegenden Schwimmwestenbeträgen von durchschnittlich 85.- DM mit ihren Familien weiterzuhungern. Trotz der seit der Währungsreform vollen Schaufenster war es bisher noch keinem Mitarbeiter möglich, auch nur die geringsten Anschaffungen an lebensnotwendigen Gütern vorzunehmen. Darüberhinaus hat die Not inzwischen einen solchen Grad erreicht, daß z. B. ein Mitarbeiter gezwungen war, sein Kind aus der Höheren Schule herauszunehmen, da ihm die Schulgeldzahlung unmöglich ist, oder daß Milchabschnitte für Kindervollmilch mangels Geld nicht eingelöst werden konnten und am Monatsende verfielen. Oder daß in einem anderen Falle keine Wohnung vorhanden ist und im Falle einer durch eigene Initiative erreichten Wohnung nicht einmal deren Bezahlung möglich ist. Von den meisten Mitarbeitern konnten die Krankenkassenbeiträge nicht bezahlt werden, so daß im Falle einer Erkrankung diese völlig schutzlos dastehen."

Diese Beispiele waren beileibe keine Einzelfälle. Besonders bei den Angestellten, die noch in den Bezirks- und Kreisgeschäftsstellen tätig waren, war der Mangel allgegenwärtig. Gehälter wurden monatelang gar nicht oder nur zu geringen Teilen ausbezahlt, das verunsicherte Personal immer wieder vertröstet ${ }^{194}$. Da es der Parteiführung nicht gelang, die finanzielle Lage der CSU zu konsolidieren und sich die Situation im Gegenteil immer mehr verschlechterte, stieß auch die Not- und Solidargemeinschaft des Personals in den Geschäftsstellen unweigerlich an ihre Grenzen ${ }^{195}$. Ihr Idealismus

164000 RM und von Juli 1948 bis Mai 1949 noch einmal 5000 DM ein. BayHStA, NL Ehard 131, Rundschreiben „Unions-Finanzen“ vom 23. 5. 1949.

193 ACSP, NL Müller 20, „Notgemeinschaft“ der Mitarbeiter der CSU-Landesgeschäftsstelle an den geschäftsführenden Landesvorstand vom 10.9. 1948; das folgende nach ebenda.

194 ACSP, NL Müller 52, Karl-Heinz Keuthen an Josef Müller vom 19. 10. 1948, NL Müller 118, Josef Amesmaier an Josef Müller vom 23. 7. 1948, NL Müller 56, Hans Bartel an Josef Müller vom 30. 3. 1949, oder auch ACSP, CSU-LTF I, 15-20/1, Hans Bartel an Alois Hundhammer vom 3. 11. 1948; selbst prominenten Funktionären wie Franz Liedig fiel es überaus schwer, ihr Geld von der CSU zu erhalten. Liedig schrieb am 4. 1. 1949 an Josef Müller und die Mitglieder des geschäftsführenden Landesvorstands: "Ich bin durch die Partei weder Minister noch Abgeordneter geworden, noch sonst etwa zu Amt und Würden gekommen, sondern stehe vielmehr, nachdem ich durch Jahre hindurch meine Arbeitskraft und Gesundheit in den Dienst der Partei gestellt und weitgehend verbraucht habe, am Anfang des Aufbaus einer neuen Existenz und habe darüber hinaus noch für sieben Menschen zu sorgen. Ich glaube, durch die Tat bewiesen zu haben, daß ich trotz allem zu jedem Opfer für die Union bereit gewesen bin, glaube aber nunmehr auch, Verständnis dafür erwarten zu können, daß ich am Ende meiner Möglichkeiten und meiner Kraft bin.“ ACSP, NL Müller 17.

195 ACSP, NL Müller 20, Schreiben prominenter Mitarbeiter der Landesgeschäftsstelle an Josef Müller, Michael Horlacher, August Haußleiter und Franz Josef Strauß vom 16. 2. 1949. Die Tätigkeit der "Notgemeinschaft“ endete Ende September 1948; ACSP, CSU-LL, Protokoll der Sitzung des geschäftsführenden Landesvorstands am 8. 10. 1948. 
und ihre ohnehin geringen persönlichen Ressourcen waren einfach erschöpft. Nicht wenige Parteiangestellte bezahlten ihren Eifer und ihr Stehvermögen mit finanziellen und beruflichen Nachteilen. Manche sahen sich sogar gezwungen, ihre Forderungen an die CSU, ihre eigene Partei, die sie mit aufgebaut hatten, vor dem Arbeitsgericht einzuklagen oder Zahlungsbefehle zu erwirken ${ }^{196}$.

Die Folgen der Währungsreform führten nicht nur zum Zusammenbruch des Parteiapparats, sondern lösten auch eine schwere Vertrauenskrise zwischen Josef Müller und Mitstreitern wie Franz Liedig oder August Haußleiter aus, die den geschäftsführenden Landesvorstand zeitweise zu lähmen drohte. Diese Auseinandersetzungen waren nur teilweise auf die Nervosität zurückzuführen, die - geschürt durch immer neue Hiobsbotschaften - in der Parteiführung um sich griff. Es waren vor allem das vermeintliche Desinteresse des Landesvorsitzenden an der Organisations- und Finanzmisere, seine fehlende Bereitschaft zur Zusammenarbeit und seine Sturheit, die selbst enge Parteifreunde schier verzweifeln ließen. Müller hatte offensichtlich kein Konzept, um einer Krise Herr zu werden, die sich täglich verschlimmerte, weigerte sich aber auch, Ratschläge von bewährten Mitarbeitern anzunehmen. Wiederholt verschleppte er dringende Entscheidungen wochenlang, um sie dann im Hau-Ruck-Verfahren durchzupeitschen, ohne auch nur die fundiertesten Einwände zu berücksichtigen ${ }^{197}$.

Unterdessen herrschte in der Landesgeschäftsstelle das blanke Chaos. Die qualifiziertesten Angestellten verließen die Parteizentrale, wenn sie Gelegenheit dazu hatten $^{198}$, Verantwortlichkeiten waren nicht klar geregelt ${ }^{199}$, Führungspositionen blieben unbesetzt ${ }^{200}$. Ende 1948 wurde die Landesgeschäftsstelle sogar durch undurchsichtige Transaktionen in zweifelhafte Export-Import-Geschäfte verwickelt ${ }^{201}$. Franz Liedig gab bereits am 30 . August 1948 vor dem geschäftsführenden Landesvorstand bekannt, daß er „keinesfalls unter den gegenwärtigen Verhältnissen länger mit der Verantwortung [für die] Landesgeschäftsstelle betraut bleiben wolle“202. Auch August Haußleiter machte Josef Müller für die unhaltbare Situation verantwortlich. Es gehe nicht an, wetterte der stellvertretende Parteivorsitzende, daß Müller selbstherrlich Entscheidungen treffe, in die Belange der Landesgeschäftsstelle eingreife, ohne die leitenden Mitarbeiter zu unterrichten, und nicht einmal davor zurückschrecke, die Verantwortlichen offen zu desavouieren. Haußleiter forderte deshalb, einen Generalsekretär oder Landesgeschäftsführer zu ernennen und mit der notwendigen Autorität auch gegenüber dem Parteivorsitzenden auszustatten.

196 BayHStA, StK 111387, Ferdinand Weber an Hans Ehard vom 3. 12. 1950 und Norbert Berger an Levin von Gumppenberg vom 30. 10. 1948; IfZ-Archiv, Smlg. Mintzel 45, Anton Hergenröder an das Arbeitsgericht Bamberg vom 8. 9. 1949 und Rundschreiben des CSU-Bezirksverbands Oberfranken, gez. Anton Hergenröder, an alle Kreisverbände Oberfrankens und die Mitglieder des Bezirksvorstands vom 3.11. 1949.

197 ACSP, CSU-LL, Protokoll der Sitzung des geschäftsführenden Landesvorstands am 30. 8. 1948.

198 ACSP, NL Müller 18, Richard Schachtner an Josef Müller vom 13. 9. 1948.

199 ACSP, NL Müller 17, Franz Liedig an August Haußleiter vom 6. 12. 1948; ACSP, CSU-LL, Protokoll der Sitzung des geschäftsführenden Landesvorstands am 23. 12. 1948.

200 ACSP, NL Müller 17, August Haußleiter an Josef Müller vom 19. 1. 1949 und 24. 2. 1949; ACSP, CSU-LL, Protokoll der Sitzung des geschäftsführenden Landesvorstands am 8.10. 1948.

$20:$ Eine Fülle von Akten zum sogenannten Weinschieber-Skandal, dem ersten großen Finanzskandal in der Geschichte der CSU, der auch mit einem Prozeß endete, findet sich im ACSP, CSU-LSG, Ordner Eutermoser - Plonner. Diese Affäre bietet Stoff für einen eigenen Aufsatz.

202 ACSP, CSU-LL, Protokoll der Sitzung des geschäftsführenden Landesvorstands am 30. 8. 1948; das folgende nach dem Protokoll dieser Vorstandssitzung. 
In die Defensive gedrängt, schlug Josef Müller vor, Franz Josef Strauß zum verantwortlichen Generalsekretär der CSU zu ernennen - und zwar möglichst schnell. Doch der Widerstand gegen diesen Vorschlag war so groß, daß keine endgültige Entscheidung fiel und Strauß nach einem Machtwort Müllers bis auf weiteres lediglich mit der Führung der Geschäfte betraut wurde. War Strauß wirklich der richtige Mann, um den Zerfall des Parteiapparats aufzuhalten und das Durcheinander in der Landesgeschäftsstelle zu beseitigen? Sicher, Strauß galt als hoffnungsvolles Nachwuchstalent, seine organisatorisch-administrativen Erfahrungen waren aber vergleichsweise gering, und er war überdies durch sein Mandat im Frankfurter Wirtschaftsrat und seine Tätigkeit als Oberregierungsrat im Innenministerium so ausgelastet, daß für andere Aufgaben kaum Zeit blieb ${ }^{203}$.

Tatsächlich war Strauß erst Ende Dezember 1948 in der Lage, sein neues Amt anzutreten $^{204}$. Inzwischen hatte sich die Krise noch verschärft. August Haußleiter, der im Januar 1949 nicht einmal mehr in der Lage war, seine Telephonrechnung zu bezahlen $^{205}$, forderte den Parteivorsitzenden ultimativ auf, endlich Abhilfe zu schaffen:

„Da meine wiederholten mündlichen Vorstellungen und Erklärungen im Landesvorstand zu keinem Ergebnis geführt haben, darf ich Dich ein letztes [M]al auf die schwierige Lage in der Landesgeschäftsstelle aufmerksam machen mit der Bitte, nun endlich die seit langem fälligen Entscheidungen zu treffen. Da Du Oberregierungsrat Franz Strauss aus Schongau als Generalsekretär vorgesehen hattest, war die Landesgeschäftsstelle vom 1.9. 48-1.1. 49 unbesetzt. Als Stellvertreter hattest Du Herrn Gerstl vorgeschlagen, von dem ich annahm, dass Du seine Zusage zur Mitarbeit hattest. [.. .] Nun stellt sich heraus, dass sich Herr Gerstl noch gar nicht entschieden hat, ob er bei uns eintreten soll ${ }^{206}$. In der Tat ist gegenwärtig in der Landesgeschäftsstelle weder ein Generalsekretär noch ein stellvertretender Generalsekretär tätig. [. . .] Auf Grund dieser Lage hat das gesamte Land den Eindruck einer völlig führungslosen Landesleitung. Die Kritik an der Landesgeschäftsstelle wächst von Tag zu Tag, da ich mich persönlich ausserstande sehe, auf die Dauer hier den Generalsekretär, den stellv. Generalsekretär und den Landesschatzmeister zu vertreten. Ich habe in der letzten Sitzung des Landesvorstandes erklärt, dass ich mein Amt zur Verfügung stellen werde, wenn Du nicht in kürzester Frist über die Besetzung der Landesgeschäftsstelle eine klare Entscheidung triffst. Ich darf Dich auf diesen meinen wiederholten Hinweis ein allerletztes [M]al aufmerksam machen. Ich habe nicht die Absicht, mich für Verhältnisse verantwortlich machen zu lassen, für die ich nicht verantwortlich bin, da Du eine Klärung bisher verhindert hast. [.. . ] In der Finanzlage der Partei ist heute eine völlig unmögliche Situation eingetreten. Wir können die Zahlungsbefehle nicht bezahlen, die nun an uns herankommen. Der Aufbau des Wirtschaftsbeirates der Union ist durch Deine Ablehnung [. . . ] verzögert worden. Er bietet die einzige Möglichkeit, die Finanzlage der Partei zu verbessern. [...] Wenn aber der Parteivorsitzende jeder personellen Klärung in den entscheidenden organisatorischen Funktionen der Partei ausweicht, sie immer wieder vertagt und hin[aus]zögert, dann ist die Möglichkeit für eine erfolgreiche Arbeit der Parteiorganisation nicht gegeben." 207

${ }^{203}$ Vgl. Wolfgang Krieger, Franz Josef Strauß. Der barocke Demokrat aus Bayern, Göttingen, Zürich 1995, S. 24. Auch Haußleiter war aufgrund der Mehrfachbelastung von Strauß skeptisch; ACSP, NL Müller 17, August Haußleiter an Josef Müller vom 19. 1. 1949.

204 Das Protokoll der Sitzung des geschäftsführenden Landesvorstands am 30. 8. 1948 nennt Strauß bereits als neuen Generalsekretär; in der Anwesenheitsliste zum Protokoll der Sitzung des geschäftsführenden Landesvorstands am 23. 12. 1948 wird Strauß als Landesgeschäftsführer geführt (ACSP, CSU-LL). Tatsächlich dürfte Strauß in diesen Tagen sein Amt angetreten haben. Im Münchner Merkur vom 7. 1. 1949 war die Notiz zu lesen, Strauß sei zum neuen Generalsekretär der CSU ernannt worden und habe die Arbeit bereits aufgenommen.

205 ACSP, NL Müller 20, August Haußleiter an Josef Müller vom 24. 2. 1949.

206 Max Gerstl, ein Münchner CSU-Politiker der ersten Stunde, lehnte das Angebot Josef Müllers nach reiflicher Überlegung ab; ACSP, NL Müller 18, Max Gerstl an Josef Müller vom 19. 1. 1949.

207 ACSP, NL Müller 17, August Haußleiter an Josef Müller vom 19. 1. 1949. 


\section{UNIONSMITGLEDER}
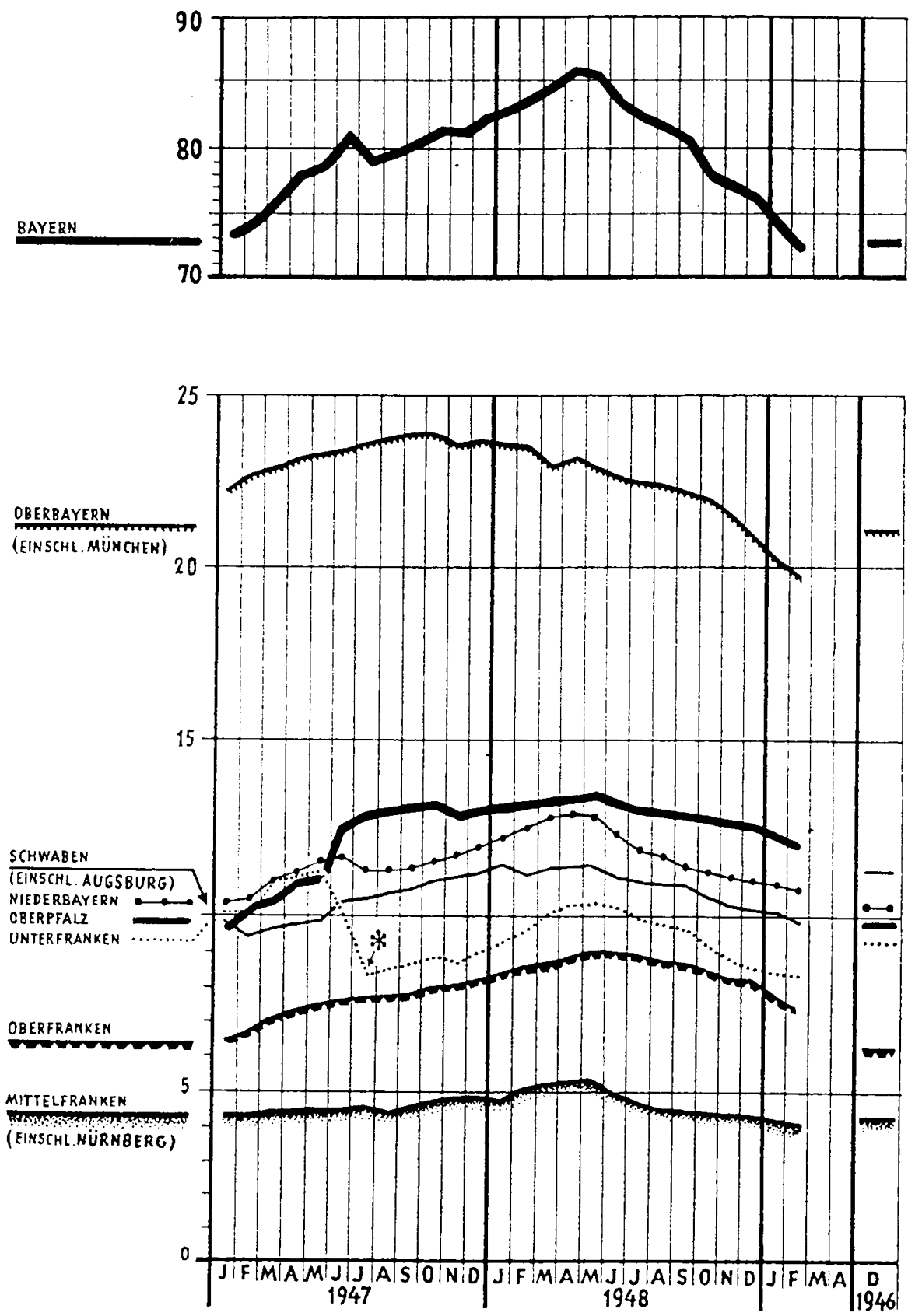

*) BERICHTSKORREKTUREN 


\section{DURCHSCHNITTLICHE ERTRAGE UND AUFWENDUNGEN}

PRO MONAT UND IHRE GUIEDERUNG

VON 100 RM DZW.DM DER ERTRAGE ENTFIELEN AUF:

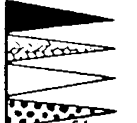

UMLAGEN UND BEITRAGE

FLUGBLATTTER,PLAKATE, ZEITSCHRIFTEN BAYER.RUNDSCHAU INFORMAT. DIENST. AUSSERORDENTL. ERTRAAGE

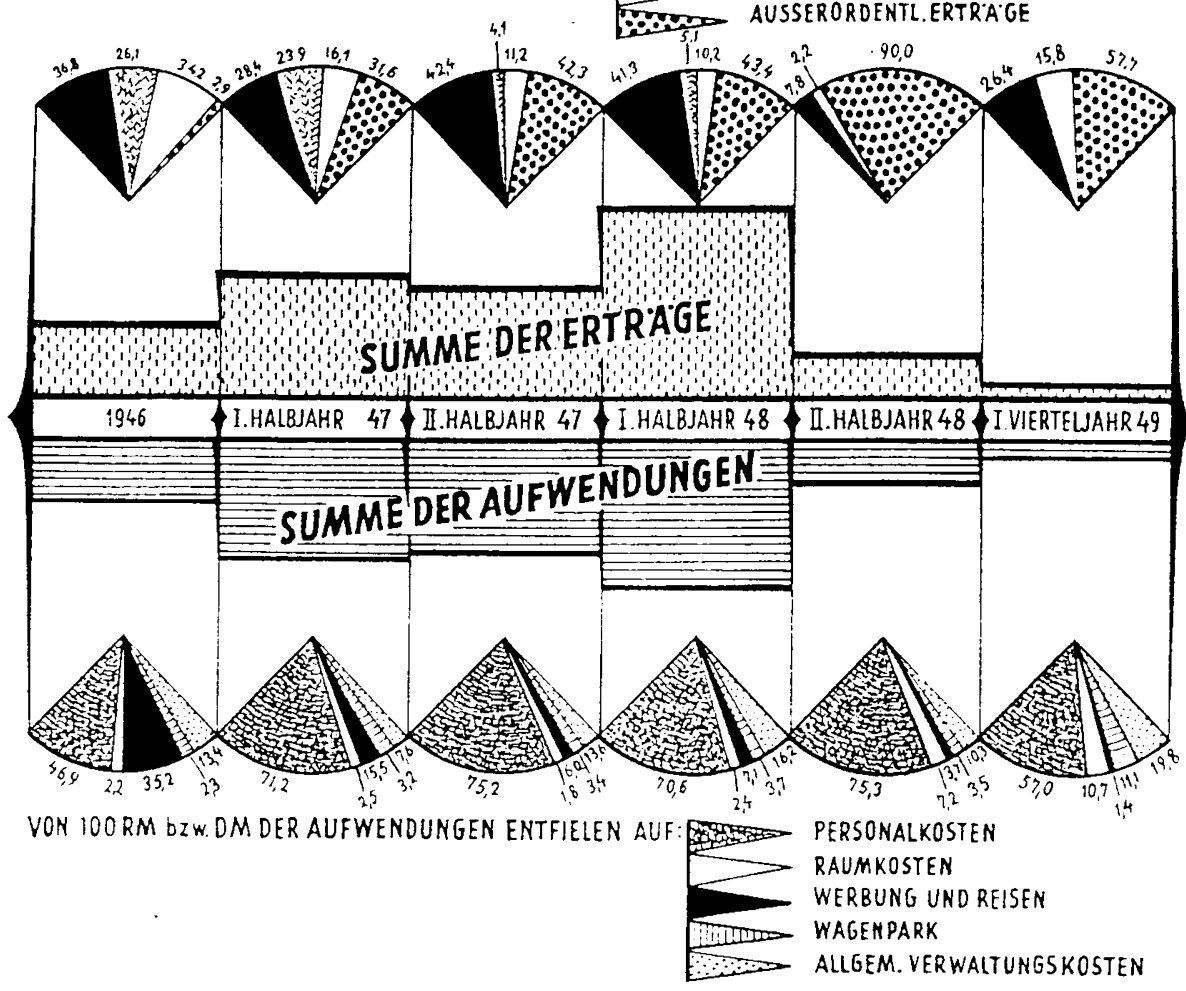

\section{ERTRA'GE AUS BEITRAGEN}

AUS AUSSEROROENTL. ERTRAGEN

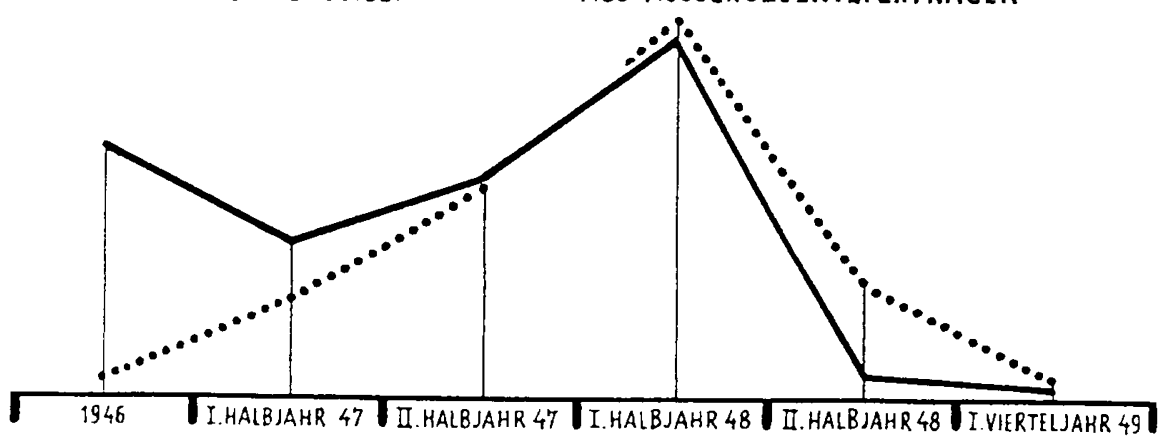




\section{VOM BEITRAGSANTEIL IN HÖHE VON 50 Pf bzw. 45 Pf u. 20 Pf WURDEN TATSACHLICH AN DIE LANDESGESCHA'FTSSTELE BEZAHLT}

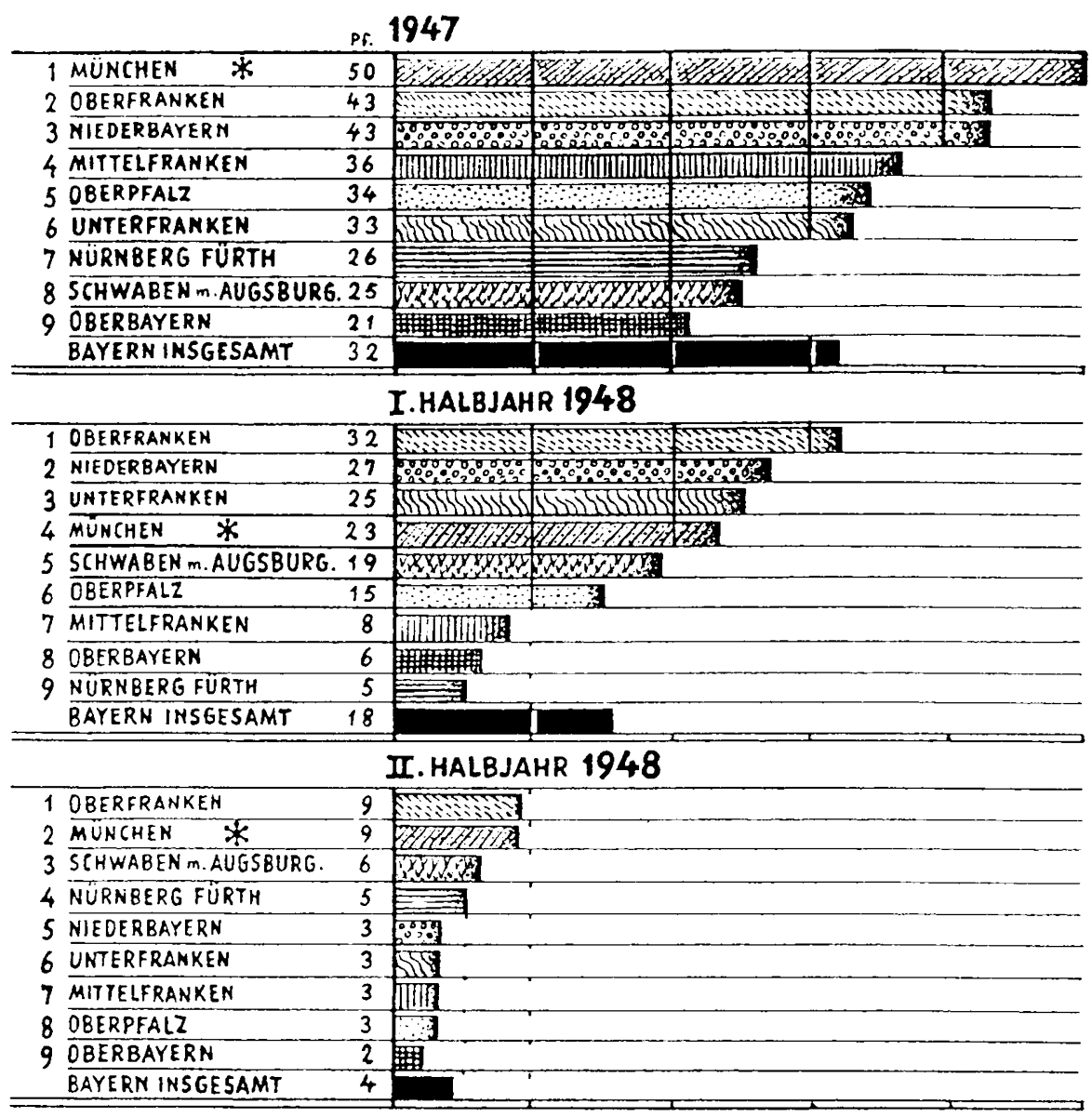

JANUAR U.FEBRUAR 1949

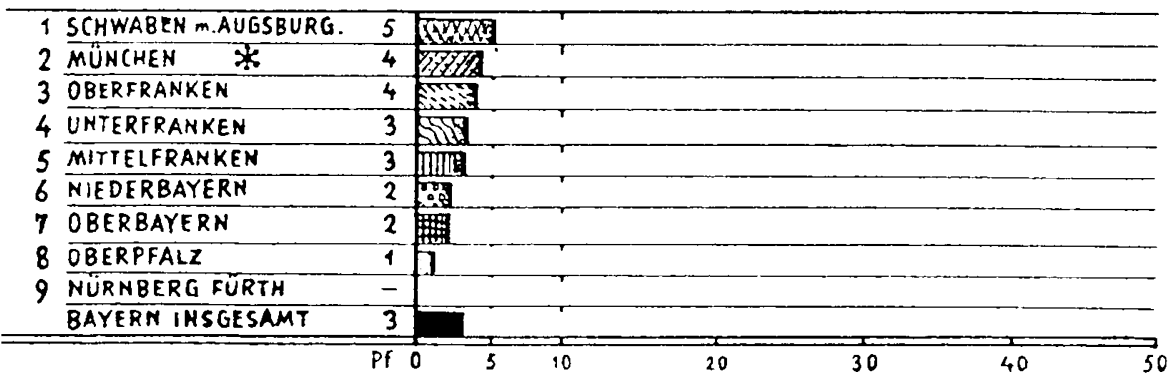

*) anrechnung von auslagen für die landesleitung 


\section{NICHTBEZAHLTE BEITRAGSANTEILE DER KREISVERBANDE}

\section{IN DEN BEZIRKEN - IN RM bZW. DM}

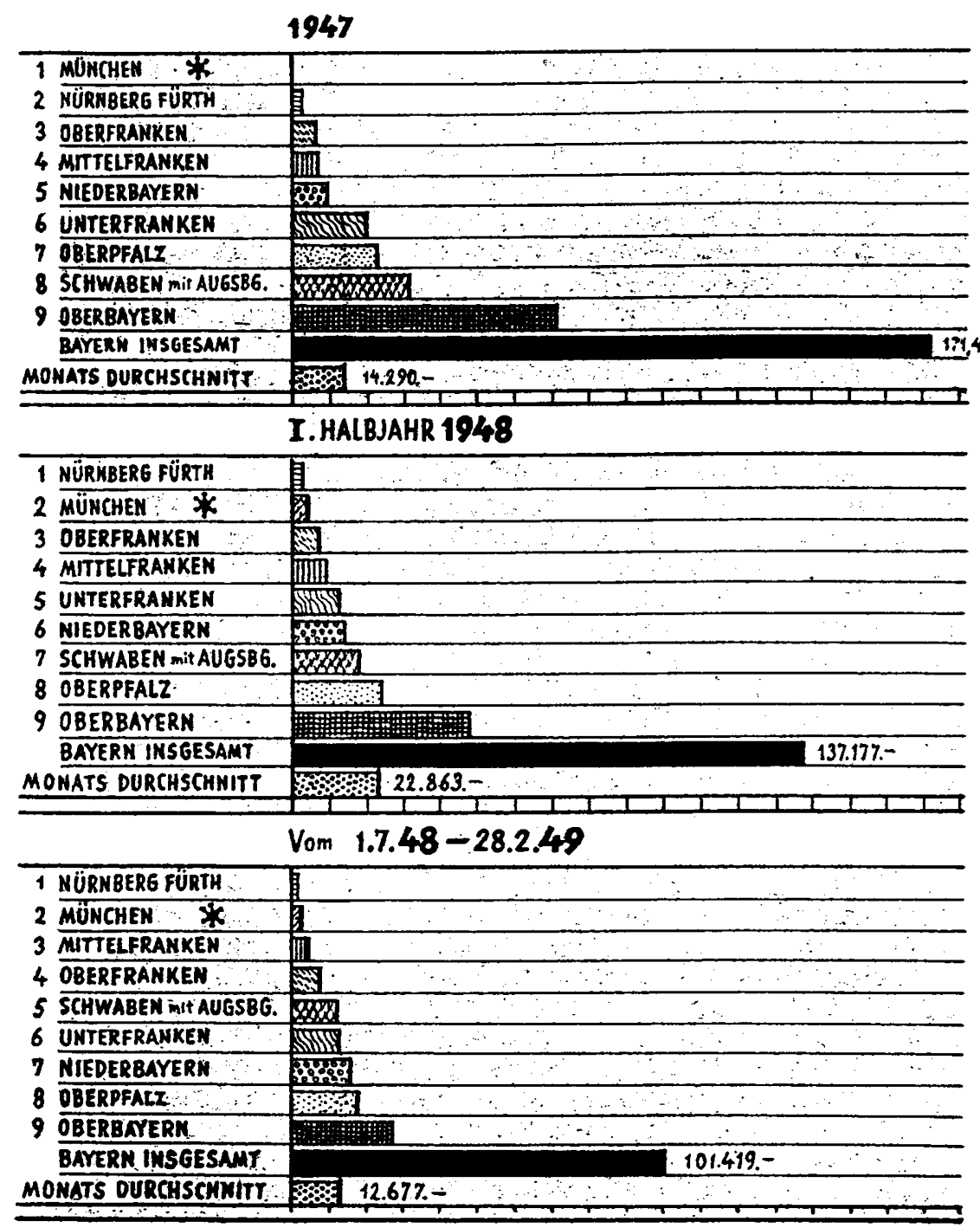

*) anrechnung von auslagen für die landesleitung 


\title{
BEZAHLTE GEH'A'TTER U.AUFWANDSENTSCHA'DIGUNGEN
}

\author{
INSGESAMT DAVON

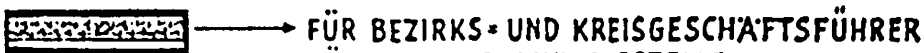 \\ $\rightarrow$ FÜR LANDESGESCHA'FTSSTELLLE
}

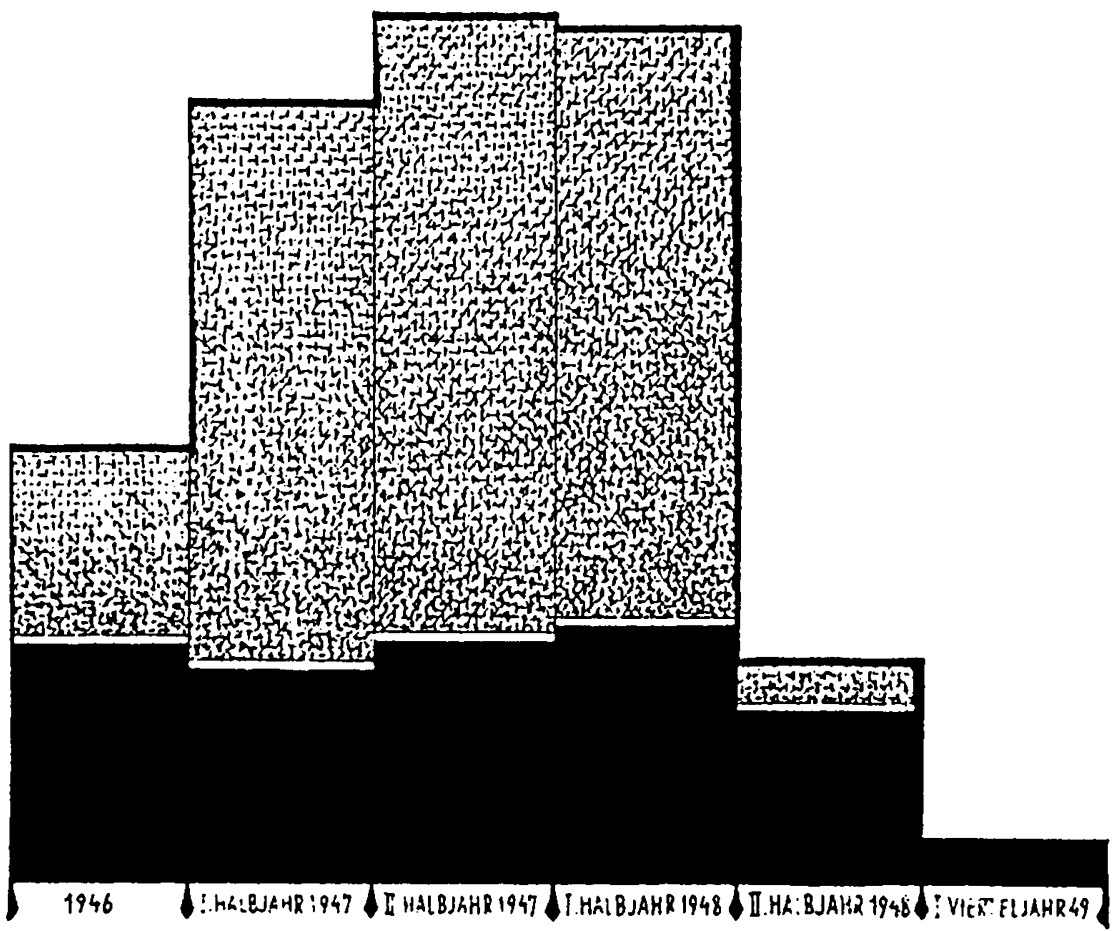

VON 100 RM 3Zw.DM ENTFIELEN AUF DIE LANDESGESCHÄFTSSTELLE

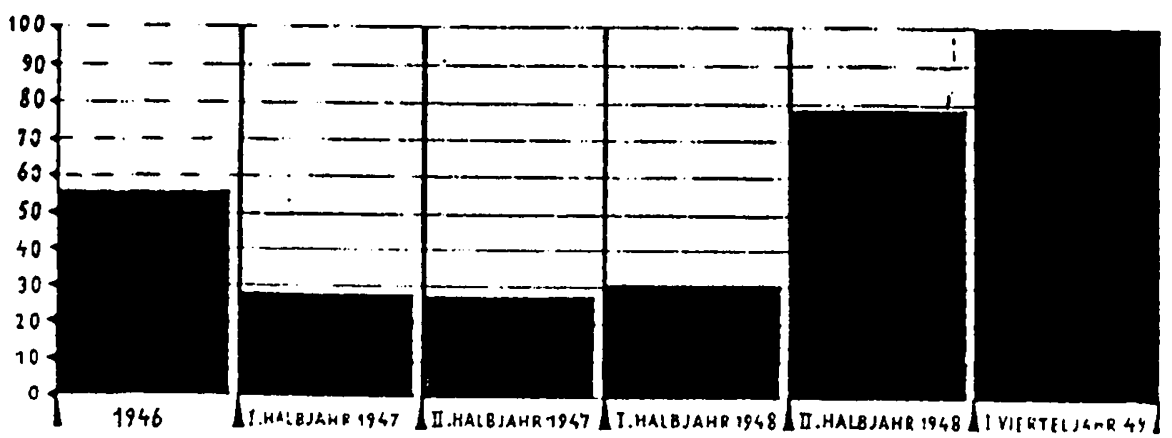


Haußleiter erhielt auf diesen Brief nicht einmal eine Antwort ${ }^{208}$. Die fatale Entscheidungsschwäche Müllers in dieser kritischen Situation war aber nicht der einzige Kritikpunkt. Heftige Kontroversen entzündeten sich auch an der Frage, wie man mit den spärlichen Finanzmitteln umgehen sollte, über die die CSU nach der Währungsreform noch verfügte. Während Haußleiter und Liedig ${ }^{209}$ forderten, zunächst die Landesgeschäftsstelle zu reorganisieren und den verbliebenen Mitarbeitern ihre Gehälter auszuzahlen, bestand Müller darauf, die dürftigen Spenden und Mitgliederbeiträge soweit wie möglich in sein Lieblingsprojekt zu investieren: eine neue Parteizeitung $^{210}$.

\section{Das gescheiterte Experiment: Die Wochenzeitung Der Gerade Weg}

Pressefragen hatten seit 1945 Müllers besonderes Interesse gefunden ${ }^{211}$. Die amerikanische Militärregierung verfolgte jedoch eine Konzeption, in der für Parteizeitungen kein Platz war. Die rigide Kontroll- und Lizenzierungspolitik der Besatzungsbehörden zielte auf die Schaffung eines weitmaschigen Netzes unabhängiger, parteipolitisch neutraler Zeitungen in der Hand unbelasteter demokratischer Lizenzträger, während die Parteien mit dünnen Mitteilungsblättern oder Wochenschriften vorliebnehmen mußten, die überdies an strenge Auflagen gebunden waren ${ }^{212}$. Erst im Sommer 1948 schien sich ein Umschwung in der amerikanischen Pressepolitik anzubahnen, und die Führungsspitze der CSU hoffte, nun endlich mit dem Aufbau eines echten Parteiorgans, am besten einer Tageszeitung, beginnen zu können ${ }^{213}$. Die Folgen der Währungsreform und die katastrophale Finanzlage der CSU ließen eine neue Parteizeitung aber zu einem mehr als riskanten Unternehmen werden ${ }^{214}$. Wie sollte man die Mittel für dieses

208 ACSP, NL Müller 20, August Haußleiter an Josef Müller vom 24. 2. 1949.

209 Liedig trat am 23. 12. 1948 offiziell von seinem Amt als Landesschatzmeister zurück (ACSP, CSULL, Protokoll der Sitzung des geschäftsführenden Landesvorstands am 23.12. 1948). Schon am 6. 12. 1948 hatte er an Haußleiter geschrieben, er lehne es schon seit Wochen ab, „in Fragen der Regelung finanzieller Verpflichtungen der Union“ mit Josef Müller oder der derzeitigen Kassenführung der Landesleitung zu verhandeln. ACSP, NL Müller 17. Liedigs Nachfolger war Richard Schachtner.

210 ACSP, CSU-LL, Protokolle der Sitzungen des geschäftsführenden Landesvorstands am 30.8., 8.10. und 23. 12. 1948. In der Sitzung am 8. 10. 1948 erklärte August Haußleiter, es sei unmöglich, von dem letzten Geld auch noch einen Teil abzuziehen. Man könne die Angestellten der Partei nicht so „über das Ohr [...] hauen“ und praktisch „verhungern“ lassen. Josef Müller erklärte dagegen nur lapidar: Die Zeitung müsse „unbedingt durchgehalten“ werden.

211 IfZ-Archiv, RG 260, 10/125-2/12, Notiz über eine Unterredung mit Josef Müller am 17.8. 1945.

212 Vgl. dazu Norbert Frei, Amerikanische Lizenzpolitik und deutsche Pressetradition. Die Geschichte der Nachkriegszeitung Südost-Kurier, München 1986, S. 7-38; eine Übersicht über die Parteipresse in Bayern gibt IfZ-Archiv, RG 84, 747/33, Ernest Langendorf an G. Speyer vom 27. 9. 1946.

213 BayHStA, NL Ehard 887, Rundschreiben Franz Liedigs an alle Bezirks- und Kreisverbände sowie die Arbeitsgemeinschaften auf Landesebene vom 23. 7. 1948; ACSP, CSU-LTF I, 15-14, Protokoll der Fraktionssitzung am 14. 12. 1948; ACSP, CSU-LL, Protokoll der Sitzung des geschäftsführenden Landesvorstands am 30.8. 1948.

214 ACSP, NL Müller 21, Rundschreiben Josef Müllers vom 3. 1. 1949. Darin heißt es: „Vor einem Jahr in der Reichsmarkzeit wäre eine solche Zeitung [Der Gerade Weg] noch ein Geschenk für uns gewesen, und wir hätten daraus Geld gewinnen können für die Parteiarbeit. Damals hat uns die MilitärRegierung keine Lizenz dafür gegeben. Heute ist die Zeitung mit dem Augenblick ihrer Geburt zunächst ein Sorgenkind, das sehr mühsam grosszuziehen ist." 
Parteiorgan - die Rede war von 120000 bis 150000 DM $^{215}$ - aufbringen, wenn sich schon die bestehenden Schriftenreihen als nicht mehr finanzierbar erwiesen, ganz zu schweigen von den Geschäftsstellen der CSU? Schon am 30. August 1948 erklärte Josef Mauerer, neben Josef Müller zweiter Lizenzträger des Parteiverlags, vor dem geschäftsführenden Landesvorstand, man müsse die Schließung des Verlags erwägen, da die erzielten Auflagen gerade ausreichten, um die Löhne und Gehälter der Mitarbeiter zu erwirtschaften, nicht aber, um die Druck- und Sachkosten zu decken ${ }^{216}$. Als Mauerer im Oktober 1948 seine Lizenz zurückgab und um seine Entlassung bat, lasteten Schulden in einer Höhe von 40000 bis 46000 DM auf dem Parteiverlag ${ }^{217}$; die drei Schriftenreihen der CSU - die Mitteilungen der Christlich-Sozialen Union, die Bayerische Rundschau und die unregelmäßig erscheinenden Fragen der Zeit - wurden eingestellt.

Dennoch stand es für Josef Müller außer Zweifel, daß die CSU zum frühestmöglichen Zeitpunkt eine neue, repräsentative Parteizeitung herausbringen müsse ${ }^{218}$. Die Gründe für diese problematische Entscheidung waren vielschichtig. Zum einen glaubte er gerade mit Blick auf kommende Wahlkämpfe, nicht ohne ein Instrument der Agitation und Propaganda auskommen zu können ${ }^{219}$, zum anderen hoffte er, mit den Erträgen einer erfolgreichen Zeitung die Parteifinanzen sanieren zu können. Die Einnahmen aus den 200000 Abonnements, die man in zwei bis drei Monaten gewinnen wollte, sollten die ausbleibenden Mitgliederbeiträge ersetzen und dem gelähmten Parteiapparat neue Mittel zuführen. Auch die Führungs- und Flügelkämpfe spielten bei dem Entschluß, eine neue Parteizeitung aufzubauen, eine nicht zu unterschätzende Rolle. Wer die Parteipresse kontrollierte, hatte schließlich auch die Möglichkeit, die innerparteiliche Willensbildung wesentlich zu beeinflussen. Setzte sich das neue Parteiorgan durch, so konnte sich Müller davon auch eine Stabilisierung seiner Position als Landesvorsitzender erwarten. Es verwundert daher nicht, daß Müller mit allen Mitteln versuchte, die Zügel fest in der Hand zu halten und die Parteipresse zu seiner alleinigen Domäne zu machen ${ }^{220}$.

Der im Herbst 1948 begonnene Aufbau einer neuen CSU-Zeitung stand jedoch von Anfang an unter einem schlechten Stern. Zunächst genehmigte die Militärregierung keine parteigebundene Tagespresse, wie es sich die Parteiführung erhofft hatte ${ }^{221}$. Auch die

215 ACSP, CSU-LL, Protokoll der Sitzung des geschäftsführenden Landesvorstands am 30. 8. 1948; BayHStA, NL Ehard 887, Rundschreiben Franz Liedigs an alle Bezirks- und Kreisverbände sowie die Arbeitsgemeinschaften auf Landesebene vom 23. 7. 1948.

216 ACSP, CSU-LL, Protokoll der Sitzung des geschäftsführenden Landesvorstands am 30. 8. 1948.

217 ACSP, NL Müller 21, Aufzeichnung über die Geschichte der Wochenzeitung Der Gerade Weg, undatiert, Aufstellung der Verbindlichkeiten des Parteiverlags der CSU zum 15. 12. 1948, Aufstellung der Verbindlichkeiten des Parteiverlags der CSU zum 31.12. 1948; eine Aufstellung der Schulden des Parteiverlags vom 3. 10. 1949 geht gar von fast 50000 DM Altschulden aus, die am 31. 10. 1948 bestanden hätten (BayHStA, NL Ehard 1362).

218 BayHStA, NL Ehard 887, Rundschreiben Franz Liedigs an alle Bezirks- und Kreisverbände sowie die Arbeitsgemeinschaften auf Landesebene vom 23. 7. 1948; die Zahl von 200000 Abonnenten, die man in spätestens einem Vierteljahr gewonnen zu haben hoffte, wird in diesem Rundschreiben genannt.

219 ACSP, CSU-LTF I, 15-14, Protokoll der Fraktionssitzung am 12. 10. 1948.

220 ACSP, CSU-LL, Protokolle der Sitzungen des geschäftsführenden Landesvorstands am 30.8., 8.10., 2.11. und 23. 12. 1948 sowie die Beschlüsse des Landesvorstands vom 18.12. 1948; ACSP, CSU-LTF I, 15-14, Protokolle der Fraktionssitzungen am 17.8., 23.11. und 14. 12. 1948 sowie am 5. 4. 1949.

221 ACSP, NL Müller 21, Aufzeichnung über die Geschichte der Wochenzeitung Der Gerade Weg, undatiert. 
Beschränkungen für Parteizeitungen, die nur wöchentlich oder monatlich erschienen, blieben vorerst bestehen, d. h. es durften keine Artikel erscheinen, die nicht mit den Zielen der Partei und der von ihr vertretenen Politik in Zusammenhang standen; allgemeine Nachrichten aus aller Welt oder ein feuilletonistischer Unterhaltungsteil waren verboten ${ }^{222}$. Ferner waren finanzielle Engpässe an der Tagesordnung. Als die Redaktionsmannschaft im November 1948 mit ihrer Arbeit begann, hatte sie einen Anfangskredit von 30000 DM zur Verfügung, um eine Zeitung herauszubringen und einen Verlag wieder flott zu machen, der mit mehr als 40000 DM Schulden belastet war ${ }^{223}$ ! Viele überhastete Aktionen und organisatorische Mißgriffe, die die kurze Geschichte des neuen Parteiorgans prägen sollten, entstanden nicht zuletzt in einer Atmosphäre ständigen Geldmangels, der eine längerfristige Planung unmöglich machte. Zeitdruck und Finanzprobleme waren unter anderem für eine folgenschwere Personalentscheidung verantwortlich. Josef Müller entschied sich nämlich dafür, eine Reihe von Journalisten vom Echo der Woche in die Redaktion der neuen Parteizeitung aufzunehmen, darunter den zweiten Lizenzträger Helmut Hammerschmidt und den Chef vom Dienst HansHubert Gensert, die zwar seiner politischen Linie nahestanden, aber wiederholt mit Kultusminister Hundhammer und dem konservativen CSU-Flügel in Konflikt geraten waren ${ }^{224}$. Gensert war überdies wegen seiner journalistischen Tätigkeit während der NS-Zeit angreifbar; eine Chance, die sich Hundhammer nicht entgehen ließ $\beta^{225}$.

Noch schwerer wog die verfehlte, der CSU nicht gemäße Konzeption der Parteizeitung, die nach den Vorgaben der Militärregierung als Wochenschrift erscheinen sollte. Man plante kein reines Agitations- und Kampfblatt und keinen bloßen Umschlagplatz von Parteinachrichten, sondern eine intellektuell anspruchs- und niveauvolle politische Wochenzeitung ${ }^{226}$ mit der Intention, die Grundlagen und Ziele der CSU gerade bei den Bevölkerungskreisen bekannt zu machen, die bisher noch wenig damit anfangen konnten. In diesem Sinne sollte sich das neue Parteiorgan intensiv mit christlicher Kulturpolitik beschäftigen, ausführlich über die Arbeit der CSU-Abgeordneten in den Parlamenten informieren und die Regierungspolitik erläutern. Die Redaktion beabsichtigte

222 ACSP, NL Müller 21, Protokoll der Redaktionssitzung am 15. 11. 1948.

223 ACSP, NL Müller 21, Aufzeichnung über die Geschichte der Wochenzeitung Der Gerade Weg, undatiert.

224 ACSP, CSU-LL, Protokoll der Sitzung des geschäftsführenden Landesvorstands am 2. 11. 1948; ACSP, NL Müller 21, „Informationen betreffend Tätigkeit des Verlages der CSU“, undatiert. Zur Kritik der innerparteilichen Opposition an Gensert, Hammerschmidt und anderen Journalisten, die bisher beim Echo der Woche beschäftigt waren, vgl. ACSP, CSU-LTF I, 15-14, Protokolle der Fraktionssitzungen am 23.11. und 14. 12. 1948.

225 Biographische Angaben finden sich in den „Informationen betreffend Tätigkeit des Verlages der CSU“ (ACSP, NL Müller 21). Zu den Aktivitäten der innerparteilichen Opposition vgl. ACSP, CSU-LTF I, 15-20/0, Notiz für Alois Hundhammer vom 17. 11. 1948, und CSU-LTF I, 15-14, Protokoll der Fraktionssitzung am 30. 11. 1948; BayHStA, NL Ehard 1209, Alois Hundhammer an Josef Müller vom 20.11. 1948 und Alois Hundhammer an Hans Ehard vom 25. 11. 1948, sowie Fränkischer Tag vom 30.11. 1948: „Der gerade Weg“ umstritten“. Hans-Hubert Gensert versuchte, die Vorwürfe wegen seiner angeblichen politischen Belastung zu widerlegen: ACSP, NL Müller 21, Emil Dovifat an Josef Müller vom 11.1. 1949.

226 ACSP, NL Müller 21, Aufzeichnung über die Geschichte der Wochenzeitung Der Gerade Weg, undatiert; darin heißt es: „Es erschien notwendig, das repräsentative Organ der CSU von allen nur auf Gefühle und Instinkte der Massen aufbauenden Veröffentlichungen freizuhalten. Es sollte wirklich ein Blatt zur Repräsentation geschaffen werden, das die grossen Linien einer christlichen und sozialen Politik aufzeigt. Nach allgemeinem Urteil ist dies redaktionell gelungen." Ähnlich auch ACSP, NL Müller 133, Hans-Hubert Gensert an den CSU-Bezirksverband Oberfranken vom 8. 3. 1949. 
zudem, sich speziell mit den Problemen der Frauen, der jungen Generation und der Flüchtlinge auseinanderzusetzen. Auch Artikel von führenden Persönlichkeiten christlich-demokratischer Parteien aus anderen Ländern waren geplant ${ }^{227}$. Doch schon nach wenigen Nummern war klar, daß die meisten Anhänger der CSU mit solch schwerer Kost wenig anzufangen wußten.

Selbst die Wahl des Namens für das neue Parteiorgan erwies sich als unglücklich. August Haußleiter hatte Das Neue Bayern vorgeschlagen ${ }^{228}$, war dabei aber bei Josef Müller auf wenig Gegenliebe gestoßen. Der Parteivorsitzende setzte im geschäftsführenden Landesvorstand durch, daß das neue Sprachrohr der CSU den Namen Der Gerade Weg erhielt ${ }^{229}$. Damit knüpfte man bewußt an das antinationalsozialistische Kampfblatt des überzeugten Katholiken Fritz Gerlich an, der 1934 von Schergen der SS im Konzentrationslager Dachau ermordet worden war $^{230}$. So hieß es in einer Werbeanzeige des Verlags für den neuen Geraden Weg:

„Im Dezember dieses Jahres erscheint in der Öffentlichkeit nach längerer Zeit wieder der Name einer Wochenzeitung, die sich in den Jahren vor 1933 einen bervorragenden Ruf geschaffen hat. Der Kampf um Wahrheit und Recht, den sie als Ziel in ihrem Untertitel angab, wurde von ihr in äußerst wirksamer Weise geführt. Sie wich schließlich nur der rohen Gewalt. Der Irrtum, den ,Der gerade Weg' bekämpfte, ist heute allgemein als Irrtum erkannt. Es soll das Bestreben auch des neuen Blattes sein, mit ebenso gutem politischen Instinkt und in genau so klarer Erkenntnis der wahren und der falschen Prinzipien zu arbeiten, wie es die Männer der gleichnamigen Wochenzeitung taten. ${ }^{\text {2231 }}$

Die hohen Erwartungen, die Redaktion und Parteiverlag damit weckten, eröffneten der CSU zwar die Chance, einen breiteren Leserkreis für das neue Blatt zu interessieren, als dies sonst möglich gewesen wäre, beschränkten aber zugleich die eigene Handlungsfreiheit. Schließlich forderte man bei jeder größeren Abweichung von der geistigen und politischen Linie des Vorbildes die Kritiker geradezu heraus. Der Schwandorfer CSU-Abgeordnete Josef Krempl empörte sich beispielsweise schon nach der Lektüre der ersten Nummer des Geraden Weges: „Dr. Gerlich war ein Heiliger. Dieses Blatt ist das Gegenteil.“232 Die Neuauflage des Geraden Weges rief auch den Fürsten Erich Waldburg zu Zeil auf den Plan, der vor 1933 der Mentor, Financier und Teilhaber Gerlichs gewesen war. Da es Josef Müller als Parteivorsitzender und Lizenzträger versäumt hatte, sich mit dem Fürsten in Verbindung zu setzen und eine Vereinbarung über die neue Verwendung des Titels zu treffen, kam es nur wenige Tage nach Erscheinen der ersten Nummer zum Eklat. Fürst Waldburg-Zeil erhob offen Einspruch gegen

227 ACSP, NL Müller 21, Protokoll der Redaktionssitzung am 15. 11. 1948, Protokoll einer Grundsatzdiskussion zwischen führenden Redaktionsmitgliedern am 1. 12. 1948, Aufzeichnung über die Geschichte der Wochenzeitung Der Gerade Weg, undatiert, Entwurf für ein Editorial Josef Müllers, undatiert.

${ }^{228}$ Haußleiter, der sich zunächst intensiv mit dem Aufbau der Parteipresse befaßt hatte, stellte seine Mitarbeit nach gravierenden Differenzen mit Josef Müller ein und übte offen Kritik am Geraden Weg; ACSP, NL Müller 21, August Haußleiter an Alois Hundhammer vom 30. 11. 1949.

${ }^{229}$ ACSP, CSU-LL, Protokoll der Sitzung des geschäftsführenden Landesvorstands am 2.11. 1948; ACSP, CSU-LTF I, 15-14, Protokoll der Fraktionssitzung am 23. 11. 1948.

230 Zur Zeitung Der Gerade Weg und zur Biographie Fritz Gerlichs vgl. Hans-Günter Richardi, Klaus Schumann, Geheimakte Gerlich/Bell. Röhms Pläne für ein Reich ohne Hitler, München 1993, S. 28-52 und S. 113-128.

231 ACSP, CSU-LTF I, 15-20/2, Werbeflugblatt des Parteiverlags der CSU für den Geraden Weg, undatiert; Hervorhebung im Original.

232 ACSP, CSU-LTF I, 15-14, Protokoll der Fraktionssitzung am 14. 12. 1948. 
die Neuauflage des Geraden Weges und drohte damit, seine Restitutionsansprüche vor Gericht geltend zu machen. „Aufbau und Niveau“ dieses Blattes entsprächen „in keiner Weise der Tradition des Titels“, stellte der Fürst fest; auch die Redaktion der neuen Zeitung biete „keinerlei Gewähr für die geistige und pressemässige Höhe [...], die den alten ,Geraden Weg' in der christlichen Welt zum Fanal gemacht hat“. Es klebe „zuviel Märtyrerblut an dem Titel“, so schloß der Fürst sein Schreiben an Josef Müller, „als dass man ihn zu Geschäftszwecken missbrauchen" dürfe ${ }^{233}$.

Darauf mußte Josef Müller reagieren, und es gelang ihm, mit dem Fürsten trotz aller bestehenden Vorbehalte ein Abkommen auszuhandeln, das der CSU den weiteren Gebrauch des Titels Der Gerade Weg erlaubte, dem Fürsten aber die Möglichkeit offen ließ, den Titel unter bestimmten Bedingungen zurückzufordern ${ }^{234}$. Seither schwebte ein mögliches Veto aus dem Hause Waldburg-Zeil wie ein Damoklesschwert über dem Geraden Weg. Tatsächlich sollte Fürst Waldburg-Zeil seine Entscheidung bald bedauern. Als sich im März 1949 das baldige Ende des Geraden Weges abzuzeichnen begann, machte er von seinem vertraglich zugesicherten Recht Gebrauch und forderte den Titel zurück. Dabei fällte er ein vernichtendes Urteil über das Parteiorgan: „Als Parteiblatt will es niemand, mit seiner halbliberalen Haltung wird es vielfach vom katholischen Bevölkerungsteil abgelehnt und wird in den übrigen Kreisen nie die benötigte Leserschaft finden. Das Blatt hat zunächst von seinem Titel gelebt; dieses Kapital ist verbraucht, nun ist nichts mehr da.“ Und er fügte hinzu: „Der Erfolg ist kurz gesagt der, daß der Titel ,Der gerade Weg' heute praktisch durch Missbrauch entwertet ist und kaum je wieder für ein grundsatzklares Blatt gebraucht werden kann. “235

Letztlich waren es aber nicht die Querelen mit dem Hause Waldburg-Zeil, sondern die Führungs- und Flügelkämpfe, die dem Geraden Weg zum Verhängnis wurden. Die Redaktion des neuen Parteiorgans hatte es sich zwar zum Ziel gesetzt, sich nicht in die Auseinandersetzungen einzumischen und keine Parteiinterna nach außen zu tragen, angesichts der mehr als gespannten Situation in der CSU war es jedoch eine Illusion zu glauben, man könne eine Art Äquidistanz zwischen den verfeindeten Gruppierungen wahren. Die Parteipresse war seit 1946 ein Zankapfel gewesen. Müller und seine Mitstreiter hatten die Druckschriften der Partei ebenso als ihre Domäne betrachtet wie den Parteiapparat, während die innerparteiliche Opposition immer wieder die Einseitigkeit der Parteiorgane kritisiert und versucht hatte, Einfluß auf ihre Form und ihren Inhalt zu gewinnen. Eine neue Parteizeitung, die der Landesvorsitzende noch dazu mit allen Mitteln gegen Einflußnahme von außen abzuschirmen suchte, mußte daher sofort den Argwohn der katholisch-konservativen Gegner Müllers wecken und offenen Widerstand provozieren. Die erste Nummer des Geraden Weges war noch gar nicht erschienen, als Alois Hundhammer bei Josef Müller gegen die einseitige Zusammensetzung der Redaktion protestierte und vor einer Verschärfung der inneren Konflikte warnte:

${ }^{233}$ ACSP, NL Müller 21, Erich Fürst Waldburg zu Zeil an Josef Müller vom 15. 12. 1948; der Fürst hatte seinen Brief aus Verärgerung über die Haltung Josef Müllers und der Verantwortlichen im Parteiverlag auch der Presse übergeben; Abendzeitung vom 22. 12. 1948: „Einspruch gegen bayerisches CSU-Organ“.

234 ACSP, NL Müller 21, Vereinbarung zwischen Erich Fürst Waldburg-Zeil und Josef Müller vom 22.12. 1948; vgl. auch den weiteren Schriftwechsel zwischen Müller und dem Fürsten unter dieser Signatur.

235 ACSP, NL Müller 21, Erich Fürst Waldburg zu Zeil an Josef Müller vom 23. 3. 1949. 
„Vor ein paar Tagen habe ich Dich fernmündlich davon unterrichtet, dass ich gegen die Zusammensetzung der Redaktion der ab kommenden Dezember geplanten Wochenzeitung unserer Partei Bedenken habe. Die in der CSU bisher zu beklagenden und in ihrer Auswirkung verhängnisvollen Misshelligkeiten sind in nicht geringem Teile zurückzuführen gewesen auf die Art, wie sowohl die ,Union' wie die ,Bayerische Rundschau“ redigiert waren. Zum guten Teil sind die Misshelligkeiten auch zurückgegangen auf Artikel, welche von Herren verfasst waren, die bisher dem Redaktionsstab des ,Echo der Woche' angehört haben. Du kennst wohl die Haltung, welche sowohl Herr Hammerschmidt wie Herr Gensert [. . . ] mir und meinen engeren politischen Freunden gegenüber eingenommen haben. Es muss deshalb überraschen, dass alle die vorgenannten Herren, gemeinsam noch mit Persönlichkeiten aus ihrer Umgebung, den Redaktionsstab der CSU-Wochenzeitung bilden werden. Ich befürchte von dieser Massnahme eine Weiterführung der Aufspaltung der CSU, dies umsomehr, als es gerade in der gegenwärtigen Auseinandersetzung innerhalb der bayerischen Politik notwendig wäre, dass die entscheidenden Redakteure unseres Parteiblattes Bayern kennen, aus Bayern stammen und Bayern lieben würden." 236

Zugleich kündigte Hundhammer an, er weigere sich, einen Artikel zur ersten Ausgabe des Geraden Weges beizusteuern. Die lautstarken Proteste des Kultusministers blieben auch der Öffentlichkeit nicht verborgen. Am 30. November 1948 berichtete der in Bamberg erscheinende Fränkische Tag, Hundhammer und Prälat Meixner hätten bei Josef Müller interveniert, um ein Erscheinen der Parteizeitung unter der gegenwärtigen Schriftleitung zu verhindern ${ }^{237}$. Damit war der Gerade Weg schon diskreditiert, ehe noch die erste Nummer vorlag. Hans-Hubert Gensert teilte Müller wenig später mit, diese Pressemeldung sei für die Redaktion sehr unangenehm; Mitarbeiter seien aus lauter Verunsicherung nicht mehr bereit, ihre Artikel zu schreiben, verschiedene Firmen hätten dringend benötigte Anzeigen zurückgezogen, weil sie nach dem Vorstoß des Kultusministers nicht mehr davon überzeugt seien, daß der Gerade Weg ein solides Unternehmen $\operatorname{sei}^{238}$. Aber Alois Hundhammer ging noch weiter. Er rief die Anhänger der CSU schließlich offen dazu auf, die neue Parteizeitung zu boykottieren ${ }^{239}$.

Daß die innerparteiliche Opposition den Geraden Weg so scharf ablehnte, lag nicht nur an ihrer Frontstellung gegen Josef Müller, der zu Recht als spiritus rector des neuen Parteiorgans galt. Vor allem die katholisch-konservativen CSU-Politiker fanden an einer einheitlichen, in München redigierten Parteizeitung ebensowenig Gefallen wie an einem zentral gesteuerten Parteiapparat mit hauptamtlich besetzten Geschäftsstellen. Sie favorisierten die Wiederbelebung der vielen Lokal- und Heimatzeitungen, die es vor 1933 gegeben hatte und die aufgrund der strengen Auflagen der Militärregierung noch nicht wieder erschienen waren ${ }^{240}$. Diese Blätter mit einer Auflage von oft nur wenigen tausend Stück hatten ihre Leser vor allem in der betont christlich eingestellten Landbevölkerung gefunden und waren schon in der Weimarer Republik eine wichtige Stütze der BVP gewesen $^{241}$. In dieser Lokal- und Heimatpresse sahen nicht wenige CSU-Politiker eine große Chance. Ihnen schwebte ein Netz von kleinen, CSU-nahen Zeitungen vor, die sich von den zuständigen Stellen der Partei leicht und kostengünstig mit Material versor-

${ }^{236}$ BayHStA, NL Ehard 1209, Alois Hundhammer an Josef Müller vom 20. 11. 1948.

${ }^{237}$ Fränkischer Tag vom 30.11. 1948: „,Der gerade Weg' umstritten“.

238 ACSP, NL Müller 21, Aktennotiz Hans-Hubert Genserts für Josef Müller vom 1. 12. 1948.

${ }^{239}$ ACSP, NL Müller 21, Notiz über eine Rede Alois Hundhammers am 3.2. 1949 in Rosenheim.

240 Zur Diskussion über die Heimatpresse ACSP, CSU-LTF I, 15-14, Protokolle der Fraktionssitzungen am 17.8.und 12. 10. 1948. Auch Josef Müller versprach halbherzig, die Heimatpresse zu unterstützen.

${ }^{241}$ Vgl. Schönhoven, BVP, S. $84 \mathrm{ff}$;; danach gab es vor 1933 etwa 120 Zeitungen mit einer Gesamtauflage von 500000 Exemplaren, die der BVP nahestanden. 
gen ließen ${ }^{242}$. Diese Pläne befürwortete auch der Druckereibesitzer und Verleger Konrad Kübler, der vor 1933 Heimatzeitungen wie das Landauer Volksblatt oder den Niederbayerischen Anzeiger herausgegeben hatte: „Die Zeitungsnot läßt sich meiner Meinung nach nur beheben durch gut geleitete Heimatzeitungen, die in den Kreisstädten selbst erscheinen“, schrieb Kübler im September 1948 an seine Fraktionskollegen. „Damit würde die CSU auch den Einfluss auf die Bevölkerung und die Wähler gewinnen,

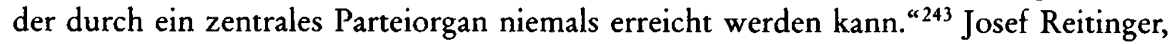
ein gut informierter Vertrauensmann Hundhammers, äußerte sich ähnlich:

„Nachdem die CSU bisher ihre Chance in der Neugestaltung der Presse am schlechtesten von allen Parteien wahrgenommen hat, darf sie nicht auch noch im Rennen um die Kleinzeitungen, die einst die Domäne des alten Zentrums und der Bayer. Volkspartei waren, unter den ,ferner liefen' bleiben. [...] Es wäre unverantwortlich, die hier sich förmlich aufdrängenden Möglichkeiten der CSU nicht nutzbar zu machen." 244

Daß hier tatsächlich Chancen für die CSU lagen, zeigte eine Initiative der Landtagsfraktion. Um festzustellen, welche christlich orientierten Zeitungsverlage und Druckereien das NS-Regime überdauert hatten und in welchen Orten mit dem Wiedererscheinen "eines weltanschaulich uns nahestehenden Blattes zu rechnen“"war, sollten die Abgeordneten eine Umfrage in ihren Stimmkreisen durchführen ${ }^{245}$. Dabei konnten immerhin 26 Betriebe ermittelt werden, davon allein zehn in Oberbayern, die stark daran interessiert waren, ihre Heimatzeitungen wieder erscheinen zu lassen, und um die tatkräftige Unterstützung der CSU baten ${ }^{246}$.

Doch die Parteiführung ging mit der neuen Parteizeitung einen anderen Weg. Schon die erste Nummer des Geraden Weges, die am 10. Dezember 1948 erschien, lieferte der innerparteilichen Opposition neue Munition. Einige ungeschickte Artikel und Illustrationen genügten, um in der Landtagsfraktion eine heftige Diskussion auszulösen. Wenn man so weitermache, empörte sich Hundhammer, ginge noch „der letzte Rest der CSU“ kaputt. Die ganze Angelegenheit sei ein Skandal ${ }^{247}$. Georg Meixner, als Leiter eines katholischen Verlags selbst ein erfahrener Pressemann, war derselben Meinung und scheute sich nicht, ihr mit drastischen Worten Ausdruck zu verleihen:

„Man kann nur sagen, es ist unerhört; hier ist alles verfehlt aufgezogen. Wir brauchen ein Parteiorgan. Ich weise auf das SPD-Blatt hin, z. B. das Erlanger Volksblatt. Hier ist nur die Rede von der Arbeit der SPD im Parlament wie im Kreistag usw. Was machen wir eigentlich für einen Mist? [...] Auch verlegerisch und technisch ist alles völlig falsch. Wir brauchen ein 8-seitiges Parteiblatt und sonst gar nichts. In den Ankündigungen zum Geraden [W]eg war von der CSU überhaupt nicht die Rede. Dabei ist die CSU die Regierungspartei in Bayern. Sind wir denn verrückt geworden?"

Die Debatte über den Geraden Weg wurde schnell zu einer Debatte über die politische Zukunft von Josef Müller. Hundhammer forderte offen den Rücktritt des Parteivorsitzenden, und die Augsburger Landtagsabgeordnete Franziska Gröber stellte den An-

242 ACSP, CSU-LTF I, 15-14, Protokoll der Fraktionssitzung am 17. 8. 1948.

243 ACSP, CSU-LTF I, 9-40, Konrad Kübler an die CSU-Landtagsfraktion vom 1. 9. 1948.

244 ACSP, CSU-LTF I, 15-20/2, Josef Reitinger an Alois Hundhammer vom 21. 2. 1949.

245 ACSP, CSU-LTF I, 9-40, Rundschreiben Alois Hundhammers an die CSU-Landtagsabgeordneten vom 20.8. 1948. Der Beschluß, diese Umfrage durchzuführen, wurde in der Fraktionssitzung am 17. 8. 1948 gefaßt; ACSP, CSU-LTF I, 15-14, Protokoll der Fraktionssitzung am 17. 8. 1948.

246 ACSP, CSU-LTF I, 9-40, Aktennotiz Wilhelm Röhrls für Alois Hundhammer vom 11. 10. 1948.

247 ACSP, CSU-LTF I, 15-14, Protokoll der Fraktionssitzung am 14. 12. 1948; das folgende nach dem Protokoll dieser Fraktionssitzung. 
trag, Müller das Mißtrauen auszusprechen; Müller sei nichts anderes - und an dieser Stelle zitierte sie den Bayernpartei-Vorsitzenden Joseph Baumgartner - als der „Totengräber der CSU“. Josef Stürmann faßte die Aussprache, in der fast nur harsche Kritik an der neuen Parteizeitung geübt wurde, kurz und bündig zusammen:

„Wir haben festgestellt, dass wir den Titel ,Der Gerade Weg' nicht wünschen. Wir haben festgestellt, dass wir die Mitarbeiter nicht akzeptieren können. Wir stellen fest, dass von Dr. Müller in diesem Blatt ein Geist manifestiert wird, der der Mehrheit der Wähler nicht entspricht. Die Zeitung ist abzulehnen, sie ist einzustellen, oder es ist für eine Herausgabe unter neuen Lizenzträgern zu sorgen."

Aus der Landtagsfraktion kamen auch in den folgenden Monaten die heftigsten Angriffe gegen den Geraden Weg. So wütete Hundhammer im April 1949:

„In diesem Zusammenhang ist scharf Stellung zu nehmen gegen das Skandalblatt, Der Gerade Weg: Wie hier unsere Abgeordneten angepackt werden, ist ein Skandal. [.. .] So hetzt das eigene Mitteilungsblatt draussen gegen unsere eigenen Abgeordneten. Dieses Blatt nennt sich Parteiorgan der CSU. Müller verwendet das letzte Geld, um diese Saunummer herauszubringen. Hier hört sich alles auf. [...] Ich glaube, es ist an der Zeit, mit dieser Parteiführung cinmal Schluss zu machen. “248

Unter diesen Umständen hatte der Gerade Weg praktisch keine Überlebenschance. Die Zahl von ca. 45000 Abonnenten, die erreicht werden mußte, um die Parteizeitung zu einem finanzkräftigen und rentablen Unternehmen $\mathrm{zu}$ machen, erwies sich schlicht als utopisch, wie der folgenden Übersicht zu entnehmen ist:

\section{Übersicht über Auflage und Verkaufszablen der Wochenzeitung Der Gerade Weg ${ }^{249}$}

$\begin{array}{lllll}\begin{array}{l}\text { Nummer } \\ \text { gedruckte } \\ \text { Auflage }\end{array} & \begin{array}{l}\text { an Händler etc. } \\ \text { gelieferte Exemplare }\end{array} & \begin{array}{l}\text { an Postabonnenten } \\ \text { gelieferte Exemplare }\end{array} & \begin{array}{l}\text { insgesamt } \\ \text { verkauft }\end{array} \\ 1 / 48 & 65000 & 6303 & 4300 & 10330 \\ 2 / 48 & 50000 & 6272 & 4400 & 10672 \\ 3 / 48 & 50000 & 5820 & 4600 & 10580 \\ 1 / 49 & 45000 & 6181 & 2770 & 8951 \\ 2 / 49 & 45000 & 7738 & 2830 & 10568 \\ 3 / 49 & \text { keine Angaben } & 2624 & 2850 & 5474 \\ 4 / 49 & \text { keine Angaben } & 6956 & 2830 & 9786 \\ 5 / 49 & \text { keine Angaben } & 6260 & 2770 & 9030 \\ 6 / 49 & \text { keine Angaben } & 5617 & 2860 & 8477 \\ 7 / 49 & \text { keine Angaben } & \text { keine Angaben } & 2940 & \text { keine Angaben } \\ 8 / 49 & \text { ausgefallen } & \text { ausgefallen } & \text { ausgefallen } & \text { ausgefallen } \\ 9 / 49 & \text { keine Angaben } & \text { keine Angaben } & 2940 & \text { keine Angaben }\end{array}$

Von den vielfältigen Ursachen für diese exorbitant schlechten Verkaufszahlen sind vor allem drei zu nennen: die verfehlte Werbe- und Vertriebsstrategie des Parteiverlags, der Zusammenbruch des Parteiapparats nach der Währungsreform und schließlich die verfehlte Konzeption der neuen Parteizeitung, die an den Bedürfnissen der meisten

248 ACSP, CSU-LTF I, 15-14, Protokoll der Fraktionssitzung am 5. 4. 1949.

249 Tabelle erstellt nach ACSP, NL Müller 21, Absatzübersichten zum 20.1., 8.2. und 12. 3. 1949. Der von Josef Müller mit der Überprüfung des Parteiverlags beauftragte Josef Hall nannte am 8. 3. 1949 die Zahl von 13000 Abonnenten; ACSP, NL Müller 21, Bericht Josef Halls über die Überprüfung des Parteiverlags der CSU vom 8. 3. 1949. 
CSU-Anhänger vorbeiging. Man muß den Verantwortlichen zugestehen, daß eine effektive Werbekampagne wegen des permanenten Geldmangels und des großen Zeitdrucks nur schwer möglich gewesen wäre; andererseits hielt man es aber auch nicht unbedingt für nötig, in großem Stil für den Geraden Weg zu werben, da man auf einen gleichsam automatischen Absatz der neuen, lange erwarteten Parteizeitung hoffte $e^{250}$. Wegen der Finanzmisere war es ebenfalls nicht möglich, in jedem Landkreis eine Agentur des Parteiverlags zur Werbung von Abonnenten, Sammlung von Annoncen und Weiterleitung von Nachrichten aus den CSU-Kreisverbänden an die Münchner Zentrale einzurichten ${ }^{251}$. Daher baute das Vertriebskonzept des Parteiverlags auf die tätige Mithilfe der Parteiorganisation, insbesondere auf die Unterstützung der Kreisgeschäftsstellen, die praktisch das nicht finanzierbare Agenturnetz ersetzen sollten. Das war im Prinzip keine schlechte Idee, da sich der Parteiapparat nach der Währungsreform aber in einem rapiden Zerfallsprozeß befand, war sie von vornherein zum Scheitern verurteilt ${ }^{252}$. Als Helmut Hammerschmidt im Januar 1949 die niederbayerischen Kreisverbände besuchte, um für eine stärkere Unterstützung des Geraden Weges zu werben, fand er in Vilsbiburg eine Situation vor, die nicht untypisch gewesen sein dürfte. Hammerschmidt hatte vor, dort mit dem Vertreter der Jungen Union, dem Landrat und dem Kreisvorsitzenden Ernst Wiedemann zu sprechen. Nach diesem Besuch schrieb er erschüttert an Josef Müller:

„Faktisch ist alles eine Person. Und diese eine Person ist wahrscheinlich die ganze Union im Landkreis. [...] Das Ganze ist der Stimmkreis des Abgeordneten Horlacher, um den sich [...] überhaupt niemand oder nur Ersatzmänner kümmern. Wiedemann, Angestellter beim Landratsamt, wurde als Vertreter der Jungen Union in den Kreistag gewählt. Kürzlich dann Landrat. Sein Rechtshelfer [...] weiss nicht einmal, ob es noch jemanden von der Union gibt. Kein Mensch weiss etwas über die CSU im Ort. ${ }^{\alpha 253}$

Nur ein Teil der Kreisverbände kümmerte sich überhaupt um die Belange des Geraden Weges, andere behandelten die Angelegenheit dilatorisch, mindestens 50 Kreisverbände weigerten sich, die 150 Exemplare der Parteizeitung, die sie unter die Leute bringen sollten, auch nur in Empfang zu nehmen, oder hatten den Parteiverlag gebeten, sie mit weiteren Lieferungen zu verschonen ${ }^{254}$. Appelle, sich im Interesse

250 BayHStA, NL Ehard 887, Rundschreiben Franz Liedigs an alle Bezirks- und Kreisverbände sowie die Arbeitsgemeinschaften auf Landesebene vom 23. 7. 1948; ACSP, NL Müller 133, Anton Hergenröder an Georg Meixner vom 18. 12. 1948.

251 ACSP, NL Müller 21, Bericht Josef Halls über die Überprüfung des Parteiverlags der CSU vom 8.3. 1949.

252 ACSP, NL Müller 21, Aufzeichnung über die Geschichte der Wochenzeitung Der Gerade Weg, undatiert; darin hieß es: „Dass sich der Erfolg nicht einstellte, liegt in der Hauptsache in der Tatsache, dass die Mehrzahl der Kreise keine bezahlten Geschäftsführer mehr hat."

253 ACSP, NL Müller 21, Bericht Helmut Hammerschmidts über seine Reise durch die niederbayerischen Kreisverbände vom 4.-6. 1. 1949.

${ }^{254}$ ACSP, NL Müller 21, Liste kooperationsunwilliger CSU-Kreisverbände vom 18. 1. 1949. In der Aufzeichnung über die Geschichte der Wochenzeitung Der Gerade Weg (NL Müller 21) heißt es dazu: „Auch wurde eine nicht unerhebliche Zahl von Kreisen von autoritärer oder autoritär scheinender Seite aufgefordert, das Blatt nicht zu verbreiten.“ Hans-Hubert Gensert schrieb am 20.1. 1949 an Franz Josef Strauß (NL Müller 21): „Die Arbeit der Kreisverbände der Christlich-Sozialen Union, die für den Vertrieb unserer Parteizeitung ,Der Gerade Weg' geleistet wird, ist in vielen Kreisen leider erstaunlich schlecht. Während eine Gruppe geradezu vorbildlich wirkt und tatsächlich Pionierarbcit leistet, lehnt die andere teilweise mit Bemerkungen wie, verschonen Sie uns mit dieser Zeitung' usw. jeglichen Einsatz für die Parteisache ab." Ähnlich auch NL Müller 21, Hans-Hubert Gensert an Josef Müller vom 23.2. 1949. 
der gesamten CSU für den Geraden Weg einzusetzen, blieben erfolglos ${ }^{255}$. Das Desinteresse der Basis kam nicht von ungefähr. Die zahlreichen Kritiker des neuen Parteiorgans - beileibe nicht nur eingefleischte Gegner Josef Müllers - verwiesen immer wieder auf dieselben Punkte: Der Gerade Weg sei zu anspruchsvoll, zeige zu wenig Verständnis für bayerische Probleme, biete kaum Informationen aus der Region und sei vor allem zu teuer ${ }^{256}$. Karl Kahn, der Geschäftsführer des mehrheitlich Müller-treuen Bezirksverbands Oberpfalz, schrieb Anfang März 1949 an den Landesvorsitzenden:

„Es hat keinen Sinn, dass wir in der Sache um den Brei herumreden; damit ist weder Ihnen noch uns gedient. Der ,Gerade Weg' ist nun leider einmal für die Bauern- und Arbeiterbevölkerung viel zu teuer, zu lebensfremd und zu akademisch hoch. Sein Monatsbezugspreis entspricht dem einer Tageszeitung. Der,Gerade Weg' ist ferner nach dem Urteil vieler Freunde und Bekannter viel zu wenig volksnahe; er bringt auch nicht das, was gerade für unsere kommunal-politische Arbeit in Stadt und Land zur Vorbereitung der künftigen Wahlen notwendig ist. "257

Kein Wunder, daß man in den Bezirksverbänden Oberfranken und Oberpfalz kein Interesse an einer Rettung des Geraden Weges hatte, sondern eigene Mitteilungsblätter forderte ${ }^{258}$ ! Versuche Josef Müllers und der Verantwortlichen im Parteiverlag, den Kritikern entgegenzukommen, den Preis des Blattes zu senken, Bezirksausgaben zu entwickeln und trotz der katastrophalen Finanzlage doch noch Agenturen in den Landkreisen einzurichten, kamen zu spät ${ }^{259}$.

Unter diesen Bedingungen war der Gerade Weg einfach nicht zu halten. Die erste Nummer war noch nicht gedruckt, da hatte im Parteiverlag bereits dieselbe Misere begonnen, die seit der Währungsreform in den Geschäftsstellen der CSU herrschte ${ }^{260}$. Der Teufelskreis von zu hohen Fixkosten und fehlenden Einnahmen ließ in kürzester Zeit einen Schuldenberg entstehen, der mit atemberaubender Schnelligkeit wuchs. Die Summe der Verbindlichkeiten erhöhte sich von 68526,62 DM am 30. November 1948 auf 141666,62 DM am 31. Dezember $1948^{261}$. Der Augsburger Verlagsdirektor Josef

255 ACSP, NL Müller 21, Rundschreiben Josef Müllers vom 3. 1. 1949, Hans-Hubert Gensert an Georg Barth vom 17. 1. 1949 und Entwurf eines Rundschreibens der CSU-Landesleitung an alle Kreisverbände vom 20.1. 1949.

256 ACSP, NL Müller 133, Bezirksverband Oberfranken, gez. Georg Barth, an die Verlagsleitung des Geraden Weges vom 8. 1. 1949; NL Müller 21, Adam Freiherr von Aretin an die Verlagsleitung des Geraden Weges vom 17. 1. 1949, Wolfram Thiele an Josef Müller vom 20.1. 1949, Beschlüsse der Kreisversammlung der CSU Dingolfing am 19. 2. 1949 und Aktennotiz Heinz Heggenreiners für Josef Müller vom 22.2. 1949.

257 ACSP, CSU-LTF I, 15-20/2, Karl Kahn an Josef Müller vom 1. 3. 1949.

258 ACSP, NL Müller 133, Hans-Hubert Gensert an den CSU-Bezirksverband Oberfranken vom 14. 3. 1949; ACSP, CSU-LTF I, 15-20/2, Karl Kahn an Josef Müller vom 1. 3. 1949. Die Delegierten des CSU-Kreisverbands im niederbayerischen Dingolfing beschlossen gar, den Geraden Weg so lange zu boykottieren, bis ihre Kritikpunkte berücksichtigt seien. ACSP, NL Müller 21, Beschlüsse der Kreisversammlung der CSU Dingolfing am 19.2. 1949.

259 ACSP, NL Müller 21, Aufzeichnung über die Geschichte der Wochenzeitung Der Gerade Weg, undatiert, Bericht Helmut Hammerschmidts über seine Reise durch die niederbayerischen Kreisverbände vom 4.-6. 1. 1949, Arbeitsbericht Rolf Engels vom 25. 1. 1949, Hans-Hubert Gensert an Josef Müller vom 23. 2. 1949, Bericht Josef Halls über die Überprüfung des Parteiverlags der CSU vom 8. 3. 1949; ACSP, CSU-LL, Beschlüsse des Landesvorstands vom 18. 12. 1948.

260 Beispiele dafür ACSP, NL Müller 21, Lorenz Sedlmayr an Josef Müller vom 22. 4. 1949, und BayHStA, NL Ehard 1209, Aktennotiz Hermann Proebsts für Hans Ehard und Karl Schwend vom 2. 6. 1949.

261 ACSP, NL Müller 21, Aufstellungen der Verbindlichkeiten des Parteiverlags der CSU zum 30.11. und 31. 12. 1948. 
Hall, der sich im März 1949 auf Wunsch Josef Müllers mit der Situation beim Geraden Weg befaßte, errechnete ein monatliches Defizit von fast $52000 \mathrm{DM}^{262}$ ! Da Partei und Verlag schon im Januar 1949 nicht mehr in der Lage waren, die Druckkosten aufzubringen und sich die Nürnberger Druckerei, in der der Gerade Weg hergestellt wurde, weigerte, weiter auf Kredit zu arbeiten, wurde jede Nummer zu einem Vabanquespiel $^{263}$. Ende Februar mußte erstmals eine Ausgabe des Geraden Weges ausfallen, weil das nötige Geld nicht aufgetrieben werden konnte.

Um die Kosten zu senken, wurde der Umfang des Geraden Weges reduziert und der Erscheinungsrhythmus von wöchentlich auf vierzehntägig umgestellt. Doch auch diese Notmaßnahmen halfen nichts mehr. Am 30. April 1949 erschien die letzte Nummer des Geraden Weges, der damit nach nicht einmal sechs Monaten von der Bildfläche verschwand. Seit April konnten die Löhne und Gehälter nicht mehr ausbezahlt werden, trotz aller Bemühungen, die Personalkosten zu senken ${ }^{264}$. Die Schuldenlast von Zeitung und Verlag betrug schließlich fast $215000 \mathrm{DM}^{265}$, und im Oktober 1949 mußte der Verlag, der wie die Wochenzeitung den Namen Der Gerade Weg trug, in einem Vergleichsverfahren liquidiert werden ${ }^{266}$.

Die CSU trug schwer an dem ruinösen Erbe, das Müllers Presseexperiment hinterlassen hatte. Woher sollte die Partei das Geld nehmen, um diese Schulden zu zahlen, wenn sie nicht einmal in der Lage war, die Verbindlichkeiten der Landesgeschäftsstelle zu begleichen? Das Abwicklungsverfahren zog sich quälend lange hin und belastete die Parteikasse erheblich. Oft waren nicht einmal die Mittel vorhanden, um den dringendsten Forderungen nachzukommen, auch wenn diese nur wenige hundert Mark betrugen $^{267}$. Die vorläufige Bilanz der Abwicklung des gescheiterten Parteiverlags wies noch im Januar 1955 Verbindlichkeiten in der stattlichen Höhe von 167000 DM aus $^{268}$. Müllers ebenso ehrgeiziger wie verzweifelter Plan, seine angeschlagene Stellung durch eine von ihm kontrollierte Parteizeitung zu stabilisieren, endete so in einem wahren Desaster.

262 ACSP, NL Müller 21, Bericht Josef Halls über die Überprüfung des Parteiverlags der CSU vom 8.3. 1949.

263 ACSP, NL Müller 107, W. Tümmels Buchdruckerei an den Verlag Der Gerade Weg vom 20. 1. 1949, NL Müller 21, Protokoll einer Besprechung zwischen Vertretern des Verlags Der Gerade Weg, W. Tümmels Buchdruckerei und der M. A. N. am 26. 1. 1949, Ludwig Kastl an Josef Müller vom 2. 2. 1949 und Hans-Hubert Gensert an Josef Müller vom 8. 3. 1949.

264 ACSP, NL Müller 21, Aufzeichnung über die Geschichte der Wochenzeitung Der Gerade Weg, undatiert, Aufstellung über die Mitarbeiter des Verlags Der Gerade Weg, ihre Löhne, Gehälter oder monatliche Fixen, undatiert, Aktennotiz Helmut Hammerschmidts und Hans-Hubert Genserts für Josef Müller vom 3. 5. 1949.

265 BayHStA, NL Ehard 1362, Aufstellung der Schulden des Verlags Der Gerade Weg vom 3. 10. 1949.

${ }^{266}$ BayHStA, NL Ehard 1745, Aktennotiz über eine Sitzung des Finanzausschusses der CSU am 25.10. 1949; NL Ehard 1209, Bericht über eine Betriebsprüfung beim Parteiverlag der CSU vom 24. 5. 1949.

267 ACSP, NL Müller 21, „Vorschlag zur Tilgung der Schulden des Geraden Weges“ vom 28. 3. 1950 und Karl Sigmund Mayr an Josef Müller vom 11.4., 30.5. und 4. 9. 1951.

268 BayHStA, NL Ehard 1711, vorläufige Bilanz der Abwicklung des Verlags Der Gerade Weg vom 15.1. 1955. 


\section{Der Zerfall des Müller-Flügels}

Wie tief die Krise ging, in der die Partei und ihr Vorsitzender steckten, war von außen zunächst noch nicht genau zu erkennen. Josef Müller, nach der Revolte des Bezirksverbands Oberbayern und den Wahlschlappen der CSU sichtlich angeschlagen, war die beherrschende Figur auf den Tagungen des Landesausschusses im Juli 1948 in Augsburg und fünf Monate später in Forchheim; die Exponenten der innerparteilichen Opposition meldeten sich dagegen kaum einmal zu Wort ${ }^{269}$. Das Nachrichtenmagazin "Der Spiegel“ mutmaßte Ende Juli 1948 sogar, die CSU sei auf dem Wege zur reinen „Müller-Partei“270.

Doch der Schein trog. Allen Einheitsbekundungen und aller vordergründig zur Schau gestellten Harmonie zum Trotz war der Riß, der seit den Gründungstagen der CSU durch die Partei ging, tiefer denn je. Allerdings begann sich die Ebene der Auseinandersetzungen zu verlagern. Während die Führungsgremien der CSU als Forum der Flügelkämpfe zunehmend an Bedeutung verloren - insbesondere der Landesausschuß drohte zeitweise zu einem reinen Akklamationsorgan zu degenerieren, dessen Beschlüsse und Resolutionen von Teilen der Partei einfach ignoriert wurden -, wählten die Widersacher Josef Müllers immer häufiger den Umweg über die Presse, um ihren Standpunkt zu vertreten, oder sie schmiedeten in konspirativen Zirkeln Pläne zum Sturz des Ochsensepp ${ }^{271}$. Angesichts der Mehrheitsverhältnisse in den Gremien der Parteiorganisation glaubten sie keine andere Möglichkeit zur Durchsetzung ihrer Vorstellungen mehr zu haben. So ist es kein Wunder, daß das Interesse an den Tagungen des Landesausschusses mehr und mehr nachließ; zwischen April und Dezember 1948 tagte der Landesausschuß wiederholt am Rande der Beschlußunfähigkeit ${ }^{272}$.

Wie stark es in der CSU weiterhin gärte, zeigte eine Resolution des schwäbischen Kreisverbands Mindelheim, in der die Delegierten dem „Frankenführer Dr. Müller“ Ende Mai 1948 offen das Mißtrauen aussprachen ${ }^{273}$. Auch die Bezirksversammlung der Münchner CSU diskutierte wenige Wochen später über die politische Zukunft ihrer Partei und ihres Landesvorsitzenden, dessen als unklar, unbayerisch und zentralistisch gebrandmarkte Politik weithin für den schleichenden Zerfall der CSU und für die Erfolge der Bayernpartei verantwortlich gemacht wurde ${ }^{274}$. Josef Stürmann, der

269 ACSP, NL Müller 10/5, Protokoll der Sitzung des Landesausschusses der CSU am 17./18. 7. 1948 in Augsburg; IfZ-Archiv, RG 260, 13/150-3/1, Bericht über die Sitzung des Landesausschusses der CSU am 17./18. 7. 1948 in Augsburg und Bericht über die Sitzung des Landesausschusses der CSU am 18./19. 12.1948 in Forchheim. Die Zeitung Der Tag berichtete am 19. 7. 1948: „Der Verlauf der Sitzung des CSU-Landesausschusses in Augsburg muß als voller Erfolg für den derzeitigen Landesvorsitzenden Dr. Josef Müller gewertet werden. Die Opposition gegen seine Politik, die nach dem Wahlsieg der Bayernpartei hohe Wellen geschlagen hatte, war fast völlig verstummt." Vgl. auch Hettler, Josef Müller, S. 379 f.

270 Der Spiegel vom 24. 7. 1948: „Der Fall ist eingetreten. Möglicherweise in die Luft“.

271 IfZ-Archiv, RG 260, 7/29-1/13-16, E. Tomlin Baily an das State Department vom 24. 1. 1949.

272 ACSP, NL Müller 10/5, Protokoll der Sitzung des Landesausschusses der CSU am 17./18.7.1948 in Augsburg; IfZ-Archiv, RG 260, 13/150-3/1, Bericht über die Sitzung des Landesausschusses der CSU am 18./19. 12. 1948 in Forchheim.

273 BayHStA, NL Ehard 887, CSU-Kreisverband Mindelheim an Hans Ehard, Alois Hundhammer und August Schwingenstein vom 31. 5. 1948.

274 ACSP, NL Müller 68, Protokoll der Bezirksversammlung der CSU München am 19. 6. 1948; die folgenden Zitate finden sich ebenda. Vgl. auch Mintzel, Anatomie, S. 241. Zum Presseecho vgl. SZ vom 
aus den Kreisen des monarchistischen Widerstands gegen den Nationalsozialismus zur CSU gestoßen war, trat mit einem Vorschlag vor die Delegierten, der in den folgenden Wochen und Monaten immer mehr Anhängern der bayerischen Unionspartei als der einzige Ausweg aus dem Dilemma der inneren Konflikte erscheinen sollte:

„Dr. Müller hat mit seiner politischen Konzeption in Franken zweifelsohne Erfolge gehabt; diese Erfolge aber haben uns in anderen Gebieten erhebliche Verluste gebracht. Die Lösung wäre die: den einen Vertreter als Flügelmann in Franken zu lassen und den anderen Vertreter dort, wo er gewünscht wird, darüber aber eine vermittelnde Person zu stellen, die uns Garantie gibt, dass der Grundgedanke der CSU so durchgeführt wird, wie er bei der Parteigründung 1945 gedacht war. Der Parteivorsitzende kann weder Dr. Müller noch Schäffer sein, sondern nur ein anderer. Eines ist klar, wir verlangen von jedem Parteivorsitzenden, dass er innerhalb einer demokratischen Partei nicht Parteimann eines Flügels ist, sondern er muss das Vernünftige aus zwei verschiedenen Meinungen in gutem Willen und guter Absicht zusammenführen."

Stürmann warnte aber zugleich davor zu glauben, die Neugestaltung der Parteiführung mit einem Mann des Ausgleichs an der Spitze sei ausreichend, um die Krise der CSU zu beenden. Er forderte vielmehr eine grundlegende Reform der Partei, als er den Delegierten zurief: „Wenn wir der CSU nicht von innen her neues Leben geben, dann geht sie mit oder ohne Dr. Müller zugrunde.“

Eigentlich kam für diese undankbare Aufgabe nur einer in Frage: Hans Ehard. Der Ministerpräsident, der vielfach als der „überragende Kopf“ und als die „einzige Rettung “ der CSU angesehen wurde, schien als einziger die Fähigkeit zu besitzen, die inneren Auseinandersetzungen zu beenden und die rivalisierenden Flügel miteinander zu versöhnen. Als gebürtiger Franke und Vertreter einer föderalistischen Realpolitik war der Ministerpräsident für den nordbayerischen Anhang Josef Müllers durchaus akzeptabel; in Altbayern stand er dagegen als energischer Verfechter bayerischer Interessen auf zonaler und überzonaler Ebene hoch im Kurs. Auch in konfessioneller Hinsicht war Ehard unverdächtig: katholisch, aber niemals in dem Verdacht, klerikal zu sein, war er mit einer protestantischen Frau verheiratet und hatte auch seinen einzigen Sohn evangelisch taufen lassen. Dies ließ ihn zwar katholischen Hardlinern suspekt erscheinen, machte aber andererseits seine Bekenntnisse zur interkonfessionellen Basis der Union für die evangelischen Anhänger der CSU um so glaubwürdiger. Letztlich waren es jedoch sein sachliches Auftreten und seine nüchterne Art, Probleme auf ihren Kern zu reduzieren und ohne sichtbare persönliche Ressentiments für alle Seiten konsensfähige Kompromißvorschläge auszuarbeiten, die Ehard wohltuend aus der Schar der CSU-Politiker heraushoben, die in den Führungs- und Flügelkämpfen oft ganz aus den Augen verloren hatten, worum es eigentlich ging. Seine Autorität als bayerischer Ministerpräsident, seine Popularität bei der Bevölkerung und seine Erfolge im Konzert der westdeutschen Ministerpräsidenten taten ein übriges, um Ehard als den wirklich starken Mann in der CSU erscheinen zu lassen ${ }^{275}$. Karl Köhler, ein engagierter Anhänger Josef Müllers, betrachtete diese Entwicklung bereits seit der außerordentlichen Landesversammlung der CSU am 30. und 31. August 1947 mit Sorge. Rückblickend schrieb er in seinen Me-

18.9. 1948: „CSU München lehnt Dr. Müller ab“. Hans Hermann von Eicken hatte bereits im Februar 1948 betont, die Bayernpartei lebe zu einem „erheblichen Teil von der Gegnerschaft gegen Dr. Müller“; ein Jahr später erklärte Alois Hundhammer kategorisch: „Der Vater der Bayernpartei ist Dr. Josef Müller“. Hans Hermann von Eicken an Hans Ehard vom 10. 2. 1948 (Kopie im Besitz des Verfassers) bzw. ACSP, CSU-LTF I, 15-14, Protokoll der Fraktionssitzung am 17. 2. 1949.

275 Vgl. Niethammer, Mitläuferfabrik, S. 434, und Mintzel, Anatomie, S. 245. 
moiren über den Ministerpräsidenten und seine Wirkung auf die zutiefst verunsicherten Delegierten:

„Wir [...] hatten den Eindruck, Müller erkenne die Gefahr, die von der Person des Ministerpräsidenten auf ihn zukäme, und daß er von einem Gefühl beherrscht werde, von jenen Kräften verdrängt zu werden, die weder im Kampf gegen den Nazismus als offene Bekenner und Kämpfer gegen den Unrechtsstaat auftraten und nach dem Zusammenbruch der Diktatur in der Gründerzeit der neuen Partei mit dem Einsatz aller persönlichen Kräfte sich abmühten noch um den Aufbau der neuen Partei bestrebt waren. In der Tat, es flogen Dr. [Eh] ard Amt und Würde einfach zu. [...] Ein beträcht[lich] großer Teil des Fußvolkes der Union blickte auf den mit der Würde eines Ministerpräsidenten Ausgestatteten mit Ehrfurcht und ehrerbietende[r] Distanz. Im Versammlungsraum wurde es still, wenn der Ministerpräsident anfing, seine Stimme zu erheben, und lauter Jubel erschallte, wenn er mit dem Verlesen seiner Rede endete. Sein Auftreten hatte den Nimbus eines Staatsmannes, sein rhetorischer Vortag war getragen, eher etwas gleichmäßig und monoton als spritzig und temperamentvoll. Bei einer [Eh]ard-Rede wurde niemand vom Stuhle gerissen [...]. Aber der Ministerpräsident wurde umjubelt. Es ist erstaunlich, wie wenig Zeit [Eh]ard brauchte, um sich mit dem höchsten Staatsamt zu identifizieren, um Zustimmung, Ehrerbietung, Respekt und Vertrauen bei der Masse der Delegierten zu gewinnen. Grübelt man nach den Gründen, die dazu führten, findet man sie in der langen Erziehung unseres Volkes zu gehorsamen Dienern der Autorität. Der Verdienstvolle gerät immer in den Schatten des Günstlings oder des Amtsträgers. ${ }^{\text {2276 }}$

Josef Müller war es tatsächlich nicht entgangen, daß sich Hans Ehard zu seinem potentiell aussichtsreichsten Konkurrenten um den Parteivorsitz gemausert hatte. Aus diesem Grund suchte er seit den Sommermonaten des Jahres 1948 einen möglichst engen Schulterschluß mit dem Ministerpräsidenten. Ging diese Strategie auf, konnte Müller einigermaßen sicher sein, daß es seinen Gegnern nicht leicht fallen würde, den zögernden Ministerpräsidenten zu einer Kandidatur für den Parteivorsitz zu bewegen. Müller ließ auch kaum eine Gelegenheit ungenutzt, um seine intensive Zusammenarbeit mit Ehard herauszustellen ${ }^{277}$; dadurch, so hoffte er, würden die Erfolge des Ministerpräsidenten zum Teil auch auf ihn zurückfallen, der in Ehards Kabinett immerhin die Ämter des Justizministers und des stellvertretenden Ministerpräsidenten bekleidete - und Erfolge brauchte Josef Müller 1948 so dringend wie kaum etwas sonst.

Hans Ehard war diese Allianz - bei aller Skepsis gegen den Ochsensepp ${ }^{278}$ - nicht unwillkommen. Die Unterstützung seiner föderalistischen Realpolitik durch den Parteivorsitzenden verschaffte dem Ministerpräsidenten eine breitere Operationsbasis

${ }^{276}$ IfZ-Archiv, MS $343 \mathrm{Smlg}$. Köhler 2, Bl. 163. Wie groß das Ansehen Ehards im Sommer 1948 bereits war, zeigt eine Resolution des Bezirksverbands Schwaben, in der einstimmig gefordert wurde, die Rede des Ministerpräsidenten am 30.8. 1947 vor der Landesversammlung als offizielles Programm der CSU zu übernehmen. ACSP, NL Müller 168, Resolution des CSU- Bezirksverbands Schwaben vom 5. 6. 1948.

277 Münchner Merkur vom 31. 1. 1949: „Enge Zusammenarbeit Ehard - Müller“; BayHStA, NL Pfeiffer 43, Bericht über die Bezirksversammlung der CSU Unterfranken am 12.2. 1949 in Schweinfurt; BSB, NL Schwend 2, Hans Ehard an Josef Müller vom 30. 12. 1948. Vor den Delegierten des Landesausschusses betonte Müller am 17. 7. 1948: „Wir haben zusammengearbeitet, und wir werden zusammenarbeiten trotz aller Gerüchte, mögen andere Störenfriede glauben, dass wir so unvernünftig wären, in einem solchen Augenblick etwa in Gegensatz zu geraten. (Sehr gut!) Es war - das darf ich wohl feststellen zu den Gerüchten, die auch in München in Umlauf gesetzt wurden - nicht eine Minute auch nur irgendeine Differenz zwischen uns beiden in den entscheidenden Stunden." ACSP, NL Müller 10/5, Protokoll der Sitzung des Landesausschusses der CSU am 17./18. 7. 1948 in Augsburg.

278 Noch in den ersten Junitagen beklagte sich Ehard bitter über den Parteivorsitzenden. Müller nehme zu wichtigen Fragen im Zusammenhang mit der bevorstehenden Weststaatsgründung „keine eigentliche Stellung ein“, ja er "weiche allen diesen Fragen aus“. Von seiten der Partei sei ebenfalls "fast 
und vergrößerte seinen Handlungsspielraum gegenüber Alois Hundhammer und seinen radikal föderalistisch, ja teilweise partikularistisch eingestellten Gefolgsleuten, die der Bayernpartei in nichts nachstehen wollten ${ }^{279}$. Für Müller hieß das, auf eigene Einfluß- und Gestaltungsmöglichkeiten zu verzichten, ungeliebte Kompromisse mitzutragen und Positionen zu vertreten, die seiner eigenen Überzeugung und der Überzeugung vieler seiner reichsfreundlichen Anhänger in Nordbayern zuwiderliefen. Die anhaltenden innerparteilichen Querelen ließen dem bedrängten Parteivorsitzenden aber keine andere Wahl.

Seit der Ministerpräsidentenkonferenz auf dem Koblenzer Rittersturz im Juli 1948 gab es eine gleichsam offizielle Arbeitsteilung zwischen Hans Ehard und Josef Müller. Der Ministerpräsident sollte bei den Verhandlungen über den künftigen westdeutschen Bundesstaat nicht nur die Politik der bayerischen Staatsregierung, sondern auch die Interessen der CSU vertreten, während Müller weiterhin für den Frankfurter Wirtschaftsrat zuständig blieb ${ }^{280}$. Diese Übereinkunft schien tatsächlich Bestand zu haben. Noch im April 1949 stand in der vertraulichen Korrespondenz der Landesleitung zu lesen, Josef Müller habe sich an keinem Punkt in die Beratungen über die Gestaltung des Weststaates eingemischt ${ }^{281}$.

Durch diese Zurückhaltung bot Müller seinen Gegnern zwar eine Angriffsfläche weniger, sein Schweigen zu den Verhandlungen des Parlamentarischen Rates stieß aber bei seinen reichsfreundlich oder gesamtdeutsch orientierten Gefolgsleuten auf Unverständnis. Sie betrachteten den föderalistischen Schulterschluß zwischen Ehard und Müller mit Argwohn, und die Vertrauensleute des Landesvorsitzenden im Parlamentarischen Rat murrten, weil Richtlinien und Handlungsanweisungen von seiten der Parteiführung ausblieben ${ }^{282}$.

Die Anlehnung an Ehard war nicht der einzige Versuch Müllers, seine Stellung als Parteivorsitzender zu festigen und zugleich sein belastendes Image als linker Flügelmann der CSU loszuwerden. Schon im Frühjahr 1948 hatte Müller erfolgreich um die Unterstützung von Michael Horlacher und Alois Schlögl geworben. Diese einflußreichen Führungspersönlichkeiten des Bauernflügels, die 1945 die Union gemeinsam mit Müller auf den Weg gebracht, sich dann aber der innerparteilichen Oppostion angeschlossen hatten, fürchteten ebenso wie der Parteivorsitzende ein Comeback Fritz Schäffers und eine Rückentwicklung der CSU zu einem Pendant der untergegangenen $\mathrm{BVP}^{283}$. Diese Faktoren erwiesen sich als so gewichtig, daß die Gründe für das Zerwürfnis zwischen Müller, Horlacher und Schlögl dahinter zurücktraten. Der Parteivor-

nichts geschehen“. BSB, NL Schwend 54, Aktennotiz über eine Besprechung zwischen Hans Ehard, Fritz Schäffer und Alois Hundhammer am 9. 6. 1948.

279 Vgl. dazu Gelberg, Hans Ehard, S. $184 \mathrm{ff}$. Interessant ist in diesem Zusammenhang auch die Rolle Ehards bei der Auseinandersetzung in der CSU-Fraktion um die Nominierung der Kandidaten für den Parlamentarischen Rat. ACSP, CSU-LTF I, 15-14, Protokoll der Fraktionssitzung am 24. 8. 1948.

280 Vgl. Die Politische Information 13/14-49.

281 Vgl. ebenda; ähnlich auch Hettler, Josef Müller, S. 399.

282 ACSP, NL Müller 133, Protokoll der Besprechung zwischen August Haußleiter, Anton Hergenröder, Gerhard Kroll, Josef Müller und Bernhard Ostwald am 1. 3. 1949.

283 IfZ-Archiv, RG 260, 13/143-3/4, „Subject: Internal Situation of the CSU“ vom 23. 3. 1949, und ACSP, NL Müller 109, vertrauliche Aktennotiz Josef Plonners für Josef Müller über die Sitzung des Bezirksvorstands der CSU Oberbayern am 20.1. 1948. Vgl. auch Hettler, Josef Müller, S. $384 \mathrm{f}$. und S. $398 \mathrm{f}$. 
sitzende erklärte dem amerikanischen Generalkonsul im April 1948 selbstsicher, vor seiner Aussöhnung mit den beiden Agrarpolitikern habe er sich nur auf ca. 65 Prozent der Partei stützen können; nun wisse er ungefähr 85 Prozent der CSU hinter sich ${ }^{284}$. Tatsächlich gelang es Müller im Verein mit den „Bauernführern“, die Rebellion Schäffers niederzuschlagen. Ob dieses Bündnis jedoch auch stark genug war, um Müllers Position als Parteivorsitzender dauerhaft zu sichern, mußte sich erst erweisen. Immerhin war seit 1946 einiges geschehen, und der Einfluß des Bauernflügels war erheblich geschwunden.

Um die explosive Situation in seiner Partei zu entschärfen, kam Müller seinen Gegenspielern zudem in einer zentralen Streitfrage entgegen und stimmte Verhandlungen über eine grundlegende Reform der Parteisatzungen zu, die den fränkischen Anhang Müllers stets bevorzugt und dem Parteivorsitzenden in der Landesversammlung wie im Landesausschuß eine bequeme Mehrheit gesichert hatten. In diesem Sinne beschlossen die Delegierten des Landesausschusses am 18. Juli 1948, eine ständige Satzungskommission zur Erarbeitung eines Entwurfs für ein neues Satzungswerk und zur Entscheidung von Streitfragen einzurichten ${ }^{285}$.

Am 30. September 1948 tagte diese Kommission, die aus Delegierten der zehn Bezirksverbände, Vertretern der fünf Arbeitsgemeinschaften und aus Mitgliedern der Parteiführung bestand, zum ersten $\mathrm{Mal}^{286}$. Auch Josef Müller nahm zeitweise an den Beratungen teil, die angesichts des Konfliktstoffes, den die Satzungsfragen boten, in erstaunlich ruhiger Atmosphäre verliefen. So bestand Einverständnis darüber, völlig neue Satzungen zu entwerfen, da sich alle bisherigen Versuche, durch eine mehr oder weniger weitgehende Reform der geltenden Bestimmungen zu einem befriedigenden Ergebnis zu kommen, als unzureichend erwiesen hatten. Die Grundsätze für das im einzelnen noch auszuarbeitende Satzungswerk, auf die sich die Kommission im Laufe einer mehrstündigen Sitzung einigte, sahen vor, die am allgemeinen Verwaltungsaufbau Bayerns orientierte horizontale Gliederung der Parteiorganisation ebenso beizubehalten wie die vertikale Gliederung „nach besonderen ,Sozialständen“ in der Form von auf Landesbasis anerkannten Arbeitsgemeinschaften“. Die Führungsgremien der Partei - Landesversammlung, Landesausschuß, Landesvorstand und geschäftsführender Landesvorstand - sollten nach den Erfahrungen der letzten Jahre so umgestaltet werden, daß ihre Arbeitsfähigkeit ebenso gestärkt würde wie das Prinzip der innerparteilichen Demokratie. Grundsätzlich neu und eine direkte Folge der Führungs- und Flügelkämpfe war der vorgesehene Modus für parteiinterne Wahlen. Im Protokoll über die erste Sitzung der ständigen Satzungskommission heißt es:

„Vor allen Dingen ist durch geeignete Maßnahmen sicherzustellen, daß nicht eine Mehrheitsgruppe allein die Vertretung für die nächst-höheren Stufen und nach außen stellt. Aus diesem Grunde ist daran festzuhalten, daß jede Delegierung in den nächst-höheren Verband zwei Personen umfassen soll, wobei durch entsprechende Gestaltung des Wahlsystems auch den Minderheitsgruppen die Chance gesichert sein muß, gegebenenfalls durch den 2 . Delegierten vertreten zu sein."

${ }^{28+}$ IfZ-Archiv, RG 260, 7/29-1/13-16, „Subject: Christian Social Union Land Committee Meeting and Effects on the Status of Dr. Fritz Schaeffer" vom 8. 4. 1948.

${ }^{285}$ ACSP, NL Müller 10/5, Protokoll der Sitzung des Landesausschusses der CSU am 17./18. 7. 1948 in Augsburg.

${ }^{286}$ ACSP, CSU-LTF I, 15-20/1, Bericht über die Sitzung der ständigen Satzungskommission der CSU vom 30. 9. 1948. Das folgende - soweit nicht anders belegt - nach ebenda. Ein kurzer Bericht über die Arbeit des Satzungsausschusses findet sich auch in der Politischen Information 1/2-48. 
Mit anderen Worten: Die geltenden Bestimmungen über die Wahl eines Delegierten, Ausschuß- oder Vorstandsmitglieds sollten so modifiziert werden, daß es einer "qualifizierten Minderheit" auf jeden Fall möglich sein würde, auch gegen die herrschende Mehrheit Vertreter der eigenen Richtung in Parteiämter zu wählen.

Auf den ersten Blick war dies ein eindeutiges Zugeständnis Josef Müllers, der in den Führungsgremien der CSU noch immer über eine sichere Mehrheit verfügte und bei einer solchen Regelung in Kauf nehmen mußte, daß prominente Vertreter der innerparteilichen Opposition mit wichtigen Ämtern betraut würden. Andererseits galt dieses Prinzip des institutionalisierten Minderheitenschutzes auch für die Parteigänger Josef Müllers, die bisher in bestimmten Suborganisationen der CSU - z. B. im von Hundhammer kontrollierten Bezirksverband Oberbayern - keine Chance hatten, bei internen Wahlen Berücksichtigung zu finden. Aber vielleicht bewogen andere Gründe den Landesvorsitzenden und seine Mitstreiter, diesem Wahlmodus zumindest vorläufig zuzustimmen: Wer konnte im Herbst 1948 sagen, wie lange sich der Ochsensepp noch als Parteichef halten konnte? Schließlich wuchs die Opposition gegen Müller von Tag zu Tag, und es erschien nicht ausgeschlossen, daß sich die Mehrheitsverhältnisse im Landesausschuß und in der Landesversammlung umkehren könnten. Für diesen Fall war der vorgesehene Wahlmodus so etwas wie eine Rückversicherung, die den Müller-Flügel davor bewahren sollte, nach einer Niederlage für unbestimmte Zeit vollständig von den Schalthebeln der innerparteilichen Macht verdrängt zu werden.

Die Parteiführung um den Ochsensepp war anscheinend auch bereit, das Prinzip der gleichberechtigten Vertretung aller Kreisverbände auf den Landesversammlungen aufzugeben, das sie bisher mit Klauen und Zähnen verteidigt hatte. Diese Regelung hatte den Müller-treuen Kreisverbänden in Nord- und Südwestbayern stets eine bequeme Mehrheit gesichert, obwohl die Kreisverbände in den altbayerischen Bezirken die Mehrheit der Mitglieder und Wähler der CSU vertraten. Die Gegner Müllers waren immer wieder Sturm gegen dieses in ihren Augen undemokratische Repräsentationsprinzip gelaufen, das sie nicht zu Unrecht als eigentliche Basis der Machtstellung des Ochsensepp ansahen; mehr als eine geringfügige Modifikation des Delegiertenschlüssels, die zahlenmäßig aber kaum ins Gewicht fiel, hatten sie aber nicht erreichen können $^{287}$. Nun einigte sich die ständige Satzungskommission auf einen Kompromiß, der den Forderungen der innerparteilichen Opposition recht nahe kam. Man wollte zwar am dem Grundsatz festhalten, daß jeder Kreisverband ohne Rücksicht auf seine Größe mindestens zwei Delegierte zu den Landesversammlungen entsenden konnte, schon um „auch der jeweiligen Minorität die Chance eines Delegierten zu geben“. Je mehr Mitglieder die einzelnen Kreisverbände jedoch aufzuweisen hatten, desto mehr Delegierte sollten sie auf den Parteitagen stellen können, und zwar - das war neu - ohne eine Begrenzung der Delegiertenzahl nach oben, wie sie noch die Kompromißformel vorgesehen hatte, die nach langen Auseinandersetzungen im Januar 1948 von der Landesversammlung beschlossen worden war. Damit hielt sich die Satzungskommission einerseits an das von Josef Müller verfochtene Prinzip, „nicht an der mechanischen Logik der toten Zahlen hängen[zu]bleiben“, sondern gerade den Regionen, die es erst noch für die Union zu gewinnen galt, eine stärkere Vertretung in den Führungsgremi-

287 Vgl. S. $223 \mathrm{f}$. 
en der CSU zuzubilligen, als es nach den Wähler- und Mitgliederzahlen angemessen gewesen wäre. Andererseits trug der Vorschlag der Satzungskommission all denen Rechnung, die eine Änderung des Delegiertenschlüssels aus Gründen der innerparteilichen Demokratie verlangten und der Einführung des Prinzips der „Leistungsbelohnung“ das Wort redeten ${ }^{288}$. Jede Partei bedürfe „einer gewissen Mindestzahl an Mitgliedern, um politisch und finanziell schlagkräftig zu sein", hieß es im ersten Arbeitsbericht der ständigen Satzungskommission. Deswegen müsse unter anderem „durch zusätzliche Delegiertensitze für entsprechende Fortschritte in der Mitgliederzahl“ oder eventuell auch für einen besonders hohen Prozentsatz an Wählerstimmen „ein Anreiz geschaffen werden".

Die Satzungskommission schlug außerdem vor, den Parteiapparat zu dezentralisieren. Bezirks- und Kreisgeschäftsführer sollten nicht mehr vom Landesverband, sondern "grundsätzlich von den Gremien angestellt und besoldet werden, für die sie tätig sind". Den höheren Parteiinstanzen sollte es lediglich vorbehalten bleiben, einer Anstellung zuzustimmen oder im gegebenen Fall Anträge auf Abberufung oder Entlassung eines Geschäftsführers zu stellen. Auch diese Kompromißformel war - zumindest vordergründig betrachtet - ein großes Zugeständnis Josef Müllers. Immerhin war der Aufbau einer zentral gesteuerten Parteiverwaltung ein integraler Bestandteil der politischen Konzeption des Parteivorsitzenden und als solcher auch ein zentraler Streitpunkt in den Führungs- und Flügelkämpfen. Daß Müller diesmal nachgab, lag aber hauptsächlich daran, daß der Parteiapparat durch die Folgen der Währungsreform ohnehin in Auflösung begriffen war und sich als nicht mehr finanzierbar erwiesen hatte. Da also nicht mehr viel zu verlieren war, bemühte sich Müller darum, Punkte zu sammeln, indem er seinen Widersachern auf dem Feld der Organisationspolitik entgegenkam.

Die innerparteiliche Opposition nahm die Vorschläge der ständigen Satzungskommission, die im Frühjahr 1949 der Landesversammlung zur Abstimmung vorgelegt werden sollten ${ }^{289}$, mit Genugtuung zu Kenntnis. Adolf Miller, ein eingeschworener Gegner des Ochsensepp, stellte mit Blick auf die anhaltende Satzungsdiskussion befriedigt fest, sogar bei den Anhängern Josef Müllers beginne es nun zu tagen ${ }^{290}$.

Der Versuch, durch Kurskorrekturen verlorenes Terrain zurückzugewinnen, ging Hand in Hand mit einer politisch-propagandistischen Offensive Müllers, die er als "Aktivierung" seiner Politik bezeichnete ${ }^{291}$. Der CSU-Vorsitzende griff gezielt unpopuläre Persönlichkeiten wie Hans Schlange-Schöningen, den Direktor der Verwaltung für Ernährung, Landwirtschaft und Forsten in Frankfurt ${ }^{292}$, und Philipp Auerbach,

${ }^{288}$ Protokoll der Landesversammlung der CSU am 24./25. 1. 1948 in Marktredwitz, in: Protokolle und Materialien, S. 1448.

289 Doch soweit kam es nicht. Die Ausarbeitung der neuen Statuten verzögerte sich immer mehr. Auf der Straubinger Landesversammlung im Mai 1949 vertagten die Delegierten die Satzungsfragen erneut und überwiesen das bislang erarbeitete Material an den Landesausschuß. ACSP, NL Müller 16, Protokoll der Landesversammlung der CSU vom 27.-29. 5. 1949 in Straubing. Zum Stand der Beratungen unmittelbar vor der Straubinger Landesversammlung: Die Politische Information $18-49$.

290 IfZ-Archiv, RG 260, 10/90-3/5, „Subject: Stimme zum neuen Müller-Skandal“ vom 21.12. 1948.

291 ACSP, NL Müller 312, August Haußleiter an Josef Müller vom 15. 12. 1948.

292 Zur Kampagne Müllers gegen Hans Schlange-Schöningen finden sich zahlreiche Dokumente und Zeitungsausschnitte im ACSP, NL Müller 312; über die Diskussion in der CDU/CSU-Fraktion im Frankfurter Wirtschaftsrat geben die entsprechenden Protokolle der Fraktionssitzungen Aufschluß, 
den Staatskommissar für die politisch, rassisch und religiös Verfolgten ${ }^{293}$, an oder führte einen Feldzug gegen politische Gegner wie den Bayernpartei-Vorsitzenden Joseph Baumgartner ${ }^{294}$. Daß es dem Ochsensepp dabei weniger um Sachfragen und Inhalte ging als darum, „aus persönlichem Prestige den starken Mann [zu] spielen“, blieb aufmerksamen Zeitgenossen nicht verborgen ${ }^{295}$. Selbst der stellvertretende Landesvorsitzende August Haußleiter warf seinem Mentor vor, er habe mit seiner Kampagne lediglich das Ziel verfolgt, „als Drachentöter an Popularität zu gewinnen“. Tatsächlich sah

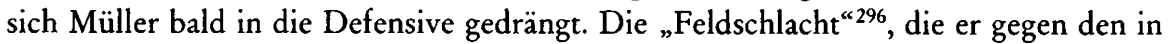
Bayern wegen seiner verbraucherfreundlichen und zentralistischen Ernährungspolitik viel kritisierten Schlange-Schöningen eröffnete, blieb ohne Erfolg: Müller mußte trotz aller Anstrengungen zurückstecken, und Schlange-Schöningen blieb im Amt. Allerdings hatte Müller mit seinen Attacken viel Porzellan zerschlagen und nicht zuletzt die Arbeits- und Fraktionsgemeinschaft der Unionsparteien vor eine unnötige Zerreißprobe gestellt. Ähnlich erging es Müller bei seinen Versuchen, dem ehemaligen Landwirtschaftsminister und amtierenden Bayernpartei-Vorsitzenden eine Korruptionsaffäre anzuhängen. Die Art und Weise, in der die Ermittlungen geführt wurden, erweckten den Eindruck, Müller schöpfe die ihm als Justizminister zu Gebote stehenden Mittel voll aus, und zwar nicht nur um der Wahrheitsfindung willen, sondern zur Ausschaltung eines prominenten politischen Gegners.

Müllers Strategie, sich als Mann der Mitte zu profilieren, um die eigene Position zu festigen, war nur begrenzt erfolgreich. Durch seine Allianz mit Horlacher und Schlögl gelang es dem Landesvorsitzenden zwar, neues Unterstützungspotential zu mobilisieren, die hartgesottene Opposition um Alois Hundhammer vermochte die "politische Wende“ Müllers dagegen kaum zu beeindrucken ${ }^{297}$. Zu oft waren sie von den taktischen Finten ihres Parteichefs überrascht worden, zu tief saßen die Ressentiments gegen den Ochsensepp, den sie für einen prinzipienlosen, krankhaft ehrgeizigen Zentralisten hielten ${ }^{298}$. So erklärte Adolf Miller, der Bezirksgeschäftsführer der Münchner CSU, einem Vertrauensmann der amerikanischen Militärregierung:

„Du weißt [...] wie sehr wir hier in München und Oberbayern immer hoffen, daß es einmal gelingen könnte, den Ochsensepp vor der Öffentlichkeit unmöglich zu machen. [.. . ] Aber der Ochsensepp ist ein - zwar unschöner - Phönix, der aus allen Feuern, die man ihm zu Unehren anzündet, siegreich hervorgeht. Das Erschütternde ist dabei nur, daß wohl alle wissen, ein wie zweifelhafter Charakter Dr. Müller im Grunde ist. Eigentlich ist er vor der Öffentlichkeit schon lange

die abgedruckt sind in: CDU/CSU im Frankfurter Wirtschaftsrat. IfZ-Archiv, RG 260, 7/29-1/ 13-16, Sam E. Woods an das State Department vom 20. 12. 1948. Zur „Schlange-Krise“ vgl. auch Hettler, Josef Müller, S. 384 f., und Trittel, Hunger und Politik, S. 196-203.

${ }^{293}$ Die Politische Information 6-48: „Der Fall Auerbach“.

${ }^{294}$ IfZ-Archiv, RG 260, 10/90-3/8, "Subject: Dr. Müller contra Dr. Baumgartner. Stimme der CSU“ vom 3. 3. 1949; Bayerische Landeszeitung vom 11. 2. 1949: „Ein starkes Gangsterstück“; Münchner Merkur vom 28. 2. 1949: „Politische Justiz?“; SZ vom 3. 3. 1949: „Ein Recke siegt...“.

${ }^{295}$ ACSP, NL Müller 312, August Haußleiter an Josef Müller vom 15. 12. 1948; das folgende Zitat ebenda.

296 Münchner Merkur vom 2. 11. 1948: „Feldschlacht um Schlange-Schöningen“.

297 Hettler, Josef Müller, S. 400.

${ }^{298}$ IfZ-Archiv, RG 260, 10/90-3/4, „Subject: Zur Krise in der CSU“ vom 20. 7. 1948; IfZ-Archiv, RG 260, 10/90-3/5, "Subject: Stimme zum neuen Müller-Skandal!“ vom 21.12. 1948 und „Subject: Dr. Josef-Müller-Affaire“ vom 21. 12. 1948; IfZ-Archiv, RG 260, 10/90-3/8, „Subject: CSU-Funktionär zu Ehards Stellung zu Bonn" vom 24. 3. 1949. 
unmöglich, und er ist immer noch oben. Weiß Gott, wenn es nicht unchristlich wäre, möchte man ihm als einzige Lösung einen baldigen Tod wünschen!“299

Hinzu kam, daß die Versuche des Parteivorsitzenden, die Opposition zu spalten oder zu pazifizieren, bei vielen treuen Gefolgsleuten Unverständnis und Mißtrauen auslösten, das in offenes Entsetzen umschlug, als Müller seinen alten Mitstreiter Georg Barth im Stich ließ und nichts unternahm, um die Wahl des bekannten Bamberger Kommunalpolitikers Anton Hergenröder zum Vorsitzenden des CSU-Bezirksverbands Oberfranken zu verhindern ${ }^{300}$. Freunde und Gegner des Landesvorsitzenden rieben sich verwundert die Augen: Hergenröder, ein Bewunderer Hans Ehards, den Schäffer schon im April 1948 als einen Mann bezeichnet hatte, der genauso denke wie $e^{301}$, sollte die oberfränkische CSU führen, die sich mehr als einmal als der stärkste Rückhalt des Parteivorsitzenden erwiesen hatte ${ }^{302}$ ? Während Müllers Anhänger die Welt nicht mehr verstanden, deutete die innerparteiliche Opposition diesen offensichtlichen Stimmungsumschwung in der oberfränkischen Heimat des Landesvorsitzenden als Signal zum endgültigen Sturz des Ochsensepp ${ }^{303}$.

Erste Risse im Gefüge des Müller-Flügels hatten sich schon 1947 gezeigt, waren aber im Zuge der Flügelkämpfe nur selten offen zutage getreten; im Frühjahr 1948 hatten das Comeback Fritz Schäffers und die von ihm angezettelte oberbayerische Rebellion die vorhandenen Spannungen noch einmal überdeckt. Als nach der Entmachtung des Staatsrats aber der gemeinsame Gegner wegfiel und Müller zudem versuchte, sein negatives Image vom zentralistischen Exponenten des linken Flügels der CSU loszuwerden, begann sich die Situation zuzuspitzen; dazu kamen noch die Folgen der Währungsreform, die zwischen Müller und einigen engen Mitstreitern zu scharfen Auseinandersetzungen über den richtigen organisationspolitischen Kurs und über den Einsatz der knappen finanziellen Ressourcen führten.

August Haußleiter etwa, einer der beiden Stellvertreter Müllers, scheute nicht davor zurück, den Landesvorsitzenden offen anzugreifen ${ }^{304}$. Er bezeichnete überdies seine eigene Partei als „überholt“ und die von ihr getragene bayerische Staatsregierung als „vergreist $^{\text {“ }} 305$ und bereitete mit der Gründung der Deutschen Union, einer vorgeblich überparteilichen Sammlungsbewegung „aller aktiven, aufbauwilligen Demokraten“ zur „Vorbereitung einer demokratischen Revolution“, seinen Absprung aus der CSU vor ${ }^{306}$.

299 IfZ-Archiv, RG 260, 10/90-3/8, „Subject: Dr. Müller contra Dr. Baumgartner. Stimme der CSU“ vom 3. 3. 1949.

300 In einem Bericht der amerikanischen Militärregierung heißt es: „The murmurs of discontent in Franconia arose to astonishment and dismay when Mueller supported Hergenroeder [...] for chairman of the CSU Oberfranken District Organization [...]. This was done to placate Ehard and Hundhammer. [.. . ] Mueller's old supporters felt betrayed and rumblings arose from the north for a change in party leadership.“ IfZ-Archiv, RG 260, 13/143-3/4, „Subject: Internal Situation of the CSU“ vom 23. 3. 1949. Vgl. auch Hettler, Josef Müller, S. 400.

301 BAK, NL Schäffer 23, Bl. 55, Fritz Schäffer an Augustinus Rösch vom 5. 4. 1948.

302 Um seine Wahl sicherzustellen und kritische Stimmen zu besänftigen, scheint Anton Hergenröder zunächst ein offenes Bekenntnis zur Politik Josef Müllers abgelegt zu haben. Mag sein, daß sich auch der Ochsensepp davon beeindrucken ließ. BAK, NL Guttenberg 277, Bl. 82, August Haußleiter an Anton Hergenröder, Datierung unleserlich (1949).

303 IfZ-Archiv, RG 260, 10/90-3/1, „Subject: Situation of CSU“ vom 5. 2. 1949.

304 ACSP, CSU-LTF I, 15-14, Protokolle der Fraktionssitzungen am 23.11. und 14. 12. 1948 sowie am 5.4. 1949.

305 ACSP, CSU-LTF I, 15-14, Protokoll der Fraktionssitzung am 17. 2. 1949.

306 SZ vom 25. 1. 1949: „Gründung einer, Deutschen Union‘. Haußleiter: Vorbereitung einer demokrati- 
Mit Gerhard Kroll, der ein Jahr lang den Bezirksverband Oberfranken im Sinne Müllers geführt hatte, zerstritt sich der Landesvorsitzende über die Frage des richtigen Vorgehens bei den Verhandlungen des Parlamentarischen Rates in Bonn. Kroll, selbst Mitglied des Parlamentarischen Rates, fühlte sich von der Parteiführung im Stich gelassen; Müller hatte dieses Feld aber aus strategischen Gründen Hans Ehard überlassen und war überdies in zentralen Fragen der Weststaatsgründung anderer Meinung als Kroll ${ }^{307}$. Zwischen Josef Müller und Franz Liedig, einem alten Freund und Kampfgefährten aus den Tagen des gemeinsamen Widerstandes gegen die nationalsozialistische Diktatur, kam es wegen der anhaltenden Finanzkrise der CSU zu einem ernsten Zerwürfnis. Andere, beispielsweise Eugen Rindt, fühlten sich von Müller persönlich brüskiert und verletzt ${ }^{308}$.

Der politische Spagat, zu dem der CSU-Vorsitzende im Herbst 1948 ansetzte, mißlang gründlich. Anstatt mehr Handlungsspielraum zu gewinnen, geriet Müller mehr und mehr zwischen die Fronten. Die alten Widersacher ließen sich nicht „bekehren“, und seine Mitstreiter weigerten sich, Müllers Kurswechsel nachzuvollziehen. Hanswolf Haunhorst und August Haußleiter, der bereits im geschäftsführenden Landesvorstand lautstark mit Müller aneinander geraten war, warfen Müller auf der Forchheimer Tagung des Landesausschusses im Dezember 1948 sogar offen vor, er betreibe „eine Politik im Sinne der alten Bayerischen Volkspartei“ ${ }^{\text {309. }}$

Doch die Kritik seiner - ehemaligen - Gefolgsleute stieß bei Müller auf taube Ohren. Der Landesvorsitzende agierte weiterhin ebenso stur wie inkonsequent, unterließ es, selbst bei wichtigen Entscheidungen die Zustimmung des Parteivorstands einzuholen, und stieß durch sein abweisendes, nicht immer verständliches Verhalten seine verbliebenen Anhänger vor den Kopf ${ }^{310}$. Zugleich schien es gerade in den kritischen Monaten des Frühjahrs 1949 so, als überließe Müller seinen Gegnern das Terrain, anstatt die letzten Kräfte für die bevorstehende Entscheidung zu mobilisieren ${ }^{311}$. Ludwig Brand, einer der wenigen Fürsprecher des Landesvorsitzenden im Bezirksverband Oberbayern, hielt Müller schon im Sommer 1948 vor, es genüge nicht, als Justizminister Gefängnisse zu besuchen und allgemeine Reden zu halten, ohne auch nur einen Versuch zu machen, die Vertrauensleute der CSU in den Kreisverbänden für sich zu gewinnen und „endlich die gemeinen Anwürfe und Verdächtigungen“ gegen ihn zurückzuweisen. Doch was mache Müller in dieser kritischen Situation? Er gehe auf Rei$\operatorname{sen}^{312}$ ! Karl Sigmund Mayr, Vorsitzender des Bezirksverbands Mittelfranken, der Mül-

schen Revolution“, und SZ vom 29. 1. 1949: „Haußleiter über die ,Deutsche Union'. ,Gegen die ideologische Sektenbildung der Parteien““. Die Politische Information 4-49: „Gründungsversammlung der Deutschen Union in Braunschweig“. Vgl. auch Richard Stöss, Vom Nationalismus zum Umweltschutz. Die Deutsche Gemeinschaft/Aktionsgemeinschaft Unabhängiger Deutscher im Parteiensystem der Bundesrepublik, Opladen 1980, S. 70-74.

307 ACSP, CSU-LTF I, 15-14, Protokoll der Fraktionssitzung am 17. 8. 1948; ACSP, NL Müller 133, Protokoll der Besprechung zwischen August Haußleiter, Anton Hergenröder, Gerhard Kroll, Josef Müller und Bernhard Ostwald am 1. 3. 1949.

308 ACSP, NL Müller 168, Eugen Rindt an Josef Müller vom 17. 7. 1948.

309 IfZ-Archiv, RG 260, 13/150-3/1, Bericht über die Sitzung des Landesausschusses der CSU am 18./ 19. 12. 1948 in Forchheim.

310 ACSP, CSU-LL, Protokolle der Sitzungen des geschäftsführenden Landesvorstands am 30. 8. und 8. 10. 1948; ACSP, CSU-LTF I, 15-14, Protokoll der Fraktionssitzung am 23. 11. 1948.

311 IfZ-Archiv, MS $343 \mathrm{Smlg}$. Köhler 2, Bl. 184 und Bl. 197.

312 ACSP, NL Müller 110, Ludwig Brand an Josef Müller vom 8. 6. 1948. 
ler bereits im Februar 1948 eine verfehlte Strategie vorgeworfen hatte ${ }^{313}$, konnte sich des Eindrucks nicht erwehren, daß sich der Landesvorsitzende durch sein eigenwilliges Vorgehen „selbst auf ein Nebengeleise gelenkt" hätte ${ }^{314}$.

Kein Zweifel, Josef Müller geriet trotz seines Sieges über Fritz Schäffer in der zweiten Hälfte des Jahres 1948 Zug um Zug in die Isolation. Jetzt sollte es sich als fatal erweisen, daß der Landesvorsitzende nie versucht hatte, neben dem Parteiapparat eine wirkliche Hausmacht in der CSU aufzubauen, sondern stets auf seine politischen Freunde an der Spitze einflußreicher Bezirks- und Kreisverbände gesetzt hatte, die ihm zum Teil Ämter und Mandate verdankten ${ }^{315}$. Die Parteiverwaltung, die Müller gezielt mit Personen besetzt hatte, auf die er sich hundertprozentig verlassen zu können glaubte, war in dem nach der Währungsreform herrschenden Finanzchaos rasch zusammengebrochen und fiel als innerparteilicher Machtfaktor praktisch aus. Die Landesleitung war nach der Preisgabe der Bezirks- und Kreisgeschäftsstellen isoliert und praktisch handlungsunfähig. Die Parteizeitung Der Gerade Weg, auf die Müller so große Hoffnungen gesetzt hatte, wurde durch finanzielle Turbulenzen und Ungeschicklichkeiten der Redaktion mehr und mehr zu einer schweren Belastung für den Parteichef.

Auch die Unterstützung, die Müller in der Mehrzahl der Bezirks- und Kreisverbände bisher genossen hatte, begann zu schwinden. Fritz Schäffer konnte einem Vertrauensmann der Militärregierung im Februar 1949 zufrieden berichten, die parteiinternen Wahlen auf allen Organisationsstufen der CSU hätten „tiefe Einbrüche in bisher absolut Müller-treue Bezirke“ ergeben, und der Staatsrat fügte hinzu, er habe jetzt „zum ersten Mal das sichere Gefühl“", daß die Ära Müller zu Ende gehe ${ }^{316}$. In der Tat waren die Ergebnisse der Wahlen in den Kreisen und Bezirken für den Landesvorsitzenden äußerst unerfreulich. Im Bezirksverband Oberfranken wurde Georg Barth als Vorsitzender durch Anton Hergenröder ersetzt, in Unterfranken wählte die Bezirksversammlung den unerfahrenen Karl Greib ${ }^{317}$ anstelle des kampferprobten Landtagsabgeordneten Franz Ludwig Sauer, der seinem Parteichef stets mit Nachdruck zur Seite gestanden hatte, nun aber schwer erkrankt war ${ }^{318}$, und auch der Bezirksverband Oberpfalz erhielt mit Fritz Dengler ${ }^{319}$ einen neuen Vorsitzenden ${ }^{320}$.

313 ACSP, NL Müller 16, Karl Sigmund Mayr an Josef Müller vom 19. 2. 1949.

314 ACSP, NL Müller 16, Karl Sigmund Mayr an Josef Müller vom 15. 3. 1949.

315 IfZ-Archiv, MS 343 Smlg. Köhler 2, Bl. 164 und Bl. 259; vgl. auch Hettler, Josef Müller, S. 396.

316 IfZ-Archiv, RG 260, 10/90-3/1, „Subject: Situation of CSU“" vom 5. 2. 1949.

$317 \mathrm{Karl}$ Greib, geb. 5. 9.1899 in Amöneburg/Hessen, gest. 24. 4. 1976, kath., Volontär in einem Baugeschäft, 1917/1918 Teilnahme am Ersten Weltkrieg, 1923 Besuch der christlich-sozialen Schule in Königswinter, 1924-1933 Geschäftsführer der Christlichen Gewerkschaften in Frankfurt am Main, Aschaffenburg und Würzburg, 1933 entlassen und zunächst Versicherungsinspektor, 1934 Gründung eines eigenen Lebensmittelgeschäfts in Würzburg, 1939-1945 Teilnahme am Zweiten Weltkrieg, 1945 Mitarbeiter von Adam Stegerwald, Mitbegründer und Geschäftsführer der CSU in Unterfranken, 1949-1957 Vorsitzender des CSU-Bezirksverbands Unterfranken, 1949-1957 Mitglied des Landesvorstands der CSU, 1949 Mitglied der Bundesversammlung (CSU), 1950-1962 MdL (CSU), seit 1946 Vorsitzender des Landesverbands des bayerischen Einzelhandels in Unterfranken und Mitglied des Vorstands des Landesverbands des bayerischen Einzelhandels.

318 BayHStA, NL Pfeiffer 43, Bericht über die Bezirksversammlung der CSU Unterfranken am 12. 2. 1949 in Schweinfurt.

319 Fritz Dengler, geb. 12. 12. 1901, kein Todesdatum ermittelt, kath., nach Studium der Rechtswissenschaft und Promotion Notar in Regensburg, 1945 Mitbegründer der CSU in Regensburg, 1949/ 1950 Vorsitzender des CSU-Bezirksverbands Oberpfalz, 1949/1950 Mitglied des Landesvorstands der CSU, 1948/1949 MdWR (CSU).

320 ACSP, CSU-LTF I, 15-20/0, Bericht über die Bezirksversammlung der CSU Oberpfalz am 2. 4. 1949 
Die Wahl Denglers, der Müllers Statthalter Georg Gamperl verdrängte, wirft ein bezeichnendes Licht auf die Unsicherheit und Erschöpfung, die weite Teile der bayerischen Unionspartei im Frühjahr 1949 erfaßt hatten. Die Aussprache in der Bezirksversammlung vor der Neuwahl des Bezirksvorsitzenden stand ganz im Zeichen der anhaltenden Führungs- und Flügelkämpfe, die an der Parteibasis immer weniger verstanden wurden. Der Landtagsabgeordnete Franz Schöner aus Weiden sprach offensichtlich vielen Delegierten aus der Seele, als er erklärte:

„Die Meinung auf dem Lande sei weitgehend die, dass Dr. Müller der Unruhepol der CSU sei. Daran ist etwas [W]ahres. Dr. Müller sei nicht im Stande, die Parteiorganisation auf die Höhe zu bringen. Die Partei stütze sich auf dem Lande nur auf ein paar Idealisten, die sich aufreiben. Der bisherige Bezirksvorsitzende Dr. Gamperl sei immer für Dr. Müller eingetreten, die heutige Versammlung aber zeige, dass sie keinen Bezirksvorsitzenden wolle, der bei der kommenden Landesversammlung sich für Dr. Müller entscheidet. Wer Müller seine Stimme gebe, ist mit der Totengräber der Partei.“

Die verbliebenen Anhänger des Parteivorsitzenden unter den oberpfälzischen Delegierten hatten diesen Angriffen nur wenig entgegenzusetzen. Zutiefst verunsichert und von der Parteiführung allein gelassen, konnte sich auch ein Teil von ihnen nicht dem wiederholt geäußerten Wunsch verschließen, „eine nach keiner Richtung gebundene Persönlichkeit“ zum neuen Bezirksvorsitzenden zu wählen und dadurch zu einem Ende der ständigen Querelen beizutragen. Sie versagten dem bisherigen Bezirksvorsitzenden Georg Gamperl, der stets dafür gesorgt hatte, daß sich Müller im Landesausschuß und in der Landesversammlung auf die Vertreter der Oberpfalz verlassen konnte, ihre Stimme und votierten für den Regensburger Notar Fritz Dengler, einen Abgeordneten des Frankfurter Wirtschaftsrats, der bisher in den innerparteilichen Auseinandersetzungen kaum hervorgetreten war.

Damit hatten Müller und seine Mitstreiter eine weitere Schlüsselposition verloren. Doch so ärgerlich dies für den Landesvorsitzenden sein mußte, so sehr hatte er sich diese Niederlage selbst zuzuschreiben. Begleitet von seinem Stellvertreter Michael Horlacher traf Müller erst kurz von der Mittagspause bei den in Nabburg tagenden Delegierten ein - eine „Nasenlänge“ zu spät ${ }^{321}$, um die Abwahl Gamperls zu verhindern. Doch dann begann die Stimmung in der Bezirksversammlung zu kippen. Horlacher hielt eine flammende Rede, in der er Josef Müller vehement verteidigte und ebenso scharf mit den Vertretern des katholisch-konservativen Flügels der eigenen Partei ins Gericht ging. Und diese Ausführungen verfehlten ihre Wirkung nicht: Als anschließend die Delegierten für den Landesausschuß gewählt wurden, konnten sich sechs Anhänger des Ochsensepp und nur ein Vertreter der innerparteilichen Opposition durchsetzen.

Die geschilderte Episode zeigt, daß es Müller bei entsprechendem Einsatz durchaus möglich gewesen wäre, den Zerfall seiner Machtbasis wenn nicht aufzuhalten, so doch einzudämmen. Diese Form der Parteiarbeit lag dem Landesvorsitzenden aber ganz und gar nicht. „Wir bekommen ja von den prominenten Vertretern“ des MüllerFlügels niemals jemanden zu sehen, klagte Otto Bogendörfer, ein Gefolgsmann des Landesvorsitzenden aus dem oberpfälzischen Eschenbach. Während die Opposition

in Nabburg; das folgende nach ebenda. Vgl. auch Mittelbayerische Zeitung vom 5. 4. 1949: "CSUBezirksverband tagte in Nabburg. Im Beisein von Justizminister Dr. Müller und Dr. Horlacher“.

321 ACSP, NL Müller 155, Otto Bogendörfer an August Haußleiter vom 4. 4. 1949; die folgenden Zitate ebenda. 
um Alois Hundhammer Veranstaltungen mit bekannten Rednern beschicke, bleibe die Parteileitung passiv. Wenn „die Führung nicht die Fühlung mit den untersten Parteiinstitutionen" aufrechterhalte, so Bogendörfer weiter, dürfe man sich nicht wundern, wenn es zu bedauerlichen Pannen und unerwünschten Betriebsunfällen komme. Auch dem mittelfränkischen Landtagsabgeordneten Heinrich Emmert war die offensichtliche Schwäche des Müller-Flügels nicht entgangen. In vertrauter Runde verhehlte er seine Enttäuschung über die Konzeptionslosigkeit und Apathie der Parteigänger Josef Müllers nicht:

„Was uns in der CSU grosse Sorge macht, ist, warum es überhaupt so weit kommen konnte. Wir sind noch immer mehr daran schuld als unsere Gegner. Müller hatte überwiegende Majorität. Daneben ste[ht] die Fraktion. Es kann nicht geleugnet werden, dass der Schwerpunkt der politischen Entscheidungen zusehens auf die Fraktion überging. Wem die Union über alles geht, muss alles daran setzen, die Partei, den Parteiapparat von innen heraus zu reinigen. Wir haben zu allem geschwiegen, ohne etwas zu sagen, wir haben zugesehen, wie eine Position nach der anderen verloren ging. Das ist überall geschehen. Die Gegenseite hat zielbewußter gearbeitet - die Entwicklung haben wir uns selbst zuzuschreiben. [...] Unser Verschulden liegt nicht darin, dass wir zu wenig geleistet haben, sondern darin, dass wir uns seit $1 \frac{1}{2}$ Jahren das Gesetz des Handelns haben aus der Hand nehmen lassen." 322

\section{Müllers Sturz}

\section{a) Hundhammers Offensive}

Als das Jahr 1949 begann, hatten die Gegner Josef Müllers auch nach mehr als dreijährigem Kampf ihre wichtigsten Ziele noch immer nicht erreicht. Wohl war es ihnen wiederholt gelungen, den Parteivorsitzenden auszumanövrieren oder seine Stellung zu untergraben, der Ochsensepp hatte sich aber trotz allem an der Parteispitze halten können. Die Tagung des Landesausschusses am 18. und 19. Dezember 1948 in Forchheim mußte den Eindruck bestätigen, daß Müller nach wie vor fest im Sattel saß ${ }^{323}$. Zwar wurde auch diesmal herbe Kritik gegen den Landesvorsitzenden laut, die unter anderem aus den Reihen seiner enttäuschten Gesinnungsgenossen kam, es bot sich jedoch niemand an, der fähig und willens gewesen wäre, dem Ochsensepp offen Paroli zu bieten. Da die Parteiführung zudem ihren Entspannungskurs fortsetzte und weitere Zugeständnisse bei den umstrittenen Fragen der Organisationspolitik und der Parteipresse machte ${ }^{324}$, drohten die Wortführer der innerparteilichen Oppo-

322 ACSP, NL Müller 43, Protokoll der Sitzung des Gautinger Kreises am 4. 5. 1949.

323 IfZ-Archiv, RG 260, 13/150-3/1, Bericht über die Sitzung des Landesausschusses der CSU am 18./ 19. 12. 1948 in Forchheim; IfZ-Archiv, RG 260, 7/29-1/13-16, Bericht des amerikanischen Generalkonsuls in München, Sam E. Woods, an das State Department vom 23. 12. 1948. Ein Protokoll dieser Landesausschußsitzung konnte nicht ermittelt werden, es steht allerdings fest, daß auch in Forchheim ein offizielles stenographisches Protokoll geführt worden ist; ein Auszug, der Ausführungen Hans Ehards enthält, findet sich in der BSB, NL Schwend 2. Das Manuskript der Rede von Wirtschaftsminister Seidel findet sich im ACSP, CSU-LTF, Ordner Hanns Seidel.

324 ACSP, CSU-LL, Beschlußprotokoll der Sitzung des Landesvorstands am 18. 12. 1948. Generalsekretär Strauß antwortete am 12.1. 1949 auf eine Resolution des niederbayerischen Kreisverbands Wegscheid vom Dezember 1948 (ACSP, NL Müller 105): „Bedauerlich ist nur, dass nicht die Anstellung der Kreisgeschäftsführer von Anfang an durch den Kreisverband erfolgt ist, was im Interesse einer föderalistischen Gliederung unserer Partei erforderlich gewesen wäre, sondern dass diese Massnahme erst nach der Währungsreform getroffen wurde." 
sition als unbelehrbare Störenfriede dazustehen, die sich dem ersehnten Friedensschluß zwischen den zerstrittenen Flügeln in den Weg stellten. Bei den Kontrahenten Müllers machte sich zunehmend Ratlosigkeit breit. Hatte man nicht alles versucht, um den verhaßten Parteichef aus dem Amt zu vertreiben? Hatte man zuletzt nicht sogar die offene Feldschlacht unter Schäffers Führung gewagt - und doch verloren? Was konnte man mehr tun, und vor allem: wer sollte einen erneuten Angriff anführen?

So, wie die Dinge lagen, kam dafür eigentlich nur Alois Hundhammer in Frage. Als Minister, Fraktions- und Bezirksvorsitzender verfügte er nicht nur über die notwendige Machtbasis, er brachte auch das politische Talent und die kompromißlose Härte mit, um die Auseinandersetzung mit dem Parteivorsitzenden erfolgreich führen zu können. In den letzten beiden Jahren hatte Hundhammer stets zu denen gehört, die im Kampf gegen die Parteiführung kein Pardon gegeben, dabei aber klug taktiert und aus dem Hintergrund heraus die Fäden gezogen hatten. So war es auch bei der oberbayerischen Rebellion gewesen, als der Kultusminister Fritz Schäffer das Feld überlassen hatte. Doch nachdem auch Schäffer mit seinen „Hammer“-Methoden $^{325}$ gescheitert war, mußte Hundhammer selbst die Initiative ergreifen ${ }^{326}$. Der Kultusminister hatte nie einen Hehl daraus gemacht, daß der Sturz Josef Müllers zu seinen wichtigsten Zielen gehörte. Für ihn war eine „Änderung in der Parteispitze“ auch dann noch eine conditio sine qua non, als die Parteiführung um den Ochsensepp den Forderungen der innerparteilichen Opposition in wesentlichen Punkten nachgegeben hatte ${ }^{327}$. Eine Beilegung der Konflikte war für Hundhammer unmöglich, solange Müller Landesvorsitzender der CSU war, und zwar nicht nur aus persönlichen Gründen, sondern auch aus der Überlegung heraus, daß mit Müller an der Spitze nur geringe Aussichten bestanden, dem Zerfall der CSU und dem Anwachsen der Bayernpartei wirkungsvoll begegnen und zugleich eine geschlossene Partei als Gralshüter einer christlichen, konservativen und föderalistischen Politik in die Bundesrepublik Deutschland hineinführen zu können ${ }^{328}$, deren Gründung im Frühjahr 1949 in eine entscheidende Phase getreten war.

Dies mochten die Motive gewesen sein, die den Kultusminister veranlaßten, eine neue Runde in den Führungs- und Flügelkämpfen zu eröffnen. „Der bayerische Staat“ sei „aufgebaut und gefestigt worden“, schrieb Hundhammer in einem aggressiven Zeitungsartikel, der am 22. und 23. Januar in der Frankenpost und der Münchner Allge-

325 Protokoll der Sitzung des Landesausschusses der CSU am 28./29. 2. 1948 in Regensburg, in: Protokolle und Materialien, S. 1628 (Gerhard Kroll).

326 Hettler, Josef Müller, S. 392, deutet an, es habe Anfang 1949 die Möglichkeit eines Kompromisses oder Waffenstillstands zwischen Müller und Hundhammer gegeben. Die Quellen - auch der von Hettler zitierte Bericht des amerikanischen Generalkonsulats in München an das State Department vom 24.1. 1949 (IfZ-Archiv, RG 260, 7/29-1/13-16) - lassen diese Interpretation jedoch wenig schlüssig erscheinen. In dem Bericht des Generalkonsulats vom 24. 1. 1949 heißt es beispielsweise: „Müller also stated that he did not feel it would ever be possible for him to make a, deal" with Hundhammer since Hundhammer was too ideological to be trusted."

327 BayHStA, NL Sedlmayr 22, Alois Hundhammer an Lorenz Sedlmayr vom 31. 12. 1948 und Lorenz Sedlmayr an Alois Hundhammer vom 4. 1. 1949.

328 IfZ-Archiv, RG 260, 10/90-3/1, „Subject: Versammlung der CSU - Dr. Hundhammer“ vom 2. 2. 1949; SZ vom 3. 2. 1949: „Hundhammer warnt die Bonner Majorität. Gefahr eines Kulturkampfes?/Die Situation in der CSU“; BAK, NL Schäffer 26, Bl. 79 ff., Der oberbayerische Informationsbrief $4 / 49$ vom 14.2. 1949. 
meinen Zeitung erschien. „Die Partei aber, deren Abgeordnete und Minister diese Arbeit geleistet" hätten, sei "geschwächt, aufgespalten und müde“. Weiter führte Hundhammer aus:

„Man muß die Lage nüchtern betrachten und handeln. Es wird Zeit: Entweder man reformiert die CSU mit wesentlichen Veränderungen in der Parteispitze, mit anderen Satzungen - wofür übrigens die Vorarbeiten schon weit gediehen sind -, mit der klaren Festlegung in der inneren Politik eines bayerischen und in der äußeren Politik eines deutschen und europäischen bundesmäßigen Kurses, der in der letzten Zeit in wachsendem Maße eingeschlagen worden ist, oder man sucht jetzt schon, drei Jahre nach der Gründung der CSU, den Weg zu einem anderen Instrument für eine christliche und bayerische Staatsführung. Würde äußersten Falles im bürgerlichen Lager ein anderes Gebilde erstehen und die Aufgaben der CSU übernehmen können oder sollte die Führung der bayerischen Politik an eine sozialistische Partei übergehen? Träte das ein, so würde der christliche und der bayerische Kurs aufhören. Das muß vermieden werden. [...] Es wird Zeit, $\mathrm{daß}$ man an die Sammlung denkt und zu ihr mahnt. Wird zum Bonner Ergebnis ein ,nein " notwendig, dann muß es ausgesprochen werden von einem sehr breiten Kreise der Abstimmenden. Soll heraufziehenden Gefahren auf anderen Gebieten begegnet werden, dann ist es doppelt notwendig, die Kräfte zu bündeln. Die Sammlung kann noch erfolgen innerhalb der CSU. Sie kann vielleicht auch geschehen außerhalb. Aber notwendig ist sie auf jeden Fall. Sie ist möglich und sie ist Pflicht." 329

Hundhammers Artikel schlug wie eine Bombe $e^{3 n^{30}}$. Nicht genug damit, daß der Kultusminister ein wenig schmeichelhaftes Bild seiner eigenen Partei zeichnete. Er ließ auch durchblicken, daß er mit der Gründung einer neuen Partei liebäugelte, sollten seine Anstrengungen zu einer grundlegenden Reform der CSU erneut ergebnislos bleiben. Diese vagen Andeutungen brachten die Gerüchteküche zum Brodeln. Hundhammer wolle die Bayerische Volkspartei wieder auferstehen lassen, vermuteten die einen ${ }^{331}$; andere Journalisten rechneten dagegen damit, daß Hundhammer eine neue Partei als „Sammelbecken für den linken Flügel der Bayernpartei und den rechten Flügel der CSU“ ins Leben rufen werde ${ }^{332}$. Intern präzisierte der Kultusminister seine Zielsetzungen. Es ginge ihm ausschließlich darum, die CSU zu stärken und sie wieder zu einer Partei zu machen, „die die Mitglieder wieder wie ein Magnet anzieht und nicht abstösst oder zu einer indifferenten Haltung veranlasst“, erklärte er am 12. Februar 1949 in einer Bezirksversammlung der oberbayerischen CSU. Um dieses Ziel zu erreichen, sei dreierlei notwendig: Erstens, die Ablösung der bisherigen Parteiführung, zweitens, die grundlegende Reform der Parteisatzung und drittens, „eine völlig klare christliche

${ }^{329}$ Frankenpost vom 22. 1. 1949: „Sammlung der Kräfte! Von Dr. Alois Hundhammer“; Münchner Allgemeine vom 23.1.1949: „Zusammenfassung statt Eintopf. Von Staatsminister Dr. A. Hundhammer".

330 ACSP, NL Seidel 35 c, Karl-Heinz Vogt an den Landesvorstand der CSU vom 28. 1. 1949 und Hanns Seidel an Karl-Heinz Vogt vom 2.2. 1949. Gottfried Witzgall schrieb am 9.2. 1949 an Fritz Schäffer (BAK, NL Schäffer 26, Bl. 109), er wolle nicht hoffen, „daß die endlich einmal offene Palastrevolution ins Leere puffe“. Zur Presseberichterstattung: SZ vom 22. 1. 1949: "Zusammenfassung statt Eintopf“, vom 27. 1. 1949: „Gespräche um eine neue christliche Partei. Die Krise um Dr. Josef Müller/Dr. Alois Hundhammer und die CSU“ und vom 29. 1. 1949: „Die Bonner Verfassung als Prüfstein der CSU. Hundhammers ,überparteiliche Abwehrfront' gegen den Zentralismus“; Freie Deutsche Presse vom 5. 2. 1949: „Die Krise in der CSU. Dr. Hundhammer unterminiert Dr. Müllers Stellung".

331 Der Sozialdemokrat vom 25. 1. 1949: „Vor dem Ende der CSU? Hundhammer versucht Restauration der Bayerischen Volkspartei“; Telegraf vom 25. 1. 1949: „Explosion in der CSU. Läßt Hundhammer die ,Bayerische Volkspartei“ wieder auferstehen?"; Telegraf vom 26. 1. 1949: „Eine Union zerbröckelt. Kommt zur CSU und zur Bayernpartei noch eine Bayerische Volkspartei?".

332 Sopade-Informationsdienst vom 30. 3. 1949 nach einem Artikel im Südost-Kurier vom 24. 1. 1949. 
und föderalistische Politik“ ${ }^{333}$. Hundhammer schloß seine programmatische Rede mit den Worten:

\begin{abstract}
„Wenn wir in die grossen Wahlen über die Bonner Entscheidung hineingehen und dabei nicht als Partei an die unbedeutende 3. Stelle zurückfallen wollen, so brauchen wir eben vorher eine schlagfertige, arbeitsfähige Partei, mit anderen Worten: Wir brauchen die Reform alsbald, noch [be]vor es zu den Wahlen über Bonn kommt. Mein Verlangen ist: Die Partei muss jetzt zu den notwendigen inneren Reformen gezwungen werden. Mein Artikel in der ,Münchner Allgemeinen' war nicht so sehr scharf, er war eben klar. In dem Stadium des herrschenden langsamen Verfalls der CSU musste eben dieser gewaltsame Stoss von aussen kommen, und er muss jetzt von uns zu einem sachlichen Ergebnis geführt werden."
\end{abstract}

Diese inneren Reformen, das hatte Hundhammer wenige Tage zuvor Staatssekretär Lorenz Sedlmayr klargemacht, sollten auch dazu dienen, „die wertvollsten Teile der Bayernpartei wieder in die CSU zurückzuführen“. Daß dies mit Josef Müller an der Spitze der bayerischen Union unmöglich sein würde, stand für den Kultusminister außer Zweifel. Hundhammer ließ auch keinen Zweifel daran, daß er es für die beste Lösung hielte, selbst den Landesvorsitz der CSU zu übernehmen, da „sein Name auf die Kreise, die zurückgeholt werden sollten, eine grosse Anziehungskraft ausüben würde ${ }^{\alpha 334}$.

Die Attacke Hundhammers traf Josef Müller zum denkbar ungünstigsten Zeitpunkt, da der CSU-Vorsitzende noch mit den Folgen einer Affäre beschäftigt war, die sein Ansehen schwer zu beschädigen drohte ${ }^{335}$. Schon 1946 hatte der Münchner Mittag in einem groß aufgemachten Artikel berichtet, Müller habe sich 1933 bei der Vertretung des insolventen katholischen Unternehmens Leofilm AG gegen den jüdischen Geschäftsmann Richard Hirschfeld der räuberischen Erpressung schuldig gemacht. Im Rahmen seines Spruchkammerverfahrens war Müller zwar von diesen Vorwürfen freigesprochen worden, dies hinderte den Münchner Rechtsanwalt Karl Gaab Ende 1948 jedoch nicht daran, dem CSU-Vorsitzenden erneut unsauberes Geschäftsgebaren im Fall Leohaus-Hirschfeld vorzuwerfen. Um dem großen öffentlichen Interesse an diesem vermeintlichen Skandal Rechnung zu tragen ${ }^{336}$ und um diese Angelegenheit ein für alle Mal aus der Welt zu schaffen, stimmte Müller der Einleitung eines Ermittlungsverfahrens gegen ihn zu und bat den Landtag, seine Immunität als Abgeordneter auf-

${ }^{333}$ BAK, NL Schäffer 26, Bl. 79 ff., Der oberbayerische Informationsbrief 4/49 vom 14. 2. 1949; Hervorhebungen im Original. Vgl. auch Bl. $123 \mathrm{f}$., Der oberbayerische Informationsbrief 3/49 vom 3. 2. 1949.

334 ACSP, NL Müller 16, Lorenz Sedlmayr an Josef Müller vom 31.1. 1949. In einem Brief an Alois Hundhammer schrieb Lorenz Sedlmayr am 8. 2. 1949 (ACSP, CSU-LTF I, 15-12/4 und 5): „Es ist [...] anzunehmen, dass ein Parteivorsitzender, der den zur B. P. abgewanderten ehem. Wählern der CSU besonders gut gefällt, in der CSU kaum als verbindendes Element wirksam werden könnte. Dass ein solcher Vorsitzender erhebliche Teile der B. P.-Wähler wieder zur CSU zurückbringen könnte, wirst auch Du kaum annehmen. Was in dieser Hinsicht zu erreichen ist, das hängt m. E. viel mehr von einer aktiven Propaganda der gesamten CSU ab, die sich vor allem gegen die rein demagogischen Methoden der B. P. richten muss." Hervorhebungen im Original.

335 Zur Affäre Müller-Gaab vgl. Hettler, Josef Müller, S. 386-390.

336 IfZ-Archiv, RG 260, 10/90-3/5, „Subject: Dr. Josef-Müller-Affäre“ vom 21. 12. 1948. Die innerparteiliche Opposition hoffte, der neue Skandal könne zum Sturz Müllers führen. Toni Böck teilte einem Informanten der Militärregierung mit, solche schmutzigen Geschichten lägen den Gegnern des Ochsensepp zwar nicht, aber sie seien vielleicht „der einzige Weg“, um Müller, dieses „tödliche Geschwür am Leib der Union“, schachmatt zu setzen. SZ vom 18. 12. 1948: „Wird der Justizminister beurlaubt? Landtag hebt Immunität Dr. Josef Müllers auf/Entscheidung in Forchheim erwartet“ und vom 21. 12. 1948: „Justizminister Dr. Müller beurlaubt. Haussuchung bei Rechtsanwalt Gaab/ Erklärung des Staatsanwaltes“. 
zuheben. Zugleich ersuchte er den Ministerpräsidenten, ihn für die Dauer des Verfahrens als Justizminister zu beurlauben ${ }^{337}$. Obwohl Gaab behauptet hatte, neue Beweise für die Schuld Müllers zu besitzen, endete das Verfahren auch diesmal mit einer Art Freispruch. Die zuständige Staatsanwaltschaft stellte ihre Ermittlungen am 10. Januar 1949 ein, die Vorwürfe gegen den Ochsensepp wurden als unbegründet zurückgewie$\operatorname{sen}^{338}$. Am 24. Januar bat deshalb Ministerpräsident Ehard seinen Justizminister, die Amtsgeschäfte wieder aufzunehmen.

Die Öffentlichkeit hatte kaum Zeit, die Affäre Müller-Gaab zu verarbeiten, als Hundhammer mit seinen weitreichenden Forderungen an die Presse ging. Doch noch waren Müller und seine politischen Freunde stark genug, um wirkungsvoll zu kontern. Nur wenige Tage nach dem Erscheinen von Hundhammers Zeitungsartikel verabschiedete der geschäftsführende Landesvorstand der CSU einstimmig eine Resolution, in der die Überlegungen des Kultusministers scharf zurückgewiesen wurden. Unter der Überschrift „Keine Spaltung in der CSU“ stellten die Vorstandsmitglieder klar, daß so weitreichende Entscheidungen wie Umbesetzungen an der Parteispitze oder die Neugestaltung der Satzungen ausschließlich von den zuständigen Gremien getroffen werden könnten ${ }^{339}$. Weiter hieß es in der Resolution:

„Dr. Josef Müller ist von der Landesversammlung in Marktredwitz mit 87\% Majorität gewählt worden; man hätte erwarten können, dass ein solches Ergebnis vollauf befriedigt und alle Kräfte sich zu gemeinsamer Arbeit einsetzen. [...] Die Äusserungen des Staatsministers Dr. Hundhammer, die ausserhalb der Gremien der Partei gemacht worden sind, können nur als seine persönliche Meinung gewertet werden."

Der geschäftsführende Landesvorstand vergaß auch nicht zu betonen, daß es zu keinerlei Differenzen zwischen Ministerpräsident Ehard und Josef Müller gekommen sei und daß alle Gerüchte über „Besprechungen des Herrn Ministerpräsidenten Dr. Ehard mit einzelnen leitenden Männern der Partei, die ein Ausscheiden eines führenden Mitglieds der CSU zum Ziele gehabt hätten, [... . falsch und aus der Luft gegriffen" seien. Dieser Passus mußte Hundhammer und seine Gesinnungsgenossen besonders schmerzen, hatte der Kultusminister doch gehofft, durch seine öffentlichen Angriffe den Ministerpräsidenten aus der Reserve locken und im Sinne der Parteieinheit zu einer Stellungnahme gegen den Landesvorsitzenden bewegen zu können ${ }^{340}$. Doch Hundham-

337 IfZ-Archiv, RG 260, 13/149-3/3, Josef Müller an Hans Ehard vom 17. 12. 1948.

338 ACSP, CSU-LTF 11/1, 15-12/1, „Ausführliche Sachdarstellung mit Rechtsgutachten über das Ergebnis des Ermittlungsverfahrens gegen Dr. Josef Müller wegen räuberischer Erpressung“. Karl Gaab wurde dagegen am 22.6. 1949 vom Landgericht München I wegen leichtfertiger falscher Anschuldigungen und übler Nachrede zu vier Monaten Gefängnis verurteilt. Vgl. Hettler, Josef Müller, S. 390.

339 ACSP, NL Müller 6, Resolution des geschäftsführenden Landesvorstands „Keine Spaltung in der CSU“ vom 27. 1. 1949. Nach einem Bericht für die Militärregierung erklärte Hundhammer dazu jedoch nur lapidar: „Wenn der Parteivorstand, um dessen Änderung er sich bemühe, eine nichtssagende Erklärung abgebe, so ändere das nichts an der Notwendigkeit, weiter für eine Neuordnung der Partei zu arbeiten." IfZ-Archiv, RG 260, 10/90-3/1, „Subject: Versammlung der CSU - Dr. Hundhammer" vom 2. 2. 1949.

340 SZ vom 29. 1. 1949: „Die Bonner Verfassung als Prüfstein der CSU. Hundhammers ,überparteiliche Abwehrfront' gegen den Zentralismus“. Unter Berufung auf einen Informanten aus der CSU hieß es, es werde dem Ministerpräsidenten in den Hundhammer nahestehenden Kreisen „als eine gewisse Lauheit" ausgelegt, daß er sich bisher weder für noch gegen Müller ausgesprochen habe. Lorenz Sedlmayr berichtete Josef Müller über ein Gespräch mit dem Kultusminister: „Am meisten missfiel Dr. H. die Ziffer 3 [der Erklärung des geschäftsführenden Landesvorstands], in der die Übereinstimmung zwischen Dr. Ehard und Dr. Müller festgestellt wird.“ ACSP, NL Müller 16, Lorenz Sedlmayr an Josef Müller vom 31. 1. 1949. 
mers Kalkül ging auch ansonsten nicht auf. Zwar stießen die Forderungen und Thesen des Kultusministers in den Bezirksverbänden München und Oberbayern auf breite Zustimmung ${ }^{341}$, in den anderen Regionen Bayerns lösten sie bei den Anhängern der Union jedoch Empörung und Bestürzung aus ${ }^{342}$. Bei manchen mittlerweile schwankenden Gefolgsleuten Müllers war sogar eine nochmalige Solidarisierung mit dem Parteivorsitzenden $\mathrm{zu}$ beobachten, während die ohnehin geringen Chancen Hundhammers, den Ochsensepp abzulösen, weiter sanken. Karl-Heinz Vogt, Geschäftsführer des CSU-Kreisverbands im unterfränkischen Obernburg, schrieb am 28. Januar 1949 zutiefst verunsichert an die Mitglieder des Parteivorstands:

„Wir Mitglieder und Funktionäre der Chr[ist]lich-Sozialen Union lesen die Zeitungen, sind täglich von neuen Meldungen überrascht, schütteln die Köpfe, glauben aber, die Parteileitung und der Landesverband würden uns schon genauestens unterrichten und diese seltsamen Vorfälle wenigstens zu klären versuchen. Das, so glauben wir, ist seine Pflicht. Denn schließlich sind ja wir diejenigen, die jene Männer, welche heut[e] ein solches Gebaren an den Tag legen, gewählt haben, sind wir es, die durch unsere propagandistische, organisatorische und [f]inanzielle Unterstützung dazu verhelfen, daß jene Männer überhaupt arbeiten können und nicht im luftleeren Raum schweben. Aber - weit gefehlt! Jene Männer sind sich dessen anscheinend gar nicht mehr bewußt und handeln wie Kaufleute, die nur auf ihre persönliche Stellung bedacht sind. Im Informationsdienst [...] hütet [man] sich, in jene Eiterbeule, die unser Siechtum verursacht, einzustechen und sie zu beseitigen, man hütet sich, klar und offen zu reden - abgesehen von wenigen Persönlichkeiten, die darob dann einen schwierigen Stand haben. Nehme man doch in Kauf, daß jene föderalistisch getarnten Separatisten, jene Reaktionäre, endlich aus unseren Reihe[n] verschwinden; sind wir uns doch eingedenk unserer unendlichen Verantwortung aus chr[ist]lichem Gewissen um das gesamte deutsche Volk! [. . . Vermögen Sie, so frage ich Sie, als aufrechter Christ noch in einer Versammlung aufzutreten und für die CSU zu werben, wenn zu der gleichen Zeit namhafte Vertreter von ihr Verrat an der Sache üben? Von uns, von mir als Kreisgeschäftsführer verlangt man es als eine Selbstverständlichkeit. Angesichts dieser Lage vermag ich es nicht mehr, und ich tue es auch [nicht,] solange hier keine eindeutige Klarheit geschaffen ist. [...] Wir bedürfen wahrhaft einer geistigen Erneuerung, einer Revolutionierung der verbürgerlichten, ja reaktionären Anschauungen. Man solle ja nicht meinen - wie es Herr D[r]. Hundhammer tut - eine neue Partei sei das Gebot der Stunde. Seien Sie überzeugt davon, daß diese ganz elenden Schiffbruch erleiden würde, denn ihre Gründer und Führer würden die Bankrotteure von gestern sein. Auf sie fällt niemand mehr herein!“343

\section{b) Die Sitzung der CSU-Fraktion am 17. Februar 1949}

Die Landtagsfraktion der CSU beschäftigte sich am 17. Februar 1949 mit dem krisenhaften Zustand der eigenen Partei und diskutierte auch eingehend über die Auseinandersetzungen, die Alois Hundhammer mit seinen jüngsten Stellungnahmen ausgelöst hatte $^{344}$. Der Kultusminister und Fraktionsvorsitzende mußte dabei bald feststellen,

341 BAK, NL Schäffer 26, Bl. 109, Gottfried Witzgall an Fritz Schäffer vom 9. 2. 1949; ACSP, CSU-LTF II/1, 15-12/1, Alois Endrich an Michael Horlacher vom 12. 2. 1949.

342 Otto Kalbskopf schrieb am 26. 3. 1949 an Josef Müller (ACSP, NL Müller 144): „Nun kam der Zeitungsartikel von Dr. Hundhammer bei uns in der Frankenpost und dadurch eine Schwächung der CSU allergrössten Au[s]masses. Die gegnerischen Parteien hätten sich niemals träumen lassen, dass aus unseren eigenen Reihen und noch dazu [von] solch prominente[n] Persönlichkeiten ihnen soviel Agitationsstoff geliefert werden würde." Karl Greib warf Hundhammer noch im April 1949 parteischädigendes Verhalten vor. BayHStA, NL Pfeiffer 535, Karl Greib an Josef Müller vom 4. 4. 1949.

343 ACSP, NL Seidel 35 c, Karl-Heinz Vogt an den Landesvorstand der CSU vom 28. 1. 1949.

344 ACSP, CSU-LTF I, 15-14, Protokoll der Fraktionssitzung am 17. 2. 1949; das folgende nach diesem Sitzungsprotokoll. 
daß er diesmal zu weit gegangen war und daß seine Kollegen nicht oder nur teilweise bereit waren, seinen Argumenten zu folgen. Bei den meisten Abgeordneten, die sich in der Diskussion zu Wort meldeten, überwogen Zorn und Enttäuschung über die erneute Eskalation der Führungs- und Flügelkämpfe. Schließlich hatte man Wichtigeres zu tun; gerade hatten ja die Verhandlungen über das Grundgesetz ein entscheidendes Stadium erreicht und die Entscheidung, ob man der Verfassung des neuen westdeutschen Staates im Landtag zustimmen sollte, stand kurz bevor ${ }^{345}$. Bei der mehrstündigen Diskussion, die zeitweise scharfe Formen annahm, kristallisierten sich schnell vier Punkte heraus: Zum einen sah die Mehrheit der Abgeordneten anders als Hundhammer in der Bayernpartei mit ihren radikal föderalistischen Parolen keine ernstzunehmende Alternative zur CSU; auch Überlegungen, die BVP wieder zu beleben, erteilten sie eine klare Absage. Finanzminister Hans Kraus, ein ehemaliger BVP-Politiker, der sich aus den innerparteilichen Auseinandersetzungen soweit wie möglich heraushielt, machte aus dieser Überzeugung keinen Hehl:

„Ich stehe zu dem Programm unserer Partei, und ich sage, wenn die CSU noch nicht bestünde, so müsste man sie gründen. Hundhammer, für mich gibt es ausserhalb dieser Partei keinen politischen Standort. [...] Es sind nur Führerstreitigkeiten, und die müssen beseitigt werden, sonst geht Bayern zugrunde.“

Der unterfränkische Abgeordete Georg Hauck ergänzte: „An das Gedankengut der BVP kann man sich heute nicht mehr anschliessen“, und für Konrad Kübler, der vor 1933 zu den führenden Politikern des Bayerischen Bauernbundes gehört hatte, waren die öffentlichen Aussagen Hundhammers sogar ein Grund, um über sein Ausscheiden aus der CSU nachzudenken:

„Wenn meine Freunde und ich zur CSU gekommen sind, dann deshalb, weil wir davon überzeugt waren, dass die CSU das Rückgra[t] des Staates bilden müsse. [. . .] Uns lag daran, aus der Partei ein Kampfinstrument zu machen. Umso grösser sind unsere Bedenken, dass diese Partei unterhöhlt wird. Wir verlieren allmählich den Glauben und damit die Kraft, dieser Sache zu dienen. Ich nenne einige Zitate Dr. Hundhammers, die angeblich als Interview in den Zeitungen stehen: ,Die Bayernpartei hat durch ihre blosse Existenz ihre Berechtigung gefunden, sozusagen aus dem Reflex, den sie auf die anderen Parteien auslöst. Baumgartners Kampf ist echt und gerecht'. Dabei erklärt Dr. Baumgartner, dass die Regierung Ehards die schlechteste sei, die Bayern jemals gehabt habe. [...] Diese Erklärungen, Dr. Hundhammer, machen es mir unmöglich, von ganzem Herzen noch weiter tätig zu sein. Die Bayernpartei stellt ihre ganze Agitation auf dieses Hundhammer-Interview ein, die Bayernpartei frägt, wie könnt ihr überhaupt noch bei der CSU bleiben, wenn ein Mann wie Hundhammer solches sagt. Geschlossene Gruppen erklären ihren Austritt. So machen wir uns selbst kaput[t]."

Zum zweiten war es der desolate Zustand der Partei und ihres Apparats, der auf vehemente Kritik stieß. Dieser Punkt wurde zwar eindeutig dem Landesvorsitzenden angelastet, es gab jedoch auch Stimmen, die den Abgeordneten in Erinnerung riefen, daß die Landesleitung "von draussen her bewusst sabotiert “ werde und daß die CSU besser dastünde, wenn man den Ochsensepp nicht bewußt „ausgehungert“ hätte. Zum dritten zeigte die Diskussion, wie übermächtig der Wunsch nach einem Ende der ständigen Streitereien inzwischen geworden war, die selbst für viele Landtagsabgeordnete kaum mehr zu durchschauen waren. Man war des Kampfes müde geworden, und manche plädierten sogar dafür, den Kontrahenten in der Parteiführung den Laufpaß zu geben,

${ }^{345}$ Vgl. dazu allgemein Gelberg, Hans Ehard, S. 188-274, und Kock, Bayerns Weg, S. 285-326. 
wenn sie sich nicht einigen könnten. „Wir stehen in einer ernsten Zeit", rief der Schwandorfer Abgeordnete Josef Krempl seinen Fraktionskollegen zu, „gibt es denn da keine Möglichkeit und keinen Weg, dass wir auf eine Ebene kommen und dass wir bei der nächsten Landesversammlung die CSU wirklich zur grossen geeinten Partei machen"? Doch den Königsweg zu diesem Ziel, und dies ist der vierte Punkt, der in der Fraktionssitzung am 17. Februar deutlich wurde, kannte keiner der Abgeordneten. Appelle und Parolen waren nur zu oft zu hören, brauchbare Vorschläge, wie die Konflikte beigelegt werden könnten, dagegen kaum.

Alois Hundhammer und Josef Müller nützten die Fraktionssitzung natürlich, um ihre Standpunkte noch einmal zu verdeutlichen. Hundhammer, der offensichtlich nicht damit gerechnet hatte, in der Fraktion so stark unter Beschuß zu geraten, machte gleich zu Anfang seiner Ausführungen klar, daß er bereit war, „alle äussersten Konsequenzen“ zu ziehen und notfalls auch zurückzutreten. Sein heftig kritisierter Artikel in der Münchner Allgemeinen sei nichts anderes als ein Reflex auf den krisenhaften Zustand der CSU. Man könne „die Dinge“ schließlich nicht weiter „faulen“ lassen, und sein „Alarmschuss in der Öffentlichkeit“ sei notwendig geworden, nachdem seine interne Kritik nichts gefruchtet habe. Man stehe vor wichtigen Entscheidungen, von denen nicht nur die Zukunft Bayerns, sondern auch die Zukunft der CSU abhänge. Wenn die Partei sich auf eine einheitliche Linie bei der Abstimmung über das Bonner Grundgesetz einigen könne, sei schon viel gewonnen, wenn nicht, sei „der Bruch unvermeidbar“. Ein weiterer Meilenstein sei die bevorstehende Wahl zum ersten Parlament des westdeutschen Staates. Wenn die CSU sich dieser Wahl in der gegenwärtigen Verfassung stelle, "nämlich als langsam sterbende Partei“, dann bestehe die Gefahr, daß sie von der Bayernpartei überflügelt werde. Weiter führte Hundhammer aus:

„Die Bayernpartei kann in Bayern die stärkste, die SPD die 2. und die CSU die 3. Partei werden. Folge ist: Der Landtag ist nicht mehr zu halten, er wird aufgelöst. In der neuen Landtagswahl aber ist dann für die CSU der Wahlkampf auch schon zur Hälfte verloren, es kommt so, dass die Bayernpartei bei uns die Regierung bildet, mit der SPD oder mit uns, - oder dass die SPD ihrerseits die Regierung bildet, allein oder mit wem sie eben will. In jedem Fall wird die Regierung von der SPD geführt, und es ist Schluss mit dem christlichen und föderalistischen Kurs. In den anderen Staaten sackt die christliche Politik dann ebenfalls hinunter. [. . .] Wenn wir die CSU in Ordnung bringen wollen, dann ist es notwendig, dass die Parteispitze geändert wird, Müller, Horlacher, Haussleiter als Spitze ist eine Unmöglichkeit, desgleichen ist der geschäftsführende Vorstand so einseitig, dass er im selben Fahrwasser segelt. Unter dieser Führung hat die CSU die Hälfte der Mitglieder verloren. In der Landesvorstandschaft und in der Landesgeschäftsstelle ist die Partei in einem Zustand, der Verwesung bedeutet. Dieser Kurs ist nicht mehr tragbar. Wenn eine Direktion die Hälfte des Geschäftsvermögens verloren hat, dann muss sie eben abgelöst werden. Die Mehrheit im bürgerlichen Lager muss so zusammengeführt werden, dass die SPD nie die stärkste Partei in Bayern werden kann. Diese Zusammenführung ist unmöglich, wenn Müller Landesvorsitzender bleibt, und deshalb muss Müller die letzten Konsequenzen ziehen.“

Und an anderer Stelle fügte Hundhammer noch hinzu: „Der Vater der Bayernpartei ist Dr. Josef Müller." Nach dieser Philippika ergriff der Parteivorsitzende, psychisch und physisch sichtlich angeschlagen, das Wort. Er stellte die Erfolge der Union heraus und appellierte an die eigene Stärke. Wo der Kultusminister das Ausmaß der Gefährdung der CSU durch die Bayernpartei überschätzte, weigerte sich der Parteichef, den Problemen ins Auge zu sehen. „Eine Partei wie die Union kann ihre Politik nicht bestimmen lassen von der Rücksichtnahme [auf eine] kleine Partei“, erklärte Müller und mahnte zugleich eine „klare Frontlinie gegen jeden Radikalismus“ an, auch gegen die Bayern- 
partei, „die zu 70\% eine Sammlung radikaler Elemente“ sei. Dem Fraktionsvorsitzenden warf Müller vor, in dieser schwierigen Zeit nicht zur Beruhigung der verunsicherten CSU-Anhänger beizutragen, sondern mit seinen öffentlichen Äußerungen zusätzliche Irritationen auszulösen. "Wenn Hundhammer dem Volk dauernd das Bewusstsein gibt, dass er sich noch nicht klar ist, ob die CSU das Richtige ist [. . . ], wie sollen dann die Leute ihrerseits klare Entscheidungen treffen?" Müller stellte den staatsbayerischbavariozentrischen Ausführungen Hundhammers wirtschafts- und sozialpolitische Leitgedanken entgegen. Die CSU könne nur dann bestehen, wenn sie wirtschaftliche Erfolge vorweisen könne und dafür sorge, „dass das Volk ein Existenzminimum“ habe. Man könne mit dem Kommunismus nur durch eine Wirtschaftspolitik fertig werden, bei der „die Persönlichkeit entwickelt [...] und die Gesellschaftsordnung evolutionär organisch neu gestaltet" werde. Müller fuhr fort:

„Sie werden mich nie in einem Lande sehen, das draussen nicht mehr ernst genommen wird; wenn sie heute ein Bayernlied spielen lassen, [be]wirken sie mehr als mit einem Appell an die Vernunft. Deshalb denke ich nach, ob man mit diesen Zeiterscheinungen noch fertig werden kann. Hundhammer, Du wirst mit ihnen nicht fertig, wenn Du nur auf der Ebene des Heimatgefühls arbeitest; mit dem Staatspräsidenten, auch mit einer Krone drauf, schaffst Du es nicht, da gibt es nur noch mehr Elend. Mir geht es um die evolutionäre soziale Entwicklung."

Daß es mit dem Parteiapparat und den Parteifinanzen seit der Währungsreform nicht zum besten stand, gab Müller offen zu. Zugleich klagte er jedoch über die Obstruktionspolitik verschiedener Bezirksverbände, die sich weigerten, die satzungsgemäßen Zahlungen an den Landesverband zu leisten, über die schlechte Zahlungsmoral der Mitglieder und über die fehlende Opferbereitschaft, ohne die eine Partei nicht zu halten sei. Resigniert und ausgelaugt gab der Parteichef den Landtagsabgeordneten auch zu verstehen, daß er unter bestimmten Umständen durchaus bereit sei, sein Amt niederzulegen und sich aus dem politischen Leben zurückzuziehen ${ }^{346}$.

Die Reden Hundhammers und Müllers blieben bei den Abgeordneten nicht ohne Wirkung. Die Kritik des Fraktionsvorsitzenden am desolaten Erscheinungsbild der CSU und seine staatspolitisch-föderalistischen Überzeugungen stießen bei der Fraktionsmehrheit auf lebhafte Zustimmung. Der Parteivorsitzende wußte dagegen seine glänzenden politischen Verbindungen in die Waagschale zu werfen und verstand es, die Abgeordneten mit seinen gesellschaftspolitischen Vorstellungen in deutscher und europäischer Perspektive zu beeindrucken. In der Fraktion wuchs deshalb im Laufe der Debatte die Überzeugung, daß es sich die CSU nicht leisten könne, Müller oder Hundhammer zu verlieren, und daß sich die Flügelkämpfe nicht einfach beenden ließen, wenn lediglich die Parteispitze ausgewechselt würde. Konstruktive Vorschläge hatte kaum einer der Abgeordneten zu machen, lediglich Georg Meixner, der Domkapitular aus Bamberg, trat mit einer Rede vor die Fraktion, die in die Zukunft wies und wieder etwas Mut machte. Meixner, der als katholischer Priester besonderes Ansehen genoß und vor 1933 bereits die BVP im Landtag vertreten hatte, stand gleichsam zwischen den Fronten. In kultur- und staatspolitischen Fragen vertrat er Hundhammers

346 Müller erklärte, er trete sofort ab, wenn die innerparteiliche Opposition seine finanziellen Verpflichtungen aus seinem Engagement für die Partei übernehme. Diese Stelle ist im Protokoll handschriftlich dick unterstrichen; ein Schreiben von Fritz Schäffer an Ernst Rattenhuber vom 23. 2. 1949 (BAK, NL Schäffer 26, o. P.), legt die Vermutung nahe, daß es bei den Gegnern Müllers Überlegungen gab, dem Ochsensepp ein entsprechendes Angebot zu machen. 
Positionen, andererseits unterstützte er Müller in seinem Bemühen, eine interkonfessionelle, sozial progressive Volkspartei aufzubauen. Meixner zog schonungslos Bilanz:

„Unsere CSU ist in einer denkbar schlechten Verfassung, organisatorisch und finanziell, aber auch in der Wertung in den Augen der Wählerschaft. Wir haben mit einem riesigen Schwung begonnen, ein riesiges Vertrauenskapital gehabt, und heute sind wir daran, das alles zu verwirtschaften. Warum ist die CSU so scharf rückläufig? Wir erkennen an, dass Gründe da sind, die nicht bei uns liegen. Eine Regierungspartei muss sich in einer Zeit der Hilflosigkeit verbrauchen. Aber es sind auch Gründe da, die wir in Händen haben: innerhalb der Führung der CSU! Es herrscht in der Partei eine allgemeine Verdrossenheit, die Landesleitung wird von draussen her bewusst sabotiert. Auch andere Parteien haben ihre inneren Differenzen. Warum können diese Differenzen bei uns nicht innerhalb der Doppeltüren ausgemacht werden? Wir sind nie vor Überraschungen sicher, wenn wir die Zeitung aufmachen [...]. Was fehlt unserer Partei? Es fehlt das gegenseitige Vertrauen, die innere Wahrhaftigkeit, die Selbstlosigkeit im Dienste einer grossen Idee und das brüderliche Zusammengehörigkeitsgefühl. Es fehlt weiter die Disziplin sowohl in der Partei, wie in der Fraktion. [.. .] Ferner fehlt der Partei die gründliche Organisationsarbeit, der gewissenhafte, fleissige, selbstlose Generalsekretär, der von oben her die Arbeit genau [...] organisiert. Die SPD ist uns weit überlegen, was Mitgliederinformierung anlangt. Es müssten endlich die Abgeordneten und die Presse mit allen notwendigen Informationen versorgt werden, diese Arbeit war vorbildlich bei der BVP. [.. .] Man muss sich schämen, wenn die Regierungspartei in solch kläglicher finanzieller Verfassung ist. Notwendig ist weiter, dass Ernst gemacht wird mit der Revision der Satzungen, mit der Angleichung der Stimmenstärken. Wir haben heute die zwei Reden der führenden Männer gehört, beide haben grosse Gesichtspunkte vorgetragen, sowohl die staatspolitischen Gedanken Dr. Hundhammers wie die aussen- und wirtschaftspolitischen Erwägungen Dr. Müllers. Ich frage: Sind hier Gegensätze zu Tage getreten? Ergänzen sich diese 2 Gedankenreihen denn nicht? Sie müssen ineinander gefügt werden. Haben wir es denn notwendig, ständig in der Defensive zu stehen? Mir sagte ein einfacher Mann, dass er in seinen Versammlungen nur eines ausspreche: $[\mathrm{H}] \mathrm{abt}$ ihr euch die Jahre nach 1945 nicht viel schlimmer vorgestellt, haben wir euch also nicht gut geführt? Haben wir nicht das Verdienst des Übertrittes von der Zwangs- zur freien Wirtschaft? Ich frage, hat nicht die Fraktion selbstlos und fleissig gearbeitet? Wir haben wirklich keinen Grund, uns zu verstecken. Denn, wir sind es gewesen, die es unternommen haben, den grossen Trümmerhaufen aufzuräumen. Vor dem Katastrophenwinter 1947/48 haben wir allein die Verantwortung übernommen und wir sind aufwärts gekommen. Was ist unsere Aufgabe: Die Sorge um die Einigkeit! Die CSU ist ein grosser Gedanke. Die Kirchen beider Konfessionen stehen zu diesem Gedanken. [...] Wir stehen vor der praktischen Frage: Was ist zur Bereinigung zu tun? Ich schätze Dr. Müller als Mann von ungeheurer Leistungsfähigkeit und grossem internationalen Ansehen. Ich schätze Dr. Hundhammer als geradlinigen Mann, auf den das ganze christliche Volk mit grösster Hochachtung schaut. Gibt es nun keine Möglichkeit zur Bereinigung? Ich sehe sie in folgendem: Zuständig ist die Landesversammlung, sie ist zum frühest möglichen Termin einzuberufen. Diese Versammlung wählt ein Direktorium von 3 Männern, sorgfältig ausgelesen, auch ein evangelischer Christ aus Franken darunter. Diese 3 Männer wählen aus ihrer Mitte den Vorsitzenden. Jeder von diesen dreien hat seine eigene Zuständigkeit, der eine vielleicht Aussenpolitik, der andere vielleicht bayerische Politik, der 3. die Organisation. Auf diesem Weg müssten wir doch die Partei in die Form bringen, in der wir sie alle haben wollen."

Der Vorschlag, ein Direktorium an die Spitze der CSU zu stellen, war nicht neu, und es ist mehr als fraglich, ob eine gedeihliche Zusammenarbeit zwischen Exponenten der verschiedenen Parteiflügel nach Jahren der erbitterten Auseinandersetzungen überhaupt noch möglich gewesen wäre. In der mehr als verfahrenen Situation des Frühjahrs 1949 schien dieser Vorschlag jedoch einen Ausweg aus der Dauerkrise zu bieten. Selbst Hundhammer nahm diese Anregung auf. Ansonsten endete die Fraktionssitzung ohne konkretes Ergebnis, und die Abgeordneten gingen auseinander, ohne einen Beschluß hinsichtlich der innerparteilichen Situation gefaßt zu haben. 


\section{c) Anton Hergenröder und die Initiative des Bezirksverbands Oberfranken}

Die Initiative, die letztlich zum Sturz Josef Müllers führte und die Chance für einen Neuanfang eröffnete, ging von einer Seite aus, von der man es niemals erwartet hätte und war vielleicht gerade deshalb erfolgreich: vom Bezirksverband Oberfranken, der bislang eine der stärksten Bastionen des Parteivorsitzenden gewesen war. Der neugewählte oberfränkische Bezirksvorstand, dem als Abgeordneter des Stimmkreises Bamberg auch Hans Ehard angehörte, diskutierte am 26. Februar 1949 über die krisenhafte Situation der Partei und die Frage des Landesvorsitzes ${ }^{347}$. Dabei zeigte sich, daß die überwiegende Mehrheit der Vorstandsmitglieder den Ministerpräsidenten als neuen Parteichef favorisierte, der aber nur vage sein Einverständnis signalisierte, die Führung der CSU zu übernehmen ${ }^{348}$. Anton Hergenröder, der Bezirksvorsitzende, Gerhard Kroll und Bernhard Ostwald, der Vorsitzende des Kreisverbands Rehau, übernahmen die unangenehme Aufgabe, Josef Müller von diesem Ergebnis in Kenntnis zu setzen. Am 1. März fand eine Besprechung statt, an der auch August Haußleiter teilnahm. Das ausführliche Protokoll, das der Ochsensepp anfertigen ließ, spiegelt die spannungsgeladene, aggressive Atmosphäre der Aussprache ebenso wider wie die immer breiter werdenden Risse im ehemals festgefügten Müller-Flügel. Der Parteichef machte keinen Hehl daraus, daß er das Vorgehen der Oberfranken als „Kampferöffnung“ betrachtete ${ }^{349}$. Gerhard Kroll, bei Müller in Ungnade gefallen, versuchte, dem zwischen Zorn und Resignation schwankenden Landesvorsitzenden die Motive des Bezirksvorstands zu erklären:

„Die Situation in Ofr. ist folgende: Man glaubt, dass der Streit in der Union im Augenblick dadurch überwunden werden könnte, wenn Dr. Müller bei der nächsten Landesversammlung erklärt, aus irgendwelchen Gründen könne er es nicht mehr machen, und an seiner Stelle Ehard vorübergehend Vorsitzender wird. Das ist die Meinung einer Versammlung, die bestimmt nicht beeinflusst war, und das ist die Meinung einer breiten Schicht. Es ist kein böses Wort gegen Müller gefallen. Ich stehe auch auf dem Standpunkt, dass es im Augenblick gut wäre, wenn ein solcher Wechsel kommen würde, einfach, weil sich die Gesamtpartei eine Beruhigung der Gesamtsituation verspricht. Es soll nicht heissen, dass Dr. Müller abgehalftert wird, dass man ihn nach Hause schickt. Die sämtlichen Versammlungsteilnehmer haben Wert darauf gelegt, dass er Justizminister bleibt und dass er in ein entsprechend hohes Amt in den Bund geschickt wird. Es ist von mir der Antrag gestellt worden, dass nicht, wie es sonst in der Union geschieht, solche Dinge hinter dem Rücken besprochen werden, sondern dass Dr. Müller sofort unterrichtet wird [...]. Es ist auch ganz offen besprochen worden, wenn kein Mann da wäre, dem man das Vertrauen entgegenbringen könne, durch die kommenden Bundeswahlen hindurchzukommen, hätte man wahrscheinlich überhaupt den Beschluss gefasst, auseinanderzugehen."

Besonders der neue Bezirksvorsitzende hatte den Unmut Josef Müllers auf sich gezogen. Denn Hergenröder war schon am 19. Februar 1949 an die anderen Bezirksvorsit-

347 IfZ-Archiv, ED 720 Smlg. Mintzel 45, Rundschreiben Anton Hergenröders an die Mitgieder des Bezirksvorstands vom 8. 2. 1949 sowie Einladung und Tagesordnung für die Sitzung des Bezirksvorstands am 26. 2. 1949 in Bamberg vom 11.2. 1949. Vgl. auch Mintzel, Anatomie, S. 242 f.

348 In einem Rundschreiben Anton Hergenröders an alle Bezirks- und Kreisverbände sowie an die Regierungsmitglieder und Landtagsabgeordneten vom 4.3. 1949 (IfZ-Archiv, ED $720 \mathrm{Smlg}$. Mintzel 45) hieß es: "Ministerpräsident Ehard erklärte in seiner Rede, daß die Union für ihn die Idee einer großen, unpersönlichen Einheit, aber keine persönliche Richtung darstelle, und daß er um der groBen Aufgabe willen seine ganze Kraft der Union zur Verfügung stelle.“

349 ACSP, NL Müller 133, Protokoll einer Besprechung zwischen Josef Müller, August Haußleiter, Anton Hergenröder, Gerhard Kroll und Bernhard Ostwald vom 1. 3. 1949. Fränkischer Tag vom 1. 3. 1949: „Oberfranken leitet CSU-Reform ein“. 
zenden herangetreten und hatte sie für den 12. März zu einer Besprechung nach Ingolstadt eingeladen, um „ausserhalb der eigentlichen Parteiorgane“ über einen Ausweg aus der verfahrenen Situation zu beraten ${ }^{350}$. An und für sich hätte dieser Vorstoß den Landesvorsitzenden nicht zu beunruhigen brauchen, da eine Konferenz der Bezirksvorsitzenden von den Statuten der CSU nicht vorgesehen war und somit auch keine bindenden Entscheidungen treffen konnte. Andererseits gehörten die Vorsitzenden der Bezirksverbände aber zu den einflußreichsten Politikern der CSU, und ihr Wort hatte vor allem dort Gewicht, wo über die künftige Parteiführung entschieden wurde: bei den Kreisverbänden und den von ihnen nominierten Delegierten für die bevorstehende Landesversammlung. Sollten sich die Bezirksvorsitzenden auf eine gemeinsame Stellungnahme zu den Flügelkämpfen und besonders zur Person des Landesvorsitzenden einigen können, dann hatten sie durchaus die Chance, die bestehenden Kräfteverhältnisse entscheidend zu verändern. Josef Müller erkannte diese Gefahr - was nach der Konferenz vom 1. März aber auch keine besondere Kunst war - und reagierte sofort. Um die Initiative Hergenröders zu konterkarieren, berief er ebenfalls für den 12. März eine Sitzung des Landesvorstands nach München ein $^{351}$; wenn sich eine offene Diskussion über die gegenwärtige Krise der CSU und damit auch über seine eigene politische Zukunft schon nicht vermeiden ließ, dann sollte sie wenigstens in einem Gremium stattfinden, dem er selbst vorstand.

\section{d) Das Wochenende der Weichenstellungen - die Tagungen und Konferenzen am 12. und 13. März 1949}

Doch die Aussprache der Bezirksvorsitzenden ließ sich nicht verhindern. Man traf sich nicht wie vorgesehen in Ingolstadt, sondern tagte am Morgen des 12. März in der Münchner Geschäftsstelle des Bezirksverbands Oberbayern, dem Zentrum der innerparteilichen Opposition ${ }^{352}$. Die Bezirksvorsitzenden, beileibe nicht nur Gegner des Ochsensepp, waren sich darüber einig, daß „das Vertrauen der Mitglieder und Wähler entscheidend von der Besetzung der Parteispitze abhinge“. Sie kamen deshalb überein, Josef Müller zum Rücktritt aufzufordern und Ministerpräsident Ehard den Landesvorsitz der CSU anzutragen. Den Bezirksvorsitzenden, die eigentlich auf der Seite Müllers standen, aber die Notwendigkeit erkannten, die inneren Konflikte endlich beizulegen, wurde diese Entscheidung durch die Erklärung Hundhammers erleichtert, der ausdrücklich feststellte, daß er nicht beabsichtige, „sich an der Neubildung der Parteispit-

350 ACSP, NL Müller 133, Rundschreiben Anton Hergenröders an die Bezirksvorsitzenden der CSU vom 19. 2. 1949.

351 BayHStA, NL Ehard 1047, Rundschreiben der Landesgeschäftsstelle der CSU, gez. Heinz Heggenreiner, an "die Mitglieder der Landesvorstandschaft“ der CSU vom 3. 3. 1949. Zu den Ereignissen des 12. und 13. 3. 1949 vgl. auch Hettler, Josef Müller, S. $394 \mathrm{ff}$.

352 IfZ-Archiv, RG 260, 7/29-1/13-16, Bericht des amerikanischen Generalkonsulats in München über die Lage der CSU an das State Department vom 17.3. 1949; IfZ-Archiv, RG 260, 13/143-3/4, Bericht Pierre M. Purves' über die Lage der CSU an den stellvertretenden Direktor von OMGBY vom 23. 3. 1949; IfZ-Archiv, ED 720 Smlg. Mintzel 45, Informations-Rundschreiben Nr. 1/49 des Bezirksverbands Oberfranken vom 15. 3. 1949; Bericht über die Sitzung des Landesvorstands am 12. 3. 1949, in: Die Politische Information 9/10-49; die beiden folgenden Zitate finden sich ebenda. Auch der Presse war die Bedeutung der Konferenz der Bezirksvorsitzenden und der anschließenden Sitzung des Parteivorstands nicht entgangen: SZ vom 8. 3. 1949: „. . . und findet die CSU eine Klärung? Der Machtkampf Dr. Josef Müllers/Die Entscheidung liegt bei Dr. Ehard“. 
ze in irgendeiner Form persönlich zu beteiligen“. Dem Kultusminister war offensichtlich klar, daß er selbst keine Chance auf den Landesvorsitz oder das Amt eines stellvertretenden Landesvorsitzenden hatte und daß der Weg zum Sturz Müllers nur über die Aufgabe eigener Ambitionen führte.

Josef Müller dachte nicht daran, kampflos das Feld zu räumen. Während die Bezirksvorsitzenden über die Neuformierung der Parteispitze verhandelten, beriet sich der in die Enge getriebene Parteichef wenige Straßen weiter mit seinen wichtigsten Gefolgsleuten ${ }^{353}$, zu denen auch wieder August Haußleiter gehörte, der durch seine Unterstützung für die angeblich überparteiliche Deutsche Union ins Abseits geraten war ${ }^{354}$. Müller und seine Getreuen einigten sich auf eine zweigleisige Strategie: Zunächst galt es, während der bevorstehenden Sitzung des Landesvorstands eine Entscheidung über den Parteivorsitz unter allen Umständen zu verhindern; diese Frage sollte zu einem günstigen Zeitpunkt der Landesversammlung vorgelegt werden. In der Zwischenzeit wollte man Hundhammers ständige Angriffe auf den Parteivorsitzenden als Hebel benutzen, um den mächtigen Kultusminister aus der Partei zu drängen.

Die Nerven der Vorstandsmitglieder waren bis zum Zerreißen gespannt, als Josef Müller die Vorstandssitzung mit einem Bericht über die desolate Finanzlage der CSU und ihres Parteiorgans Der Gerade Weg eröffnete ${ }^{355}$. Das Thema Parteifinanzen war ein mehr als heißes Eisen; schließlich hatten die Wortführer der innerparteilichen Opposition, allen voran Alois Hundhammer, dem Landesvorsitzenden wiederholt schwerwiegende organisationspolitische Versäumnisse und Mißmanagement vorgeworfen ${ }^{356}$, und in der Öffentlichkeit kursierten die wildesten Gerüchte über den Schuldenstand der CSU. Müller blieb nichts anderes übrig, als die schwere Finanzkrise der Partei einzugestehen, aber er versuchte aus diesem Eingeständnis eine Waffe gegen seine Widersacher zu schmieden. Die Partei habe Schulden, ja, aber dies sei nicht auf Fehler der Parteiführung zurückzuführen, sondern resultiere daraus, daß die Bezirksverbände ihren Zahlungsverpflichtungen nicht nachgekommen seien. Der Durchschnitt der seit der Währungsreform geleisteten Zahlungen betrage nur 13 Prozent, und der Bezirksverband Oberbayern, immerhin der größte und mitgliederstärkste Bezirk, habe überhaupt nur vier Prozent seiner Beitragsverpflichtungen erfüllt. Man kön-

${ }^{353}$ IfZ-Archiv, RG 260, 7/29-1/13-16, Bericht des amerikanischen Generalkonsulats in München über die Lage der CSU an das State Department vom 17. 3. 1949.

${ }^{354}$ ACSP, CSU-LTF I, 15-14, Protokoll der Fraktionssitzung am 17. 2. 1949; BSB, NL Schwend 2, ungezeichnete Notiz „Bevorstehende Wahl des Landesvorsitzenden“ vom 17.3. 1949.

355 IfZ-Archiv, RG 260, 7/29-1/13-16, Bericht des amerikanischen Generalkonsulats in München über die Lage der CSU an das State Department vom 17. 3. 1949; IfZ-Archiv, RG 260, 13/143-3/4, Bericht Pierre M. Purves' über die Lage der CSU an den stellvertretenden Direktor von OMGBY vom 23.3. 1949; IfZ-Archiv, ED $720 \mathrm{Smlg}$. Mintzel 45, Informations-Rundschreiben Nr. $1 / 49$ des Bezirksverbands Oberfranken vom 15.3. 1949; Bericht über die Sitzung des Landesvorstands am 12. 3. 1949, in: Die Politische Information 9/10-49; BSB, NL Schwend 2, Franz Xaver Butterhof an Hans Ehard vom 14. 3. 1949 und Rundschreiben Nr. 3/49 des CSU-Bezirksverbands Unterfranken vom 16.3. 1949; ACSP, NL Müller 144, Otto Kalbskopf an die CSU-Landesleitung vom 26. 3. 1949. Ein Protokoll der Sitzung des Landesvorstands am 12.3. 1949 wurde „aus Geheimhaltungsgründen" nicht geführt (ACSP, NL Müller 133, Josef Müller an Anton Hergenröder vom 14.4. 1949); in den Akten (ACSP, NL Müller 9) findet sich neben der Anwesenheitsliste lediglich eine kurze Notiz über die besprochenen Finanz- und Organisationsfragen, Anträge und eine Presseerklärung, die jedoch fälschlicherweise auf den 11.3. datiert ist.

356 BAK, NL Schäffer 26, Bl. 79 ff., Der oberbayerische Informationsbrief 4/49 vom 14. 2. 1949; ACSP, CSU-LTF I, 15-14, Protokoll der Fraktionssitzung am 17.2. 1949. 
ne nicht erwarten, erklärte Müller kämpferisch, daß er diesem „finanziellen Terror“ weiche ${ }^{357}$.

Mit diesem nicht ungeschickten Versuch, selbst in die Offensive zu gehen und den Schwarzen Peter an seine Gegner zurückzugeben, hatte Müller aber auch ungewollt die Debatte über die Neuformierung der Parteiführung eingeleitet. Die finanzielle Krise der CSU könne „ohne eine Behandlung der Frage der Parteiführung auf die Dauer nicht gelöst werden", machten Konrad Kübler und Anton Hergenröder, die Vorsitzenden der Bezirksverbände Niederbayern und Oberfranken, nachdrücklich klar, und Alois Hundhammer und sein Münchner Kollege Hugo Geiger stellten wenig später unter Beweis, daß sie solche Worte durchaus ernst nahmen. Als Michael Horlacher vorschlug, alle Anwesenden sollten der Partei 100 DM spenden, um die größte Not zu lindern, weigerten sie sich, solchen Aufforderungen nachzukommen, bis die Partei in den richtigen Händen sei. Müller konnte sich zwar lautstark über das Ergebnis dieser Sammlung beschweren und darüber klagen, daß sich hier wieder einmal zeige, wie „ein Teil der Parteifreunde versuche, ihn durch Entzug der Geldmittel aktionsunfähig zu machen“, aber er hatte keine Handhabe, um gegen diese Obstruktionspolitik vorzugehen. Wie so oft in entscheidenden Situationen wurde auch diesmal weniger über mögliche Auswege aus der Dauerkrise der Partei diskutiert als über die Affären und Skandale, die die CSU in den letzten Jahren in Atem gehalten hatten. Daß dies nicht gerade dazu beitrug, die Atmosphäre zu entgiften, liegt auf der Hand.

Müller und Haußleiter versuchten immer wieder, der Diskussion eine andere Richtung zu geben und durch eigene Attacken noch unentschlossene Vorstandsmitglieder auf ihre Seite zu ziehen. Haußleiter ging sogar so weit, seine schon in der Presse erhobenen Vorwürfe zu wiederholen, die jüngsten Angriffe gegen den Parteivorsitzenden seien nichts anderes als die „Frühjahrsoffensive der Staatskanzlei“358. Damit traf er selbstverständlich auch Ministerpräsident Ehard, die zentrale Figur im Kampf um den Parteivorsitz, der nur mit Mühe davon abgehalten werden konnte, die Sitzung unter Protest zu verlassen. Ehards eigene Rede, in der er alle offen und verdeckt gegen ihn erhobenen Vorwürfe ungewöhnlich heftig zurückwies, war von allen Anwesenden mit Spannung erwartet worden. Doch der Ministerpräsident vermied es auch diesmal, eindeutig zu der brennenden Frage Stellung zu nehmen, ob er bereit sei, den Parteivorsitz zu übernehmen oder nicht. Der amerikanische Generalkonsul konnte deshalb nur berichten, Ehard habe lediglich durchblicken lassen, er sei unter bestimmten Umständen zu einer Kandidatur bereit. Dies war einem offiziösen Bericht über die Sitzung des Landesvorstands, der in der von der Landesleitung herausgegebenen vertraulichen Korrespondenz Die Politische Information erschien, nicht unbedingt zu entnehmen.

357 Bericht über die Sitzung des Landesvorstands am 12. 3. 1949, in: Die Politische Information 9/10-49; das folgende Zitat findet sich ebenda. Zutiefst empört schrieb Otto Kalbskopf am 26. 3. 1949 an die Landesleitung der CSU (ACSP, NL Müller 144): „In der Landesvorstandssitzung wurde von uns allen erwartet, dass Dr. Hundhammer und sein Anhang gegen Dr. Josef Müller nun wirklich schwerwiegende Gründe vorbringen würden. Nichts dergleichen. Schulden waren vorhanden. Ja, jeder alte Politiker weiss, dass schon immer die politischen Parteien Schulden hatten. [. . .] Wenn aber diese Schulden besonders dadurch entstanden sind, dass die eigenen Bezirksverbände der Landesleitung die Luft abschnüren durch Verweigerung der satzungsmässigen Beiträge und wieder gerade der Bezirk Oberbayern, dessen Vorsitzender Dr. Hundhammer ist, mit $4 \%$ weit unter der untersten Grenze liegt, so ist damit klar erwiesen, wo die wirklich Schuldigen sitzen."

358 IfZ-Archiv, RG 260, 7/29-1/13-16, Bericht des amerikanischen Generalkonsulats in München über die Lage der CSU an das State Department vom 17. 3. 1949; das folgende nach diesem Bericht. 
Der Ministerpräsident wurde dort mit den Worten zitiert, „er strebe nicht danach, Parteivorsitzender zu werden“" ${ }^{359}$. Weiter hieß es in dem Bericht über die Rede Ehards:

„Was wir brauchen, ist eine homogene Parteileitung. Ich habe mich stets bemüht, mit allen in der Partei zusammenzuarbeiten. Er sähe die Zukunft der Union so an, entweder habe sie soviel Kraft, dass sie die grosse Masse zusammenhält, dann ist unter Umständen eine Reorganisation denkbar, oder es hängt nur an einer Person oder auch an mehreren, dann ist alles andere zwecklos, dann wird auch bei den Bundeswahlen die SPD die Mehrheit bekommen. Was das bedeutet, wenn für 4 Jahre die SPD im Bund regiert, den Präsidenten und den Bundeskanzler stellt, könne jeder selbst ermessen. Wenn wir in der Union nicht zu einem echten Zusammenspiel kommen, kann auch kein Einzelner, und möge er noch soviel Ansehen geniessen, die Sache retten."

Kurz vor dem Ende der mehrstündigen Vorstandssitzung wurde die Frage, wer die Partei künftig führen sollte, noch einmal angeschnitten. Es war Karl Sigmund Mayr, der Vorsitzende des Bezirksverbands Mittelfranken, der Müller, unterstützt von einflußreichen oberfränkischen und niederbayerischen Kollegen, darum bat, freiwillig zurückzutreten und den Weg für eine Parteiführung der Mitte unter der Führung Hans Ehards freizumachen. Der Appell Mayrs, der lange Zeit zu den treuesten Gefolgsleuten des Landesvorsitzenden gehört hatte, zeigte einmal mehr, wie dünn die Luft für Josef Müller geworden war ${ }^{360}$. Der Ochsensepp erklärte aber lediglich stereotyp, die bevorstehende Landesversammlung werde über die Führungsfrage entscheiden. Wann dieser Parteitag jedoch einberufen werden sollte, blieb offen. Hundhammers Forderung, die Delegierten baldmöglichst zusammenzurufen, fand keine Mehrheit, und so konnte sich Müller mit der Ankündigung aus der Affäre ziehen, die Landesversammlung werde Anfang Mai tagen ${ }^{361}$.

Als die Landesvorstandssitzung zu Ende ging, hatte der Parteivorsitzende zwei wesentliche Ziele erreicht: Es war ihm gelungen, jede Entscheidung über die künftige Parteiführung zu vermeiden, und er hatte durch das Hinausschieben der bevorstehenden Landesversammlung mehrere Wochen Zeit gewonnen. Die Konferenz der Bezirksvorsitzenden und die Sitzung des Parteivorstands am 12. März machten jedoch überdeutlich, daß Josef Müller kaum noch mehr war als ein Landesvorsitzender auf Abruf.

Damit war das Wochenende der Weichenstellungen aber noch nicht vorüber. Einen Tag nach der Marathonsitzung des Landesvorstands trafen sich am Sonntag, den 13. März in Nürnberg etwa 30 führende Politiker der CSU, Landtagsabgeordnete, Mitglieder des Wirtschaftsrats und des Parlamentarischen Rats und verschiedene Kreisund Bezirksvorsitzende, um erneut über die Krise der Union und die Person des künftigen Parteivorsitzenden zu beraten ${ }^{362}$. Es waren vor allem Politiker aus dem fränkischprotestantischen Raum, die Josef Müller, den Garanten der interkonfessionellen Idee und Bannerträger gesamtdeutschen Gedankengutes, stets unterstützt hatten. Sollten

359 Bericht über die Sitzung des Landesvorstands am 12. 3. 1949, in: Die Politische Information 9/10-49; das folgende Zitat ebenda.

360 ACSP, NL Müller 16, Karl Sigmund Mayr an Josef Müller vom 15. 3. 1949.

361 Der Antrag Müllers, der bei vier Gegenstimmen angenommen wurde, lautete: „Die Landesversammlung findet statt nach Vorliegen des Bonner Ergebnisses, wenn möglich spätestens um die Zeit des 1. Mai 1949.“ ACSP, NL Müller 9.

362 Bericht über die Sitzung des Landesvorstands am 12. 3. 1949, in: Die Politische Information 9/10-49; IfZ-Archiv, ED $720 \mathrm{Smlg}$. Mintzel 45, Informations-Rundschreiben Nr. 1/49 des Bezirksverbands Oberfranken vom 15.3. 1949; ACSP, NL Müller 16, Karl Sigmund Mayr an Josef Müller vom 15. 3. 1949, Paul Nerreter an Josef Müller vom 16.3. 1949 und Paul Nerreter an Georg Meixner vom 16. 3. 1949 . 
sie ihn nun fallenlassen, weil der Druck aus den Reihen der innerparteilichen Opposition übermächtig zu werden drohte? Sollten sie den Mann, in den sie so große Hoffnungen gesetzt hatten, im Verein mit denen stürzen, die keine Gelegenheit ausgelassen hatten, Müllers Politik zu torpedieren? Franz Xaver Butterhof, seit 1946 ein enger Gefolgsmann des Parteivorsitzenden, bekannte offen, „daß man damit letzten Endes das eindeutige Unrecht" sanktioniere, das die „Gruppe um Schäffer und Hundhammer an der Union begangen“ habe. Er könne „vielleicht den Schmerz ermessen“, schrieb Butterhof am Tag nach der Nürnberger Konferenz an den Parteivorsitzenden, mit dem er sich den Gegebenheiten beuge, aber auch er teile die in Nürnberg einmütig zum Ausdruck gebrachte Überzeugung, daß in der gegenwärtigen Krise nur „eine Umgruppierung in der Führung unserer Partei eine Besserung der Lage“ verspreche ${ }^{363}$.

Die Versammlung im Nürnberger Ratskeller zeigte, wie groß die Wertschätzung war, die Müller vor allem im fränkisch-protestantischen Raum nach wie vor genoß. Die Versammlung bewies jedoch auch, daß immer mehr Anhänger Josef Müllers bereit waren, eigene Positionen zu opfern, um den Zusammenhalt und die organisatorische Einheit der CSU zu retten ${ }^{364}$. Die Person des künftigen Parteivorsitzenden war kaum umstritten, dafür kam nur Hans Ehard in Frage. Wie die neue Parteiführung aber sonst aussehen sollte, blieb auch in Nürnberg unklar ${ }^{365}$. Dagegen wurde rasch deutlich, daß man sich in Nordbayern nicht mit der Zusage Hundhammers zufrieden gab, selbst keinen Platz in einer neuformierten Führungsspitze zu beanspruchen; die Versicherung, einer der neu zu wählenden stellvertretenden Parteivorsitzenden solle auch in Zukunft von den evangelischen Mitgliedern der Union gestellt werden, genügte ebenfalls nicht. Darüber hinaus wurde in Nürnberg die Forderung laut, Hundhammer müsse den Vorsitz der Landtagsfraktion niederlegen, wenn Müller den Parteivorsitz abgebe. Dann und nur dann - sei es möglich, die Flügelkämpfe zu beenden und die CSU grundlegend zu erneuern. Nach den ständigen Auseinandersetzungen zwischen Parteiführung und Fraktionsmehrheit, so wurde in Nürnberg nicht zu Unrecht festgestellt, sei „in Zukunft ein gedeihliches Zusammenarbeiten zwischen Partei und Fraktion“ ohne einen Wechsel in der Fraktionsführung „undenkbar ${ }^{\text {“ } 366}$. Doch es ging für die Anhänger

${ }^{363}$ ACSP, NL Müller 16, Franz Xaver Butterhof an Josef Müller vom 14. 3. 1949.

364 "Ich weiß nicht, ob Du über den ausgezeichneten Verlauf unserer Versammlung in Nürnberg unterrichtet worden bist", schrieb Karl Sigmund Mayr am 15. 3. 1949 an Josef Müller (ACSP, NL Müller 16). „Hättest Du zuhören können, dann wärst Du tief beeindruckt gewesen, daß es auch einmal in unserer Partei möglich ist, über ernste und kritische Probleme eine wirklich sachliche Aussprache zu führen. Es war erhebend, mit welcher Verehrung über Dich gesprochen wurde und wie schmerzlich wir es aber alle empfinden, daß Dir die Führung unserer Partei aus den Händen geglitten ist."

${ }^{365}$ Namen und mögliche Konstellationen waren dagegen viele im Gespräch. So wurde ein Triumvirat Ehard-Semler-Schwalber gefordert, andere schlugen ein Direktorium Ehard-Müller-Hundhammer vor. Im Gespräch waren auch Hanns Seidel oder Josef Schwalber als Parteichef und Johannes Semler oder Friedrich Wilhelm von Prittwitz und Gaffron als weitere Mitglieder der engeren Parteiführung. ACSP, NL Müller 16, Lorenz Sedlmayr an Josef Müller vom 31. 1. 1949 und Paul Nerreter an Josef Müller vom 16. 3. 1949; BAK, NL Schäffer 26, Bl. 127, Fritz. Schäffer an Franz Schäfer vom 2. 2. 1949; SZ vom 8. 3. 1949: „... und findet die CSU eine Klärung? Der Machtkampf Dr. Josef Müllers/Die Entscheidung liegt bei Dr. Ehard“".

366 Bericht über die Sitzung des Landesvorstands am 12. 3. 1949, in: Die Politische Information 9/10-49; Franz Xaver Butterhof schrieb am 14. 3. 1949 an Josef Müller (ACSP, NL Müller 16): „Ich habe dabei [am 13. 3. 1949 in Nürnberg] ausdrücklich erklärt, es könne und dürfe Ihnen keine Schuld an Dingen zugeschoben werden, für die Dr. Hundhammer und seine Gruppe verantwortlich sei, und es müsse außerdem eine zweite wesentliche Korrektur erfolgen: Dr. Hundhammer müsse aus der Führung der Fraktion ausscheiden. Diese letzte Forderung wurde mit großem Beifall aufgenom- 
Müllers, die nun für Ehard und gegen den Ochsensepp stimmen sollten, vor allem auch darum, das eigene Gesicht zu wahren und den Eindruck zu vermeiden, sie hätten vor der innerparteilichen Opposition kapituliert. Wenn es gelang, die Macht Alois Hundhammers, dieser katholisch-konservativen Symbolfigur, zu beschneiden, so konnte man das in den protestantischen Regionen Bayerns durchaus als Erfolg verkaufen. $\mathrm{Ob}$ Hundhammer jedoch bereit war, auf diesen Handel freiwillig einzugehen, blieb von vornherein zweifelhaft, und ob es gelingen konnte, genügend Druck auf den Fraktionsvorsitzenden auszuüben, ebenfalls ${ }^{367}$.

$\mathrm{Da}$ es in den nächsten Wochen nicht nur um Personalentscheidungen gehen würde, sondern damit verbunden auch um die politische Linie der Partei, blieb zumindest denjenigen nicht verborgen, die in den scharfen Auseinandersetzungen der letzten Wochen einen einigermaßen kühlen Kopf bewahrt hatten. Franz Xaver Butterhof schrieb in diesem Sinne an Josef Müller, er glaube, „daß jetzt der Kampf um die Linie der Union eigentlich erst“ beginne, da man die von Hans Ehard offensichtlich präferierte prononciert bürgerliche Politik nicht mitmachen könne. „Wir werden uns [...] mit allen zur Verfügung stehenden Mitteln gegen eine Überlagerung des Sozial-Evolutionären durch die bürgerliche Richtung zu wehren haben“, teilte Butterhof seinem Parteivorsitzenden entschlossen mit $^{368}$.

\section{e) Hans Ehard - Hoffnungsträger und Zauderer}

Obwohl derartige Bedenken auch von anderen CSU-Politikern geteilt wurden, die bisher im Lager Josef Müllers gestanden hatten - Paul Nerreter fürchtete beispielsweise einen „Ruck nach rechts“, wenn dem Ochsensepp „die Leitung der Union entzogen“ würde ${ }^{369}$-, kristallisierte sich doch eine eindeutige Mehrheit für den Ministerpräsidenten heraus. Aber stand Ehard überhaupt für eine Kandidatur zur Verfügung? Bisher hatte der Ministerpräsident nur vage Erklärungen abgegeben, die ihm alle Optionen offenließen, und wiederholt betont, er strebe nicht nach dem Parteivorsitz. Solche Aussagen waren durchaus glaubhaft; schließlich war es kein Geheimnis, daß Ehard nur wenig Verlangen verspürte, partei- und organisationspolitische Kärrnerarbeit zu verrichten, und auch die Konflikte, die ihn als Vorsitzenden einer so zerrissenen Partei wie der CSU erwarteten, waren seine Sache nicht ${ }^{370}$. Daß Ehard anders als Müller auch wenig Verständnis für das Potential hatte, das in einer großen Volkspartei steckte, kam erschwerend hinzu. Zudem hatte das innerparteiliche Machtgefüge für Ehard durchaus Vorteile. Der katholisch-konservative Flügel um Alois Hundhammer und die Anhänger Josef Müllers neutralisierten sich oft genug gegenseitig, so daß dem zwischen oder besser über den Flügeln stehenden Ministerpräsidenten ein hohes Maß an Autonomie und Handlungsfreiheit zuwuchs ${ }^{371}$. Keine Fraktion in der CSU konnte es sich leisten, offen gegen den allseits verehrten Regierungschef aufzutreten, vielmehr ver-

men.“ Ähnlich auch ACSP, NL Müller 55, Willi Hönekopp an Alois Hundhammer vom 25. 3. 1949, und NL Müller 144, Otto Kalbskopf an die CSU-Landesleitung vom 26. 3. 1949.

367 Vgl. S. $336 \mathrm{ff}$.

368 ACSP, NL Müller 16, Franz Xaver Butterhof an Josef Müller vom 14. 3. 1949; diese Bedenken teilte Butterhof am 14. 3. 1949 auch Hans Ehard mit (BSB, NL Schwend 2).

369 ACSP, NL Müller 16, Paul Nerreter an Georg Meixner vom 16. 3. 1949.

370 Vgl. Gelberg, Hans Ehard, S. 275 ff.

371 Vgl. ebenda, S. 49. 
suchten alle Seiten, Ehard für sich zu vereinnahmen. Da der Ministerpräsident in der CSU jedoch über keine eigene Hausmacht verfügte, war er andererseits durchaus angreifbar. Die CSU verfügte zwar im Landtag nach wie vor über eine sichere absolute Mehrheit, aber wenn nur ein Dutzend Abgeordnete gegen ihre Fraktion stimmten, konnte es damit schnell vorbei sein. Man spekulierte wiederholt, Müller würde eher die Regierung stürzen als den Parteivorsitz aufgeben, und obwohl nicht feststand, ob Müllers Einfluß in der CSU-Fraktion noch so weit reichte, dürfte die bloße Möglichkeit einer Regierungskrise mit anschließender Landtagsauflösung Ehard zur Zurückhaltung bewogen haben ${ }^{372}$. Schließlich konnte es keinen Zweifel daran geben, daß die Absicherung seiner föderalistischen Politik für den Ministerpräsidenten oberste Priorität besaß und daß er nichts unternehmen würde, was diese gefährdet hätte, schon gar nicht im Frühjahr 1949, als die Weichen für einen deutschen Weststaat gestellt wurden.

Außerdem waren da noch Gerüchte, es gebe „Material“ über seine Tätigkeit als Jurist während der NS-Zeit, das den Ministerpräsidenten schwer belasten, wenn nicht gar „politisch vernichten“ würde, die Ehard zur Zurückhaltung veranlaßten ${ }^{373}$. Schon im Dezember 1948 hatte Joseph Baumgartner dem Ministerpräsidenten mit Enthüllungen gedroht ${ }^{374}$, und auch die amerikanische Militärregierung war auf die Angelegenheit aufmerksam geworden, ohne jedoch irgendwelche Maßnahmen zu ergrei$\mathrm{fen}^{375}$. Auf dem Höhepunkt der Führungs- und Flügelkämpfe hielt man es nun für möglich, daß der in die Enge getriebene Josef Müller den Versuch unternehmen würde, den Ministerpräsidenten durch Drohungen so einzuschüchtern, daß er freiwillig alle Ambitionen auf den Parteivorsitz aufgab, oder Ehards Ansehen in der Öffentlichkeit durch lancierte Presseveröffentlichungen so zu beschädigen, daß er als Landesvorsitzender der CSU nicht mehr in Frage $\mathrm{kam}^{376}$. Es gibt keinen gesicherten Hinweis darauf, daß Müller tatsächlich solch dunkle Pläne mit sich herumtrug, der Ochsensepp galt aber als intrigant genug, um entsprechende Vermutungen glaubwürdig erscheinen zu lassen.

Die Vorstellung, Hans Ehard könnte die ihm angetragene Kandidatur ausschlagen, wurde zum Alptraum all derer, die in Müllers Sturz die einzige Chance für eine Rettung der CSU sahen. Wenn der Ministerpräsident nicht für das Amt des Parteivorsitzenden kandidierte, dann mußten die Karten neu gemischt werden, das war allen Beteiligten klar. In diesem Falle, schrieb Karl Sigmund Mayr an Josef Müller, habe er seine Bitte, den Parteivorsitz niederzulegen, wohl zu früh ausgesprochen, da eine Partei-

372 IfZ-Archiv, RG 260, 13/143-3/4, Bericht Pierre M. Purves' über die Lage der CSU an den stellvertretenden Direktor von OMGBY vom 23. 3. 1949; Neue Zeitung vom 19. 3. 1949: „Parteivorsitzender dringend gesucht. Konflikt in der CSU beeinflußt politische Gesamtentwicklung“.

${ }^{373}$ Frankenpost vom 30. 4. 1949: „Loritz droht mit neuen Enthüllungen. Dr. Müller gegen Dr. Ehard Dr. Ehard gegen Loritz - Wer wird abgeschossen?“ Im Vorfeld der Straubinger Landesversammlung gewannen diese Vorwürfe eine besondere Brisanz (BSB, NL Schwend 2, ungezeichnete Notiz "Bevorstehende Wahl des Landesvorsitzenden" vom 17.3. 1949). Ehard selbst setzte sich in einer Pressekonferenz am 1.7. 1949 (BayHStA, NL Ehard 385) gegen die kursierenden Anschuldigungen und Gerüchte zur Wehr. Zum Gesamtzusammenhang vgl. Gelberg, Hans Ehard, S. 27-32.

374 BSB, NL Schwend 24, Notiz über eine Besprechung zwischen Hans Ehard und Joseph Baumgartner am 10. 12. 1948.

375 IfZ-Archiv, RG 260, 15/102 2/11, Bericht Donald R. Sheas über Hans Ehard vom 3. 1. 1949.

376 Frankenpost vom 30. 4. 1949: „Loritz droht mit neuen Enthüllungen. Dr. Müller gegen Dr. Ehard Dr. Ehard gegen Loritz - Wer wird abgeschossen?". 
führung ohne Ehard, aber „unter dem Einfluß der Parteifreunde Dr. Pfeiffer und Dr. Hundhammer" untragbar sei ${ }^{377}$. Hanns Seidel wäre vielleicht schon 1949 eine Alternative zu Müller und Ehard gewesen, aber der Wirtschaftsminister stand loyal zu seinem Parteivorsitzenden und dachte nicht ernsthaft daran, gegen ihn zu kandidieren ${ }^{378}$. Die innerparteiliche Opposition mußte daher alles versuchen, um die Bedenken Hans Ehards zu zerstreuen. In diesem Sinne empfahl Fritz Schäffer, der aus dem Hintergrund die Fäden zu ziehen versuchte, seinem Freund Alois Hundhammer, alle Bezirksverbände davon zu unterrichten, daß der Ministerpräsident bereit sei, auch den Parteivorsitz zu übernehmen, wenn er nur von allen Seiten darum gebeten würde ${ }^{379}$. So geschah es auch. Ehard, der schon im Sommer 1948 von Kreisverbänden aus allen Teilen Bayerns bestürmt worden war, den Parteivorsitz zu übernehmen, um einen Zerfall der CSU zu verhindern ${ }^{380}$, sah sich nun einer wahren Welle von Bitten, Petitionen und Resolutionen gegenüber, die nur ein Ziel hatten: den Ministerpräsidenten dazu zu bewegen, sich auch als Parteichef zur Verfügung zu stellen.

Den Anfang machte der Bezirksverband München, seit den Gründungstagen eine Bastion der Gegner Müllers. Am 7. April 1949 sprach sich der Bezirksvorsitzende Hugo Geiger offen gegen eine Wiederwahl des Ochsensepp und für Hans Ehard als künftigen Parteivorsitzenden aus ${ }^{381}$. Auch andere führende Vertreter der Münchner CSU hieben in dieselbe Kerbe und fanden zum Teil drastische Worte für den gegenwärtigen Zustand ihrer Partei. So erklärte Ludwig Huber vor den Delegierten der Bezirksversammlung:

„Die Situation ist heute die, dass man mit dem Namen der CSU keinen Hund, geschweige denn einen Menschen mehr hinter dem Ofen hervorlockt. Was infolge dessen dringend not tut, ist eine radikale Reform der Partei. Man mag zu Müller stehen wie man will, über die Feststellung wird man nicht hinwegkommen, dass die Partei ihre katastrophalen Wahlverluste zu einer Zeit erlitten hat, da Dr. Müller die verantwortliche Führung der Partei inne hatte. Es ist infolge dessen im Interesse der Partei unbedingt notwendig, an Stelle Dr. Müllers schleunigst einen anderen Parteivorsitzenden zu wählen. Ich stimme mit meinen Vorrednern darüber überein, dass Ministerpräsident Ehard die geeignetste Persönlichkeit ist, die die Nachfolge Dr. Müllers antreten könnte. Unser ganzes Bemühen muss infolgedessen darauf hinausgehen, Dr. Ehard dazu zu bewegen, dass er sich als Parteivorsitzender zur Verfügung stellt. [...] Es würde eine Katastrophe für die Partei bedeuten, wenn Dr. Müller neuerdings zum Landesvorsitzenden gewählt würde. Für diesen Fall wäre es am gescheitesten, d[en] Laden mit der Firmenbezeichnung CSU rasch[es]tens zu schliessen, weil dann nämlich bestimmt die Kundschaft völlig ausbleiben würde.“

377 ACSP, NL Müller 16, Karl Sigmund Mayr an Josef Müller vom 15. 3. 1949.

378 ACSP, NL Müller 16, Lorenz Sedlmayr an Josef Müller vom 31. 1. 1949, und ACSP, CSU-LTF I, 15-12/4 und 5, Lorenz Sedlmayr an Alois Hundhammer vom 8. 2. 1949.

379 BAK, NL Schäffer 26, B1. 24, Fritz Schäffer an Alois Hundhammer vom 14. 4. 1949.

380 BayHStA, NL Ehard 1047, CSU-Kreisverband Berchtesgaden an Hans Ehard vom 16. 8. 1948, CSU-Kreisverband Bad Aibling an Hans Ehard vom 15.8. 1948, CSU-Kreisverband Freising an Hans Ehard vom 3. 8. 1948, CSU-Kreisverband Starnberg an Hans Ehard vom 30.7. 1948, CSUKreisverband Mindelheim an Hans Ehard vom 30.7. 1948, CSU-Kreisverband Traunstein an Hans Ehard vom 19. 7. 1948, CSU-Kreisverband Brückenau an Hans Ehard vom 27. 7. 1948.

381 ACSP, NL Müller 68, Protokoll der Bezirksversammlung der CSU München am 7. 4. 1949; das folgende Zitat ebenda. Zum Presseecho vgl. Münchner Merkur vom 11. 4. 1949: Resolution gegen Dr. Müller“; SZ vom 9. 4. 1949: „Münchner CSU für Dr. Ehard. Dr. Josef Müller soll seine Kandidatur zurückziehen", vom 16.4. 1949: "Geiger bleibt bei seinen Äusserungen“, und vom 20. 4. 1949: "Horlacher contra Geiger“. Zum Echo in der CSU vgl. BAK, NL Schäffer 26, Bl. 27, Der oberbayerische Informationsbrief 11/49 vom 9. 4. 1949; BSB, NL Schwend 2, Aktennotiz über die Bezirksversammlung der CSU München am 7. 4. 1949; BayHStA, NL Pfeiffer 535, Hugo Geiger an Anton Pfeiffer vom 22. 4. 1949. 
Die Bezirksversammlung teilte diese Meinung und beauftragte den Vorstand einstimmig, den Ministerpräsidenten zu bitten, „die Kandidatur zum Landesvorsitzenden im Interesse der Einigung und Erneuerung der Christlich-Sozialen Union anzunehmen“. Zugleich sollte Josef Müller nachdrücklich gebeten werden, auf eine erneute Kandidatur zu verzichten, „um eine solche Einigung und Erneuerung möglich zu machen“ ${ }^{382}$. Nur zwei Tage später sprach sich Anton Hergenröder in einer Bezirksversammlung der oberfränkischen CSU einmal mehr für Hans Ehard als Parteivorsitzenden aus ${ }^{383}$, und Ende April setzte Alois Hundhammer den Ministerpräsidenten davon in Kenntnis, daß der Vorstand des CSU-Bezirksverbands Oberbayern mit großer Mehrheit „eine entschiedene und begeisterte Stellungnahme“ für Ehard als Parteivorsitzenden abgegeben habe ${ }^{384}$. Am 21. Mai, nur wenige Tage bevor die Landesversammlung in Straubing zusammentreten sollte, befürwortete auch der Vorstand der mittelfränkischen CSU eine Kandidatur des Ministerpräsidenten ${ }^{385}$.

Der Druck auf Josef Müller kam jedoch nicht nur aus den Reihen der CSU. Auch Konrad Adenauer, der mächtige Vorsitzende der CDU in der Britischen Besatzungszone und Präsident des Parlamentarischen Rates, trug seinen Teil zum Sturz des Ochsensepp bei ${ }^{386}$. Daß er die Wahl Hans Ehards offen unterstützte, hatte vor allem zwei Gründe. Zum einen war das Verhältnis zwischen Müller und Adenauer noch nie besonders gut gewesen. Der spätere Bundeskanzler, der keinen Hehl daraus machte, daß er von den menschlichen und politischen Qualitäten seines bayerischen Kollegen wenig hielt, war schon wiederholt mit Müller aneinandergeraten und betrachtete insbesondere dessen gesamtdeutsches Engagement mit Argwohn ${ }^{387}$. Hans Ehard erschien ihm als der kalkulierbarere Partner, der sich vielleicht auch leichter unterordnen würde, wenn es nicht gerade um vitale Fragen der föderalistischen Politik ging. Zum anderen stand Adenauer klar vor Augen, daß ein weiterer Zerfall der CSU die Chancen der Union, bei den bevorstehenden Wahlen zu einem westdeutschen Parlament eine Mehrheit zu erringen, insgesamt schmälern mußte ${ }^{388}$. „Soweit ich orientiert bin, lässt sich

382 ACSP, CSU-LTF 1, 15-20/0, Resolution der Bezirksversammlung der Münchner CSU vom 7. 4. 1949.

383 Sopade-Informationsdienst vom 7. 5. 1949 nach einer Agenturmeldung vom 14. 4. 1949. Allerdings wurde nicht nur die Auffassung vertreten, daß Müller auf eine erneute Kandidatur für den Landesvorsitz verzichten solle, sondern auch, daß Hundhammer den Fraktionsvorsitz niederlegen müsse. SZ vom 16. 4. 1949: „Müller und Hundhammer sollen verzichten“. Alois Hundhammer stellte es am 25. 4. 1949 in einem Schreiben an Hans Ehard (BayHStA, NL Ehard 1047) so dar, daß sich die Bezirksversammlung der oberfränkischen CSU „in ihrer überwältigenden Mehrheit “ für den Ministerpräsidenten ausgesprochen habe. Wegen der aus seiner Sicht einseitigen Berichterstattung sah sich August Haußleiter gezwungen, bei Hergenröder zu intervenieren. ACSP, NL Müller 133, August Haußleiter an Anton Hergenröder vom 22. 4. 1949.

384 BayHStA, NL Ehard 1047, Alois Hundhammer an Hans Ehard vom 25. 4. 1949.

385 BSB, NL Schwend 2, Telegramm des Vorstands der mittelfränkischen CSU an Hans Ehard vom 23.5. 1949.

${ }^{386}$ Zur Rolle Adenauers im Vorfeld der Straubinger Landesversammlung vgl. Schwarz, Adenauer I, S. 610; Mintzel, Anatomie, S. 245 ff.; Hettler, Josef Müller, S. 411-415; Gelberg, Hans Ehard, S. 275; vgl. auch die eigene Darstellung des CSU-Vorsitzenden in: Müller, Konsequenz, S. 352-358 („Von Adenauer bis Straubing").

387 Vgl. S. $97 \mathrm{f}$.

${ }^{388}$ Aufschlußreich zur Rolle der CSU in Adenauers Kalkül vor den ersten Bundestagswahlen und zur Perzeption der Führungs- und Flügelkämpfe in der CSU bei führenden Politikern der CDU ist das Protokoll der dritten Sitzung des Wahlrechts- und des Presse- und Propagandaausschusses der Arbeitsgemeinschaft der CDU/CSU am 19. 5. 1949 in Königswinter, in: Unionsparteien, S. 583-597. Auffällig ist, daß Adenauer wie auch den anderen Rednern der CDU das tiefere Verständnis für die 
eine Spaltung der CSU nur vermeiden, wenn eine vom allgemeinen Ansehen getragene, bisher noch nicht parteipolitisch zu sehr exponierte Persönlichkeit [...] den Vorsitz übernimmt“, schrieb Adenauer am 19. Mai 1949 in einem streng persönlichen Eilbrief an Ministerpräsident Ehard ${ }^{389}$. Und Adenauer fuhr fort: „Sie wissen, dass nach meiner Meinung nur Sie dafür in Frage kommen. Ich bitte Sie sehr herzlich, doch diesen Schritt zu tun."

Adenauer beließ es nicht bei dieser Aufforderung. Wenige Tage vor der entscheidenden Landesversammlung in Straubing versandte er drängende Briefe an die Vorsitzenden der Bezirksverbände Oberpfalz und Unterfranken sowie an verschiedene Kreisvorsitzende in Regionen, in denen Müller noch am meisten Unterstützung fand, und bat „im Namen ungezählter Mitglieder der CDU ebenso herzlich wie dringend“ darum, in Straubing aus dem übergeordneten Interesse an einem Wahlsieg der Union bei den bevorstehenden Bundestagswahlen für einen Weg aus der Dauerkrise der CSU zu votieren $^{390}$. Daß dieser Weg nur in einem Sturz Müllers und in der Wahl Ehards zum neuen CSU-Vorsitzenden bestehen konnte, stand außer Zweifel, auch wenn Adenauer darauf verzichtet hatte, dies explizit auszusprechen. Tief getroffen von dieser Einmischung in die innersten Angelegenheiten der von ihm geführten Partei, hat der Ochsensepp Konrad Adenauer noch in seinen Memoiren vorgeworfen, letztendlich für seinen Sturz verantwortlich zu $\operatorname{sein}^{391}$. In dem Bemühen seine Niederlage so darzustellen, als sei sie vom Gründungskanzler der Bundesrepublik Deutschland initiiert worden, ist Müller sicherlich zu weit gegangen. Adenauers Interventionen zählten lediglich zu den vielen Faktoren, die schließlich zur Abwahl Josef Müllers führten.

Am energischsten gingen Hundhammer und seine Gesinnungsgenossen zu Werke, um sicherzustellen, daß in Straubing die richtige Entscheidung getroffen wurde. Sie zählten schon seit längerer Zeit die Delegiertenstimmen, mit denen sie auf dem Parteitag rechnen konnten ${ }^{392}$. Trotz der Krisenstimmung, die auch die Basis der CSU erfaßt hatte, und obwohl sich die Bezirksvorsitzenden bereits auf Hans Ehard als neuen Parteichef geeinigt hatten, stand eine Mehrheit für den Ministerpräsidenten nicht hundertprozentig fest, vor allem keine Mehrheit, die groß und eindrucksvoll genug gewesen wäre, um nicht den Eindruck zu erwecken, der Regierungschef Bayerns hätte nicht einmal seine eigene Partei hinter $\operatorname{sich}^{393}$. Hundhammer und seine politi-

bayerischen Probleme fehlte. Der ungenannte „Vertreter aus Bayern“ dürfte Generalsekretär Franz Josef Strauß gewesen sein.

389 BayHStA, NL Ehard 2064, Konrad Adenauer an Hans Ehard (streng persönlich und durch Eilboten) vom 19. 5. 1949; Hervorhebung im Original; abgedruckt in: Adenauer, Briefe 1945-1947, S. 461.

390 Adenauer, Briefe 1949-1951, S. 24-27. Auch Alois Hundhammer wurde von Adenauer am 19.5. 1949 ermahnt, "unter allen Umständen dafür zu sorgen, dass die CSU geschlossen“ bleibe, und sich keinesfalls aus der Partei drängen zu lassen. BayHStA, NL Ehard 2064; abgedruckt in: Adenauer, Briefe 1947-1949, S. 462. Karl Sigmund Mayr berichtete Josef Müller schon am 4. 4. 1949 (ACSP, NL Müller 16), Adenauer überlege, wie man seine erneute Kandidatur für den Landesvorsitz verhindern könne.

391 Müller (Konsequenz, S. 357) schrieb in seinen Erinnerungen: „Wer mich stürzte, war Adenauer, der nicht nur den Nimbus des Alters für sich hatte, sondern auch den des beginnenden Erfolges."

392 BAK, NL Schäffer 26, Bl. 33, Der oberbayerische Informationsbrief 10/49 vom 2. 4. 1949.

393 In einem Rundschreiben des CSU-Bezirksverbands Unterfranken, gez. Karl Greib, an die Bezirksvorsitzenden sowie an die Mitglieder des Bezirksvorstands Unterfranken und die unterfränkischen Kreisvorsitzenden vom 3. 5. 1949 (ACSP, NL Müller 16) hieß es: „Nach der allgemeinen Übersicht ist nicht damit zu rechnen, daß Dr. Ehard ein einstimmiges Vertrauensvotum erhält. Wenn nun der Herr Ministerpräsident in der eigenen Partei nur 60 oder $70 \%$ der Stimmen erhalten würde, könnte er dann noch im Auftrage des gesamten bayerischen Volkes sprechen? Wie sehr würden gerade hier 
schen Freunde unternahmen deshalb alles, was in ihrer Macht stand, um innerparteiliche Wahlen auf Kreis- und Bezirksebene in ihrem Sinne zu beeinflussen, schwankende Delegierte für ihre Pläne zu gewinnen oder unsichere Kantonisten unter Druck zu setzen ${ }^{394}$. Kundgebungen wurden veranstaltet, Vertrauensleute in Kreisund Bezirksversammlungen geschickt, und in einer Vielzahl von Einzelgesprächen wurde versucht, ein möglichst genaues Bild von den Kräfteverhältnissen in der Partei zu bekommen. Wie stark waren Müllers Bataillone noch? Wo war am meisten Widerstand zu erwarten? Welche Trümpfe hatte der gefürchtete Ochsensepp noch in der Hinterhand?

Einer, der nicht müde wurde, am Stuhl des Landesvorsitzenden zu sägen, war Fritz Schäffer. Der ehemalige BVP-Politiker hatte zwar der CSU im September 1948 den Rücken gekehrt, das hinderte ihn jedoch nicht daran, seinen Rachefeldzug gegen die „Schweinehunde in der bayerischen Politik“ mit unveränderter Intensität fortzusetzen $^{395}$. Schäffer stand seinem Freund Alois Hundhammer nicht nur mit Rat und Tat zur Seite, er warf auch sein persönliches Prestige in die Waagschale und nutzte alle Verbindungen, um Müllers Sturz voranzutreiben ${ }^{396}$. In diesem Sinne schrieb Schäffer an den Präsidenten der Handwerkskammer für München und Oberbayern, Karl Schmid, den er der Komplizenschaft mit Müller verdächtigte, einen Brief, der an Deutlichkeit nichts zu wünschen übrig ließ:

„Ich kann Dich wirklich nicht verstehen. Ich habe dafür gekämpft, dass die Einheit der katholischen, bodenständigen Bevölkerung in Bayern erhalten bleibt. Du hast Dich von den Totengräbern der CSU in einen Kurs gegen die alte bayer. Volkspartei hineinreden lassen, die hundertmal besser war wie die CSU, hast damit Deine alten Freunde sämtliche [sic!] vor den Kopf gestoßen und wunderst Dich nun, dass die bodenständige Bevölkerung Bayerns, die in 2 Teile auseinandergefallen ist und dieses törichte Gerede von der Erhaltung der Einheit, das nur Schwäche und Blindheit war, zum Gegenteil, nämlich zur dauernden Uneinigkeit geführt wird. “397

Während seine Gegner alle Hebel in Bewegung setzten, um seine Wiederwahl zu verhindern, vergrub sich der Ochsensepp in seiner Kanzlei, der legendären Gedonstr. 4, oder in seinen Amtsräumen im Justizpalast. Es schien fast, als sei der gefürchtete Kampfgeist des CSU-Vorsitzenden einer lähmenden Lethargie gewichen ${ }^{398}$. Müller setzte sich immer weniger gegen öffentliche Angriffe zur Wehr, trat den mannigfaltigen Gerüchten über seine politische Zukunft und die Zukunft der CSU nur halbherzig oder gar nicht mehr entgegen und unterließ es, Handlungsanweisungen an seine verbliebenen Getreuen in den Kreisen und Bezirken hinausgehen zu lassen, deren Verunsicherung und Niedergeschlagenheit von Tag zu Tag wuchs ${ }^{399}$. Die entmutigenden Berichte über die Stimmung an der Parteibasis und die Briefe vieler alter Weggefährten,

unsere Gegner diese Gelegenheit wünschen, um gegen den Herrn Ministerpräsidenten ins Feld zu ziehen."

394 IfZ-Archiv, MS 343 Smlg. Köhler 2, Bl. 259; BayHStA, NL Pfeiffer 535, Hans Wutzlhofer an Karl Schwend vom 29. 3. 1949 und Hans Wutzlhofer an Karl Greib vom 8. 4. 1949.

395 BAK, NL Schäffer 26, Bl. 78, Fritz Schäffer an Karl Schmid vom 18. 2. 1949.

396 BAK, NL Schäffer 26, Bl. 157, Fritz Schäffer an Alfred Lobinger vom 18. 1. 1949, Bl. 127, Fritz Schäffer an Franz Schäfer vom 2. 2. 1949, Bl. 72, Fritz Schäffer an Dekan Josef Ruf vom 26. 2. 1949, und Bl. 34, Fritz Schäffer an Alois Hundhammer vom 1. 4. 1949.

397 BAK, NL Schäffer 26, Bl. 78, Fritz Schäffer an Karl Schmid vom 18. 2. 1949.

398 IfZ-Archiv, MS 343 Smlg. Köhler 2, Bl. 184 und Bl. 259.

399 BSB, NL Schwend 2, ungezeichnete Notiz „Bevorstehende Wahl des Landesvorsitzenden“ vom 17.3. 1949; ACSP, NL Müller 144, Heinz Fischer an Josef Müller vom 19.3. und 4. 5. 1949. 
die Müller beschworen, den Kampf aufzugeben und den Weg für einen neuen, von den Führungs- und Flügelkämpfen unberührten Kandidaten frei zu machen, trugen ebenfalls nicht gerade dazu bei, den Parteivorsitzenden aus seinen trüben Gedanken zu reißen ${ }^{400}$. So schrieb Karl Greib, der Vorsitzende des Bezirksverbands Unterfranken, am 4. April an Müller, ,in allen Kreisen und Schichten der Partei und nicht weniger [in] der gesamten Wählerschaft der CSU“ sei eine „eindeutige Abneigung gegen die gesamte [Partei-]Führung " zu spüren, die man nicht wegdiskutieren könne. Landauf, landab gebe es nur ein Gesprächsthema: „Sind das noch christliche Männer, die sich dauernd selbst in den Haaren liegen, ist das noch eine christliche Partei, die sich gegenseitig selber in aller Öffentlichkeit bekämpft?" In Bad Kissingen habe ein CSUBürgermeister sogar erklärt, er bekomme „von keinem Menschen auch nur einen Pfennig Beitrag [...], wenn nicht in München ganz neue Leute in Erscheinung treten würden" ${ }^{401}$.

Auf der anderen Seite gab es nicht mehr viele, die offen für Müller Partei ergriffen. Dazu gehörten seine Stellvertreter Michael Horlacher ${ }^{402}$ und August Haußleiter ${ }^{403}$, der allerdings durch seine Experimente mit der Deutschen Union selbst stark unter Beschuß geraten war, der evangelische Rechtsanwalt Paul Nerreter aus dem mittelfränkischen Dinkelsbühl ${ }^{404}$, der nicht verstehen konnte, „warum sich plötzlich Parteifreunde, die zu Deinem engsten Kreise gehörten“, gegen Müller gestellt hatten, oder der JUAktivist Heinz Fischer, der sich zwar über die fehlenden Informationen und Regieanweisungen beklagte, aber dennoch alles versuchte, um die Delegierten des Bezirksverbands Oberfranken für den Ochsensepp zu gewinnen ${ }^{405}$. Der 29jährige Fischer scheute sich auch nicht, Ministerpräsident Ehard als dem aussichtsreichsten Kandidaten für den Landesvorsitz seine Bedenken mitzuteilen, um diesen von einer Kandidatur abzuhalten:

„Herr Ministerpräsident, es wird seit Wochen Ihre Person als neuer Landesvorsitzender der CSU in Erwägung gezogen. Für mich als jungen Menschen, der ich Sie und Ihre geleistete Arbeit mit Bewunderung ansehe, erhebt sich die nüchterne Frage, ob die Verquickung beider Ämter das Richtige ist. Ich will es Ihnen ganz offen gestehen, ich halte es für einen Fehler, weil ich es mir nicht vorstellen kann, daß die menschliche Kraft ausreicht, um solch verantwortliche Posten in einer Person zu vereinigen. Vielleicht ist die viele Ämterhäufung der größte Schaden, der der heutigen jungen Demokratie widerfahren konnte. Bitte verstehen Sie mich recht. Ich bin nur ein einfaches Mitglied der Partei, und deshalb kommt man auch schwerlich zu Wort, aber ich hänge mit allen meinen Fasern des Herzens an der CSU. Ihre Person ist mir zu wertvoll, als daß man Sie als letzten Notnagel betrachten darf $[\ldots]^{\mathrm{u}} 406$

400 ACSP, NL Müller 16, Franz Xaver Butterhof an Josef Müller vom 14. 3. 1949, Karl Sigmund Mayr an Josef Müller vom 15. 3. 1949; NL Müller 55, Willi Hönekopp an Josef Müller vom 25. 3. 1949; wie beherrschend die Sehnsucht nach einem Ende der Auseinandersetzungen geworden war, zeigen auch NL Müller 16, Hugo Karpf an Josef Müller vom 23. 2. 1949 und Hans Schwägerl an Josef Müller vom 23.2. 1949.

401 BayHStA, NL Pfeiffer 535, Karl Greib an Josef Müller vom 4. 4. 1949.

402 IfZ-Archiv, MS 343 Smlg. Köhler 2, Bl. 188-191; ACSP, NL Müller 144, Heinz Fischer an Josef Müller vom 19. 3. 1949.

${ }^{403}$ Zum Verhältnis Haußleiters zu Müller vgl. Haußleiters eigene Darstellung in: Schröder, Bayern 1945, S. 91-104.

${ }^{404}$ ACSP, NL Müller 16, Paul Nerreter an Josef Müller vom 16. 3. 1949.

405 ACSP, NL Müller 144, Heinz Fischer an Josef Müller vom 4. 5. 1949.

406 ACSP, NL Müller 144, Heinz Fischer an Hans Ehard vom 19. 3. 1949; ähnlich auch NL Müller 16, Albert Vollmann an Josef Müller und Alois Hundhammer vom 27. 4. 1949, und BayHStA, NL Pfeiffer 535, Karl Greib an Josef Müller vom 4. 4. 1949. 


\section{f) Müllers letztes Aufgebot: Der Gautinger Kreis}

Doch all die gut gemeinten Vorschläge und Initiativen bewirkten nichts, teils, weil sie völlig an der Realität vorbeigingen, teils, weil Müller selbst nichts unternahm, um die vereinzelten Vorstöße zu koordinieren. Bezeichnenderweise war es auch nicht der CSU-Vorsitzende selbst, der gleichsam fünf Minuten vor zwölf doch noch einmal versuchte, das Blatt zu seinen Gunsten zu wenden, sondern der Maler und Kunstpädagoge Karl Köhler, ein Mitbegründer der CSU aus dem oberbayerischen Gauting, und der stellvertretende Parteivorsitzende Michael Horlacher. Köhler hatte schon in den Gründungstagen der Partei zu den entschiedenen Verfechtern der Unionsidee gehört und unterstützte seither die politische Linie seines alten Freundes Josef Müller im selben Maße, wie er die Politik Hundhammers bekämpfte ${ }^{407}$. In einer von Hundhammer dominierten CSU, in einer Art Neuauflage der BVP, sah er für sich keinen Platz. Tief beunruhigt über die Entwicklung der Partei und über den unübersehbaren Machtverlust der Parteiführung, suchte Köhler in jenen entscheidenden Frühlingstagen Müller und seinen frischgebackenen Generalsekretär Franz Josef Strauß auf, um mit ihnen über die Strategie der Müller-treuen Kräfte in der bevorstehenden Auseinandersetzung zu beraten. Doch Köhler wurde enttäuscht; weder Müller noch Strauß machten Anstalten, die Initiative zu ergreifen und endlich gegen die Frondeure um den Kultusminister und Fraktionsvorsitzenden vorzugehen ${ }^{408}$. Dagegen rannte Köhler bei Michael Horlacher offene Türen ein, der den Plänen Hundhammers ebenso ablehnend gegenüberstand. Köhler und Horlacher kamen schnell überein, „eine letzte Anstrengung zu unternehmen, um den Einfluß Dr. Hundhammers zurückzudrängen “409. Zu diesem Zweck sollten alle einflußreichen CSU-Politiker, die noch auf der Seite Müllers standen, insbesondere aber die zuverlässigen Bezirksvorsitzenden, zu einer Besprechung nach Gauting eingeladen werden.

Am 25. März 1949 traf sich tatsächlich eine Reihe von Unionspolitikern bei Karl Köhler in Gauting. Neben den Initiatoren nahmen unter anderem Landwirtschaftsminister Alois Schlögl, die Bezirksvorsitzenden von Unterfranken, Nürnberg-Fürth und Augsburg-Schwaben, Karl Greib, Alfred Euerl und Josef Fischer, sowie einige Landtagsabgeordnete an den Beratungen teil ${ }^{410}$. „Nach einer lang andauernden gründlichen Analyse des Zustandes der Union“, so berichtet Karl Köhler in seinen Memoiren, sei der einstimmige Beschluß gefaßt worden, „die bevorstehende Neuwahl des Landesvorsitzenden so in den Griff zu bekommen, daß die CSU nicht in eine Entwicklung komme, die mit der alten Bayerischen Volkspartei vergleichbar wäre“. Vielmehr wollte man sich verstärkt darum bemühen, „die politischen Ziele der Gründerzeit wieder neu zu beleben und in den Vordergrund der Politik der Partei zu rücken“411.

407 Vgl. Köhler, Mittwochskreis, in: Schröder, Bayern 1945, S. 68-87.

408 IfZ-Archiv, MS 343 Smlg. Köhler 2, Bl. $184 \mathrm{f}$.

409 Ebenda, Bl. 188-191; das Zitat findet sich auf Bl. 190.

410 Münchner Merkur vom 25. 3. 1949; SZ vom 26. 3. 1949: „Was wird aus Dr. Müller?“.

411 IfZ-Archiv, MS $343 \mathrm{Smlg}$. Köhler 2, Bl. 191. In einer handschriftlich auf den 1. 4. 1949 datierten Aktennotiz aus der Staatskanzlei heißt es über die erste Tagung des Gautinger Kreises: „Ergebnis: 1) Beschluss, Neuwahl so zu beeinflussen, dass die CSU keineswegs zu einer Partei alten Stils wird, sondern vielmehr zu einem politischen Instrument, das ein wirksamer Faktor bei der Behebung der wirtschaftlichen und sozialen Not des Volkes sein kann. 2) Die Ziele, die 1945/46 zur Gründung 
Den weiteren Zerfall der CSU verhindern und den Idealen aus den ersten Tagen der Union wieder zu ihrem Recht verhelfen - das waren Ziele, mit denen sich alle identifizieren konnten, die nach Gauting gekommen waren. An einer Wiederwahl Josef Müllers zeigten sich aber nach Presseberichten keineswegs alle Teilnehmer interessiert. Der Südost-Kurier wußte zu berichten, daß sich gerade einige von den mächtigen Bezirksvorsitzenden deutlich von Müller distanziert und für Hans Ehard als künftigen Parteichef ausgesprochen hätten, da sie sachliche Argumente über persönliche Erwägungen gestellt hätten ${ }^{412}$. Nach außen gab sich die neue Gruppierung, die bald unter dem Namen Gautinger Kreis bekannt werden sollte, neutral ${ }^{413}$. Man wolle nur die müde gewordene CSU aktivieren, hieß es in einer Presseerklärung ${ }^{414}$. Die innerparteiliche Opposition ließ sich davon jedoch nicht täuschen. Der Gautinger Kreis sei „nichts anderes als ein mehr oder weniger gut getarnter Versuch Dr. Müllers, auf dem Weg über vorgebliche Neutralität in Parteizwistigkeiten den verlorenen Einfluß wieder aufzuholen“, berichtete Anfang April Ludwig Huber, ein leidenschaftlicher Anhänger Hundhammers und Schäffers, einem Vertrauensmann der Militärregierung ${ }^{415}$. Damit hatte Huber fast den Nagel auf den Kopf getroffen, allerdings sah er fälschlicherweise in Müller selbst den Initiator des Gautinger Kreises.

Tatsächlich war es das primäre Ziel Horlachers und Köhlers, durch eine Zusammenfassung der verbliebenen Kräfte und deren taktisch geschickten Einsatz die Wiederwahl Müllers auf der bevorstehenden Landesversammlung zu sichern ${ }^{416}$. Köhler schwebte ein Netz von Vertrauensleuten in allen Bezirksverbänden vor, die gleichsam „von Mann zu Mann“ an der Basis der Partei für den Ochsensepp werben sollten ${ }^{417}$. Daneben stand aber eine andere zentrale Frage im Mittelpunkt der Diskussion: Wie konnte man Hans Ehard davon abhalten, für den Landesvorsitz zu kandidieren? Trat Ehard auf der kommenden Landesversammlung an, soviel war klar, hatte Müller nur geringe Chancen. Gelang es dagegen, den Ministerpräsidenten zum Verzicht zu bewegen, war wieder alles offen. Die Initiatoren des Gautinger Kreises, die um Ehards zögerliche Haltung und seine Abneigung gegen führende Parteiämter wußten, setzten auf eine Strategie der Verunsicherung und der Abschreckung. Sie versuchten, möglichst oft in der Presse präsent zu sein, gaben bereitwillig Informationen an Journalisten, ohne jedoch die Aura des Geheimnisvollen und Konspirativen, das die Zusam-

der CSU gefuehrt haben, sollen wieder als alleiniges Programm der Partei gelten.“ BSB, NL Schwend 2; Hervorhebung im Original.

412 Südost-Kurier vom 30. 3. 1949: „Kampfabstimmung bei der CSU? Für und gegen Dr. Müller. ,Gautinger Kreis' eindeutig gegen Dr. Pfeiffer“.

$413 \mathrm{BSB}, \mathrm{NL}$ Schwend 2, handschriftlich auf den 1. 4. 1949 datierte Aktennotiz.

${ }^{414}$ IfZ-Archiv, MS 343 Smlg. Köhler 2, Bl. 192; Tagespost (Augsburg) vom 29. 3. 1949: „Der, Gautinger Kreis' der CSU“.

415 IfZ-Archiv, RG 260, 10/90-3/8, „Subject: Zum ,Gautinger Kreis““ vom 7. 4. 1949. Franz Sackmann erklärte einem Informanten der Militärregierung in realistischer Einschätzung der Lage: „Der Gautinger Kreis hat sich aus dem Bestreben entwickelt, gegen die massive Opposition des süddeutschen Unionsteiles ein Gegengewicht zu bilden. Sein Nachteil ist natürlich, daß er zu einem ausgesprochenen Dr. Müller-Kreis geworden ist. Dadurch ist er sofort den Hundhammer-Leuten verdächtig. Aber es ist ja im Grunde gar nicht möglich, ein neutrales Gremium zustandezubringen. “ IfZ-Archiv, RG 260, 10/90-3/9, „Subject: Gautinger Kreis“ vom 26. 5. 1949.

${ }^{416}$ In einer Sitzung des Gautinger Kreises am 4. 5. 1949 erklärte Michael Horlacher, bei der bevorstehenden Landesversammlung müsse der Gautinger Kreis eine "geschlossene Phalanx“ bilden. ACSP, NL Müller 43.

417 IfZ-Archiv, MS 343 Smlg. Köhler 2, Bl. 191. 
menkünfte des Gautinger Kreises umgab, zu zerstören, und nannten sogar die Zahl der Versammlungsteilnehmer, wobei sie selbstverständlich eher über- als untertrieben ${ }^{418}$. Die offiziellen Stellungnahmen des Gautinger Kreises ließen dann auch erkennen, daß man einer Kandidatur Ehards skeptisch gegenüberstand. Einmal wurde darauf hingewiesen, daß es schädlich sei, den Parteivorsitz und das Ministerpräsidentenamt in einer Hand zu vereinigen, da aufgrund der außerordentlichen Arbeitsbelastung beide Ämter leiden würden, dann erklärte man, Ämterhäufung sei generell ungesund für ein demokratisches System, oder man warnte den Ministerpräsidenten davor, sein Amt und sein persönliches Ansehen durch den Abstieg in "die Niederung des Parteistreites“ zu beschädigen $^{419}$. Intern wurde mit härteren Bandagen gekämpft, und die Initiatoren des Gautinger Kreises ließen gegenüber Ehard und Karl Schwend, dem stellvertretenden Leiter der bayerischen Staatskanzlei, durchblicken, daß der Bestand des Kabinetts Ehard gefährdet sei, wenn Josef Müller als CSU-Vorsitzender abgewählt würde ${ }^{420}$. Um dieser Warnung Nachdruck zu verleihen, lancierte man Pressemeldungen, wonach sich mehr als 30 Landtagsabgeordnete der CSU zu den Zielen des Gautinger Kreises bekannten ${ }^{421}$. Wenn nur 15 Abgeordnete Ehard die Gefolgschaft verweigerten, würde die Regierung stürzen, das war allen Beteiligten und nicht zuletzt Ministerpräsident Ehard klar.

Dennoch scheiterten Köhler und Horlacher. Das Rad der Geschichte ließ sich nicht aufhalten. Die Krise der CSU war mittlerweile so tiefgehend, das Bedürfnis nach neuen Gesichtern und von den Flügelkämpfen unbelasteten Personen so groß, daß die Chancen für einen Erfolg des Gautinger Kreises von vornherein schlecht standen. Die Initiative kam auch zu spät, um den innerparteilichen Willensbildungsprozeß noch wesentlich beeinflussen zu können. Zudem verfügte der Gautinger Kreis über keinerlei materielle Mittel, um wirklich ein effektives Netz von Vertrauensleuten aufbauen und mit Informationen versorgen zu können ${ }^{422}$. Am schwersten wog aber, daß Müller selbst nicht wirklich hinter diesem Vorstoß seiner verbliebenen Getreuen stand und es nicht einmal für notwendig hielt, auch nur eine Veranstaltung des Gautinger Kreises zu besuchen.

\section{g) Aufstand der "Filser “423? Die CSU und die Verabschiedung des Grundgesetzes}

Die Zeit arbeitete gegen den Ochsensepp, und niemand wußte das besser als er selbst. Müllers Aussichten, gegen die innerparteiliche Opposition $\mathrm{zu}$ bestehen, wurden schlechter, je näher der Termin des Parteitages rückte. Was ihn noch retten konnte, war ein eklatanter Fehler seiner Gegenspieler, ein taktischer Mißgriff, der es Müller er-

\footnotetext{
418 IfZ-Archiv, RG 260, 10/130-3/1, „Subject: Gautinger Kreis. Interview mit dem CSU-Abgeordneten Ferdinand Neumann" vom 4. 5. 1949; IfZ-Archiv, RG 260, 13/150-3/12, Karl Köhler an Albert C. Schweizer vom 6. 5. 1949; IfZ-Archiv, MS 343 Smlg. Köhler 2, B1. 251.

419 IfZ-Archiv, MS 343 Smlg. Köhler 2, Bl. 251.

${ }^{420}$ Ebenda, Bl. $251 \mathrm{f}$.

421 Abendzeitung (München) vom 28. 4. 1949: „31 Abgeordnete im Gautinger Kreis“; Münchner Merkur vom 29. 4. 1949: ",Gautinger Kreis“ wird größer“.

422 IfZ-Archiv, MS 343 Smlg. Köhler 2, Bl. $258 \mathrm{f}$.

423 August Haußleiter karikierte mit dieser Reminiszenz an Ludwig Thomas Figur Josef Filser die in seinen Augen partikularistischen und monarchistischen Teile der Partei. ACSP, NL Müller 43, Protokoll der Sitzung des Gautinger Kreises am 4. 5. 1949
} 
laubt hätte, seine zunehmende Isolation zu durchbrechen und die Koalition zu spalten, die sich auf Ehard als Landesvorsitzenden geeinigt hatte. Diese Möglichkeit eröffnete sich tatsächlich ganz unverhofft Anfang Mai 1949, als Alois Hundhammer mit einer Rede für Aufsehen sorgte und so etwas wie eine Regierungskrise auslöste ${ }^{424}$. Anläßlich einer Tagung der ehemaligen „Bayerischen Widerstandsbewegung“ am 1. Mai 1949 nahm Hundhammer auch zu den Bonner Verfassungsberatungen und zur Zukunft Bayerns Stellung. Laut Presseberichten ${ }^{425}$ - ein Redemanuskript oder stenographische Aufzeichnungen liegen nicht vor - erklärte der Kultusminister, es sei unmöglich, aus der augenblicklichen Situation heraus eine Verfassung zu machen, die Bayern auf Jahrhunderte binde. Falls das Grundgesetz in Bayern abgelehnt würde - Hundhammer dachte dabei an eine Volksabstimmung -,

„könnten entweder die Alliierten die Lage klären, oder aber der Bund würde zunächst ohne Bayern entstehen. Das sei durchaus möglich, da diesem vorläufig auch die Länder der Ostzone und die Westsektoren Berlins nicht angehören. Bayern bräuchte sich deshalb nicht abzuschließen, da die wirtschaftlichen Beziehungen zwischen den deutschen Stellen schon vorhanden gewesen seien, als man an einen Bund noch gar nicht dachte."

Ob Hundhammer darüber hinaus auch zur Frage der Wiedereinführung der Monarchie Stellung nahm, ist umstritten und läßt sich nicht mehr eindeutig klären ${ }^{426}$. Tatsache ist jedoch, daß seine Äußerungen mit den Reden des Bayernpartei-Vorsitzenden Joseph Baumgartner und des CSU-Staatssekretärs und Hundhammer-Intimus' Josef Schwalber in Verbindung gebracht wurden ${ }^{427}$, die am selben Tag während einer Festveranstaltung in Dachau ebenfalls gegen das Grundgesetz Stellung genommen und eine Volksabstimmung verlangt hatten ${ }^{428}$; Baumgartner hatte überdies eine Grußadresse an Kronprinz Rupprecht von Wittelsbach gerichtet, dessen 80 . Geburtstag unmittelbar bevorstand, und gefordert, „das Volk müsse selber bestimmen, welche Staatsform es haben wolle".

Das Echo, das Hundhammers Rede - oder besser die Berichterstattung darüber - in der CSU auslöste, war enorm und zeigte einmal mehr die ganze Zerrissenheit der bayerischen Unionspartei. Während die zahllosen Anhänger des Kultusministers in

${ }^{424}$ Vgl. dazu Gelberg, Hans Ehard, S. 262-265, und Kock, Bayerns Weg, S. $319 f$.

${ }^{425}$ SZ vom 3. 5. 1949: „Bundesrepublik ohne Bayern?“; das folgende Zitat findet sich ebenda. Eine Gegendarstellung von Franz Peter Weixler, einem Gefolgsmann Hundhammers aus dem oberbayerischen CSU-Bezirksverband, in: Tagespost (Augsburg): „Was Dr. Hundhammer tatsächlich gesagt hat. Keine Geschichtsfälschung - Widerstandskämpfer gegen Haußleiter"; eine atmosphärisch dichte Schilderung in den Erinnerungen von Karl Köhler: IfZ-Archiv, MS 343 Smlg. Köhler 2, Bl. 214-224.

${ }^{426}$ Zur Monarchismus-Debatte IfZ-Archiv, RG 260, 10/90-3/8, „Subject: Bonn und bayerische Königsfrage" (Gespräch mit Karl Köhler) vom 6. 5. 1949, „Subject: Bonn und Königsfrage" (Gespräch mit Karl Anzenhofer) vom 6. 5. 1949; IfZ-Archiv, RG 260, 13/150-3/10, Bericht über eine Rede Franz Facklers zum Thema CSU und Monarchie am 10.5. 1949. Der geschäftsführende Landesvorstand diskutierte am 5. 5. 1949 (ACSP, NL Müller 9) darüber und einigte sich auf eine Erklärung für die Presse.

427 Im Protokoll der Sitzung des geschäftsführenden Landesvorstands am 5. 5. 1949 (ACSP, NL Müller 9) heißt es: „Sämtliche Anwesende sind sich darüber einig, dass eine separatistische Einstellung innerhalb der CSU, wie sie durch die Gleichzeitigkeit der Verlautbarungen Dr. Baumgartners und Dr. Hundhammers in Dachau für die Öffentlichkeit als gegeben erscheinen muss, aufs schärfste abzulehnen sei. Dem dadurch hervorgerufenen Eindruck im deutschen und bayerischen Volk müsse sofort wirksam begegnet werden. Monarchistische Einstellung als persönliche Überzeugung steht zwar den Mitgliedern der CSU frei, ihre Betätigung im Zusammenhang mit separatistischen Bestrebungen könnte jedoch in keinem Falle innerhalb der CSU geduldet werden.“

${ }^{428}$ SZ vom 3. 5. 1949: „Bundesrepublik ohne Bayern?“; das folgende Zitat findet sich ebenda. 
München und Oberbayern, denen weder radikal föderalistische noch monarchistische Gedankengänge fremd waren, Hundhammers Ausführungen begeistert zustimmten ${ }^{429}$, verstanden die reichstreuen, liberalen Kräfte in der CSU die Rede des Kultusministers als offene Kampfansage, ja als Aufkündigung des labilen Konsenses, auf dem die Union in Bayern bisher geruht hatte. Die "Zerreißprobe für das Land Bayern sei nun gekommen“, erklärte August Haußleiter. Baumgartner und Hundhammer hätten nun ihre "separatistischen Karten offen auf den Tisch gelegt“. Wer mit ihnen zusammenarbeite, „könne nicht Mitglied der CSU sein “430. Und während einer Tagung des Gautinger Kreises forderte Haußleiter, alle Kräfte zu sammeln, „die gesamtdeutsch denken“, und die „Filser" - Synonym für die kurzsichtigen, partikularistischen und monarchistischen Teile der Partei - zu isolieren. Man müsse in der CSU einen scharfen „Trennungsstrich" zwischen den „bayerisch und gesamtdeutsch Orientierten“ ziehen, rief der stellvertretende Parteivorsitzende kämpferisch aus ${ }^{431}$. Michael Horlacher, der sich nach den Äußerungen Hundhammers wie ein Mensch fühlte, „dem man aufs Hirn gehaut hat", ging noch einen Schritt weiter, und zwar einen entscheidenden Schritt: Er forderte, der Parteivorstand müsse vor dem Landesschiedsgericht ein Ausschlußverfahren gegen Hundhammer beantragen.

Ein Parteiausschluß des Kultusministers oder ein „freiwilliger“ Rückzug aus der CSU nach dem Vorbild Fritz Schäffers hätte der Parteiführung um Josef Müller in letzter Minute die Möglichkeit eröffnet, das Blatt doch noch zu wenden und gleichsam der Hydra der Opposition das Haupt abzuschlagen ${ }^{432}$. Ein Schiedsgerichtsverfahren gegen Hundhammer konnte aber auch etwas ganz anderes bedeuten, nämlich die endgültige Parteispaltung und das Ende der CSU als große Sammlungspartei der nichtsozialistischen bayerischen Bevölkerung. Dieses Risiko wollte letztlich niemand eingehen, auch Josef Müller nicht, der stets die Einheit der Partei, seiner Partei, im Auge hatte.

Vielleicht hoffte man aber auch auf eine elegantere, wenn auch für die CSU nicht weniger schmerzhafte Lösung des Konflikts, die es Müller vielleicht doch erlaubt hätte, im Amt zu bleiben. Da die bayerische Unionspartei noch nicht entschieden hatte, ob sie dem Grundgesetz zustimmen sollte, das in diesen Tagen fertiggestellt wurde, waren in der Landtagsfraktion wie in den Führungsgremien der Partei schwere Auseinandersetzungen zu erwarten ${ }^{433}$. Beide Seiten hatten wiederholt deutlich gemacht, daß von der Entscheidung über das Grundgesetz auch die Zukunft der CSU abhängen könnte. Für Hundhammer und seine Mitstreiter kam ein zustimmendes Votum keinesfalls in Frage, Müllers Anhänger plädierten dagegen selbst dann für einen Eintritt Bayerns in die Bundesrepublik, wenn die neue Verfassung nicht unbedingt ihren Vorstel-

${ }^{429}$ IfZ-Archiv, RG 260, 10/90-3/8, „Subject: CSU-Versammlung: CSU und Monarchie“ vom 11. 5. 1949.

${ }^{430}$ Neue Zeitung vom 5. 5. 1949: „Haußleiter hält Spaltung der CSU für möglich“.

431 ACSP, NL Müller 43, Protokoll der Sitzung des Gautinger Kreises am 4. 5. 1949; das folgende Zitat findet sich ebenda.

${ }^{432}$ Heinz Fischer schrieb am 4. 5. 1949 an Josef Müller: „Im übrigen glaube ich, daß die Fronten sich durch die Äußerungen Dr. Hundhammers und Dr. Schwalbers wesentlich geklärt haben, das Richtigste wäre es, Du würdest beide sofort ausschließen, was meines Erachtens die Vorstandschaft in Anbetracht der Ungeheuerlichkeit durchaus verantworten kann. Bei uns hier oben spricht man von einem verspäteten Faschingsscherz mit ,Knecht Rupprecht'. Es liegt nun, lieber Sepp, wesentlich an Dir, die Entscheidung herbeizuführen. " ACSP, NL Müller 144.

${ }^{433}$ So in der Rückschau Michael Horlacher; ACSP, NL Müller 16, Protokoll der Landesversammlung der CSU vom 27.-29. 5. 1949 in Straubing. 
lungen entsprechen sollte ${ }^{434}$. Zerfiel die CSU, insbesondere die Landtagsfraktion, auch bei der Abstimmung über diese Frage, ließ sich auch diesmal kein Kompromiß finden, der für alle Seiten einigermaßen tragbar war, dann war auch der Zerfall der CSU kaum mehr aufzuhalten ${ }^{435}$. Mit anderen Worten: Wenn es Müller und seinen Freunden gelang, eine Entscheidung herbeizuführen, die Hundhammer nicht akzeptieren konnte, dann verließ dieser vielleicht mit seinem Anhang die CSU, die sich dann zwar geschwächt, aber endlich einigermaßen geschlossen präsentieren würde.

Daß derartige Überlegungen letztlich folgenlos blieben, lag vor allem an Ministerpräsident Ehard. Nach der Rede seines Kultusministers am 1. Mai war der Ministerpräsident zunächst um Schadensbegrenzung bemüht. Doch auch zwei außerordentliche Sitzungen des Ministerrats, eine Erklärung Hundhammers, in der er seinen Standpunkt noch einmal darlegte und die Pressemeldungen über seine Ausführungen stark relativierte, und ein Communiqué der Staatsregierung reichten nicht aus, um den Eindruck zu verwischen, Bayern sei auch bei weitgehenden föderalistischen Zugeständnissen keinesfalls bereit, dem Bonner Verfassungsentwurf zuzustimmen ${ }^{436}$. Damit hatte Hundhammer - beabsichtigt oder unbeabsichtigt - die Strategie des Ministerpräsidenten konterkariert, noch im letzten Moment Konzessionen als Gegenleistung für ein bayerisches Ja zum Grundgesetz herauszuverhandeln. Um so drängender stellte sich nun die Frage, wie sich die CSU endgültig entscheiden sollte - für oder gegen die neue westdeutsche Verfassung, die der Parlamentarische Rat am 8. Mai verabschiedet hatte. „Aufgeschreckt durch Hundhammers Äußerungen und gewahr der breiten radikal föderalistischen Ablehnungsfront in CSU und BP, sogar die Spaltung der CSU vor Augen“, brachte der Ministerpräsident eine Kompromißformel in die Debatte ein, die den radikal föderalistischen Kräften in der CSU weitgehend ihre Argumentationsbasis entzog und die auch für die gesamtdeutsch-national denkenden Anhänger der bayerischen Unionspartei einigermaßen tragbar war. „Nein zum Grundgesetz und Ja zu Deutschland“ hieß die Devise. Damit sprach sich Ehard zwar offen für eine Ablehnung des Grundgesetzes durch den Landtag aus, forderte jedoch zugleich, die Rechtsverbindlichkeit der neuen Verfassung anzuerkennen, sollte diese in zwei Drittel der westdeutschen Länder angenommen werden. Der Ministerpräsident setzte seine ganze Kraft und sein ganzes Prestige ein, um dieser Kompromißformel zum Durchbruch zu verhelfen. Ehard drohte vor der eigenen Fraktion sogar mit seinem Rücktritt, wenn die Abgeordneten nicht bereit sein sollten, seinem Kurs zu folgen ${ }^{437}$. Dem Ministerpräsidenten gelang es tatsächlich, sich durchzusetzen. Bei den entscheidenden Abstimmungen lehnte der bayerische Landtag in den frühen Morgenstunden des 20. Mai nach fünfzehnstündiger Debatte das Grundgesetz mit 101 gegen 63 Stimmen bei neun Enthaltungen ab, zugleich wurde seine Rechtsverbindlichkeit mit $97 \mathrm{Ja}$-Stimmen bei sechs Nein-Stimmen und 70 Enthaltungen anerkannt ${ }^{438}$. Wider Erwarten war die CSU nicht

\footnotetext{
${ }^{434}$ Zur Diskussion in der CSU: ACSP, CSU-LTF I, 15-14, Protokolle der Fraktionssitzungen am 11.3., 7.5., 18.5. und 19. 5. 1949, sowie ACSP, NL Müller 16, Protokoll der Landesversammlung der CSU vom 27.-29. 5. 1949 in Straubing.

435 ACSP, CSU-LTF I, 15-14, Protokoll der Fraktionssitzung am 17. 2. 1949 (Alois Hundhammer).

${ }^{436}$ Vgl. hierzu und zum folgenden Gelberg, Hans Ehard, S. 264; das folgende Zitat ebenda, S. 268.

437 Vgl. ebenda, S. 266-273.

438 Vgl. Kock, Bayerns Weg, S. 324 ff., und IfZ-Archiv, RG 260, 7/29-1/13-16, Bericht des amerikanischen Generalkonsuls in München, Sam E. Woods, über die Sitzung des Landtags am 19./20.5. 1949 an das State Department vom 26. 5. 1949.
} 
an der Abstimmung über das Grundgesetz zerbrochen. Nachdem dieses Problem vom Tisch war, stellte sich wieder mit aller Schärfe die Frage, wer die Partei in Zukunft führen sollte.

\section{b) Die Straubinger Landesversammlung vom 27. bis zum 29. Mai 1949}

Für dieses Problem war die Landesversammlung der CSU zuständig, die am 27. Mai erstmals nach eineinhalb Jahren wieder zusammentrat ${ }^{439}$. Im Januar 1948 war Josef Müller noch mit einer beeindruckenden Mehrheit von 348 von 447 Stimmen für 18 Monate in seinem Amt bestätigt worden ${ }^{440}$, aber man brauchte kein Prophet zu sein, um vorherzusagen, daß das Ergebnis diesmal anders lauten würde. Es lag eine kaum erträgliche Spannung in der Luft, als Müller den Parteitag eröffnete. Die Delegierten mußten ihr Temperament jedoch zunächst zügeln, da die Tagesordnung Debatten über die Haltung der CSU zum Grundgesetz und über die Politik der Partei im Landtag und im Wirtschaftsrat vorsah, bevor endlich der entscheidende Programmpunkt aufgerufen werden konnte: die Neuwahl des Landesvorsitzenden ${ }^{441}$. Die Aussprache über das Ergebnis der Bonner Verfassungsberatungen und die Ehardsche Kompromißformel verlief erstaunlich ruhig. Alle Redner waren um eine sachliche Argumentation bemüht und vermieden es, die Tagung durch unnötige Schärfen oder persönliche Verletzungen zusätzlich zu belasten. Selbst August Haußleiter, der auf den Kultusminister und seinen altbayerischen Anhang wie ein rotes Tuch wirkte, und Karl Sigmund Mayr, der sich erdreistet hatte, im Parlamentarischen Rat für das Grundgesetz zu stimmen ${ }^{442}$,

${ }^{439}$ Der Termin für die Straubinger Landesversammlung war heftig umstritten. Während die innerparteiliche Opposition auf einen möglichst frühen Zeitpunkt drängte, wies Müller - unterstützt von Ministerpräsident Ehard - darauf hin, ein Parteitag habe erst dann Sinn, wenn die Delegierten auch über das Ergebnis der Bonner Verfassungsberatungen entscheiden könnten. Aus diesem Grund könne man die Landesversammlung erst in der zweiten Mai-Hälfte einberufen. Schon bloße Gerüchte, die Parteiführung versuche, den Termin erneut auf Juni oder gar Juli zu verschieben, provozierten heftige Reaktionen bei den Gegnern Müllers, die versuchten, die "alsbaldige“ Einberufung der Landesversammlung zu erzwingen. ACSP, NL Müller 16, Anton Hergenröder an Josef Müller vom 25. 4. 1949, August Haußleiter an Anton Hergenröder und nachrichtlich an sämtliche Kreisverbände Oberfrankens vom 29. 4. 1949, Rundschreiben des CSU-Bezirksverbands Unterfranken, gez. Karl Greib, an die Bezirksvorsitzenden, die Mitglieder des Bezirksvorstands Unterfranken und die unterfränkischen Kreisvorsitzenden vom 3. 5. 1949, Alois Hundhammer an die Landesleitung der CSU vom 3. 5. 1949; IfZ-Archiv, Fh 56, Rundschreiben des CSU-Bezirksverbands Oberfranken, gez. Anton Hergenröder, vom 25. 4. 1949, Rundschreiben Nr. 2/49 des CSU-Bezirksverbands Oberfranken vom 2. 5. 1949; Bericht über die Sitzung des Landesvorstands am 12.3. 1949, in: Die Politische Information 9/10-49.

${ }^{440}$ Protokoll der Landesversammlung der CSU am 24./25. 1. 1948 in Marktredwitz, in: Protokolle und Materialien, S. 1498.

${ }^{441}$ ACSP, NL Müller 16, Protokoll der Landesversammlung der CSU vom 27.-29. 5. 1949 in Straubing; das folgende - soweit nicht anders belegt - nach diesem Parteitagsprotokoll. Das Protokoll dieses Parteitags hatte auch Berberich, Historische Entwicklung, S. 96-100, zur Verfügung. Zur Straubinger Landesversammlung vgl. auch die Hintergrundberichte amerikanischer Stellen: IfZ-Archiv, RG 260, 13/150-3/8, „Subject: Special Report on Annual CSU Land Assembly at Straubing/Niederbayern" vom 3. 6. 1949, und IfZ-Archiv, RG 260, 7/29-1/13-16, Bericht des amerikanischen Generalkonsuls in München, Sam E. Woods, über die Straubinger Landesversammlung der CSU an das State Department vom 7. 6. 1949; das Kapitel über die Straubinger Landesversammlung bei Hettler, Josef Müller, S. 403-409, basiert überwiegend auf diesen beiden Dokumenten.

${ }^{442}$ Vgl. Gelberg, Hans Ehard, S. 269; Mayr galt bei den meisten Abgeordneten der CSU im Parlamentarischen Rat schon früh als unsicherer Kantonist. Als die Vertreter der bayerischen Unionspartei am 7.1. 1949 beschlossen, künftig regelmäßige Gruppenbesprechungen abzuhalten, wurde Mayr explizit ausgeschlossen. Vgl. ebenda, S. $198 \mathrm{f}$. 
konnten sprechen, ohne von allzu großen Unmutsäußerungen der Hundhammer-Riege unterbrochen zu werden.

Auch Josef Müller wirkte trotz aller Anspannung gelassen. Vielleicht täuschte dieser Eindruck, vielleicht war sich der Ochsensepp seiner Sache aber auch sicher und hatte noch ein letztes As im Ärmel. Müller berichtete später, Ehard habe ihm noch kurz vor Beginn der Landesversammlung versichert, nicht für das Amt des Parteivorsitzenden zu kandidieren ${ }^{443}$. Mit dieser Zusage im Rücken konnte Müller den kommenden Auseinandersetzungen fürwahr ohne große Aufregung entgegensehen. Denn wenn Ehard nicht gegen ihn antrat, brach die Strategie seiner Gegner zusammen wie ein Kartenhaus ${ }^{444}$.

Tatsächlich sah zunächst alles nach einem Schulterschluß zwischen dem Parteivorsitzenden und dem Ministerpräsidenten aus. Müller lobte die Verhandlungsführung Ehards während der Verfassungsberatungen und betonte, Staatsregierung und Parteiführung seien sich jederzeit "absolut einig" gewesen, während Ehard seinerseits die reibungslose Zusammenarbeit zwischen Partei und Regierung würdigte. Diese Entwicklung dürfte die innerparteiliche Opposition schwer beunruhigt haben ${ }^{445}$, doch bevor es endgültig zum Schwur kam, mußten die Delegierten am Vormittag des 28. Mai die Referate von Wirtschaftsminister Hanns Seidel, Generalsekretär Franz Josef Strauß, Eugen Rindt, dem stellvertretenden Vorsitzenden der Landtagsfraktion, und Landwirtschaftsminister Alois Schlögl zur Kenntnis nehmen. Müller hatte diese Redner nicht ohne Bedacht ausgewählt. Seidel, Schlögl und Strauß, längst schon zum Sprecher der CSU-Abgeordneten im Frankfurter Wirtschaftsrat avanciert ${ }^{446}$, zählten zu den letzten Aktivposten im Lager Müllers, und ihre positive Leistungsbilanz auf dem Feld der Wirtschafts- und Agrarpolitik sollte nicht zuletzt dazu beitragen, die politische Bilanz des Parteivorsitzenden zu verbessern.

Als danach Josef Müller das Wort für seinen Rechenschaftsbericht ergriff, trat die Landesversammlung in ihre entscheidende Phase. Der Ochsensepp wußte, wie viel

443 IfZ-Archiv, RG 260, 7/29-1/13-16, Bericht des amerikanischen Generalkonsuls in München, Sam E. Woods, über die Straubinger Landesversammlung der CSU an das State Department vom 7.6. 1949. Darin heißt es: „Müller told a legal officer of Military Government [...] that Ehard had practically promised him before the land assembly that he would not be a candidate for the party chairmanship."

${ }^{444}$ Ein Vertrauensmann der Militärregierung berichtete wenige Tage vor der Landesversammlung über ein Gespräch mit Josef Brunner, Ludwig Huber und Charlotte Fleischmann: Es sei bisher nicht gelungen, Ehard zu einer Kandidatur zu bewegen, obwohl man genügend Kreisverbände für den Ministerpräsidenten gewonnen habe. Und Charlotte Fleischmann wurde mit den Worten zitiert: „Aber wann ist es überhaupt möglich, ihn [Hans Ehard] einmal festzulegen!" IfZ-Archiv, RG 260, 10/ 90-3/9, „Subject: Landesversammlung der CSU“, undatiert.

${ }^{445}$ Im Anschluß an die Referate über die Bonner Verfassungsberatungen stellten Friedrich Freiherr von der Heydte, Ludwig Huber und Alois Braun den Antrag, die Landesversammlung möge der Landtagsfraktion und den Abgeordneten der CSU, die gegen das Grundgesetz gestimmt hätten, ihren Dank aussprechen. Die Parteiführung wurde bewußt mit keiner Silbe erwähnt, den beiden CSU. Vertretern, die in Bonn für das Grundgesetz gestimmt hatten (Karl Sigmund Mayr und Kaspar Schlör), implizit das Mißtrauen ausgesprochen. Nach einer teilweise heftigen Debatte und einer Intervention Ehards, der sowohl Josef Müller als auch die beiden Bonner Außenseiter in Schutz nahm, wurde der folgende Antrag Michael Horlachers bei vier Enthaltungen einstimmig angenommen: „Die Landesversammlung der CSU spricht dem Ministerpräsidenten, der bayerischen Staatsregierung, der Landesleitung der CSU, den CSU-Abgeordneten in Bonn und im bayerischen Landtag für die beim Bonner Grundgesetz geleistete Arbeit Dank und Anerkennung aus und billigt die dabei eingenommene Haltung."

446 Protokoll der Sitzung des Landesausschusses der CSU am 28./29. 2. 1948 in Regensburg, in: Protokolle und Materialien, S. 1635 (Franz Josef Strauß). 
von dieser Rede abhängen konnte, und er zog alle Register, die ihm zu Gebote standen. Er erinnerte die Delegierten an die Gründung der CSU wenige Wochen nach dem Zusammenbruch der nationalsozialistischen Diktatur und beschwor die Ideale, die die Union beseelten:

„Nach dem Zusammenbruch des Jahre[s] 1945 haben wir die Sammlung der Kräfte vollzogen, die bereit waren, die christliche Politik, die christliche Weltanschauung anzuerkennen, den christlichen Kulturbegriff gegen den Kollektivbegriff durchzusetzen, die aber auch bereit waren, das Christentum so auszulegen, dass eine evolutionär-soziale Politik dem Volk aus seiner Not helfen soll. Wir werden den Kollektivismus nicht verhindern, wenn wir nur Predigten über das Christentum halten. (Beifall.) Wir werden ihn nur verhindern und bekämpfen, wenn wir zu einer Sozialpolitik bereit sind, die notfalls radikal mit der Not des Volkes fertig wird. (Lebhafter Beifall.) Wir haben von vornherein festgestellt: Die christlich-soziale Union ist keine Rechtspartei, sie ist keine bürgerliche Partei; sondern es ist dies eine Partei, die alle Schichten, alle Stände des Volkes zusammenschliessen will, die bereit sind, für die christliche Kultur einzutreten (Bravo!). Würde die Partei eine bürgerliche Partei werden, dann dürften wir nie und nimmer das Wort ,Christentum' als Namen für die Partei aufnehmen (Beifall). Denn angesichts der Verarmung, angesichts der Katastrophe, die über unser Volk hereingebrochen ist, ist der alte Begriff des Bürgertums überwunden worden."

Die Rede Müllers stand zweifellos auf hohem intellektuellen Niveau und gehörte sicherlich zu den besten, die er in den vergangenen Jahren vor der Landesversammlung oder dem Landesausschuß gehalten hatte. Ob er mit seinen gesellschaftspolitischen Ausführungen, mit der Erinnerung an sein Engagement im Widerstand gegen das NSRegime und mit der Herausstellung seiner eigenen Verdienste beim Aufbau der Partei aber die Mehrheit der Delegierten erreichte, die an ganz konkreten Problemen und vor allem an einer Beilegung der Führungs- und Flügelkämpfe interessiert waren, ist zweifelhaft. Diesen Delegierten mochte Müllers Rede als ebenso kunstfertiges wie wortreiches, letztlich aber doch schwerfälliges Ablenkungsmanöver erscheinen.

Nach einer kurzen Ansprache von Landtagspräsident Horlacher, der für die politische Debatte und die Neuwahl des Parteivorsitzenden die Leitung der Landesversammlung übernommen hatte, trat als erster Redner Alfons Bernhard, ein Müller-treuer Delegierter aus dem Kreisverband Würzburg-Stadt, ans Rednerpult. Mit dem Beginn der Diskussion über die Person des künftigen Landesvorsitzenden brach die bislang gewahrte Fassade der Leidenschaftslosigkeit zusammen. Von nun an bestimmten die sachlichen Gegensätze und die tiefgehenden persönlichen Differenzen das Geschehen. Das bekam Alfons Bernhard schon nach wenigen Sätzen zu spüren, als er wiederholt durch Zwischenrufe und lautstarke Unmutsäußerungen unterbrochen wurde. Bernhard nannte die Mißstände in der CSU beim Namen und kritisierte die Obstruktionspolitik des südbayerischen Anhangs scharf: „Die Politik einer gewissen Gruppe in Altbayern glaubt, uns majorisieren zu können, und sie ist diejenige, die den Unfrieden in die Partei hineinträgt“, rief der Würzburger Delegierte seinen Kollegen zu, nachdem er die innerparteiliche Opposition zuvor aufgefordert hatte, endlich auszusprechen, „was eigentlich gegen Dr. Josef Müller ernstlich einzuwenden“ sei. Der Parteivorsitzende habe eine wirtschaftspolitische Linie verfolgt, die unzweifelhaft erfolgreich gewesen sei, und der Parteivorsitzende sei es auch gewesen, der während des Generalstreiks in Bayern im Januar 1948 einen Sturz von Ministerpräsident Ehard verhindert habe. Bernhard verglich die Entscheidung, vor der die CSU stand, mit zwei folgenschweren Entscheidungen aus den Jahren der Weimarer Republik. Nach dem Tod 
Friedrich Eberts habe man sich - auch in Teilen Bayerns - für Hindenburg als neuen Reichspräsidenten entschieden und nicht für den Zentrumspolitiker Wilhelm Marx, und 1932 sei Heinrich Brüning als Reichskanzler gestürzt worden, als er „kurz vor dem Ziel“" stand. Bernhard beschwor die Delegierten, nicht noch einmal einen solchen Fehler zu machen, sondern Josef Müller - „den Mann, der uns bisher durch die Geschichte so prächtig hindurchgeführt hat" - wieder zu wählen, das Kriegsbeil zu begraben und geschlossen in die bevorstehenden Bundestagswahlen hineinzugehen ${ }^{447}$.

Wenig später trat Josef Fischer mit einem Antrag vor die Delegierten, auf den sich die Bezirksvorsitzenden am Morgen des 28. Mai verständigt hatten. Fischer forderte nichts weniger als ein Ende der Debatte über die Person des Landesvorsitzenden, die ja noch gar nicht richtig begonnen hatte, und eine sofortige Neuwahl des Parteichefs. Schließlich seien die Fronten seit Wochen geklärt, eine Fortsetzung der Diskussion würde nur zu neuen Auseinandersetzungen und neuen Verletzungen führen. Spätestens mit diesem Antrag wurde klar, daß die Bezirksvorsitzenden gleichsam in die Rolle von Königsmachern geschlüpft waren und daß sie alles versuchen würden, um den Kandidaten durchzusetzen, auf den sie sich im Vorfeld geeinigt hatten. Als August Haußleiter seine Bedenken gegen ein Ende der Debatte vorbringen wollte, wurde er minutenlang am Sprechen gehindert und mußte sich gegen Sprechchöre durchsetzen, die eine sofortige Abstimmung über den Antrag der Bezirksvorsitzenden forderten.

Die Landesversammlung hatte ihren Höhepunkt erreicht. Gelang es den Gegnern Müllers, die Diskussion abzubrechen, nahmen sie dem Ochsensepp jede weitere Gelegenheit, Punkte im Kampf um die Parteiführung zu sammeln. Wurde die Debatte jedoch fortgesetzt, so war vielleicht doch noch eine Überraschung möglich. Wie nicht anders zu erwarten, sprach sich Haußleiter scharf gegen die „Kulissenstrategie ${ }^{\text {“ der }}$ Bezirksvorsitzenden aus und forderte eine offene Aussprache, um nicht den Eindruck entstehen zu lassen, „als sollte hier eine Gruppe unversehens überrannt werden“. Wenn ein Teil der Delegierten die Überzeugung gewinne, man habe sie hier absichtlich nicht zu Wort kommen lassen, so Haußleiter weiter, dann trage dies sicher nicht zu einer Stärkung des Zusammenhalts bei, sondern fördere lediglich die „innere Vergiftung“. Überraschenderweise hieb auch Ministerpräsident Ehard in diese Kerbe und lehnte das von den Bezirksvorsitzenden vorgeschlagene Procedere ebenfalls ab. Zugleich griff er die Forderung des Delegierten Bernhard auf, die Vorwürfe gegen Josef Müller offen vorzubringen:

"Ich habe mich in der Frage des Parteivorsitzes die ganze Zeit über vollkommen zurückgehalten, sehr bewusst und sehr überlegt. Aber ich bin der Meinung, daß man die Frage des Parteivorsitzes nicht lösen kann, bevor einmal eine Aussprache stattgefunden hat. (Lebhafter Beifall.) Meines Er-

447 Bevor die innerparteiliche Opposition auf Bernhards Vorwürfe und Vorschläge antworten konnte, unterbrach eine kurze Geschäftsordnungsdebatte die Sitzung. Unterstützt von den Bezirksverbänden München und Oberbayern stellte Wirtschaftsminister Seidel den Antrag, die Gäste und Pressevertreter so lange von der Tagung auszuschließen, bis die Wahl des Landesvorsitzenden abgeschlossen sei. Die Delegierten stimmten mit großer Mehrheit zu, und Michael Horlacher verfügte eine kurze Pause, um den Gästen und Journalisten Gelegenheit zu geben, den Saal zu verlassen. Lediglich dem Korrespondenten der Dena wurde es erlaubt, der Tagung weiterhin beizuwohnen. Die restlichen Journalisten rangen - entsprechend erbost über ihren Ausschluß - um die besten Horchposten an den Türen und auf dem Dachboden über dem Versammlungssaal. Mittelbayerische Zeitung vom 31. 5. 1949: „Unter Ausschluß der Öffentlichkeit“. Vgl. auch Groß, Hanns Seidel, S. $108 \mathrm{f}$. 
achtens muss einmal die Atmosphäre gereinigt werden, und ich bin der Meinung: Gewitter reinigen die Luft. (Zustimmung.) Ich habe aus meiner bisherigen Arbeit in der Partei auch die Überzeugung gewonnen: Es wird zwar manchmal heftig gestritten; die Gegensätze, auch die persönlichen Gegensätze, prallen oft sehr stark aufeinander. Aber wenn es sich darum handelt, eine gemeinsame Plattform zu finden, dann halten alle doch wieder zusammen, weil sie der Meinung sind: Sie müssen zusammenhalten. (Lebhafter Beifall.) Dazu kommt noch etwas. Nachdem einer unserer Parteifreunde ja vorhin die Frage aufgeworfen hat: Was habt Ihr gegen den einen? Sagt uns doch von der anderen Seite, was Ihr dagegen habt?, halte ich es nicht für richtig, diese Frage offen zu lassen. (Beifall.) Liebe Parteifreunde! Wir müssen einmal über das Stadium hinwegkommen, daß einer den anderen direkt oder indirekt abwürdigt - abschiesst, will ich nicht sagen. Ich meine, es muss soviel persönliches gegenseitiges Vertrauen geschaffen werden können, daß einer den anderen achtet und daß einer mit dem anderen auf unserer gemeinsamen christlich-sozialen Basis auch dann zusammenarbeitet, wenn er in seiner Anschauung von dem anderen variiert. (Sehr richtig!) Ich meine noch etwas anderes. Wenn unser Parteivorsitzender, unser Freund Josef Müller, angegriffen wird und man sagt, man sei aus irgendwelchen Gründen mit ihm nicht mehr zufrieden, dann muss man es auch aussprechen. (Beifall.) Es gibt Situationen, die gar nicht die Schuld des Einzelnen sind, sondern die schicksalsmässig auf einen zukommen oder einen auf die Seite schieben, und sei es vorübergehend. (Sehr gut!) Aber man muss sich darüber aussprechen."

Ehard lieferte auch gleich einen Alternativvorschlag: Nur ausgewählte Exponenten der beiden großen Lager sollten sprechen und ihre Standpunkte darlegen. Dann sei es an den Delegierten, sich für "den einen oder den anderen oder einen dritten“ zu entscheiden. Damit hatte der Ministerpräsident nicht nur die Strategie der Bezirksvorsitzenden konterkariert, die mit allen Mitteln versuchten, ihn selbst auf den Schild zu heben, sondern auch Alois Hundhammer gezwungen, selbst anzutreten und den Kampf gegen den verhaßten Parteivorsitzenden mit offenem Visier zu führen. Es schien fast so, als stünden Ehard, der sich nach wie vor nicht dazu geäußert hatte, ob er überhaupt als Landesvorsitzender zur Verfügung stand, und Müller auf derselben Seite. Damit war aber zumindest für die Delegierten, die nicht in das System der Vorabsprachen und Winkelzüge eingeweiht waren, die Lage völlig undurchsichtig geworden. Nach der kurzen Rede des Ministerpräsidenten hatte die Initiative der Bezirksvorsitzenden keine Chance mehr; ihr Antrag, die Neuwahl des Landesvorsitzenden ohne weitere Diskussion vorzunehmen, wurde von den Delegierten mit großer Mehrheit abgelehnt.

Bevor es jedoch zum großen Schlagabtausch kam, ergriff der stellvertretende CSUVorsitzende Michael Horlacher das Wort, um den amtierenden Parteichef formell zur Wiederwahl vorzuschlagen. Horlacher lobte Müllers Verdienste in den höchsten Tönen, verwies auf seine glänzenden nationalen und internationalen Verbindungen und verlieh seiner Überzeugung Ausdruck, daß eine Debatte über die Person des Landesvorsitzenden eigentlich überflüssig sei, da das „Ergebnis von Bonn, die Einheit zwischen Staatsregierung, Fraktionsleitung und Parteileitung [...] auch ein Verdienst der Haltung von Josef Müller und des Parteivorstandes“ gewesen sei. Zugleich sprach er den Bezirksvorsitzenden mit Entschiedenheit das Recht ab, in die angestammten Rechte der Delegierten einzugreifen, und ging mit Alois Hundhammer und seinen Anhängern hart ins Gericht:

„Auch was uns die Opposition angetan hat - wir wollen sie heute nicht anklagen, um die Debatte nicht zu verschärfen -, was sie alles zu ungunsten der CSU während der Bonner Debatte verbrochen hat, war ein gutes Stück zur Heruntersetzung des Ansehens der gemeinsamen CSU. Gerade aus diesen Gründen halte ich meinen Vorschlag aufrecht, den Herrn Dr. Josef Müller wieder zu wählen." 
Bis zu diesem Zeitpunkt waren fast nur Vertreter des Müller-Flügels zu Wort gekommen, während sich die innerparteiliche Opposition stark zurückgehalten hatte. Doch nachdem auch Michael Horlacher noch einmal verlangt hatte, die Vorwürfe gegen Müller endlich offen auszusprechen, blieb Alois Hundhammer kaum noch etwas anderes übrig, als seine Forderung nach einer Ablösung Josef Müllers selbst zu begründen und er tat dies mit jener Vehemenz, die man von ihm gewohnt war, wenn es gegen den Ochsensepp ging ${ }^{448}$. Hundhammer machte aber nicht den Fehler, die ganze Konfliktgeschichte seit 1945 von neuem aufzurollen, und er ließ sich auch nicht zu persönlichen Angriffen oder gar Beleidigungen hinreißen, sondern konzentrierte sich auf wenige, dafür aber zentrale Argumente, die er zum Teil gebetsmühlenartig wiederholte. Müller sei von Anfang an kein Mann gewesen, der „auf die Dauer eine zusammenfassende Führung " der CSU habe gewährleisten können, sondern der Repräsentant einer kleinen „Spezialgruppe“. Dies habe sich insbesondere bei der Abstimmung in der Verfassunggebenden Landesversammlung gezeigt, als Müller gegen die Mehrheit seiner eigenen Fraktion gegen das Staatspräsidentenamt votiert habe. Die CSU, so Hundhammer weiter, brauche aber einen Landesvorsitzenden, der „in der Mitte der Partei“ stehe und der geeignet sei, den Parteifreunden, die die CSU verlassen hätten, „wieder ein Magnet zu sein, der sie zurückführt und denen, die noch da sind, ein Mittelpunkt ist, der ihnen das Vertrauen gibt, dass sie bei dieser Partei bleiben und an ihr festhalten können“. Die Führung der CSU durch einen Flügel müsse endlich aufhören. Und Hundhammer fuhr fort:

„Wir stehen jetzt, liebe Parteifreunde, vor den Wahlen zu Bonn. Wir müssen in diese Wahlen hineingehen können mit einer grossen inneren Geschlossenheit der Partei, (sehr richtig!) mit einer Parteispitze, die das Vertrauen von allen Seiten auf sich vereinigt. (Sehr gut!) Wenn das nicht der Fall ist, wenn wir in die Wahlen unter der Führung von Dr. Josef Müller hineingehen, werden weitere Parteifreunde, und nicht wenige, weiterhin wieder von uns absplittern, und werden insbesondere viele Leute im Lande wieder der CSU ihre Stimme geben, wenn an der Spitze der Name Ehard steht, (stürmischer Beifall) werden viele Leute der CSU die Stimme nicht geben, wenn an der Parteispitze der Name Dr. Josef Müller bleibt. (Sehr richtig!) [. . .] Mit Ehard werden wir die Wahl zum Bonner Bundestag gut bestehen, (lebhafte Zustimmung) mit Ehard werden wir einen Grossteil auch der Stimmen zurückgewinnen können, die uns verlorengegangen sind oder die jetzt abwartend beiseitestehen. Durch Dr. Josef Müller hingegen werden wir zu den Verlusten, die schon da sind, weitere Verluste erleiden. (Zustimmung.)"

Außerdem warf Hundhammer dem Parteivorsitzenden eine verfehlte Organisationspolitik und schwere Mißgriffe in der Geschäftsführung vor. Die Partei müsse den kommenden Wahlkampf ohne einen intakten Parteiapparat und ohne ein Parteiorgan bestreiten, nachdem sich das Experiment mit dem Geraden Weg als überaus kostspieliger Fehlschlag erwiesen habe. Überhaupt seien die Parteifinanzen in einem desolaten $\mathrm{Zu}$ stand; seit der Währungsreform seien in der Münchner Parteizentrale Schulden in einer Höhe von mehr als 200000 DM aufgelaufen! Hundhammer gab zwar zu, daß viele Kreisverbände ihre Beitragsverpflichtungen nicht erfüllt hätten, machte aber auch dafür den Landesvorsitzenden verantwortlich. Er wisse, behauptete der Kultusminister, daß in vielen Kreisen und Bezirken die Auffassung herrsche: "Es hat keinen Sinn, in einen Sack, der keinen Boden hat, Geld hinein zu werfen." Zugleich versprach er den

${ }^{448}$ Hundhammer erklärte den Delegierten, es sei für ihn eine "Gewissenspflicht“, gegen einen Parteivorsitzenden aufzutreten, den er für ungeeignet halte. 
Delegierten, daß „die finanzielle Opferfreudigkeit unserer Mitglieder eine ganz andere werden“ würde, wenn eine neue Parteiführung gewählt und das Vertrauen da sei, daß „vernünftig und zweckmässig gewirtschaftet“ würde.

Hundhammer versuchte also nichts anderes, als Josef Müller die alleinige Verantwortung für die Flügelkämpfe, das organisationspolitische Chaos und die letzten Wahlniederlagen anzulasten - und er erweckte den Eindruck, man brauche nur den erfolgreichen Ministerpräsidenten zum Parteivorsitzenden zu wählen, um die Misere zu beenden.

Müller konterte unglücklich. Seine durchaus berechtigten Argumente gegen Hundhammers simplifizierende Vorwürfe, sein Hinweis auf strukturelle Probleme und auf die unbestreitbaren Erfolge der CSU unter seiner Führung traten hinter die oft nur angedeuteten, schlecht belegten persönlichen Anschuldigungen gegen den Kultusminister zurück, dem er wiederholten Vertrauensbruch vorwarf und geradezu konspirative Aktivitäten gegen die Mehrheit der eigenen Partei unterstellte. Kein Wunder, daß sich die Anhänger Hundhammers und auch er selbst mit wütenden Zwischenrufen zur Wehr setzten. Der Tumult steigerte sich so sehr, daß sich Müller zu der Bemerkung gezwungen sah, man wolle doch hier keine Schlägerei veranstalten. Wie tief der Parteivorsitzende verletzt war, zeigte sich in dem Ausruf, er sei „in der Öffentlichkeit zum Schwein gemacht worden“, und in dem bitteren Satz: „Eine Partei, die keine innere Moral und Kraft hat, bricht zusammen, und zwar mit Recht.“

Müller versuchte den Delegierten aber auch eindringlich vor Augen zu führen, daß die Krise der CSU ihre Ursachen nicht nur in persönlichen Zwistigkeiten habe und daß es nicht mit bloßem „Kleistern“ getan sei. Er verwies auf die grundsätzlichen Meinungsverschiedenheiten in der Frage, wie mit der Bayernpartei umzugehen sei, und forderte anders als Hundhammer einen entschiedenen Kampf gegen die BP als Voraussetzung für Stimmengewinne bei den bevorstehenden Bundestagswahlen. Zuvor hatte Müller bereits die grundlegenden Auffassungsunterschiede zwischen ihm und dem Kultusminister in der Föderalismusfrage herausgestellt. Was die Geschäftsführung und den Schuldenstand der CSU anging, verteidigte sich Müller nicht ungeschickt. Er stellte nicht nur klar, daß die Schulden der Partei durch die „rückständigen Beitragszahlungen“ der Kreisverbände mehr als gedeckt seien, sondern entlarvte auch Hundhammers Behauptung, bei einer Wahl Hans Ehards würde das Beitragsaufkommen schnell wieder steigen, als bloße Propaganda. Schließlich, so Müller, gelinge es nicht einmal Hundhammer, in seinem eigenen Bezirksverband die fälligen Beiträge einzutreiben, und der Kultusminister habe als letzter das Recht, dem Landesvorsitzenden die Schulden der Partei vorzuwerfen, solange er selbst systematisch Zahlungen an den Landesverband verhindere. Müller schloß seine Rede mit den Worten:

„Entscheiden Sie, wie Sie wollen, ich bin niemand[em] böse für seine Entscheidung. Habe ich die Möglichkeit, eine politische Konzeption weiter zu verwirklichen, dann werde ich es tun, wenn Sie sich dafür entscheiden. Im anderen Falle bin ich dankbar, dass ich meine persönliche Freiheit zurückgewinne. Denn der Landesvorsitzende ist in der CSU der unfreieste Mensch, wenn jeder das Recht hat, ihn anzugreifen, und er mit Rücksicht auf die CSU sich nicht immer verteidigen kann. Wenn Sie gegen mich entscheiden, machen Sie mich zu einem freien Mann.“

Nach diesem Schlagabtausch zwischen Hundhammer und Müller ging alles ziemlich schnell. Vor der Wahl erhielten nur noch zwei Redner die Möglichkeit, für den Ochsensepp oder für Hans Ehard zu sprechen. Für Müller trat der junge Franz Josef 
Strauß an, von dem sich die Anhänger des Landesvorsitzenden eine flammende Rede erwarteten. Aber sie wurden enttäuscht ${ }^{449}$. Strauß wiederholte lediglich die schon häufig vorgetragenen Bedenken gegen eine Personalunion von Ministerpräsidentenamt und Parteivorsitz. Es sei nicht nur eine „Sünde an der CSU“, sondern geradezu ein „Verbrechen am bayerischen Volke“, wenn der Ministerpräsident „damit auch in den Strudel der gemeinen, niedrigen Parteiintrigen und Parteiauseinandersetzungen [...] hineingezogen würde“. Ehard sei für die CSU unersetzlich, so Strauß, die Partei könne aber auch auf die "geistigen, diplomatischen und politischen Fähigkeiten“ Josef Müllers nicht verzichten. Er machte den Delegierten daher den Vorschlag, die Statuten der Partei zu ändern und ,in der Parteiführung den Ministerpräsidenten und den bisherigen Landesvorsitzenden an einen Wagen [zu] spannen". Wußte Strauß, daß Müllers Sache verloren war? Wollte sich der Generalsekretär seine weitere Karriere nicht dadurch verbauen, daß er einem Geschlagenen allzu große Loyalität erwies? Oder war sein Vorschlag ein letzter Versuch zu retten, was noch zu retten war, zumal er ihn mit der Warnung verband, die Partei könne sich spalten, wenn sich die Delegierten über die berechtigten Interessen einer Minderheit hinwegsetzten ${ }^{450}$.

Als Sprecher gegen eine Wiederwahl Josef Müllers trat Gerhard Kroll auf, der sich zugleich vehement für Hans Ehard als neuen Parteichef stark machte. Kroll hatte als Mitbegründer der Union in Bamberg und als Verfasser der Bamberger Denkschrift wesentlich zu einem Erfolg des interkonfessionellen Gedankens und der Sammlungsidee beigetragen. Bevor er Anfang 1949 die Seiten wechselte, hatte er zu Müllers wichtigsten Stützen im fränkischen Raum und später auch in der Landtagsfraktion gehört. Kroll traf wohl genau den richtigen Ton, als er dem Ochsensepp für seine Verdienste um die Gründung der CSU dankte, ihm aber gleichzeitig zu verstehen gab, daß seine Zeit vorbei sei. Der neue Parteivorsitzende, so Kroll, könne nur Hans Ehard heißen:

"Ich habe in vielen Auseinandersetzungen, in sehr vielen Auseinandersetzungen, auch mit Konrad dem Grossen unter dem Drachenfels, gesehen, in unserem Ministerpräsidenten Ehard haben wir [sic!] - (Lebhafter Beifall.) Ich habe die Qualität der anderen nicht angezweifelt, aber die Gaben hat Gott jedem gesondert in die Wiege gelegt, und daran kann ich nichts ändern. Und daß Ehard die Qualität hat, Gegensätze auszugleichen, ohne neue zu schaffen, daß er es versteht, selbst die bis zum Bersten gewachsenen Spannungen in sich wieder so auszugleichen, daß ein Weiterleben, ein echt bayerisches Weiterleben möglich ist, das habe ich kennen gelernt. Darum, meine lieben Freunde, habe ich damals gesagt: Die Zeit ist da, die Stunde der Union. Wir sind nicht mehr im Zustand der Gründung; wir sind im Zustand einer Revision. Jetzt heisst es endlich einmal nicht erweitern, sondern schaffen. Jetzt heisst es nicht: Wer hat recht, was hat uns der getan, was hat der getan; sondern: Wie kommen wir voran? Da allerdings, muss ich Ihnen sagen, kenne ich persönlich - das ist meine Gewissensüberzeugung - keinen Mann, der besser wäre als Dr. Hans Ehard. (Bravo-Rufe und stürmischer, anhaltender Beifall.) Ich bin nicht hier heraufgestiegen, um Dr. Josef Müller anzugreifen, den ich persönlich schätze. - Ich habe es ihm vorher gesagt, wie ich die Situation sehe. - Ich bin hier heraufgestiegen, weil ich mich frage: Wie bekommen wir

${ }^{449}$ Karl Köhler schrieb in seinen Erinnerungen: „Auf Dr. Hundhammers Rede hin ergriff der Generalsekretär Franz Josef Strauß das Wort. Mit großer Erwartung verfolgten die Delegierten seine Ausführungen. Man hoffte, besonders in den Kreisen um Dr. Müller, Strauß werde die Entscheidung der Versammlung herbeiführen. Seine Rede aber war ein eindeutiger Appell an alle Anhänger der Union, in Einigkeit zusammenzustehen. Er sprach mit keinem Wort für, noch gegen Dr. Müller, sondern verhielt sich völlig neutral. [...] Die Anhänger des Gautinger Kreises saßen wie versteinert auf ihren Plätzen. Sie hatten die Hoffnung auf Strauß gesetzt und nun diese neutrale Rede!“ IfZ-Archiv, MS 343 Smlg. Köhler 2, Bl. 262.

${ }^{450}$ Zur Rolle von Strauß in Straubing aus der Sicht des Ochsensepp vgl. Müller, Konsequenz, S. $359 \mathrm{f}$. 
die Union über die Stunde der grossen Krisis hinüber? Wie leisten wir die Bewährungsprobe in den kommenden Wahlen? Ich darf Ihnen sagen, Ihre Parteifreunde innerhalb und ausserhalb Bayerns sind heute der Meinung: Nur wenn es gelingt, die Zügel dem Manne anzuvertrauen, der überragende Taktik, der Scharfsinn, der Klugheit, der gerechtes Auswägungsvermögen in schwierigsten und heikelsten Situationen bewiesen hat, nur wenn wir so verfahren, können wir die Union retten."

Anschließend begann der Wahlvorgang, und nachdem die Stimmen ausgezählt waren, gab Michael Horlacher das Ergebnis bekannt: Von 556 abgegebenen Stimmen entfielen 396 auf Hans Ehard (71,22 Prozent), 151 auf Josef Müller (27,16 Prozent), eine auf Hanns Seidel, acht Stimmen waren ungültig. Damit war Ministerpräsident Ehard mit einer überzeugenden Mehrheit zum CSU-Vorsitzenden gewählt worden, ohne daß er öffentlich erklärt hatte, ob er überhaupt bereit war, dieses Amt zu übernehmen.

Die Regisseure im Hintergrund, die Bezirksvorsitzenden, wußten freilich mittlerweile, daß sie mit Ehard rechnen konnten. Sie hatten sich während der Tagung noch einmal zu einer Geheimsitzung getroffen und über die Neuwahl des Landesvorsitzenden konferiert. Sieben Bezirksvorsitzende sprachen sich dabei endgültig gegen Müller und für die Wahl Ehards aus. Nach einem Bericht der Militärregierung präsentierten Gerhard Kroll und ein Vertreter Hundhammers oder dieser selbst dem Ministerpräsidenten daraufhin ein Ultimatum. Sie stellten ihn vor die Alternative, entweder die Führung der CSU zu übernehmen oder die Spaltung der Partei in Kauf zu nehmen. Außerdem konfrontierten sie Ehard mit der Drohung, die Auflösung des Landtags und Neuwahlen zu erzwingen, wenn er den Landesvorsitz ablehne ${ }^{451}$. Dem Regierungschef blieb damit nichts anderes übrig, als einzuwilligen, wollte er nicht seine eigene Regierung gefährden. Sollte der eine oder andere noch Überraschungen erwartet haben, wurde er enttäuscht. Als die nach dem Wahlvorgang unterbrochene Landesversammlung am Morgen des 29. Mai wiederaufgenommen wurde, stellte Michael Horlacher nicht einmal die Frage, ob Ehard die Wahl annehme; der Ministerpräsident übernahm wie selbstverständlich den Vorsitz.

451 IfZ-Archiv, RG 260, 7/29-1/13-16, Bericht des amerikanischen Generalkonsuls in München, Sam E. Woods, über die Straubinger Landesversammlung der CSU an das State Department vom 7.6. 1949; vgl. auch Hettler, Josef Müller, S. 403. 